\title{
AQUECIMENTO GLOBAL E O MERCADO DE CARBONO: UMA APLICAÇÃO DO MODELO CERT
}

\author{
MARCELO THEOTO Rocha
}

Tese apresentada à Escola Superior de Agricultura

"Luiz de Queiroz", Universidade de São Paulo, para obtenção do título de Doutor em Ciências, Área de Concentração: Economia Aplicada.

P I R A C I C A B A

Estado de São Paulo - Brasil

Janeiro - 2003 


\section{AQUECIMENTO GLOBAL E O MERCADO DE CARBONO: UMA APLICAÇÃO DO MODELO CERT}

\section{MARCELO ThEOTO Rocha}

Engenheiro Agrônomo

Orientador: Prof. Dr. PEDRO CARVALHO DE MELLO

Tese apresentada à Escola Superior de

Agricultura "Luiz de Queiroz",

Universidade de São Paulo, para obtenção

do título de Doutor em Agronomia, Área de Concentração: Fitopatologia.

P I R A C I C A B A

Estado de São Paulo - Brasil

Janeiro - 2003 


\section{Dados Internacionais de Catalogação na Publicação (CIP) DIVISÃO DE BIBLIOTECA E DOCUMENTAÇÃO - ESALQ/USP}

Rocha, Marc elo Theoto

Aquec imento global e o merc ado de carbono: uma a plic ação do modelo CERT/ Marcelo Theoto Rocha. - - Piracic aba, 2003.

$196 \mathrm{p}$.

Tese (doutorado) - Escola Superior de Agricultura Luiz de Queiroz, 2003. Bibliografia.

1. Administração de projetos 2. Carbono 3. Climatologia 4. Economia ambiental 5. Efeito estufa 6. Mercado futuro 7. Poluição atmosférica prevenção e controle I. Titulo

CDD333.7

"Permitida a cópia total ou parcial deste documento, desde que citada a fonte - $\mathrm{O}$ autor" 
A elaboração desta tese emitiu aproximadamente $12 \mathrm{t} / \mathrm{CO}_{2}$. Para torná-la "carbon neutral" seria necessário o plantio de 30 árvores ${ }^{1}$, ou a compra de 12 CER

(Certificados de Emissões Reduzidas)

\footnotetext{
${ }^{1}$ A memória de cálculo encontra-se nos Apêndice 1.
} 


\section{AGRADECIMENTOS}

Aos professores: Pedro (meu orientador), Geraldo, Bento, Guilhoto, Estraviz e Grütter pelas instruções e amizade.

Aos colegas do CEPEA: Wick, Silvia, Dani, Vítor, Mariano, André, Allan, Odair, Patrícia, Janaina e Lu pelo trabalho bem feito e pela companhia.

Aos colegas do "mercado de carbono": Edu e Cláudio (IPÊ), Elci, Bia e Mário (SOS Mata Atlântica), Divaldo (Ecológica), Maria José e Hans (IIEB), André (SPVS), Carlos e Ricardo (Ecoinvest), Samy (ERM), Paulo, Nuno e Alex (Ecosecurities), Fujihara (PriceWatterHouse), Lap (EcoMapuá), Giovanni e Lombardi (De Rosa Siqueira), Flávio e Flávia, Ludovino, Vânia (AMCHAM), Gylvan, Thelma, Miguez, Branca, Newton e Haroldo (MCT), Éverton e Maria Rita (MRE), Adriano e Leonardo (MMA/COPPE), João e Dione (CETESB), Marina (FBMC), Aline e André (COPPE), Klink (UnB), Alexandre (Banco Mundial), Lucas (UNCTAD), André (BioAtlântica), Pedro e Geórgia (FUNBIO), Joe, Patrícia e Miguel (TNC), Laura (ICLEI), Philipe, Mark e tantos outros pelo debate construtivo e pelas boas risadas.

Aos amigos: Rodrigo (Aza), Valter (Toz), Gianpaolla (Peres) e Rodrigo (Xu) pela amizade e descontração.

Ao meus pais: Armando e Marly, pelas oportunidades e apoio.

E acima de tudo à minha esposa, Fernanda, pelo amor, dedicação e compreensão. 


\section{SUMÁRIO}

Página

LISTA DE FIGURAS....................................................................................... vii

LISTA DE TABELAS........................................................................... xi

LISTA DE QUADROS .............................................................................. xii

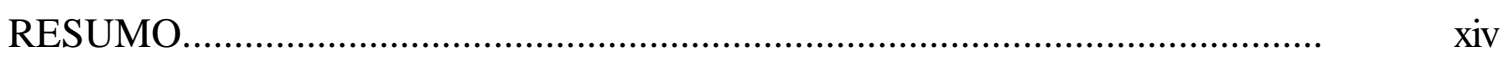

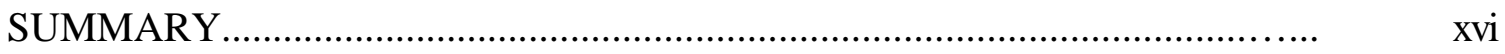

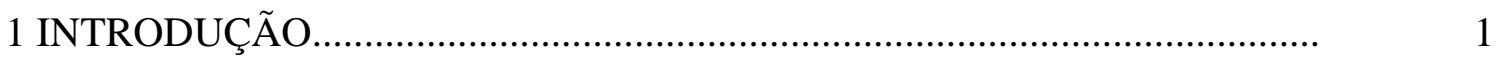

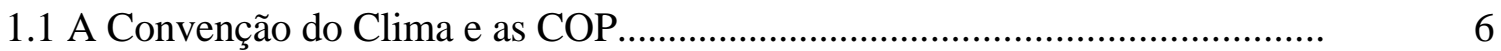

1.2 O MDL - "Mecanismo de Desenvolvimento Limpo"............................................. 8

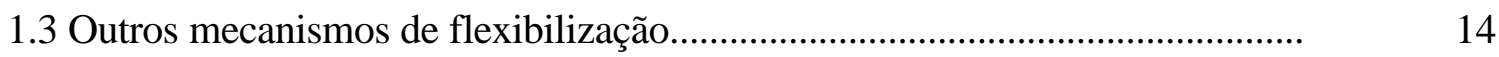

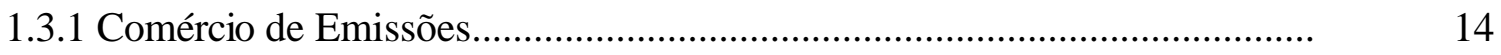

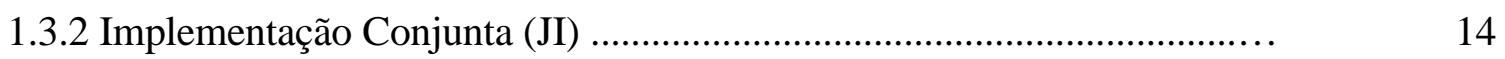

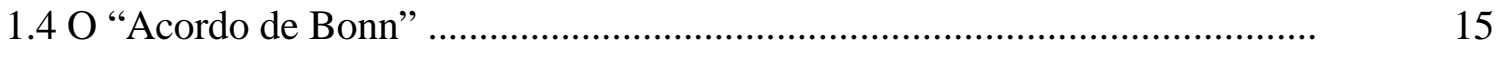

1.5 A COP 7 e o "Acordo de Marrakesh" ............................................................... 17

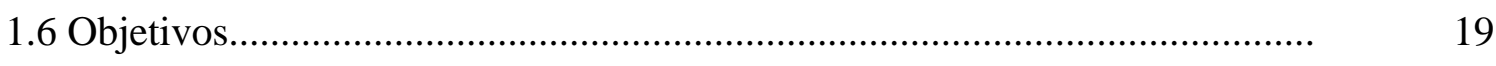

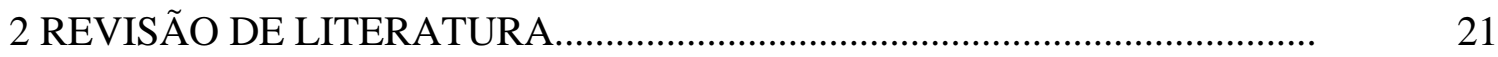

2.1 As atividades de LULUCF (seqüestro de carbono) ........................................... 21

2.1.1 As atividades de LULUCF no Brasil..........................................................

2.1.1.1 A Comissão Interministerial de Mudança Global do Clima............................. 23

2.1.1.2 Projetos de LULUCF no Brasil................................................................ 24

2.1.2 Atividades Conjuntamente Implementadas.................................................... 30

2.1.3 Projetos de LULUCF em outros países........................................................... 32

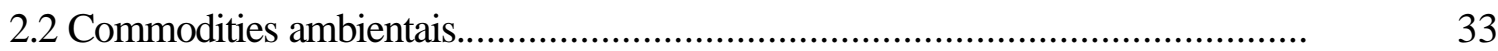


$2.3 \mathrm{O}$ custo das reduções de emissões e o valor de mercado do carbono.................... 35

2.4 Instrumentos de mercado para "emission trade" .............................................

2.4.1 A experiência norte-americana................................................................

2.5 A formação do mercado de carbono.................................................................

2.5.1 Os mercados de carbono já existentes..........................................................

2.5.1.1 Emissions Trading Scheme do Reino Unido................................................. 50

2.5.1.2 CERUPT/ERUPT do governo holandês................................................. 52

2.5.1.3 Chicago Climate Exchange.................................................................... 53

2.5.1.4 O Prototype Carbon Fund do Banco Mundial............................................. 54

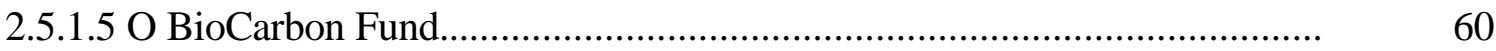

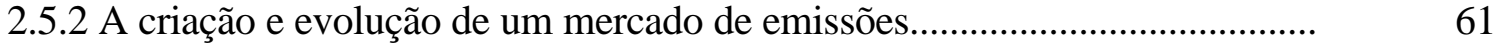

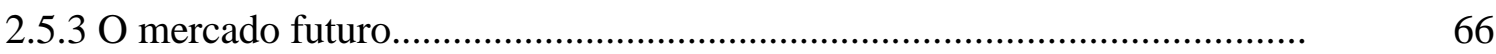

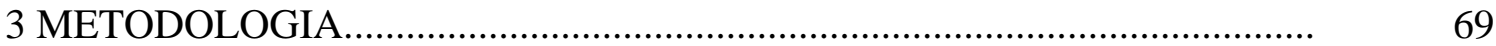

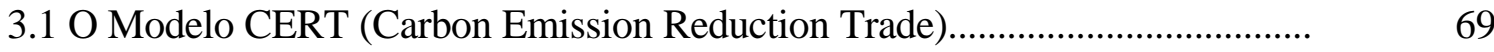

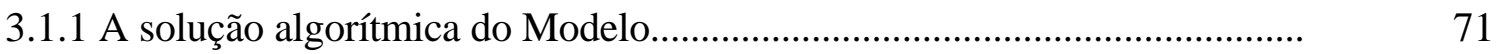

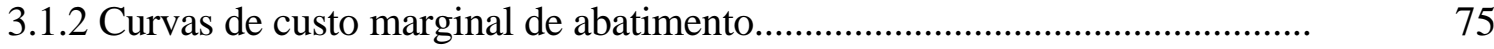

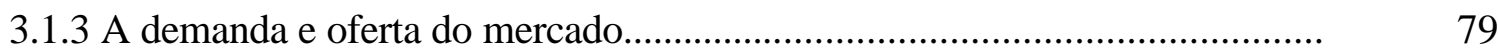

3.1.4 Os cenários de referência do Modelo...........................................................

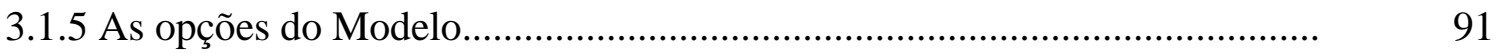

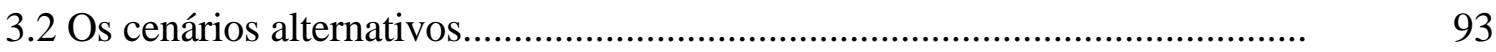

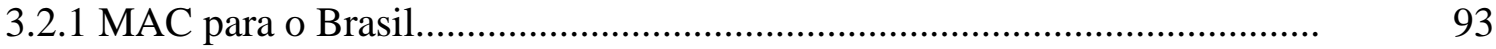

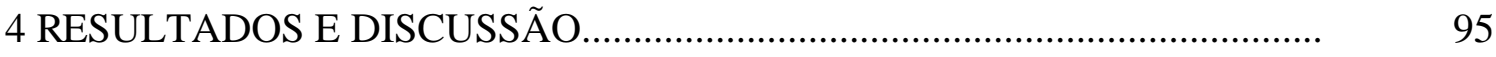

4.1 O resultado das entrevistas..................................................................

4.2 A participação brasileira nos cenários de referência........................................... 101

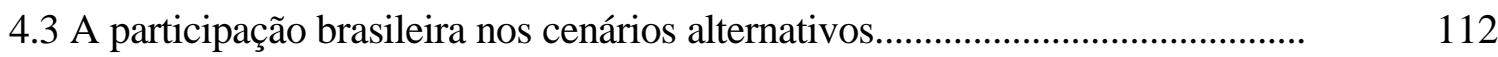

5 CONCLUSÕES E RECOMENDAÇÕES..................................................... 122

REFERÊNCIAS BIBLIOGRÁFICAS....................................................... 131

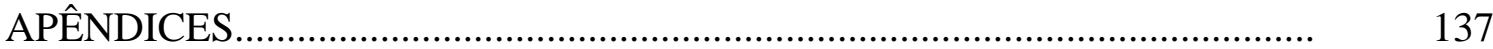




\section{LISTA DE FIGURAS}

Página

1 Emissões de CO2 (em 106 toneladas métricas) no Brasil, provenientes da utilização de diversos tipos de combustíveis.

2 O efeito estufa.

3 Ciclo de um projeto de MDL proposto pelo Comitê Executivo.

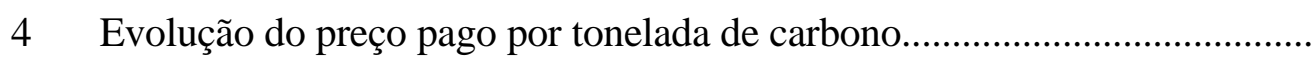

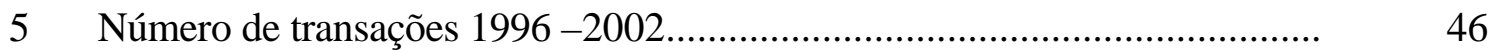

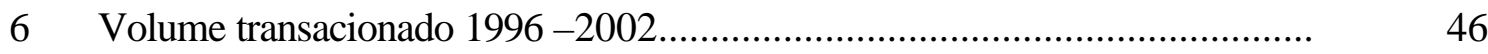

7 Porcentagem da participação dos países compradores no volume

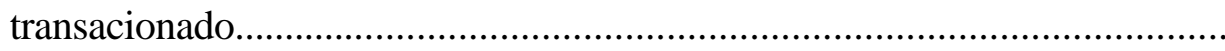

8 Porcentagem da participação do tipo de projeto no volume transacionado.....

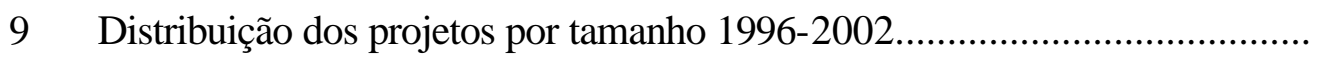

10 Distribuição do volume transacionado por tipo de país 2001-2002................ 


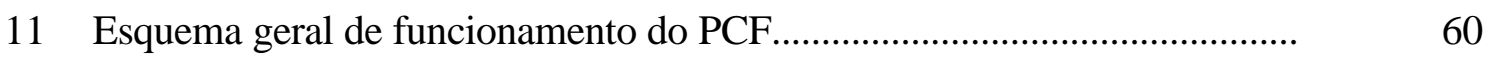

12 Como será o mercado de carbono em 2006 e em 2010................................ 65

13 Curva de custo marginal de abatimento para a região R.................................. 76

14 Curvas de custo marginal de abatimento para diferentes regiões....................... 77

15 Importação / Exportação de "permissões para emissão" ................................. 78

16 Demanda e oferta do mercado de carbono.................................................. 80

17 MAC Cenários 1, 2 e 3 - Países ANEXO B................................................. 82

18 MAC Cenários 1, 2 e 3 - Países não-ANEXO B............................................. 83

19 MAC Cenários 4, 5 e 6 - Países ANEXO B................................................... 85

20 MAC Cenários 4, 5 e 6 - Países não-ANEXO B............................................... 86

21 MAC Cenário 7 - Países ANEXO B............................................................. 87

22 MAC Cenário 7 - Países não-ANEXO B...................................................... 88

23 MAC Cenário 8 - Países ANEXO B............................................................ 89

24 MAC Cenário 8 - Países não-ANEXO B..................................................... 90

25 Taxa de implementação dos projetos de MDL para Brasil, China, Índia e resto do mundo 
26 Porcentagem de "hot air" a ser comercializada.............................................. 98

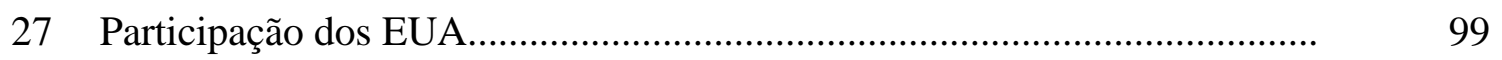

28 Custos de transação dos projetos de MDL para Brasil, China, Índia e resto do mundo..

29 Volume de vendas dos CER de MDL nos cenários de referência - 2010.......

30 Preço de venda dos CER de MDL nos cenários de referência - 2010.............

31 Receita líquida das vendas de CER (US\$) nos cenários de referência 2010.

32 Volume de vendas de CER (M t C) nos cenários de referência - 2010

33 Participação dos países no mercado de carbono via MDL (cenário de referência - melhor caso para o Brasil), 2010.

34 Equilíbrio de mercado para o cenário de referência aonde a participação brasileira é maior (Cenário 7)

35 Preços de equilíbrio de mercado nos cenários de referência e alternativos.....

36 Volume de vendas dos CER de MDL nos cenários alternativos - 2010.........

37 Preço de venda dos CER de MDL nos cenários alternativos - 2010.............

38 Receita líquida das vendas de CER (US\$ milhões) nos cenários alternativos $-2010$ 
39 Volume de vendas de CER (M t C) nos cenários alternativos - 2010.............

40 Participação dos países no mercado de carbono via MDL (cenário alternativo - melhor caso para o Brasil), 2010............................................ 118

41 Receita líquida das vendas de CER (US\$ milhões), Brasil nos cenários de

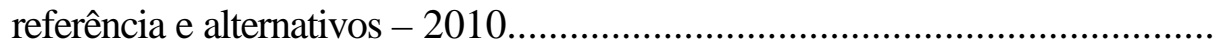

42 Volume de vendas de CER (M t C), Brasil, nos cenários de referência e

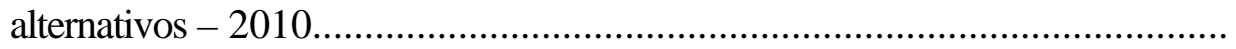




\section{LISTA DE TABELAS}

Página

1 Concentrações globais de alguns Gases de Efeito Estufa geradas por

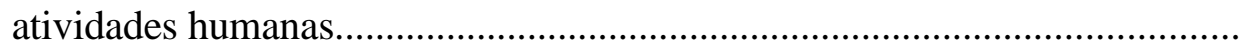

2. Ranking dos maiores responsáveis pelas emissões totais de $\mathrm{CO} 2$ provenientes da produção e uso de energia e da produção de cimento.

3 Análise de diferentes atividades de LULUCF.

4 Projetos de "sequiestro de carbono" originados durante a fase de Atividades

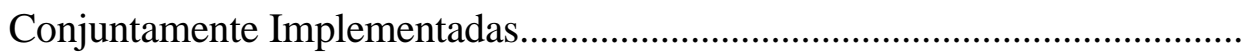

5 Projetos de seqüestro de carbono em outros países.

6 Lista das empresas que participaram do leilão de lançamento do UK Emissions Trading Scheme

$7 \quad$ Lista de projetos aprovados pelo PCF 


\section{LISTA DE QUADROS}

Página

1 Possíveis impactos decorrentes do aquecimento global................................. 5

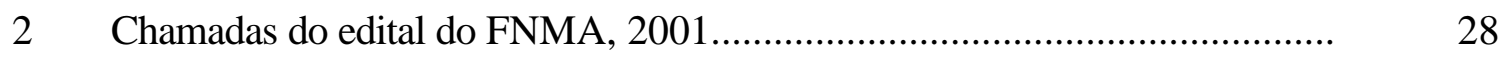

3 Programas de "Emissions Trade", EUA.......................................................

4 Exemplos recentes de transações envolvendo carbono.................................. 45

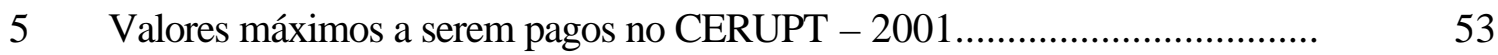

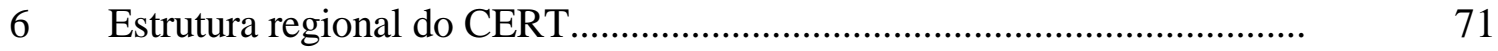

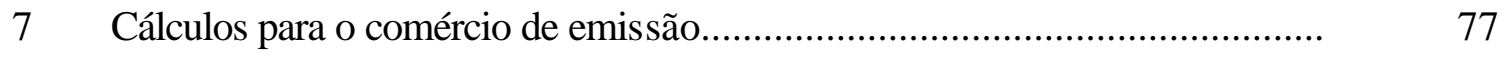

8 Parâmetros utilizados nas MAC dos cenários de referência 1 (Modelo

EPPA - função tipo quadrática) e 6 (Modelo GTEM - função tipo exponencial)....

$9 \quad$ MAC para CO2 e todos os GEE........................................................ 107

10 Parâmetros utilizados nas MAC dos cenários de referência 5 (curvas tipo “top-down") e 8 (curvas tipo "bottom-up") para projetos de MDL/JI 
11 Comparação entre os cenários de referência 1 (menor participação brasileira) e 7 (maior participação brasileira) ...................................................

12 Passos necessários para a criação do mercado de carbono e iniciativas tomadas para diminuir o grau de incerteza........................................................ 


\title{
AQUECIMENTO GLOBAL E O MERCADO DE CARBONO: UMA APLICAÇÃO DO MODELO CERT
}

\author{
Autor: MARCELO THEOTO ROCHA \\ Orientador: Prof. Dr. PEDRO CARVALHO DE MELLO
}

\section{RESUMO}

As ações decorrentes das atividades econômicas e industriais têm provocado alterações na biosfera, resultando na quase duplicação da concentração de Gases de Efeito Estufa (GEE) na atmosfera durante o período de 1750 a 1998. A alteração da concentração dos GEE poderá desencadear um aumento da temperatura média no planeta entre 1,4 e $5,8^{\circ} \mathrm{C}$ nos próximos cem anos (IPCC, 2001a). Para tratar do problema do efeito estufa e suas possíveis conseqüências sobre a humanidade foi estabelecida em 1992, durante a Rio 92, a Convenção Quadro das Nações Unidas sobre Mudanças Climáticas. A Conferência das Partes realizada em Quioto em 1997 destaca-se como uma das mais importantes, uma vez que durante sua realização foi estabelecido um acordo onde se encontram definidas metas de redução da emissão de GEE para os países do ANEXO B (países do ANEXO I com compromissos de redução das emissões de GEE), além de critérios e diretrizes para a utilização dos mecanismos de mercado. Este acordo ficou conhecido como Protocolo de Quioto e estabelece que os países industrializados devem reduzir suas emissões em 5,2\% abaixo dos níveis observados em 
1990 entre 2008-2012 (primeiro período de compromisso). O Protocolo criou o Mecanismo de Desenvolvimento Limpo (MDL). A idéia do MDL consiste em que cada tonelada de $\mathrm{CO}_{2}$ deixada de ser emitida, ou retirada da atmosfera por um país em desenvolvimento, poderá ser negociada no mercado mundial através de Certificados de Emissões Reduzidas (CER). Esta tese teve como objetivo geral caracterizar o "mercado de carbono", em especial a participação do Brasil através do MDL. Para tanto foi feita uma análise de como este mercado está sendo formado e como deverá ser sua evolução até a possível formação de mercados futuros. Os objetivos específicos foram: 1) Determinar o tamanho do mercado global e a participação do Brasil (através do MDL) em diversos cenários; e, 2) Analisar se os CER gerados em projetos de MDL, em especial por projetos de seqüestro de carbono, poderiam se tornar uma "commodity ambiental" ou não. Ficou claro que o mercado de carbono já é uma realidade, porém encontra-se em um estágio inicial de sua formação. Para estimar o tamanho do mercado utilizourse o Modelo CERT (Carbon Emission Reduction Trade). Nos cenários de referência do Modelo a maior participação brasileira no mercado de CER foi de apenas 3,4\% (Cenário 7), através da venda de 14,4 milhões de toneladas de carbono, gerando um receita de US\$ 237 milhões ao custo de US\$ 106,3 milhões. O lucro de todos os projetos de MDL no Brasil foi de US\$ 130,7 milhões. Nos cenários alternativos a maior participação foi de 17,8\% (Cenário Alternativo 7), através da venda de 32,1 milhões de toneladas de carbono, gerando um receita de US\$ 525,6 milhões ao custo de US\$ 198 milhões. O lucro de todos os projetos de MDL no Brasil neste caso foi de US\$ 327,6 milhões. 


\title{
GLOBAL WARMING AND THE CARBON MARKET: AN APPLICATION OF THE CERT MODEL
}

\author{
Author: MARCELO THEOTO ROCHA \\ Adviser: Prof. Dr. PEDRO CARVALHO DE MELLO
}

\section{SUMMARY}

The economic and industrial anthropogenic activities are increasing the Green House Gas (GHG) atmospheric concentration. These gases can increase the atmosphere temperature in 1.4 to $5.8^{\circ} \mathrm{C}$ in the next hundred years (IPCC, 2001a). To solve this problem was created in 1992 the United Nations Framework Convention on Climate Change. The Conference of the Parties held at Kyoto in 1997 was one of the most important, since it created an international agreement about the GHG emission reductions to the ANNEX B countries. This agreement is called the Kyoto Protocol and it determine that the industrialized countries should decrease the GHG emissions in 5,2\% below the 1990 levels between 2008-2012 (first period commitment). The Protocol also created the Clean Development Mechanism (CDM). The idea of the CDM is that each tone of $\mathrm{CO}_{2}$ that is reduced or sequestered from the atmosphere by a developing country can be negotiated through Certified Emission Reduction (CER).This thesis had the main objective of understand the "carbon market", in special the Brazilian participation through the CDM. The specific objectives was: 1) Determine 
the size of the global market and the Brazilian participation (through the CDM) in different scenarios; and, 2) To analyze if the CER created by forest projects can be a environmental commodity. It was clear that the carbon market exists but is in an initial phase. To estimate the size of the market the CERT (Carbon Emission Reduction Trade) Model was used. In the reference scenarios the best Brazilian participation, through the CER, was only 3.4\% (Scenario 7), selling 14.4 millions tons of carbon, with a revenue of US\$ 237 millions and costs of US\$ 106.3 millions. The profits of all CDM projects in Brazil was US\$ 130,7 millions. In the alternative scenarios the best Brazilian participation was $17.8 \%$ (Alternative Scenario 7), selling 32.1 millions tons of carbon, with a revenue of US\$ 525.6 millions and costs of US\$ 198 millions. In this case the profits of all CDM projects in Brazil was US\$ 327.6 millions. 


\section{INTRODUÇÃ̃O}

As ações decorrentes das atividades econômicas e industriais têm provocado alterações na biosfera, resultando na quase duplicação da concentração de Gases de Efeito Estufa $^{1}$ (GEE) na atmosfera durante o período de 1750 a 1998, como mostra a Tabela 1.

Tabela 1. Concentrações globais de alguns Gases de Efeito Estufa geradas por atividades humanas.

\begin{tabular}{lccc}
\hline & $\begin{array}{c}\mathrm{CO}_{2} \\
\text { (gás carbônico) }\end{array}$ & $\begin{array}{c}\mathrm{CH}_{4} \\
\text { (metano) }\end{array}$ & $\begin{array}{c}\mathrm{N}_{2} \mathrm{O} \\
\text { (óxido nitroso) }\end{array}$ \\
\hline Concentração em 1750 & $280 \mathrm{ppm}$ & $700 \mathrm{ppb}$ & $270 \mathrm{ppb}$ \\
Concentração em 1998 $^{\text {Taxa de alteração }}$ & $365 \mathrm{ppm}$ & $1745 \mathrm{ppb}$ & $314 \mathrm{ppb}$ \\
Taxa $^{\text {Residência na Atmosfera (anos) }}$ & $1,5 \mathrm{ppm} / \mathrm{ano}^{\mathrm{b}}$ & $7,0 \mathrm{ppb} / \mathrm{ano}^{\mathrm{b}}$ & $0,8 \mathrm{ppb} /$ ano \\
\hline
\end{tabular}

Fonte: Adaptado de Intergovernmental Panel on Climate Change - IPCC (2001a)

Legenda:

ppm = partes por milhão; $p p b=$ partes por bilhão.

a - Calculada durante o período de 1990 a 1999.

b - A taxa para $\mathrm{CO}_{2}$ tem flutuado entre 0,9 e 2,8 ppm/ano e para $\mathrm{CH}_{4}$, entre 0 e 13 ppb/ano durante o período de 1990 a 1999.

\footnotetext{
1 São considerados GEE: dióxido de carbono $\left(\mathrm{CO}_{2}\right)$, metano $\left(\mathrm{CH}_{4}\right)$, óxido nitroso $\left(\mathrm{N}_{2} \mathrm{O}\right)$, hezafluoreto de enxofre $\left(\mathrm{SF}_{6}\right)$ e as famílias dos perfluorcarbonos (compostos completamente fluorados, em especial erfluormetano $\mathrm{CF}_{4}$ e perfluoretano $\mathrm{C}_{2} \mathrm{~F}_{6}$ ) e dos hidrofluorcarbonos (HFCs) (Miguez, 2000).
} 
Um dos principais GEE é o gás carbônico $\left(\mathrm{CO}_{2}\right)$, cujas emissões no Brasil, provenientes da utilização de diversos tipos de combustíveis, cresceram vertiginosamente nos últimos 40 anos, como pode ser visto na Figura 1. Porém, é preciso salientar que os países desenvolvidos são os que mais contribuem para o aumento da concentração dos GEE, como pode ser visto na Tabela 2 da classificação dos maiores responsáveis pelas emissões de $\mathrm{CO}_{2}$. Nesta tabela, o Brasil encontrava-se na $21^{\mathrm{a}}$ posição, em 1995.

Porém, ao incluir as queimadas e desmatamentos, o Brasil passa a estar entre os seis primeiros emissores de GEE (Moutinho e Bueno, 2002). Estima-se que existam de 10.000 a 25.000 toneladas de carbono para cada quilômetro quadrado de floresta tropical, sendo que, com as queimadas, cerca de $2 / 3$ deste carbono seria transformado em $\mathrm{CO}_{2}$ (Rezende et al., 2001).

Diante disso, o país se vê pressionado, em especial pelos Estados Unidos, a assumir compromissos voluntários de redução das emissões de GEE. Os impactos de tais compromissos sobre a economia brasileira ainda são controversos, podendo ser significativos em alguns setores ${ }^{2}$.

${ }^{2}$ ROCHA, M.T. Como determinar os impactos da redução das emissões de carbono sobre a economia brasileira e os seus setores. (compact disk). In: CONGRESSO BRASILEIRO DE ECONOMIA E SOCIOLOGIA RURAL, 38., Rio de Janeiro. Anais. Brasília: SOBER, 2000. 


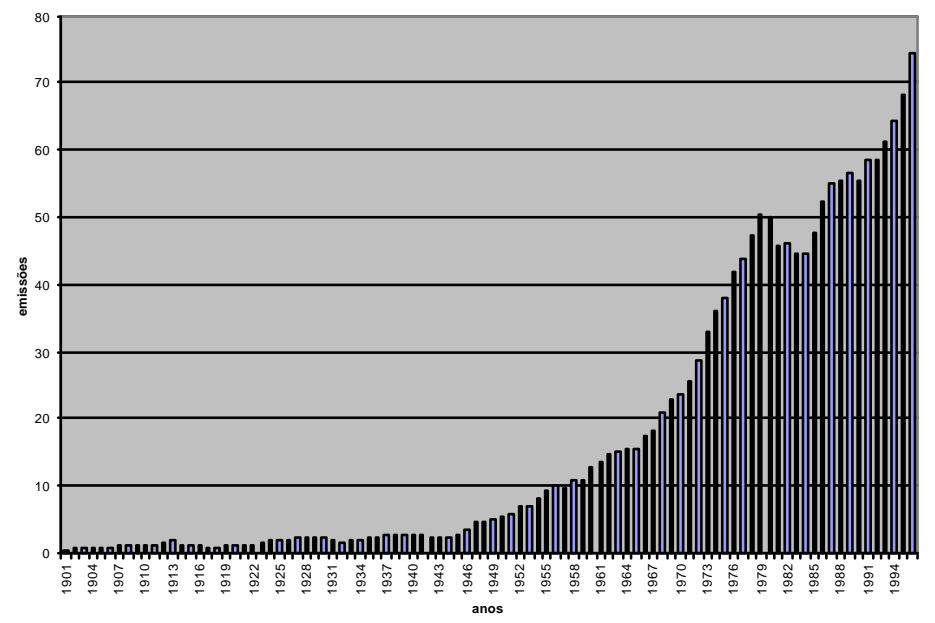

Figura 1 - Emissões de $\mathrm{CO}_{2}$ (em $10^{6}$ toneladas métricas) no Brasil, provenientes da utilização de diversos tipos de combustíveis.

Fonte: Marland et al. (1999)

Tabela 2. Ranking dos maiores responsáveis pelas emissões totais de $\mathrm{CO}_{2}$ provenientes da produção e uso de energia e da produção de cimento.

\begin{tabular}{lcc}
\hline País & Ranking 1994 & Ranking 1950 \\
\hline Estados Unidos da América & 1 & 1 \\
China & 2 & 10 \\
Rússia & 3 & $2 *$ \\
Japão & 4 & 9 \\
Índia & 5 & 13 \\
Alemanha & 6 & 3 \\
Reino Unido & 7 & 4 \\
Canadá & 8 & 7 \\
Ucrânia & 9 & $2 *$ \\
Itália & 10 & 17 \\
México & 11 & 20 \\
Polônia & 12 & 8 \\
Coréia do Sul & 13 & 58 \\
França & 14 & 5 \\
África do Sul & 15 & 14 \\
Austrália & 16 & 15 \\
Coréia do Norte & 17 & 73
\end{tabular}




\begin{tabular}{lcc}
\hline País & Ranking 1994 & Ranking 1950 \\
\hline Irã & 18 & 164 \\
Indonésia & 19 & 31 \\
Kasaquistão & 20 & $2 *$ \\
\hline
\end{tabular}

Fonte: The US Oak Ridge National Laboratory - ORNL, citado por Banco Nacional de Desenvolvimento Econômico e Social (BNDES) \& Ministério da Ciência e Tecnologia (MCT), 1999.

* URSS - União das Repúblicas Socialistas Soviéticas

A alteração da concentração dos GEE poderá desencadear um aumento da temperatura média no planeta entre 1,4 e $5,8^{\circ} \mathrm{C}$ nos próximos cem anos (IPCC, 2001a). Esse aumento da temperatura irá ocorrer devido ao bloqueio da saída da radiação solar que estes gases causam (Figura 2).

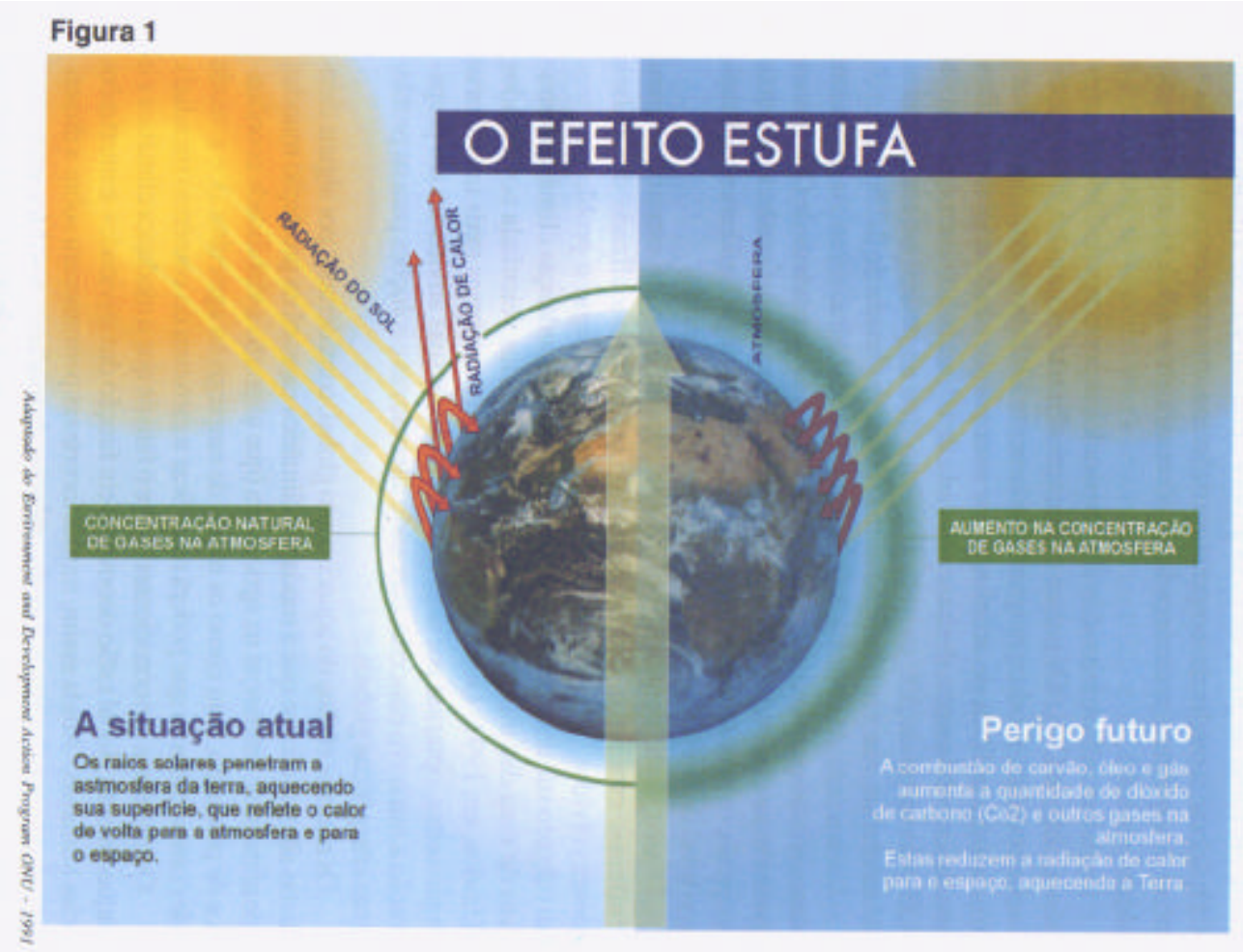

Figura 2 - O efeito estufa.

Fonte: Rezende et al. (2001) 
Segundo o IPCC (2001b), os impactos econômicos, sociais e ambientais decorrentes do aquecimento global afetarão todos os países, porém, serão sentidos de maneira diferenciada. O Quadro 1 resume algumas previsões desses impactos em diversas regiões do mundo.

\begin{tabular}{|c|c|}
\hline Região & Prováveis impactos \\
\hline 1. África & $\begin{array}{l}\text { a. Diminuição da produção agrícola } \\
\text { b. Diminuição da disponibilidade de água na região } \\
\text { do Mediterrâneo e em países do sul } \\
\text { c. Aumento dos vetores de diversas doenças } \\
\text { d. Aumento da desertificação } \\
\text { e. Extinção de animais e plantas }\end{array}$ \\
\hline 2. Ásia & $\begin{array}{l}\text { a. Diminuição da produção agrícola } \\
\text { b. Diminuição da disponibilidade de água nas } \\
\text { regiões árida e semi-árida } \\
\text { c. Aumento do nível do mar deverá deslocar } \\
\text { dezenas de milhões de pessoas }\end{array}$ \\
\hline 3. Austrália e Nova Zelândia & $\begin{array}{l}\text { a. Diminuição da disponibilidade de água } \\
\text { b. Extinção de animais e plantas }\end{array}$ \\
\hline 4. Europa & $\begin{array}{l}\text { a. Desaparecimento de geleiras nos Alpes } \\
\text { b. Aumento da produção agrícola em algumas } \\
\text { regiões } \\
\text { c. Impactos no turismo }\end{array}$ \\
\hline 5. América Latina & $\begin{array}{l}\text { a. Diminuição da produção agrícola } \\
\text { b. Aumento dos vetores de diversas doenças } \\
\text { c. Extinção de animais e plantas }\end{array}$ \\
\hline 6. América do Norte & $\begin{array}{l}\text { a. Aumento da produção agrícola em algumas } \\
\text { regiões } \\
\text { b. Aumento dos vetores de diversas doenças }\end{array}$ \\
\hline 7. Polar & $\begin{array}{l}\text { a. Diminuiçãa da calota polar } \\
\text { b. Extinça de animais e plantas }\end{array}$ \\
\hline 8. Pequenas ilhas & $\begin{array}{l}\text { a. Aumento do nível do mar deverá deslocar } \\
\text { dezenas de milhões de pessoas } \\
\text { b. Diminuição da disponibilidade de água } \\
\text { c. Diminuição da atividade pesqueira } \\
\text { d. Diminuição no turismo }\end{array}$ \\
\hline
\end{tabular}

Quadro 1 - Possíveis impactos decorrentes do aquecimento global.

Fonte: Adaptado de IPCC (2001b) 
Como mostra o Quadro 1, a grande maioria dos impactos será negativa, trazendo enormes prejuízos para a humanidade. Para tentar solucionar este importante problema ambiental, a Organização das Nações Unidas (ONU) vem debatendo o tema em conferências internacionais. Como resultado desses debates, alguns instrumentos de mercado foram propostos para auxiliar os países industrializados a reduzirem suas emissões de GEE.

Esta tese irá abordar um desses instrumentos: o Mecanismo de Desenvolvimento Limpo (MDL). Será discutido o mercado que está sendo formado a partir da comercialização de "certificados de emissões reduzidas" (CER) de GEE: o "mercado de carbono". O tamanho desse mercado e a participação do Brasil (através do MDL) serão determinados em diversos cenários; e, por último, será analisado se os CER gerados em projetos de MDL, em especial por projetos de "seqüestro de carbono", poderiam se tornar uma "commodity ambiental" ou não.

\subsection{A Convenção do Clima e as COP}

Para tratar do problema do efeito estufa e suas possíveis conseqüências sobre a humanidade, foi estabelecida, em 1992, durante a Rio 92, a Convenção Quadro das Nações Unidas sobre Mudanças Climáticas (em inglês, United Nations Framework Convention on Climate Change - UNFCCC, 2001a). Adotada em 1992, a Convenção do Clima tem como meta propor ações para os países do ANEXO I (basicamente países industrializados $)^{1}$, para que estes estabilizem as concentrações atmosféricas dos gases de efeito estufa (GEE) de forma a impedir que atividades antrópicas levem a uma "interferência perigosa" no clima do planeta. A Convenção do Clima entrou em vigor em 21 de março de 1994 e conta atualmente com 186 "Partes" (países). Desde então, as Partes têm se reunido para discutir o assunto e tentar encontrar soluções para o problema

\footnotetext{
${ }^{1}$ A lista de países membros do ANEXO I encontra-se no Apêndice 2.
} 
apresentado. Até o presente momento, foram realizados oito encontros, denominados Conferências das Partes (COP).

As ações propostas durante as últimas Conferências das Partes (Quioto/1997, Buenos Aires/1998, Bonn/1999, Haia/2000, Bonn/2001, Marrakesh/2001 e Nova Déli/2002) deram ênfase à utilização de mecanismos de mercado, visando não somente à redução dos custos da mitigação do efeito estufa, assim como ao estabelecimento do desenvolvimento sustentável em países subdesenvolvidos.

A Conferência das Partes realizada em Quioto em 1997 destaca-se como uma das mais importantes, uma vez que, durante sua realização, foi estabelecido um acordo que define as metas de redução das emissões de GEE para os países do ANEXO B (países do ANEXO I com compromissos de redução das emissões de GEE) ${ }^{2}$, além de critérios e diretrizes para a utilização dos mecanismos de mercado. Esse acordo ficou conhecido como Protocolo de Quioto (UNFCCC, 2001b) e estabelece que os países industrializados devem reduzir suas emissões em 5,2\% abaixo dos níveis observados em 1990 entre 2008-2012 (primeiro período de compromisso).

Para que este Protocolo entre em vigor, é necessário que pelo menos 55 países, que representem pelo menos 55\% das emissões de GEE, o ratifiquem. Atualmente, 102 paises, representando $43,9 \%$ das emissões, já o ratificaram ou estão no processo de realizá-lo. No Brasil, o Protocolo foi ratificado no dia 19 de junho de 2002 e sancionado pelo presidente da República em 23 de julho do mesmo ano.

$\mathrm{Na}$ Conferência das Partes realizada em Haia (Holanda), entre os dias 13 e 25 de novembro de 2000, não foi possível estabelecer as regras operacionais do Protocolo, em especial devido a divergências entre os Estados Unidos e países europeus. Em função do impasse criado, a Conferência foi suspensa.

Em 28 de março de 2001, a EPA (Environmental Protection Agency) anunciou oficialmente que a administração Bush não tinha mais interesse em prosseguir com as negociações internacionais para a implementação do Protocolo de Quioto. No dia 09 de 
abril de 2001, o vice-presidente norte-americano (Richard Cheney), chegou a declarar que o Protocolo estava "morto".

Dessa forma, a retomada das regociações em Bonn (Alemanha), entre 16 e 27 de julho, foi fundamental para definir a sobrevivência e os novos rumos do Protocolo. Esta Conferência ficou conhecida como COP 6 BIS e o seu produto mais importante foi o "Acordo de Bonn", um acordo político que garantiu a sobrevivência do Protocolo (ver o item O “Acordo de Bonn").

Durante os dias 29 de outubro e 09 de novembro de 2001, as Partes se reuniram em Marrakesh (Marrocos) durante a $7^{\text {a }}$. Conferência das Partes (COP 7), para transformar em decisões práticas o acordo político alcançado em Bonn e definir as regras operacionais do Protocolo de Quioto (ver o item A COP 7 e o "Acordo de Marrakesh").

A $8^{a}$. Conferência das Partes (COP 8) foi realizada entre os dias 23 de outubro e $1^{\circ}$. de novembro, no Centro de Convenções Vigyan Bhawan (Nova Déli - Índia). Estiveram presentes 4.352 participantes de 167 Partes; 213 organizaçõos nãogovernamentais e intergovernamentais; e 222 jornais e TVs. Apesar de importantes avanços, a COP 8 não determinou quais seriam as definições e modalidades para as atividades de reflorestamento e florestamento elegíveis ao Mecanismo de Desenvolvimento Limpo (MDL). Tais definições e modalidades serão estabelecidas na COP 9, a ser realizada na Itália, entre os dias $1^{\circ}$. e 12 de dezembro de 2003.

\subsection{O MDL - "Mecanismo de Desenvolvimento Limpo"}

A partir do Protocolo de Quioto ficou claro que o mercado poderia auxiliar no processo de redução das emissões de GEE, através da proposta de se criar um valor transacionável para essas reduções, semelhante aos mecanismos existentes para alguns gases poluidores na Europa e Estados Unidos (ver item Instrumentos de mercado para “emission trade” na página 37).

\footnotetext{
${ }^{2}$ A lista de países membros do ANEXO B e seus compromissos de redução encontram-se no Apêndice 3.
} 
Dentro desse princípio, foram estabelecidos mecanismos de flexibilização, entre eles o Mecanismo de Desenvolvimento Limpo ${ }^{1}$ (MDL - Artigo 12 do Protocolo de Quioto). A proposta do MDL consiste em que cada tonelada de $\mathrm{CO}_{2}$ deixada de ser emitida ou retirada da atmosfera por um país em desenvolvimento poderá ser negociada no mercado mundial, criando um novo atrativo para redução das emissões globais. Os países do ANEXO I estabelecerão em seus territórios metas para redução de $\mathrm{CO}_{2}$ junto aos principais emissores. As empresas que não conseguirem (ou não desejarem) reduzir suas emissões poderão comprar Certificados de Emissões Reduzidas (CER) em países em desenvolvimento e usá-los para cumprir suas obrigações. Os países em desenvolvimento, por sua vez, deverão utilizar o $\mathrm{MDL}$ para promover seu desenvolvimento sustentável.

Artigos 12.2 e 12.3 do Protocolo de Quioto (UNFCCC, 2001b):

Artigo 12.2 - O objetivo do Mecanismo de Desenvolvimento Limpo deve ser assistir às Partes não incluídas no Anexo I para que atinjam o desenvolvimento sustentável e contribuam para o objetivo final da Convenção, e assistir às Partes incluídas noAnexo I para que cumpram seus compromissos quantificados de limitação e redução de emissões, assumidos no Artigo 3.

Artigo 12.3 - Sob o Mecanismo de Desenvolvimento Limpo:

(a) As Partes não incluídas no Anexo I beneficiar-se-ão de atividades de projetos que resultem em reduções certificadas de emissões; $e$

(b) As Partes incluídas no Anexo I podem utilizar as reduções certificadas de emissões, resultantes de tais atividades de projetos, para contribuir com o cumprimento de parte de seus compromissos quantificados de limitação e redução de emissões, assumidos no Artigo 3, como determinado pela Conferência das Partes na qualidade de reunião das Partes deste Protocolo.

A princípio, os projetos de MDL seriam divididos nas seguintes modalidades: 
Fontes renováveis e alternativas de energia;

Eficiência / conservação de energia; e,

$>$ Reflorestamento e estabelecimento de novas florestas ${ }^{2}$.

Os créditos das reduções certificadas de emissões podem advir a partir de 2000:

Artigo 12.10 do Protocolo de Quioto (UNFCCC, 2001b):

Artigo 12.10 - Reduções certificadas de emissões obtidas durante o período do ano 2000 até o início do primeiro período de compromisso podem ser utilizadas para auxiliar no cumprimento das responsabilidades relativas ao primeiro período de compromisso.

Para que isso se concretize, é fundamental, como primeiro passo, o estabelecimento de um Conselho Executivo do MDL (Executive Board) e também que a Conferência das Partes, na qualidade de reunião das Partes do Protocolo (COP/MOP), designe entidades operacionais cujas funções incluam certificação.

Artigo 12.4 do Protocolo de Quioto (UNFCCC, 2001b):

Artigo 12.4 - O Mecanismo de Desenvolvimento Limpo deve sujeitar-se à autoridade e orientação da Conferência das Partes na qualidade de reunião das Partes deste Protocolo e à supervisão de um conselho executivo do Mecanismo de Desenvolvimento Limpo.

O Conselho Executivo deve unir os interesses egítimos das Partes do Protocolo e deve ser composto de forma equilibrada por Partes incluídas e também por Partes não incluídas no ANEXO I. As funções do Conselho Executivo devem abranger:

\footnotetext{
${ }^{1}$ Em inglês: Clean Development Mechanism, CDM.

${ }^{2}$ É nesta modalidade que estão a maioria dos projetos de seqüestro de carbono, ou no inglês, "carbon sink".
} 
$>$ Promoção e transparência de mercado;

Responsabilidade final pela certificação e verificação das reduções; e,

Registro e validação das agências de certificação.

A certificação de projetos propriamente dita deve ser atribuída a instituições que estejam trabalhando diretamente sob a direção e supervisão rigorosa do Conselho Executivo; deve ter um processo regulatório e de auditoria forte, ser transparente e com credibilidade.

Artigos 12.5, 12.6 e 12.7 do Protocolo de Quioto (UNFCCC, 2001b):

Artigo 12.5 - As reduções de emissões resultantes de cada atividade de projeto devem ser certificadas por entidades operacionais a serem designadas pela Conferência das Partes na qualidade de reunião das Partes deste Protocolo, com base em:

(a) Participação voluntária aprovada por cada Parte envolvida;

(b) Benefícios reais, mensuráveis e de longo prazo relacionados com a mitigação da mudança do clima, $e$;

(c) Reduções de emissões que sejam adicionais as que ocorreriam na ausência da atividade certificada de projeto.

Artigo 12.6 - O Mecanismo de Desenvolvimento Limpo deve prestar assistência quanto à obtenção de fundos para atividades certificadas de projetos quando necessário.

Artigo 12.7- A Conferência das Partes na qualidade de reunião das Partes deste Protocolo deve, em sua primeira sessão, elaborar modalidades e procedimentos com o objetivo de assegurar transparência, eficiência e prestação de contas das atividades de projetos por meio de auditorias e verificações independentes.

Um diagrama sobre as diferentes etapas que um projeto deverá seguir para receber os CER dentro do MDL pode ser visto na Figura 3. 


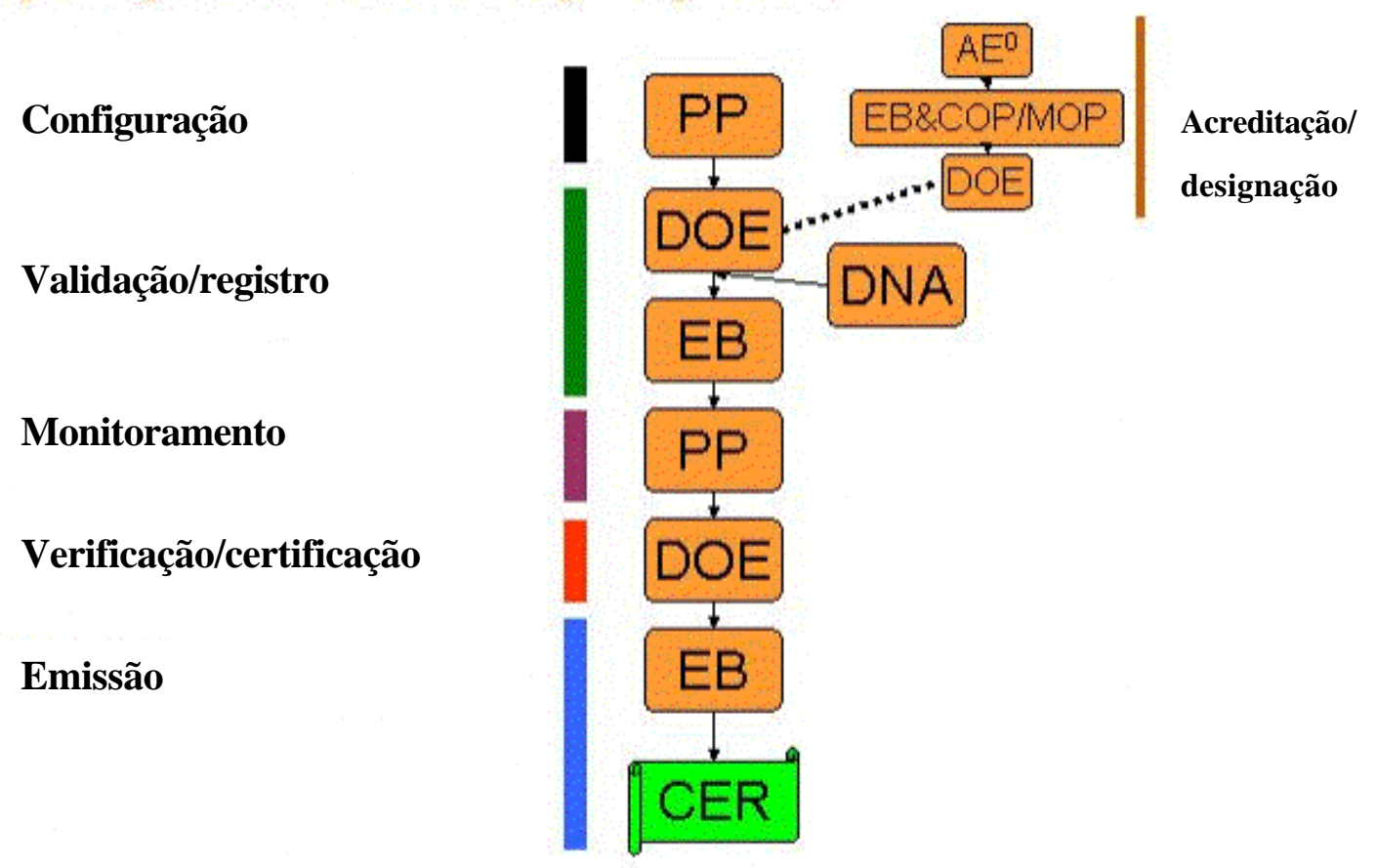

Figura 3 - Ciclo de um projeto de MDL proposto pelo Comitê Executivo.

Fonte: UNFCCC (2002c)

Legenda:

PP - Participantes do projeto

$\mathrm{AE}$ - Entidade proponente

EB - Comitê Executivo do MDL

DOE - Entidade operacional designada

DNA - Autoridade nacional designada para o MDL

CER - Certificado de redução de emissões

De acordo com as regras estabelecidas nas COPs, a participação em um projeto de MDL deve ser voluntária. As Partes interessadas em participar do MDL devem, em primeiro lugar, designar uma autoridade nacional (DNA) que será responsável pela aprovação ou não dos projetos de MDL no país hospedeiro.

$\mathrm{Na}$ fase de configuração do projeto, é necessário estabelecer a adicionalidade e a linha de base (baseline) do projeto, além da metodologia de monitoramento que será utilizada para verificar o cumprimento das metas de redução de emissões e/ou de seqüestro de carbono. As atividades de um projeto de MDL são consideradas adicionais 
se as emissões antropogênicas de GEE forem menores que as que ocorreriam na ausência do projeto; e/ou se o seqüestro de carbono for maior aquele que ocorreria na ausência do projeto. A linha de base de um projeto de MDL é o cenário que representa as emissões antropogênicas de GEE que ocorreriam na ausência do projeto. Para auxiliar as Partes na apresentação de tais informações, o Comitê Executivo do MDL (EB) desenvolveu um documento base denominado "project design document" (PDD) ${ }^{3}$.

A entidade operacional designada (DOE) selecionada pelos participantes do projeto (PP) para validar o projeto deve revisar o PDD e outros documentos relevantes, tais como comentários das partes interessadas ("stakeholders") e possíveis impactos ambientais do projeto. O Comitê Executivo irá dizer se aceita ou não a linha de base e a metodologia de monitoramento propostas. Uma vez aceitas, o projeto pode ser registrado no Comitê Executivo. O registro é um pré-requisito para a verificação, certificação e emissão dos CER.

Uma vez registrado o projeto passa para a fase de monitoramento, a ser feito de acordo com a metodologia previamente aprovada. Esse monitoramento irá acontecer seguindo um plano estabelecido pela metodologia e terá como resultados relatórios que serão submetidos para a entidade operacional para a verificação do projeto. A verificação é a revisão periódica e independente realizada pela entidade operacional e o monitoramento posterior às reduções de GEE e/ou seqüestro de carbono ocorridos durante o período de verificação. A certificação, por sua vez, é a garantia por escrito, dada pela entidade operacional, de que durante um determinado período o projeto alcançou as reduções de GEE e/ou seqüestro de carbono propostos.

Com a certificação, é possível solicitar do Comitê Executivo a emissão dos CER relativos à quantidade reduzida e/ou seqüestrada.

\footnotetext{
${ }^{3}$ Uma cópia do PDD pode ser obtida em http://unfccc.int/cdm.
} 


\subsection{Outros mecanismos de flexibilização}

Além do MDL, existem outros dois mecanismos de flexibilização incluídos no Protocolo de Quioto. São eles o Comércio de Emissões (Emissions Trade) e a Implementação Conjunta (JI). Entretanto esses mecanismos não podem ser utilizados pelo Brasil, porque são válidos apenas para os países membros do ANEXO I, dessa forma, não serão abordados nesta tese.

\subsubsection{Comércio de Emissões}

Também denominado Emission Trade é definido no Artigo 17 do Protocolo de Quioto. Cada país do ANEXO I pode comercializar parte da redução de suas emissões que exceder as metas compromissadas.

Artigo 17 do Protocolo de Quioto (UNFCCC, 2001b):

Artigo 17 - A Conferência das Partes deve definir os princípios, as modalidades, regras e diretrizes apropriados, em particular para verificação, elaboração de relatórios e prestação de contas do comércio de emissões. As Partes incluídas no Anexo B podem participar do comércio de emissões com o objetivo de cumprir os compromissos assumidos sob o Artigo 3. Tal comércio deve ser suplementar às ações domésticas com vistas a atender os compromissos quantificados de limitação e redução de emissões, assumidos sob esse Artigo.

\subsubsection{Implementação Conjunta (JI)}

Foi um instrumento proposto pelos EUA, que permite a negociação bilateral de implementação conjunta de projetos de redução de emissões de GEE entre países integrantes do ANEXO I.

Através do JI, um país industrializado, pode compensar suas emissões participando de sumidouros e projetos de redução de emissões em outro país do ANEXO I. Implica, portanto, em constituição e transferência do crédito de emissões de gases de efeito estufa do país em que o projeto está sendo implementado para o país emissor. Este 
pode comprar "crédito de carbono" e, em troca, constituir fundos para projetos a serem desenvolvidos em outros países. Os recursos financeiros obtidos serão aplicados necessariamente na redução de emissões ou em remoção de carbono.

Artigo 6.1 do Protocolo de Quioto (UNFCCC, 2001b):

Artigo 6.1 - A fim de cumprir os compromissos assumidos sob o Artigo 3, qualquer Parte incluída no Anexo I pode transferir para ou adquirir de qualquer outra dessas Partes unidades de redução de emissões resultantes de projetos visando a redução das emissões antrópicas por fontes ou o aumento das remoções antrópicas por sumidouros de gases de efeito estufa em qualquer setor da economia, desde que:

(a) O projeto tenha a aprovação das Partes envolvidas;

(b) O projeto promova uma redução das emissões por fontes ou um aumento das remoções por sumidouros que sejam adicionais aos que ocorreriam na sua ausência;

(c) A Parte não adquira nenhuma unidade de redução de emissões se não estiver em conformidade com suas obrigações assumidas sob os Artigos 5 e 7; $e$

(d) A aquisição de unidades de redução de emissões seja suplementar às ações domésticas realizadas com o fim de cumprir os compromissos previstos no Artigo 3.

\subsection{0 "Acordo de Bonn"4}

Na Conferência das Partes realizada em Haia (Holanda), entre os dias 13 e 25 de novembro de 2000 (COP 6), não foi possível estabelecer as regras operacionais do Protocolo de Quioto, em especial devido a divergências entre os Estados Unidos e países europeus. Em função do impasse criado, a Conferência foi suspensa.

Em 28 de março de 2001, a EPA (Environmental Protection Agency) anunciou oficialmente que o EUA não tinha mais interesse em prosseguir com as negociações internacionais para a implementação do Protocolo de Quioto. Cabe lembrar que o EUA é um dos principais emissores de GEE. Dessa forma, a retomada das negociações em

\footnotetext{
${ }^{4}$ Esta seção está baseada nas anotações de viagem do autor, que participou da COP 6 BIS como membro da delegação brasileira.
} 
Bonn (Alemanha), entre 16 e 27 de julho, foi fundamental para definir a sobrevivência e os novos rumos do Protocolo. Esta Conferência ficou conhecida como COP 6 BIS.

A COP 6 BIS foi definida como a Conferência que "salvou" o Protocolo de Quioto, através do estabelecimento de um acordo político entre as Partes. O "Acordo de Bonn”, segundo o então ministro de Energia da Nova Zelândia, Peter E. Hodgson, pode ser considerado o mais difícil da história da humanidade. A razão de tanto entusiasmo é o fato de que muito poucos analistas apostavam em um resultado positivo para a COP 6 BIS. Porém, a euforia durou pouco. Já na segunda semana da COP 6 BIS, muitos começaram a criticar as concessões que foram feitas para atingir tal Acordo, como também começaram a fazer diferentes interpretações do mesmo.

As concessões foram feitas em especial para garantir a permanência de países como o Japão e a Federação Russa; ao mesmo tempo em que procuravam respeitar os interesses da União Européia e dos países subdesenvolvidos. Algumas dessas concessões dizem respeito à utilização de sumidouros de carbono ("sinks") como créditos para os países da “Umbrella Group” (Japão, Austrália, Canadá e Federação Russa).

Quanto às diferentes interpretações que começaram a ser dadas ao Acordo durante o processo de transformá-lo em decisões práticas, merecem destaque as diferentes leituras dos temas LULUFC (Land Use, Land Use Change and Forestry) e "regime de cumprimento". A Federação Russa se opôs fortemente ao valor a ela concedido para a utilização de suas florestas como créditos de abatimento de seus compromissos. Já no tema de "regime de cumprimento", as diferentes leituras podem ser explicadas devido à saída dos EUA do processo de negociação. Durante a COP 6 os EUA, juntamente com a União Européia, Canadá e países do G77/China (países em desenvolvimento) sugeriram um sistema de "regime de cumprimento" que seria obrigatório e com penalidades para aqueles que não honrassem seus compromissos. Por outro lado, a Austrália, Japão e a Federação Russa preferiam um sistema mais brando. Com a saída dos EUA e a necessidade de se garantir a ratificação por parte do Japão e Federação Russa, muitos países começaram a rever suas posições e a interpretar de 
forma diferente o "Acordo de Bonn".

\subsection{A COP 7 e o "Acordo de Marrakesh" 5}

Com um acordo político (Acordo de Bonn) frágil nas mãos, 172 Partes, totalizando 2.432 delegados, iniciaram em 29 de outubro de 2001, em Marrakesh, as negociações da COP 7 para tentar definir as regras operacionais do Acordo de Bonn e do Protocolo de Quioto. Ao final de duas semanas de muitas negociações oficiais e de bastidores, foi fechado um pacote com tais regras, mantendo a integridade política do Acordo de Bonn e a integridade ambiental do Protocolo de Quioto.

Para se chegar a tal pacote, foi necessário que a União Européia e o Grupo G77/China (do qual faz parte o Brasil) cedessem espaço aos países do "Umbrella Group" (Japão, Austrália, Canadá e Federação Russa). O objetivo destes países era conseguir um Acordo em que o "regime de cumprimento" fosse não vinculante, ou seja, não obrigatório, que houvesse poucos critérios de elegibilidade para a utilização dos mecanismos de flexibilização (MDL, Implementação Conjunta e Emission Trading), que houvesse pouca participação pública e transparência, e que não houvesse necessidade de fornecer informações detalhadas sobre sumidouros. Para os mais pessimistas, esses objetivos foram alcançados, de tal maneira que o Protocolo não será capaz de reduzir as emissões de GEE 5,2\% abaixo dos níveis de 1990. Isto ocorreria principalmente, devido à ausência dos EUA, das dificuldades em medir os poços de carbono de floresta e agricultura e da grande quantidade de "hot air" da Federação Russa (excesso de reduções de emissões disponíveis naquele país, devido ao colapso da economia desde 1991). Porém existem interpretações mais otimistas que chegam a afirmar que "um acordo barato é melhor do que nenhum acordo" e que a real importância do Protocolo está no fato de que ele é apenas o primeiro passo para o estabelecimento de reduções futuras.

\footnotetext{
${ }^{5}$ Esta seção está baseada nas anotações de viagem do autor, que participou da COP 7 como membro da delegação brasileira.
} 
O Acordo de Marrakesh, entre os pontos, define as regras operacionais para LULUCF (Land Use, Land Use Change and Forestry), para os mecanismos de flexibilização e para os Artigos 5, 7 e 8 que tratam, respectivamente, da definição do sistema nacional para o inventário de emissões, das informações adicionais à Convenção derivadas do Protocolo e do processo de revisão das comunicações nacionais.

De maneira geral, o Acordo determinou que o não cumprimento irá ter conseqüências legais, incluindo a impossibilidade de participar dos mecanismos de mercado. É importante ressaltar que este regime só irá ocorrer depois que o Protocolo entrar em vigor, na $1^{\text {a }}$. Conferência das Partes servindo de Reunião das Partes do Protocolo (COP/MOP).

No Acordo de Marrakesh foram estabelecidas regras que limitarão a utilização de créditos oriundos de florestas e agricultura, incluindo a criação de uma nova unidade de medição (RMU - Removal Unit) que não poderá ser transferida para períodos de cumprimento futuros (banking). A transferência de outras unidades (AAU/CER/ERU ${ }^{6}$ ) para períodos futuros de compromissos será permitida, porém créditos gerados por MDL e JI terão limites máximos para transferência. A transferência de AAU/CER/ERU/RMU entre as Partes do ANEXO I será irrestrita.

Existirá fungibilidade entre todas as unidades, o que irá contribuir para um mercado com maior liquidez. Projetos unilaterais de MDL (sem a participação de um país do ANEXO I) serão permitidos. Fundos internacionais foram estabelecidos para auxiliar os países menos desenvolvidos a se adaptarem aos efeitos das mudanças climáticas, entre eles o Fundo de Adaptação que será mantido com uma taxa de $2 \%$ sobre os projetos de MDL.

\footnotetext{
${ }^{6}$ AAU - assigned amount units (permissões de emissões); CER - certified emission reduction (créditos gerados por projetos de MDL); ERU - emissions reduction units (créditos gerados por projetos de JI).
} 
Outro resultado importante da COP 7 foi a criação do Comitê Executivo do MDL, do qual faz parte um brasileiro (Luiz Gylvan Meira Filho). Este Conselho estará autorizado a aprovar metodologias de linhas de base, planos de monitoramento e limites para projetos, acreditar entidades operacionais e desenvolver e manter registros dos projetos de MDL.

Por fim merece destaque como resultado da COP 7, a declaração que foi enviada à RIO+10 (World Summit on Sustainable Development, realizada em setembro de 2002 na África do $\mathrm{Sul}$ ), em que foi enfatizada a estreita relação que existe entre o desenvolvimento sustentável e mudanças climáticas. Nesse documento são reafirmadas como prioridades dos países em desenvolvimento a erradicação da pobreza e o desenvolvimento; além do que foi chamada a atenção dos países para a sinergia que existe entre as Convenções do Clima, Biodiversidade e Desertificação.

\subsection{Objetivos}

Este trabalho tem como objetivo geral caracterizar o "mercado de carbono", em especial a participação do Brasil através do MDL. Será feita uma análise de como este mercado está sendo formado e como deverá ser sua evolução até a possível formação de mercados futuros de CER.

Os objetivos específicos são: 1) Determinar o tamanho do mercado global de CER e a participação do Brasil (através do MDL) em diversos cenários; e 2) Analisar se os certificados de emissões reduzidas (CER) gerados em projetos de MDL de seqüestro de carbono (florestamento e reflorestamento) poderão se tornar uma "commodity ambiental'.

Para tanto, o trabalho está dividido da seguinte maneira: Introdução onde são apresentadas a Convenção do Clima e as COP, o Mecanismo de Desenvolvimento Limpo, o "Acordo de Bonn" e o "Acordo de Marrakesh"; Revisão de Literatura sobre projetos de seqüestro de carbono, commodities ambientais, instrumentos de mercado 
para "emission trade" e a formação do mercado de carbono; Metodologia, onde é descrito o Modelo CERT (Carbon Emission Reduction Trade), utilizado para determinar o tamanho do mercado de CER e a participação do Brasil; Resultados e Discussão sobre os cenários de referência e alternativos do Modelo; e Conclusões sobre a viabilidade da aplicação do Modelo, tamanho do mercado, participação brasileira e a possível comoditização dos CER. 


\section{REVISÃO DE LITERATURA}

\subsection{As atividades de LULUCF (seqüestro de carbono)}

As atividades de Uso da Terra, Mudança de Uso da Terra e Florestas (em inglês Land Use, Land Use Change and Forestry - LULUCF), chamadas por muitos de sumidouros ("sinks"), sempre foram motivos para controvérsias dentro do processo de negociação da Convenção do Clima. O fracasso da COP 6 pode ser explicado, em parte, pela divergência existente entre vários países quanto à utilização de tais atividades para atingir as metas de redução de emissões de GEE.

A fim de solucionar os impasses criados dentro deste tema, na COP 7 as Partes acordaram que os projetos de seqüestro de carbono relacionados à LULUCF devem ser elaborados de acordo com os seguintes princípios (UNFCCC, 2002d):

(a) As atividades de LULUCF devem ser baseadas em sólido conhecimento científico;

(b) Metodologias consistentes devem ser utilizadas ao longo do tempo para determinação das estimativas (de seqüestro de carbono) e do monitoramento das atividades de LULUCF;

(c) A meta estabelecida no Artigo 3.1 do Protocolo de Quioto não deve ser alterada pela contabilização das atividades de LULUCF;

(d) A simples presença de estoques de carbono deve ser excluída da contabilidade;

(e) A implementação de atividades de LULUCF deve contribuir para a conservação da biodiversidade e para o uso sustentável dos recursos naturais;

(f) A contabilização de atividades de LULUCF não implica na transferência de 
compromissos para períodos futuros;

(g) A reversão das atividades de LULUCF deve ser contabilizada em um determinado período do tempo;

(h) A contabilização exclui a remoção (seqüestro) proveniente de: i) concentrações elevadas de $\mathrm{CO}_{2}$ acima do seu nível pré-industrial; ii) deposição indireta de nitrogênio; e iii) dos efeitos dinâmicos resultantes do crescimento decorrente de atividades e práticas anteriores ao ano de referência.

A COP 7 também decidiu que para projetos de MDL, somente serão elegíveis as atividades de reflorestamento e florestamento e que, para o primeiro período de compromisso (2008-2012), o total de CER resultante desses projetos utilizados por uma Parte para contabilizar suas reduções não pode ser superior a 1\% das emissões do anobase multiplicado por cinco (UNFCCC, 2002d). Esse limite evidentemente traz restrições ao tamanho do mercado de CER, como será visto na seção Resultados e discussão.

É preciso estar atento para o fato de que existem vários tipos de atividade de LULUCF e cada uma delas apresenta características distintas. A Tabela 3 apresenta as diferenças entre os diversos tipos de atividades.

Tabela 3. Análise de diferentes atividades de LULUCF.

\begin{tabular}{lccccc}
\hline $\begin{array}{c}\text { Natureza das } \\
\text { Atividades }\end{array}$ & $\begin{array}{c}\text { Carbono } \\
\text { retirado ano } \\
\text { ton. C/ha/ano }\end{array}$ & $\begin{array}{c}\text { Rotação } \\
\text { (anos) }\end{array}$ & $\begin{array}{c}\text { Total carbono } \\
\text { retirado, } \\
\text { rotação }\end{array}$ & $\begin{array}{c}\text { Custo ton. } \\
\text { Carbono/ha } \\
\text { (US\$) }\end{array}$ & $\begin{array}{c}\text { Ciclo vida } \\
\text { carbono } \\
\text { (anos) }\end{array}$ \\
\hline Reflorestamento & $10-14$ & 10 & $100-140$ & $2-5$ & $2-50$ \\
Agroflorestas & $6-9$ & 40 & $240-360$ & $4-8$ & $5-100$ \\
Restauração & $8-12$ & $>100$ & $800-1200$ & $5-9$ & $\begin{array}{c}\text { Acima de } \\
100\end{array}$ \\
\hline
\end{tabular}

Fonte: Adaptado de Amaral (1999) 


\subsubsection{As atividades de LULUCF no Brasil}

\subsubsection{A Comissão Interministerial de Mudança Global do Clima}

Conforme apontado na Figura 1, cada país deverá ter a sua Autoridade Nacional Designada para o MDL, cujo objetivo principal é aprovar ou não dos projetos de MDL no país hospedeiro. Em outras palavras, essa entidade deverá definir se os projetos de MDL estão cumprindo com o seu objetivo duplo: redução das emissões de GEE e/ou seqüestro de carbono; e, a promoção do desenvolvimento sustentável.

No Brasil, foi criada em 07 de julho de 1999 a Comissão Interministerial de Mudança Global do Clima, "com a finalidade de articular as ações de governo decorrentes da Convenção Quadro das Nações Unidas sobre Mudança do Clima e seus instrumentos subsidiários de que o Brasil seja parte" (Brasil, 1999).

A Comissão é integrada por representantes dos seguintes Ministérios: Relações Exteriores, Agricultura e do Abastecimento, Transportes, Minas e Energia, Planejamento, Orçamento e Gestão, Meio Ambiente, Ciência e Tecnologia,

Desenvolvimento, Indústria e Comércio Exterior e da Casa Civil da Presidência da República. Aos ministros de Ciência e Tecnologia e do Meio Ambiente, cabem, respectivamente, a presidência e a vice-presidência da Comissão.

Dentre as atribuições da Comissão, merecem destaque a emissão de pareceres e o fornecimento de subsídios para políticas setoriais e posições do governo nas negociações da Convenção. Compete também "definir critérios de elegibilidade conforme as políticas nacionais de desenvolvimento sustentável" (Brasil, 1999). A Secretaria de Qualidade Ambiental nos Assentamentos Humanos (SQA), do Ministério do Meio Ambiente está elaborando uma lista de critérios e indicadores de elegibilidade para avaliação de projetos candidatos ao MDL (Brasil, 2002) ${ }^{7}$.

Caberá à Comissão ainda a "apreciação de pareceres sobre projetos que resultem em redução de emissões e que sejam considerados elegíveis para MDL e aprová-los, se for o caso" (Brasil, 1999). Como o Brasil ainda não definiu os critérios 
de elegibilidade os projetos de MDL que estão sendo desenvolvidos, ainda não tem uma aprovação oficial.

\subsubsection{Projetos de LULUCF no Brasil}

Os projetos que se enquadram nas atividades de LULUCF no Brasil que merecem destaque são os seguintes ${ }^{8}$ :

- Plantar - Minas Gerais (Curvelo, Itacambira e Sete Lagoas): inicialmente o projeto propunha, através do plantio de eucalipto e da produção de carvão vegetal, evitar a emissão (consumo de carvão mineral) de 2.117.381 toneladas de carbono e seqüestrar 953.100 toneladas de carbono durante um período de 21 anos. O total de créditos gerados estava sendo negociado por US\$13.648.033,40. O projeto da Plantar foi aceito pelo PCF (Prototype Carbon Fund) ${ }^{9}$ e deverá vender para o fundo do Banco Mundial apenas os créditos oriundos da substituição de carvão mineral por carvão vegetal (PCF, 2002a).

- Peugeot - Mato Grosso: a empresa automotiva francesa investiu US\$ 15 milhões num projeto de recuperação florestal, em Jurema, no Mato Grosso, visando ao seqüestro de carbono atmosférico, porém sem o objetivo de comercialização de CER. Esse projeto deverá cobrir uma área de 12.000 hectares, terá a capacidade de armazenar cerca de 50.000 toneladas métricas de carbono por ano, ou o equivalente a 183.000 toneladas métricas de $\mathrm{CO}_{2} /$ ano. Para tanto estima-se que serão plantadas cerca de 10 milhões de árvores (Peugeot, 2000).

- CSW-Utilities em Guaraqueçaba/PR: a Central and South West Corporation (CSW) investiu US\$ 5,4 milhões na conservação e preservação de 7.000 ha de mata atlântica no Paraná. Participam dessa iniciativa The Nature Conservancy

\footnotetext{
${ }^{7}$ A lista preliminar pode ser visto no Apêndice 4.

${ }^{8}$ Cabe notar que cada um deles se encontra em fases distintas de implementação, sendo que alguns são ainda propostas.

${ }^{9}$ Uma descrição do PCF pode ser vista na seção O Prototype Carbon Fund do Banco Mundial na página 54.
} 
(TNC) e a Sociedade de Pesquisa em Vida Selvagem (SPVS). "O projeto de Ação Contra o Aquecimento Global, implantado pela SPVS em Guaraqueçaba, prevê a proteção e o gerenciamento de cerca de 7 mil hectares de Floresta Atlântica, além de promover a recuperação de áreas desmatadas e gerar oportunidades de desenvolvimento econômico compatíveis com o meio ambiente para as comunidades vizinhas. Na área será desenvolvido um projeto experimental para estabelecer e testar metodologias de mensuração dos gases de efeito estufa, especialmente dióxido de carbono $\left(\mathrm{CO}_{2}\right)$. O trabalho visa diminuir a ameaça do aquecimento global e contribuir com subsídios técnicos na avaliação de futuros projetos de combate à emissão de gases de efeito estufa na atmosfera. É a primeira experiência de mensuração de carbono realizada na Floresta Atlântica” (SPVS, 2002).

- AES-Barry na Ilha do Bananal/MS: "O principal objetivo do Projeto de Sequiestro de Carbono da Ilha do Bananal e seu Entorno (PSCIB) é desenvolver e implementar um sistema inovador, eqüitativo e sustentável para equilibrar as emissões dos gases causadores do efeito estufa através do Seqüestro de Carbono, compatível com as realidades sociais e ambientais da região da Ilha do Bananal. O Projeto será desenvolvido em um período de vinte e cinco anos" (Rezende, 2001). As estimativas de seqüestro e a garantia da preservação de estoque de carbono, considerando-se o horizonte de 25 anos, são assim calculadas: 1) Preservação de 200 mil hectares, incluindo florestas de terra firme e florestas alagadas: 200.000 x 105 t/C = 21.000.000 t/C; 2) Regeneração de 60 mil hectares de áreas de florestas e cerrado: 60.000 x 65 t/C = 3.900.000 t/C; 3) Implantação de Sistemas Agroflorestais: 3.000 hectares x $70 \mathrm{t} / \mathrm{C}=210.000 \mathrm{t} / \mathrm{C}$ (Rezende et al., 2001).

- Manejo de Babaçuais - Carajás - Instituto Pró-Natura: "O projeto proposto difundirá tecnologia para manejo e enriquecimento de florestas nativas da palmeira babaçu para aumentar a biomassa e a produtividade do coco, seqüestrar carbono e produzir carvão, amêndoa oleaginosa e outros bio-produtos do coco babaçu". O projeto prevê o seqüestro de 175.000 t/C/ano, além da compensação 
da emissão de 64.000 t/C/ano, decorrente da substituição do coque mineral nos fornos de ferro-gusa de Carajás. Com a incorporação dos CER (US\$ 5,00/t C) estima-se uma taxa interna de retorno de 15,8\% (Brazil/U.S. Aspen Global Forum, 2000).

- Plantação de Teca/MT: com o plantio de 3 mil ha de teca no Mato Grosso espera-se que haja o seqüestro de 325.000 t/C (rotação perpétua) ou $178.000 \mathrm{t} / \mathrm{C}$ (período de 30 anos). Nesse projeto, o valor presente líquido, com a venda de CER, seria de US\$ 3,5 a 4,6 milhões (rotação perpétua) ou de US\$ 3,5 a 3,6 milhões (período de 30 anos). Sem a venda, o valor presente líquido seria de US\$ 2,0 milhões para a rotação perpétua, assim como para o período de 30 anos. Cabe ressaltar que os valores acima foram calculados para uma taxa de desconto de 15\% (Brazil/U.S. Aspen Global Forum, 2000).

- Plantação de Seringueira/MT: o projeto consiste na plantação de 1 mil ha de Hevea brasiliensis. Estima-se que em rotação perpétua o projeto venha a seqüestrar $239.000 \mathrm{t} / \mathrm{C}$, enquanto que com uma vida útil de 35 anos sejam seqüestradas $107.000 \mathrm{t} / \mathrm{C}$. O valor presente líquido estimado sem os créditos de carbono seria de US\$ 2,2 milhões para a rotação perpétua. Com a venda dos CER, o valor presente líquido passa a ser de US\$ 3,3 milhões. Não foram observadas diferenças significativas quando os cálculos foram feitos para o período de 35 anos. Porém, a taxa de desconto influi significativamente: alterando a taxa de $15 \%$ para $20 \%$, os valores passam para US\$ 381 mil e US\$ 1,2 milhão, respectivamente, sem a venda e com a venda de CER (Meyers et al., 2000).

- Plantação de Dendê/PA: o projeto pretende estabelecer 5 mil ha de palmeiras no Estado do Pará, seqüestrando, com isso 649.000 t/C no sistema de rotação perpétua e 504.000 t/C em um manejo de 32 anos. Sem a venda de CER, o valor presente líquido para o projeto é de - US\$ 465 mil e - US\$ 555 mil, respectivamente, para a rotação perpétua e para o manejo de 32 anos. Com a venda de CER, esses valores passam a US\$ 305 mil e US\$ 197 mil, respectivamente (Meyers et al., 2000). 
- 'Projeto Corumbatẩ”: esse projeto prevê a utilização do MDL como uma fonte de recursos para a recuperação dos fragmentos florestais e reflorestamento de áreas degradadas. Propõe-se a recuperação da mata ciliar na Bacia do Corumbataí, abrangendo uma área total de 28.750 ha, com o potencial seqüestro de 1.838.000 t/C (Manfrinato \& Viana, 1999).

- Fundo Especial para Controle do Efeito Estufa - Proflorar: esse projeto prevê que as fontes fixas e móveis emissoras de GEE do Estado do Rio de Janeiro destinem recursos para o plantio de florestas de fins econômicos e ambientais, assim como também para a preservação de florestas nativas existentes (Berna, 2000).

- Projeto FLORAM - Florestas para o Meio Ambiente: conceito desenvolvido no Instituto de Estudos Avançados da USP, no início da década de 80, consistindo em projetos de reflorestamento em grande escala (14 milhões de hectares em 20 a 30 anos). Apesar de nunca ter sido colocado em prática, vem sendo novamente debatido, buscando o estabelecimento de projetos-modelo (florestas de rápido crescimento, recuperação de áreas degradadas, atividades agroflorestais e florestas sociais - reflorestamento urbano).

- Os projetos canavieiros: segundo Macedo (2000), o balanço líquido das emissões na agroindústria canavieira com o uso do etanol é bastante favorável: são evitadas emissões de aproximadamente $12 \times 10^{6}$ toneladas de carbono. Reduzindo-se em 55\% a área de cana queimada e com a recuperação de $50 \%$ da palha, seriam evitadas $25 \times 10^{6}$ toneladas de $\mathrm{CO}_{2} /$ ano (Macedo, 2000). Moraes (1999) salienta as oportunidades de captação de recursos externos pela agroindústria canavieira no mercado de carbono. Como exemplo de um "projeto canavieiro" podemos citar a co-geração de eletricidade a partir de bagaço de cana, realizada pela Cia. Vale do Rosário. Espera-se que sejam evitadas a emissão de 168.000 t/C durante toda a vida útil do projeto e que este possua uma taxa interna de retorno de 33\% com a venda de CER (Brazil/U.S. Aspen Global Forum, 2000).

O Fundo Nacional do Meio Ambiente (FNMA) lançou em novembro de 2001 
um edital para a "seleção de propostas orientadas a projetos que contribuam para a mitigação das mudanças climáticas e para a promoção do desenvolvimento sustentável". Os recursos do Edital foram provenientes do Projeto de Cooperação Técnica firmado entre o governo brasileiro e o governo do Reino dos Países Baixos que tem por objetivo “o apoio direto e descentralizado a projetos-piloto em bases locais, visando a geração de conhecimentos (técnicos, científicos e sociais) que contribuam para a implementação dos tratados ambientais internacionais que envolvam os temas Mudanças Climáticas e Desertificação" (FNMA, 2001).

O edital foi composto por duas chamadas descritas no Quadro 1.

\begin{tabular}{|l|c|c|c|c|}
\hline \multicolumn{1}{|c|}{ Chamadas } & \multirow{2}{*}{$\begin{array}{c}\text { Prazo Máximo } \\
\text { de Execução }\end{array}$} & \multicolumn{2}{c|}{ Valor de apoio (R\$) } & \multicolumn{1}{c|}{$\begin{array}{c}\text { Recursos } \\
\text { Previstos (R\$) }\end{array}$} \\
\cline { 5 - 5 } & & Mínimo & Máximo & \\
\hline $\begin{array}{l}\text { I. ESTUDO DE VIABILIDADE DE } \\
\text { PROJETO VOLTADO À ADOÇÃO DE } \\
\text { MDL }\end{array}$ & 6 meses & $20.000,00$ & $50.000,00$ & $300.000,00$ \\
\hline $\begin{array}{l}\text { II. IMPLEMENTAÇÃO DE PROJETO } \\
\text { DE “AÇÃO CLIMÂTICA” }\end{array}$ & 24 meses & $100.000,00$ & $750.000,00$ & $750.000,00$ \\
\hline
\end{tabular}

Quadro 2 - Chamadas do edital do FNMA (2001).

Fonte: FNMA (2001)

Foram aprovados os seguintes projetos na Chamada I (FNMA, 2002):

1. "Estudo de viabilidade para implantação de modelos de reflorestamento para seqüestro de carbono com produtores rurais na Amazônia", do Instituto Brasileiro de Pesquisas e Estudos Ambientais (Pró-Natura);

2. 'Estudo de viabilidade de projetos de 'carbono social' no Pontal do Paranapanema (SP)", do Instituto de Pesquisas Ecológicas (IPÊ);

3. "Melhoramento do processo produtivo de cerâmica estrutural com ação mitigadora para estabilização ou redução adicional nas emissões de gases de efeito estufa", da Universidade do Amazonas;

4. "Projeto de seqüestro de carbono e conservação da biodiversidade na área rural 
do campus da Escola de Agronomia da UFBA - Cruz das Almas", do Centro de Desenvolvimento Sustentável e Agroecológico de Sapucaia;

5. "Geração de energia através de uma usina termelétrica movida a biomassa para operar acoplada a uma pequena central hidrelétrica em Rondônia" e "A utilização da casca de arroz na co-geração de energia e a decorrente mitigação de gases que contribuem para o efeito estufa como Mecanismo de Desenvolvimento Limpo", ambos da Fundação Coordenação de Projetos, Pesquisas e Estudos Tecnológicos;

6. "Estudo de viabilidade para implantação de florestas fixadoras de carbono: estudo de caso no sul do estado do Paraná", do Instituto Ecoplan;

7. "Estudo de viabilidade de projeto de utilização do Mecanismo de Desenvolvimento Limpo (MDL) na área de ocorrência do mico-leão-dourado (leontopithecus rosalia)/Silva Jardim", da Associação Mico-Leão-Dourado;

8. "Estudo de viabilidade da implantação e operação de sistemas solares residenciais em comunidades rurais não-eletrificadas da Bahia para a redução da emissão de gases do efeito estufa", da Universidade de Salvador;

9. "Produção de energia renovável proveniente de resíduos florestais em Jaguaraíva”, da Fundação de Estudos Agrários Luiz de Queiroz;

10. "Reflorestamento de manguezais e o valor do resgate do seqüestro de carbono atmosférico", da Associação de Proteção a Ecossistemas Costeiros; e

11. "Estudo de viabilidade para projetos de ação climática em Santa Catarina, nas regiões dos municípios de Abelardo Luz e Santa Terezinha”, da Associação de Preservação do Meio Ambiente do Alto Vale do Itajaí.

Foram reprovados os projetos: "Semeando sustentabilidade", da Prefeitura de Guaçuí; "Ação climática e recuperação ambiental da microbacia do Ribeirão Lavapés", da Prefeitura de Botucatu; e "Estudo das mudanças climáticas em Santa Maria", da Fundação de Apoio à Tecnologia e Ciência.

$\mathrm{Na}$ Chamada II foi aprovado o "Projeto fotossíntese", da Prefeitura de Linhares. Foram reprovados: "Borracha natural - um produto ecológico no desenvolvimento sustentável", da Associação Nacional dos Fabricantes de Artefatos de Borracha; 
"Geração de energia através do aproveitamento do biogás do lixo, evitando a emissão de metano e sequiestrando $\mathrm{CO}_{2}$ " e "Implementação de planta de co-geração de energia elétrica e térmica, em Sinop/MT, utilizando-se como combustível a casca de arroz para mitigação de gases que contribuem para o efeito estufa", ambos da Fundação Coordenação de Projetos, Pesquisas e Estudos Tecnológicos; "Rio dourados vivos", da Associação de Recuperação Florestal Flora Sul; e "As mudanças climáticas em Santa Maria”, da Fundação de Apoio à Tecnologia e Ciência (FNMA, 2002).

\subsubsection{Atividades Conjuntamente Implementadas}

Esta seção apresenta exemplos de projetos de LULUCF durante a fase piloto da Implementação Conjunta. Esta fase piloto denominou-se Atividades Conjuntamente Implementadas (em inglês Activities Implemented Jointly - AIJ) e tem como principal objetivo identificar quais são os projetos mais sustentáveis para JI e MDL.

Em novembro de 1998, 122 projetos de AIJ forma iniciados, 43 em países em desenvolvimento e 79 em economias em transição. Os tipos de projetos iniciados foram: energia renovável, fontes de energia com pouca ou nenhuma utilização de carbono, biomassa, eficiência energética, mudança de combustíveis, florestas e hidroelétricas. Aproximadamente $75 \%$ desses projetos estavam relacionados com eficiência energética e combustíveis renováveis. Os projetos de LULUCF estão apresentados na Tabela 4.

Tabela 4. Projetos de "seqüestro de carbono" originados durante a fase de Atividades Conjuntamente Implementadas.

\begin{tabular}{lcccc}
\hline Tipo & País-Sede & Investidor & $\begin{array}{c}\text { Carbono Seqüestrado } \\
\left(\mathrm{CO}_{2} \text { equivalente em toneladas }\right)\end{array}$ & Duração (anos) \\
\hline Agricultura & México & EUA & 3.065 .333 & 30 \\
Agricultura & México & EUA & 3.255 & 60 \\
Florestamento & Vietnam & Austrália & 646.590 & 30 \\
Florestamento & Rússia & EUA & 292.728 & 60 \\
Florestamento & Chile & EUA & 3.977 .307 & 51 \\
Reflorestamento & Panamá & EUA & 57.640 & 25 \\
Reflorestamento & Costa Rica & EUA & 7.216 .000 & 46 \\
Reflorestamento & Costa Rica & Noruega & 230.842 & 25 \\
Reflorestamento & Rússia & EUA & 858.000 & 60 \\
Reflorestamento & México & EUA & 1.210 .000 & 30 \\
\hline
\end{tabular}




\begin{tabular}{lcccc}
\hline Conservação & Equador & EUA & 1.170 .108 & 30 \\
Conservação & Costa Rica & EUA & 1.342 .733 & 16 \\
Conservação & República Techca & Países Baixos & 9.834 .120 & 15 \\
Conservação & Bolívia & EUA & 55.345 .286 & 30 \\
Conservação & Indonésia & EUA & 134.379 & 40 \\
Conservação & Argentina & EUA & 1.430 .130 & 30 \\
Conservação & Belize & EUA & 10.184 .101 & 42 \\
Conservação & Chile & EUA & 6.359 .828 & 60 \\
Conservação & Costa Rica & EUA & 57.467 .271 & 25 \\
\hline
\end{tabular}

Fonte: Adaptado de UNFCCC (2002e)

É importante ressaltar que, nesta fase (AIJ), os projetos de conservação, também denominados de desmatamento evitado (emissões evitadas), ainda eram considerados elegíveis ao MDL. Foi somente com a realização da COP 7 que esta atividade foi considerada não elegível, ou seja, não poderia gerar certificados de emissões reduzidas. Observa-se também que os projetos variam bastante entre si, tanto em termos de duração como de escala: de 15 anos de duração até 60 e seqüestro de 3.255 toneladas de $\mathrm{CO}_{2}$ equivalente até a 57.467.271 toneladas. Os EUA foram os principais investidores nesta fase. Naquela época, o governo federal norte-americano ainda estava disposto a ratificar o Protocolo de Quioto. Existia também uma predominância de países hospedeiros na América Latina.

\subsubsection{Projetos de LULUCF em outros países}

Além dos projetos da fase piloto do JI, outros projetos de LULUCF foram iniciados, como pode ser visto na Tabela 5.

Tabela 5. Projetos de seqüestro de carbono em outros países.

\begin{tabular}{lccc}
\hline \multicolumn{1}{c}{ Projetos } & País & $\begin{array}{c}\text { Carbono seqüestrado durante a } \\
\text { vida útil do Projeto } \\
\text { (milhões de t) }\end{array}$ & Custo \\
\hline Agricultura, reflorestamento & EUA & 0,47 & US\$ 176.493 \\
Agroflorestas, & Guatemala & 15,5 a 58 & US\$ 14 milhões \\
reflorestamento, conservação & Paraguai & 14,6 & US\$ 3,4-4,5 milhões \\
Agroflorestas, conservação & EUA & 0,564 a 0,747 & Menos de US\$ 1,00 t/C \\
Florestamento & & & \\
\hline
\end{tabular}




\begin{tabular}{lccc}
\hline Florestas urbanas & EUA & 0,005 & US $\$ 10-15$ t/C \\
Manejo florestal & Malásia & 0,3 a 0,6 & US $\$ 450.000$ \\
Manejo florestal & Malásia & 0,379 & Menos de US\$ 1,00 t/C \\
Manejo florestal & Costa Rica & 2 & US $\$ 2,73$ t/C \\
Manejo florestal/conservação & Belize & 5 & US $\$ 2,6$ milhões \\
Manejo florestal/conservação & EUA & 0,242 & Menos de US $\$ 1,00$ t/C \\
Reflorestamento & Uganda & 7,1 & US $\$ 5,6$ milhões \\
Reflorestamento & República Techa & 1,6 & US $\$ 5,9$ milhões \\
Reflorestamento & Equador & 9,5 & US $\$ 5,6$ milhões \\
Reflorestamento & EUA & 0,25 & US $\$ 2,00$ t/C \\
Reflorestamento & EUA & 0,045 & Menos de US $\$ 2,00$ t/C \\
Reflorestamento & EUA & 0,066 & US $\$ 2,00-2,50 \mathrm{t} / \mathrm{C}$ \\
Uso da terra & Peru, Equador e Bolívia & 70 & US $\$ 2$ milhões \\
\hline
\end{tabular}

Fonte: Adaptado de World Resource Institute - WRI (2002)

Ao comparar esses novos projetos com os projetos de AIJ, observa-se que as atividades de conservação não existem isoladamente. Há uma diversidade maior de atividades. A escala continua bastante variada: de 0,005 milhão de toneladas de carbono seqüestrada até 70; assim como o custo por tonelada: de US\$ 0,03 a US\$ 15.

\subsection{Commodities ambientais}

Os Certificados de Emissões Reduzidas (CER) gerados pelos projetos de Mecanismo de Desenvolvimento Limpo (MDL) decorrentes de atividades de LULUCF nada mais serão do que títulos. Esses títulos terão uma padronização, que está sendo negociada através das Conferências das Partes. Essa padronização poderá criar um certificado/título com características homogêneas a tal ponto que o CER torne-se uma commodity? Nesse caso, seria uma commodity ambiental, uma vez que o seu valor deriva de um produto/serviço ambiental?

De forma geral, uma commodity pode ser definida como: "Um artigo de comércio ou um produto que pode ser utilizado para comércio. Os tipos de commodity incluem produtos agrícolas, metais, petróleo, moedas estrangeiras e instrumentos 
financeiros e indices, entre outros." (Chicago Board of Trade - http://www.cbot.com).

Segundo Khalili (2000), "as commodities ambientais são mercadorias originadas de recursos naturais: água, energia, madeira, biodiversidade, reciclagem, emissão de poluentes e minério, ou seja, matérias-primas vitais para a sobrevivência da agricultura no Brasil e no mundo".

O Sindicato dos Economistas do Estado de São Paulo, através do Projeto CTA (Consultant, Trade and Adviser) ${ }^{10}$ propõe a criação de uma Bolsa Brasileira de Commodities Ambientais (BECE - Brazilian Environment Commodities Exchange), "onde seriam negociadas mercadorias à vista, com entrega física e no mercado futuro, através de financiamentos nos prazos adequados para a produção sustentável" (Khalili, 2000).

"A vantagem de comercializar bens ambientais na bolsa e não no balcão é que a transação ganha transparência e publicidade, podendo atingir um mercado muito maior, por tabela, melhores preços" (Scharf (2000), citando Khalili).

Segundo Scharf (2000), a Environmental Protection Agency (EPA) vem emitindo, desde 1994, milhares de certificados autorizando emissões de toneladas de dióxido de enxofre, monóxido de carbono e outros gases poluentes ${ }^{11}$. Desde então, o órgão calcula que as emissões de dióxido de enxofre foram reduzidas em $30 \%$. "Segundo The Wall Street Journal, 7,2 milhões de certificados foram comercializados no país no ano passado, sendo que cada bônus, cotado em US\$ 90, equivale a uma tonelada de poluentes. Quem não cumpre as metas de redução progressiva estabelecidas por lei tem que comprar certificados das empresas mais bem sucedidas. $\mathrm{O}$ sistema tem a vantagem de permitir que cada empresa estabeleça seu próprio ritmo de adequação às leis ambientais".

Em relação a emissões de GEE ou ao seqüestro de carbono, o governo da Costa Rica foi pioneiro, lançando os "Certified Tradable Offsets" (CTO - Certificados Transacionáveis de Absorção de Carbono) na Chicago Board of Trade em 1997. Os CTO são títulos emitidos a partir do seqüestro de carbono originado de um programa

\footnotetext{
${ }^{10}$ Uma descrição do Projeto CTA pode ser vista em Khalili (2000).

11 Ver o item Instrumentos de mercado para "emission trade" na página 37 e A experiência norte-
} 
nacional de conservação de áreas vizinhas a parques nacionais. Os montantes de carbono derivados desse projeto foram calculados e verificados pela certificadora internacional SGS-Forestry. A estruturação financeira e comercialização desses CTO foi feita pelo Centre Financial Products, companhia sediada na Chicago Board of Trade, especializada em desenvolvimento de vários produtos financeiros inovadores como o "Interest Rate Swaps". Cada CTO equivale a uma tonelada de carbono, e a Costa Rica estipulou um preço mínimo de venda de US\$10,00 (Moura-Costa, 1997).

A experiência costarriquenha poderia ser definida como uma das primeiras transações de um título (“commodity ambiental”) relacionadas com a redução da emissão de GEE e/ou seqüestro de carbono. Porém, os Certificados de Emissões Reduzidas (CER) que atualmente estão sendo gerados não possuem características de commodity. 
Em primeiro lugar, porque conforme visto nas seções Projetos de LULUCF no Brasil; Atividades Conjuntamente Implementadas e Projetos de LULUCF em outros países, os projetos propostos ou em andamento variam bastante. Além disto, não existe atualmente regras definidas sobre as atividades de reflorestamento e florestamento elegíveis ao MDL. Essas regras somente serão estabelecidas durante a realização da COP 9. E por último, a(s) característica(s) de desenvolvimento sustentável exigida(s) poderá(ão) diferenciar os projetos entre si. Desta forma, é possível afirmar que os CER gerados por projetos de MDL baseados em atividades de LULUCF não possuem hoje características similares a ponto de caracterizá-los como uma commodity ambiental. Essa conclusão preliminar será explicada em maior profundidade no item Conclusões e recomendações.

\subsection{O custo das reduções de emissões e o valor de mercado do carbono}

Se os CER não podem ser considerados uma commodity, por que existe interesse em comercializar tais títulos? A principal razão decorre das diferenças de custos de redução (abatimento) das emissões de GEE que existem entre os países.

Segundo Ellerman et al. (1998), no Japão os custos de abatimento das emissões de GEE podem chegar a US\$ 584,00 por tonelada de carbono, enquanto que nos EUA atingiriam US\$ 186,00 e na Comunidade Européia US\$273,00. Os valores observados podem fazer com que projetos de abatimento em outros países se tornem mais interessantes, ou seja, sejam menos onerosos. 
Por exemplo, o custo de seqüestro de carbono em projetos agroflorestais e de reflorestamento foram estimados, segundo Rezende et al. (2001) entre US\$ 1 e US\$ 30/tC (Dixon et al. ${ }^{12}$ ), US\$ 10 a US\$ 50/tC $\left(\right.$ Trexler $\left.^{13}\right)$ e US\$ $1 / \mathrm{tC}\left(\mathrm{FACE}^{14}\right)$. Esses custos podem ser derivados a partir de curvas de custo marginal de abatimento (MAC). As MAC representam os "preços-sombra" das metas de emissão, em função da quantidade abatida de emissões ${ }^{15}$. Outra forma de se calcular o custo da tonelada de carbono é através das estimativas dos impactos que cada tonelada emitida causaria, ou seja, quantificar quais seriam as perdas econômicas causadas pelas emissões. Pearce at al. (1999) citam Fankhauser \& Pearce $(1994)^{16}$, que estimam estes custos em US\$20; Eyre et al. (1997) ${ }^{17}$, que apontam para valores entre US\$ 30 e US\$ 40; Rezende et al. (2001) citam Houghton $(1997)^{18}$, aponta o custo do dano por tonelada de carbono emitida entre US\$ 50 e US\$ 100.

Uma vez que existem diferentes custos de abatimento de GEE, passam a existir incentivos econômicos para que empresas comecem a oferecer este tipo de serviço, denominado comércio de emissões ("emissions trade"). Cria-se, portanto, um valor de mercado para o carbono. Este valor é estimado em US\$ 12 t/C ou aproximadamente US\$ 4 por tonelada de $\mathrm{CO}_{2}{ }^{19}$, segundo Moura-Costa (1998). Uma evolução dos preços da tonelada de carbono pode ser vista na Figura 4. O Banco Mundial, citado em BNDES \&

12 DIXON, R.; SCHROEDER, P.; WINJUM, J. Assessment of promising forest management practices and technologies for enhancing the conservation and sequestration of atmospheric carbon and their costs at the site level. EPA, 1991.

13 TREXLER, M.C. Minding the carbon store: weighing US forestry strategies to slow global warming. Washington: World Resource Institute, 1999.

14 FOREST ABSORVING CARBON EMISSION - FACE. Forests absorbing carbon dioxide emission. Annual Report 1993. Arnheim, 1994.

${ }^{15}$ Ver o item Curvas de custo marginal de abatimento na página 75.

16 FANKHAUSER, S.; PEARCE, D.W. The social costs of greenhouse gas emission. IN: ORGANIZATION FOR ECONOMIC CO-OPERATION AND DEVELOPMENT - OECD. The Economics of Climate Change. Paris, 1994.

17 EYRE, N.; DOWING, T.; HOEKSTRA, R.; RENNINGS, K.; TOL, R. Global warming damages: Final report of the Extern Global Warning Sub-Task, DGXII. European Commission, 1997.

${ }^{18}$ HOUGHTON, J. Global warming: the complete briefing. Cambridge: University of Cambridge, 1997.

${ }^{19}$ Uma tonelada de carbono equivale a 3,67 toneladas de $\mathrm{CO}_{2}$, o que significa dizer que uma tonelada de $\mathrm{CO}_{2}$ equivale a 0,27 toneladas de $\mathrm{C}$. 
MCT (1999), estima que o valor de mercado dos CER de gases de efeito estufa estará entre US\$ 5 e US\$ 15 por tonelada de carbono reduzida.

No total, estima-se que os recursos a serem negociados no mundo podem chegar a US\$ 3 bilhões por ano (Goldemberg, 1999) ou de US\$ 5 bilhões a US\$ 17 bilhões por ano a partir de 2010 (Austin et al., 1999). A United Nations Conference on Trade and Development citada por Moura-Costa (1997), prevê que a demanda por créditos de emissões de carbono chegará a cerca de US\$ 20 bilhões por ano, quando os mecanismos para esse comércio estiverem devidamente definidos e aceitos pela comunidade internacional.

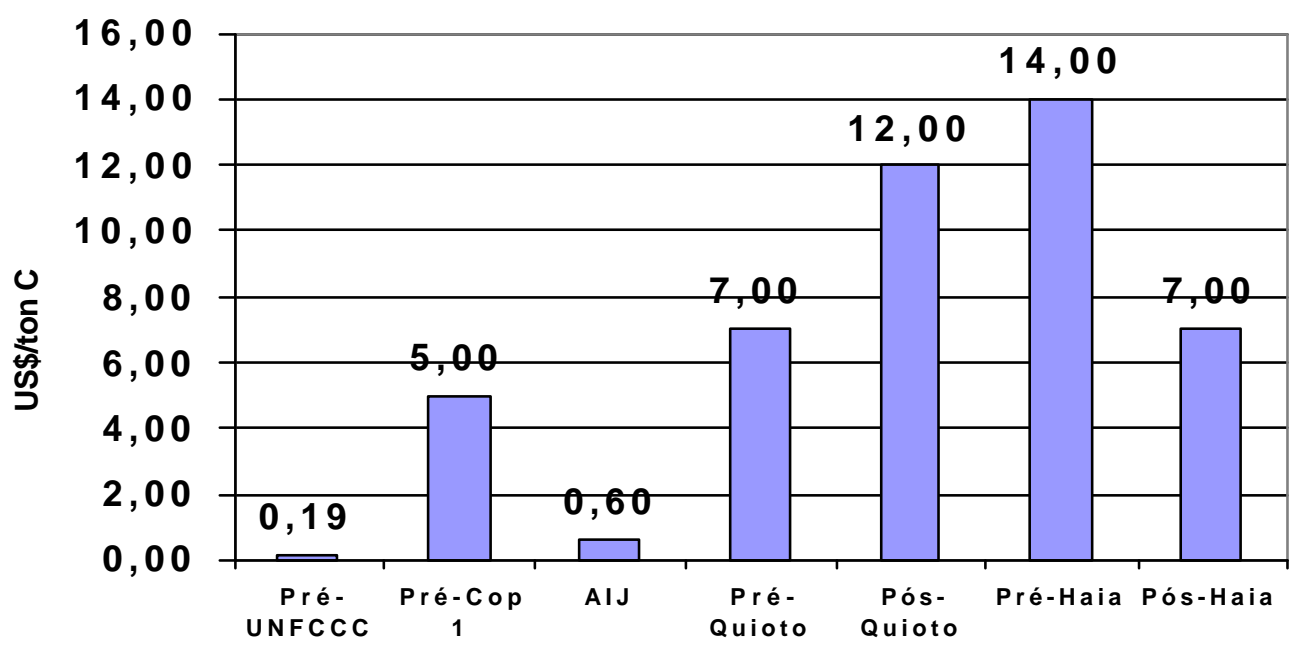

Figura 4 - Evolução do preço pago por tonelada de carbono.

Fonte: Adaptado de Moura-Costa (1998)

OBS: AIJ - Activities Implemented Jointly- denominação dada à fase piloto internacional da Implementação Conjunta (JI), é uma modalidade de implementação conjunta introduzida na COP 1.

\subsection{Instrumentos de mercado para "emission trade"}

Os títulos, instrumentos de crédito e/ou permissão para emissão de gases (poluentes ou não) já são utilizados em outros países com relativo sucesso há vários 
anos. A idéia básica é de que a redução, estabilização e/ou eliminação de um determinado poluente pode ser alcançada através da comercialização de créditos de redução e/ou permissões de emissão entre as empresas poluidoras. Esse comércio faz com que as empresas tenham maior flexibilidade no cumprimento das metas ambientais estabelecidas pela legislação vigente. Outra vantagem é que, com a sua utilização, o poder público fica apenas encarregado de definir os objetivos ambientais a serem alcançados, monitorar e penalizar os infratores; enquanto que a escolha dos melhores meios para se atingir os objetivos fica a cargo das próprias empresas, que irão sempre buscar a melhor relação custo/benefício.

Existem diferenças na utilização de créditos ou permissões como mostra Tietenberg (1998). Normalmente os créditos são estabelecidos baseados em fluxos de poluentes (Ex.: toneladas/ano), enquanto que as permissões baseiam-se em medidas discretas (Ex.: toneladas). Isso implica que os créditos estão associados a um direito contínuo de emissão e as permissões ao direito de emitir uma quantidade definida em um determinado período. Uma vez exercido o direito de emissão, a permissão deixa de ter validade.

Outras diferenças entre crédito e permissão são que: (i) o primeiro refere-se apenas a reduções permanentes, enquanto que o segundo permite tanto reduções permanentes como temporárias; (ii) o crédito necessita de uma linha de base, na qual possa se basear para determinar a quantidade a ser comercializada, enquanto que a permissão não necessita de tal determinação; (iii) a permissão autoriza por si só impor limites que não serão ultrapassados pelo crescimento econômico, enquanto que o crédito necessita de alguma outra restrição para evitar tal ultrapassagem.

Em ambos os casos a alocação pode ser feita através de leilões ou distribuída para cada empresa poluidora através de uma regra qualquer (normalmente baseada no histórico de emissões). As despesas financeiras associadas à aquisição de créditos ou permissões em um sistema de leilão podem ser suficientemente grande a ponto de tornar este instrumento mais oneroso do que o tradicional sistema de comando e controle 
(Lyon ${ }^{20}$ citado por Tietenberg, 1998). Quanto às regras existentes para a distribuição, normalmente a mais utilizada é conhecida como "grandfathered rules", que dá prioridade às empresas preexistentes. Nessa regra, as empresas já estabelecidas só precisam adquirir em leilão créditos ou permissões adicionais a sua posição inicial, enquanto que as novas empresas devem buscar todos os créditos e permissões necessários em leilões (Tietenberg, 1998).

Ambos os instrumentos são direcionados a uma determinada população-alvo, sendo que, normalmente esta população não engloba todas as fontes poluidoras, seja por razões de monitoramento ou outras quaisquer. Ao deixar de fora essas fontes, as oportunidades de trocas ficam reduzidas e conseqüentemente o custo mais elevado. Para minimizar esse problema, Tietenberg (1998) sugere a inclusão de um mecanismo voluntário de adesão. As empresas teriam interesse em participar deste mercado por uma série de motivos, entre eles: vantagens econômicas advindas da troca, precaução quanto a restrições futuras etc.

Ainda segundo Tietenberg, outro ponto que esses instrumentos precisam levar em consideração é uma boa distribuição entre a melhoria ambiental e a redução de custos. Os novos programas de redução de emissões que utilizam esses instrumentos buscam uma melhor qualidade do ar, através do controle mais rígido ou de um "deadline" menor, com o menor custo possível para as empresas. Esta distribuição de benefícios faz com que haja uma melhor aceitação, em especial, por parte de grupos ambientais que, em alguns casos (Programa de Chuva Ácida), podem também adquirir permissões.

${ }^{20}$ LYON, R.M. Auctions and alternative procedures for allocating pollution rights. Land Fconomics, v.58, n.1, p.16-32, 1982. 
A implementação de tais instrumentos não é fácil, sendo que para Tietenberg (1998) as principais dificuldades são:

1. Custos de transação: esses custos incluem as despesas para identificar o parceiro ideal, estabelecer os termos da troca e efetivar o negócio. $\mathrm{Na}$ ausência de custos de transação, o controle da poluição seria alcançado ao custo mínimo para a sociedade (Baumol \& Oates, 1971) ${ }^{21}$, citados por Tietenberg, 1998). Porém, custos de transação elevados podem inviabilizar economicamente a utilização de tais instrumentos, fazendo com que algumas transações não ocorram (Stavins ${ }^{22}$, citado por Tietenberg, 1998). Uma maneira de reduzir tais custos seria aumentar a disponibilidade de informações de mercado, em especial referentes a preços, tanto para compradores como para vendedores.

2. Localização geográfica: os instrumentos de crédito e permissão funcionam muito bem em situações em que apenas o nível de emissão precisa ser controlado. Quando a localização da emissão também é importante, tais instrumentos podem gerar algumas imperfeições, como altas concentrações de poluentes em determinadas localidades. A fim de evitar essas imperfeições, pode-se restringir o comércio entre determinadas regiões ou impor restrições quanto à utilização de créditos e/ou permissões.

3. Poder de mercado: com a utilização de instrumentos de mercado, torna-se possível que determinados agentes adotem comportamentos monopolísticos ou monopsônicos e, com isso, possam manipular preços e quantidades. Além disso, algumas empresas podem utilizar estes instrumentos para eliminar concorrentes. A utilização de leilões e reservas estratégicas pode diminuir a possibilidade de tais eventos.

21 BAUMOL, W.J.; OATES, W.E. The use of standards and prices for protection of the environment. Swedish Journal of Economics, v.73, p.42-45, 1971.

22 STAVINS, R.N. Transaction costs and tradable permits. Journal of Environmental Economics and Management, v.29, n.2, p.133-148. 1995. 
4. Dimensão temporal: a fim de obter a melhor relação custo/benefício, os créditos ou permissões precisam ser livremente utilizados no tempo, seja através de empréstimos ou poupança. Essa liberdade de uso pode gerar, a exemplo da localização geográfica, concentrações em determinadas épocas, além de dificuldades de impor penalidades.

\subsubsection{A experiência norte-americana}

Vários países utilizam instrumentos de mercado para controlar a emissão de diferentes gases. Merece destaque a experiência norte-americana, que criou na década de 70 o que hoje é conhecido como Emissions Trading Program, cujo objetivo era oferecer maior flexibilidade às empresas atingidas pelo "Clean Air Act". Qualquer empresa que conseguisse reduzir as emissões de um determinado poluente abaixo dos níveis exigidos poderia ofertar "créditos de redução de emissões" a empresas que não atingissem os níveis exigidos.

Segundo Tietenberg (1998) vários outros programas ocorreram nos Estados Unidos, entre eles merecem destaque os seguintes:

$>\quad$ Eliminação do chumbo na gasolina (1982-1987) - com o objetivo de flexibilizar a eliminação do chumbo presente na gasolina, a EPA criou um "lead banking program". Segundo este programa uma quantidade fixa de permissões (autorizando o uso de uma quantidade fixa de chumbo - 0,01 grama por galão durante o período de transição) foi alocada em diferentes refinarias. As refinarias que não utilizassem essas permissões, devido a reduções anteriores ou acima do requerido, poderiam vendê-las a outras refinarias. Quanto mais cedo as refinarias eliminassem o chumbo da gasolina, mais cedo elas poderiam vender suas permissões. Segundo a EPA esse programa gerou economias da ordem de US\$ 65 milhões para as refinarias. É importante ressaltar que o programa visou à eliminação de um poluente e não a sua estabilização e/ou redução.

Ozônio (1988) - o Protocolo de Montreal determinou o fim da utilização dos clorofluorcarbono (CFCs), principais responsáveis pela destruição da camada de ozônio, até o fim de 2000. Em 12 de agosto de 1998, a EPA criou um sistema de 
trocas de permissões com o objetivo de cumprir as obrigações do Protocolo. Foram estimadas linhas de base para produtores e consumidores de CFCs a partir da produção e consumo registrados em 1986. As permissões foram inicialmente estipuladas em função dessas linhas de base e são reduzidas de tempos em tempos. As trocas são permitidas entre produtores e consumidores e também entre diferentes países. As restrições impostas pelo Protocolo reduziram a oferta de CFCs, e uma vez que a demanda pelas permissões é inelástica, a alocação das permissões entre os maiores produtores gerou "lucros" que tiveram que ser eliminados com a imposição de taxas sobre os poluentes. Esse programa foi inovador por permitir trocas internacionais e utilizar dois instrumentos distintos: taxas e permissões.

Chuva ácida (1993) - as emissões de $\mathrm{SO}_{2}$ das empresas de eletricidade, responsáveis pelas chuvas ácidas, estão sendo controladas através de permissões que são negociadas na Bolsa de Chicago. As permissões criadas serão gradualmente eliminadas com o objetivo de reduzir em 10 milhões de toneladas as emissões observadas em 1980 em 2010. Cada permissão autoriza a emissão de uma tonelada de $\mathrm{SO}_{2}$ em um determinado ano. As permissões são livremente negociadas entre as empresas e podem ser utilizadas em outros períodos, desde que sejam reportadas ao "Allowance Tracking System". Não é permitido emitir acima da quantidade estipulada pelas permissões (originalmente alocadas e negociadas), sob a pena de multa de US\$2.000/tonelada de $\mathrm{SO}_{2}$. Todo ano, a EPA retém 2,24\% das permissões e as leiloa na Bolsa de Chicago em conjunto com permissões oferecidas pelas empresas. Essas empresas estipulam qual será o preço mínimo aceito. Inicialmente, os valores e o volume negociados foram menores do que os esperados, mas o programa está cumprindo com seus objetivos (EPA, 2002).

California Regional Clear Air Incentives Market (RECLAIM - 1994) - Esse programa regional elaborado pela South Coast Air Quality Management District, responsável pela região metropolitana de Los Angeles, criou e alocou créditos para $\mathrm{NO}_{\mathrm{x}}$ e $\mathrm{SO}_{2}$ entre as principais empresas poluidoras. Esses créditos podem ser negociados e serão reduzidos até 2003. 
Para Kosobud (2000), merecem destaque o Programa de Chuva Ácida, o U.S. EPA Final Rule for $\mathrm{NO}_{\mathrm{x}}$, o RECLAIM, e o Emissions Reduction Market System (ERMS), o primeiro mercado para controle de componentes orgânicos voláteis (VOC volatile organic compounds). O Quadro 2 adaptado de Kosobud (2000) compara tais mercados.

\begin{tabular}{|c|c|c|c|c|}
\hline & Chuva Ácida & $\mathrm{NO}_{\mathrm{x}} \mathrm{EPA}$ & RECLAIM & ERMS \\
\hline Poluente & $\mathrm{SO}_{2}$ & $\mathrm{NO}_{\mathrm{x}}$ & $\mathrm{NO}_{\mathrm{x}} \mathrm{SO}_{2}$ & VOC \\
\hline $\begin{array}{l}\text { Cobertura } \\
\text { Geográfica }\end{array}$ & Nacional & 23 estados & $\begin{array}{l}\text { Região de Los } \\
\text { Angeles }\end{array}$ & Região de Chicago \\
\hline $\begin{array}{l}\text { Número e tipo de } \\
\text { empresas cobertas }\end{array}$ & $\begin{array}{c}\text { Fase I - } 110 \\
\text { Fase II - todas as } \\
\text { empresas de energia }\end{array}$ & $\begin{array}{l}\text { Vários tipos de } \\
\text { indústrias }\end{array}$ & $\begin{array}{c}\text { Vários tipos de } \\
\text { indústrias }(313 / 65)\end{array}$ & $\begin{array}{l}\text { Vários tipos de } \\
\text { indústrias (283) }\end{array}$ \\
\hline $\begin{array}{l}\text { Total das emissões } \\
\text { cobertas }(\%)\end{array}$ & 69 & 33 & $33 / 75$ & 26 \\
\hline Agentes & $\begin{array}{l}\text { Qualquer um } \\
\text { registrado }\end{array}$ & A ser determinado & $\begin{array}{l}\text { Qualquer um } \\
\text { registrado }\end{array}$ & $\begin{array}{l}\text { Qualquer um } \\
\text { registrado }\end{array}$ \\
\hline $\begin{array}{l}\text { Nome e } \\
\text { denominação do } \\
\text { crédito a ser } \\
\text { negociado }\end{array}$ & $\begin{array}{l}\text { Permissão (1 ton de } \\
\mathrm{SO}_{2} \text { ) }\end{array}$ & $\begin{array}{l}\text { Permissão (1 ton de } \\
\left.\mathrm{NO}_{\mathrm{x}}\right)\end{array}$ & $\begin{array}{l}\text { RECLAIM trading } \\
\text { credit (libras de } \mathrm{SO}_{2} / \\
\mathrm{NO}_{\mathrm{x})}\end{array}$ & $\begin{array}{c}\text { Allotment trading } \\
\text { unit } \\
\text { (200 libras de VOC) }\end{array}$ \\
\hline Período de uso & $\begin{array}{c}\text { No ano da emissão e } \\
\text { períodos } \\
\text { subsequentes }\end{array}$ & $\begin{array}{l}\text { No ano/estação da } \\
\text { emissão e períodos } \\
\text { subsequentes }\end{array}$ & $\begin{array}{c}\text { No ano da emissão e } \\
\text { no próximo ciclo } \\
\text { anual }\end{array}$ & $\begin{array}{l}\text { No ano/estação da } \\
\text { emissão e períodos } \\
\text { subsequentes }\end{array}$ \\
\hline Início das atividades & 1995 & 2003 & $1994 / 1994$ & 2000 \\
\hline Linha de base geral & 1980 & 2007 (projeção) & 2003 (projeção) & $\begin{array}{c}\text { Média de } 1994 \text { e } \\
1996\end{array}$ \\
\hline Redução esperada & $50 \%$ em 2007 & $\begin{array}{c}69 \% \text { (empresas de } \\
\text { energia) }\end{array}$ & $\begin{array}{l}75 \% \text { em } 2003 / \\
63 \% \text { em } 2003\end{array}$ & $12 \%$ em 2000 \\
\hline $\begin{array}{l}\text { Linha de base } \\
\text { individual }\end{array}$ & $\begin{array}{c}\text { Médias de 1985- } \\
1987\end{array}$ & A ser definida & $\begin{array}{c}\text { Maior valor de } 1989 \\
\text { a } 1992\end{array}$ & $\begin{array}{c}\text { Média de } 1994 \text { e } \\
1996\end{array}$ \\
\hline $\begin{array}{l}\text { Alocação das } \\
\text { permissões }\end{array}$ & $\begin{array}{c}\text { Custo zero }(2,8 \% \text { em } \\
\text { leilões })\end{array}$ & A ser definida & $\begin{array}{c}\text { Custo zero/Custo } \\
\text { zero }\end{array}$ & $\begin{array}{c}\text { Custo zero ( } 1 \% \\
\text { vendas) }\end{array}$ \\
\hline $\begin{array}{l}\text { Monitoramento de } \\
\text { preços e transações }\end{array}$ & $\begin{array}{c}\text { Preços - corretores } \\
\text { e leilões } \\
\text { Transações - EPA }\end{array}$ & $\begin{array}{c}\text { Preços - a ser } \\
\text { definido } \\
\text { Transações - EPA }\end{array}$ & $\begin{array}{c}\text { Preços e } \\
\text { Transações - } \\
\text { RECLAIM }\end{array}$ & $\begin{array}{c}\text { Preços e } \\
\text { Transações - Illinois } \\
\text { EPA }\end{array}$ \\
\hline $\begin{array}{l}\text { Monitoramento de } \\
\text { emissões e } \\
\text { cumprimento das } \\
\text { regras }\end{array}$ & $\begin{array}{c}\text { EPA } \\
\text { US\$ } 2.000 \text { por } \\
\text { tonelada }\end{array}$ & $\begin{array}{c}\text { EPA } \\
\text { Penalidades a serem } \\
\text { determinadas }\end{array}$ & $\begin{array}{c}\text { RECLAIM } \\
\text { Excesso é retirado da } \\
\text { próxima alocação }\end{array}$ & $\begin{array}{c}\text { EPA } \\
\text { Excesso é retirado da } \\
\text { próxima alocação, } \\
\text { além de multa }\end{array}$ \\
\hline
\end{tabular}

Quadro 3 - Programas de "Emissions Trade", EUA.

Fonte: Adpatado de Kosobud (2000)

\subsection{A formação do mercado de carbono}

O MDL, como visto anteriormente, é o instrumento de flexibilização cujo 
objetivo é assistir as Partes não constantes do ANEXO I da Convenção do Clima (países em desenvolvimento) fornecendo capital para o financiamento de projetos que visem à redução de gases de efeito estufa ou seqüestro de carbono. Os países desenvolvidos relacionados no ANEXO B que não atinjam suas metas de redução podem comprar os CER gerados por esses projetos e utilizá-los no cumprimento de suas metas (BNDES \& MCT, 1999).

Essas transações de CER fazem parte de um novo mercado, chamado de mercado de carbono. Atualmente o mercado de carbono não está totalmente regulamentado uma vez que o Protocolo de Quioto não está ratificado. Isso significa dizer que a comercialização do carbono, ainda no mercado de balcão, entre países do ANEXO B e países como o Brasil ainda não tem todas as suas regras definidas.

Porém, várias empresas já estão em busca de "early credits", ou seja, créditos de projetos já em andamento. Estes "créditos" não podem ser denominados de CER, uma fez que o Protocolo de Quioto ainda não entrou em vigor e, conseqüentemente, não existe o MDL. Sandor \& Walsh (2000) listam algumas transações destes "early credits" no Quadro 3. 


\begin{tabular}{|l|l|}
\hline Ano & Transação \\
\hline 1996 & $\begin{array}{l}\text { Niagara Mohawk e Arizona Public Service, ambas empresas de energia, fazem swap de créditos } \\
\text { de carbono por permissões de emissão de } \mathrm{SO}_{2}\end{array}$ \\
\hline 1996 & $\begin{array}{l}\text { Um consórcio envolvendo empresas norueguesas e o governo da Noruega compra da Costa Rica } \\
\text { créditos de carbono oriundos de projetos florestais privados }\end{array}$ \\
\hline 1997 & $\begin{array}{l}\text { Environmental Financial Products Limited compra da Costa Rica créditos de carbono oriundos de } \\
\text { projetos florestais privados }\end{array}$ \\
\hline 1997 & $\begin{array}{l}\text { Ontario Hydro concorda em comprar créditos de carbono da Southern California Edison } \\
\text { provenientes dos projetos de melhoria da eficiência energética }\end{array}$ \\
\hline 1998 & $\begin{array}{l}\text { Tesco, rede de postos de gasolina com sede no Reino Unido anuncia que pretende ofertar créditos } \\
\text { de carbono provenientes de projetos florestais de seqüestro da Uganda. }\end{array}$ \\
\hline 1998 & $\begin{array}{l}\text { Sumitomo anuncia plano de converter termoelétricas baseadas em carvão em gás natural na } \\
\text { Rússia, e gerar créditos de carbono. }\end{array}$ \\
\hline 1998 & Suncor Energy (Canadá) compra créditos de carbono da Niagara Mohawk \\
\hline 1998 & $\begin{array}{l}\text { Governo da Costa Rica oferece na Bolsa de Chicago créditos de carbono provenientes de projetos } \\
\text { de seqüestro em parques nacionais }\end{array}$ \\
\hline
\end{tabular}

Quadro 4 - Exemplos recentes de transações envolvendo carbono.

Fonte: Adaptado de Sandor \& Walsh (2000)

\subsubsection{Os mercados de carbono já existentes}

Em vários países, já estão sendo criados mercados domésticos para a comercialização dos futuros CER. Entre eles merecem destaque: Noruega (Anderson et al., 1999), Austrália (Australian Greenhouse Office (AGO), 1999) e Reino Unido (Emissions Trading Group (ETG), 2000).

Segundo dados do Banco Mundial (Figuras 5 e 6), desde 1996 ocorreram 211 transações internacionais de redução de emissões (ER), totalizando $160 \quad \mathrm{MtCO}_{2} \mathrm{e}(228$ $\mathrm{MtCO}_{2} \mathrm{e}$ incluindo certificados posteriores a 2012). Nos mercados nacionais (transações ocorridas entre empresas de um mesmo país), ocorreram 35 leilões públicos de permissões de emissões. O valor total desse mercado foi estimado entre US\$ 350 a US\$ 500 milhões. 


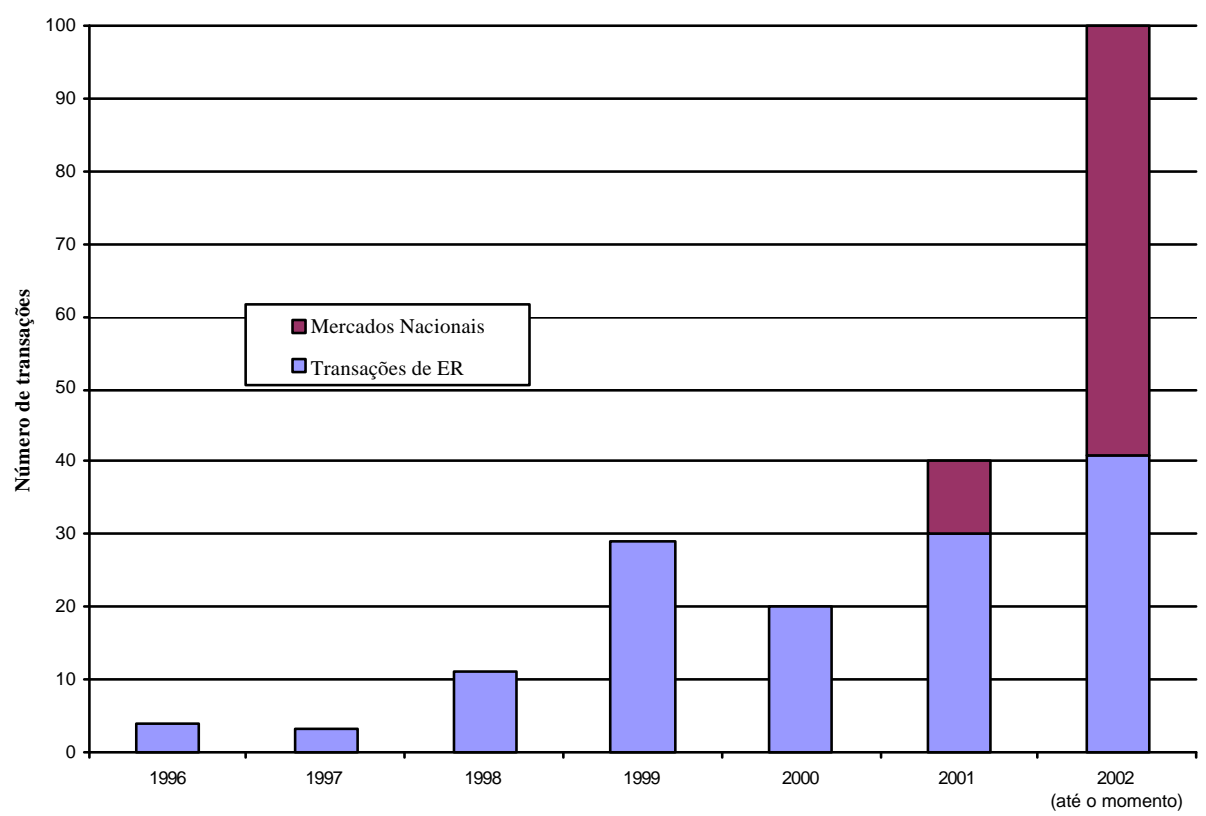

Figura 5 - Número de transações 1996/2002.

Fonte: Adaptado de Lecocq \& Capoor (2002)

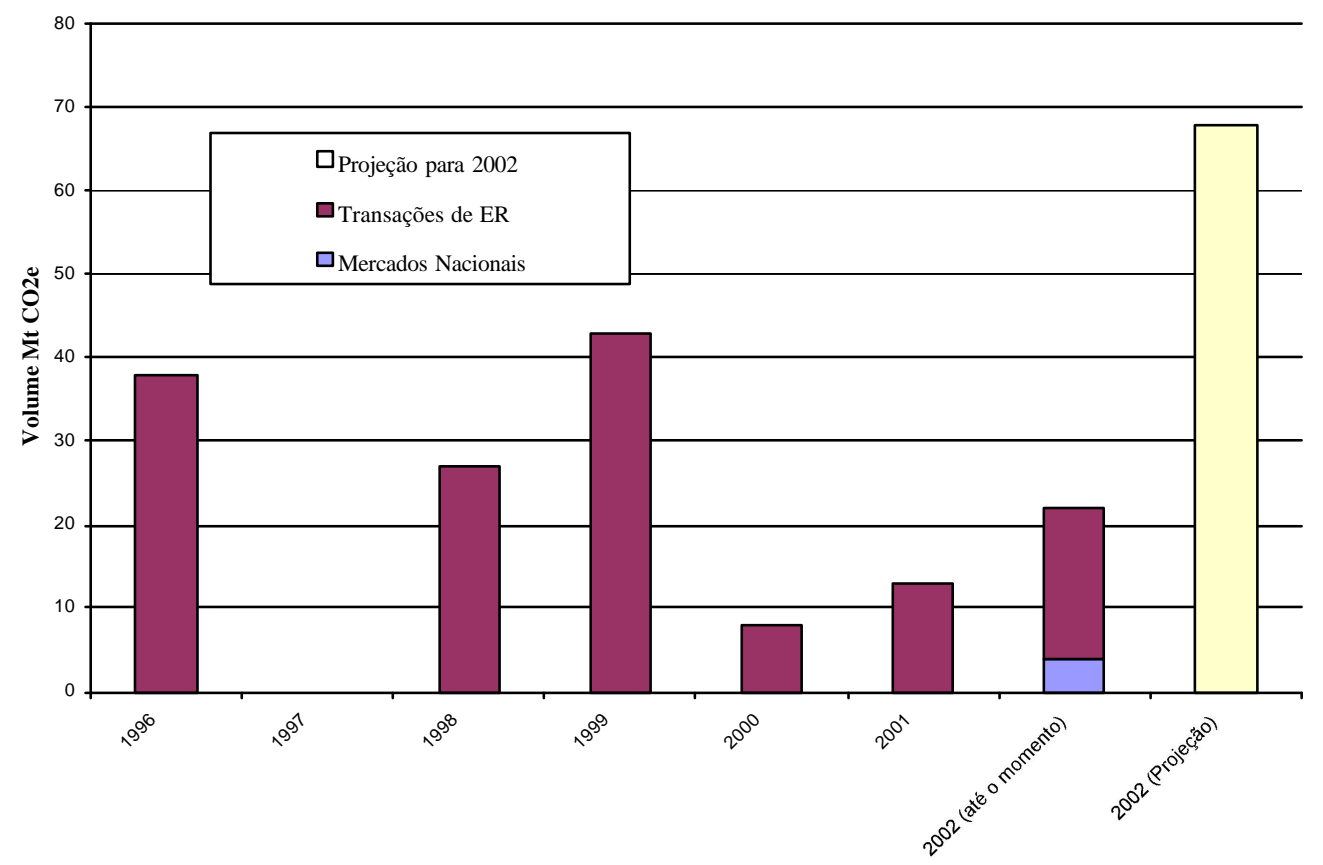

Figura 6 - Volume transacionado 1996/2002.

Fonte: Adaptado de Lecocq \& Capoor (2002) 


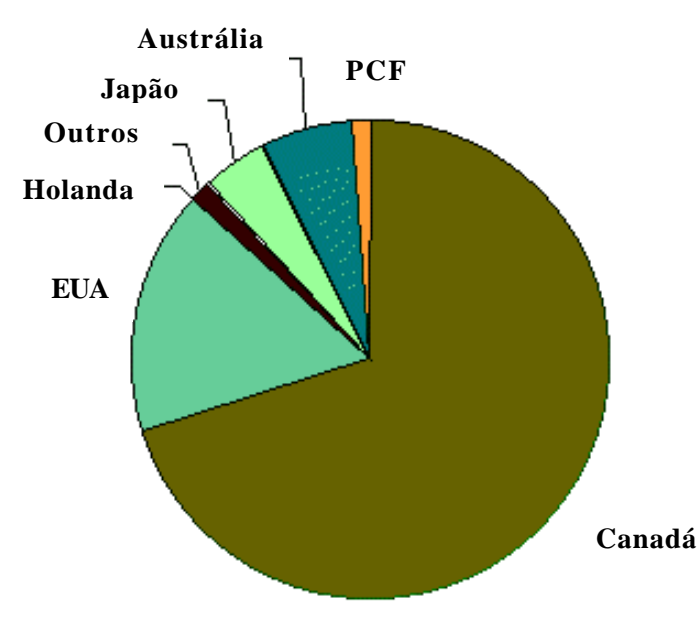

1996-2000

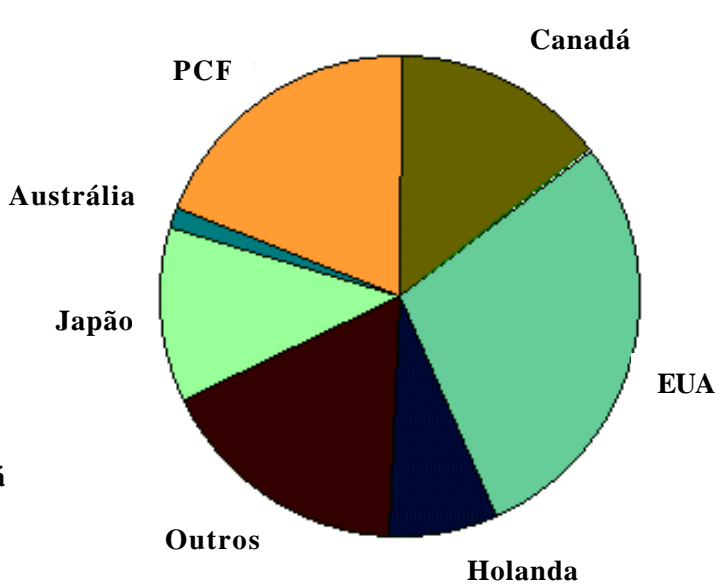

2001-2002

Figura 7 - Porcentagem da participação dos países compradores no volume transacionado.

Fonte: Adaptado de Lecocq \& Capoor (2002)

De 1996 a 2000, o Canadá, seguido dos EUA foram os principais compradores de "early credits" ou redução de emissões (ER) como mostra a Figura 7. Nos últimos dois anos (2001-2002), houve uma melhor distribuição dos países compradores, merecendo destaque a participação do Prototype Carbon Fund do Banco Mundial (PCF - ver página 54). Os EUA continuam sendo um dos principais compradores, apesar do atual governo federal ter afirmado que não irá ratificar o Protocolo de Quioto. Dessa maneira, as empresas norte-americanas não teriam o compromisso de reduzir suas emissões de GEE. Porém, alguns estados norte-americanos estão criando legislações estaduais que irão obrigar as empresas a reduzirem suas emissões; e algumas empresas estão assumindo compromissos voluntários, seja por causa de uma estratégia de marketing, seja por causa de uma estratégia de "learning by doing".

Entre 1996 e 2000, o tipo predominante de projeto por volume transacionado foi o de LULUCF (Land Use, Land Use Change and Forestry - Figura 8). Este tipo de projeto não foi muito transacionado nos últimos dois anos, por causa das restrições criadas durante a COP 7 (ver o A COP 7 e o "Acordo de Marrakesh"). Em 
compensação, os projetos relacionados a energia aumentaram sua participação.

O tamanho médio dos projetos entre 1996 e 2002 foi de 1 milhão de toneladas $\mathrm{CO}_{2} \mathrm{e}$, enquanto que entre 2001 e 2002, foi de 483 mil t $\mathrm{CO}_{2} \mathrm{e}$. O valor mediano dos projetos de 1996 a 2002 foi de 200 mil t $\mathrm{CO}_{2}$ e; e de 2001 a 2002, de 125 mil t $\mathrm{CO}_{2} \mathrm{e}$ (Figura 9).

O Canadá continua sendo um dos principais ofertantes de ER (cerca de $1 / 3$ do volume em 2001-2002). Um pouco menos da metade (46\%) das transações que ocorreram nos últimos 2 anos ocorreram em países em desenvolvimento (26\% CDM Countries) ou em economias em transição (19\% JI Countries) - Figura 10.

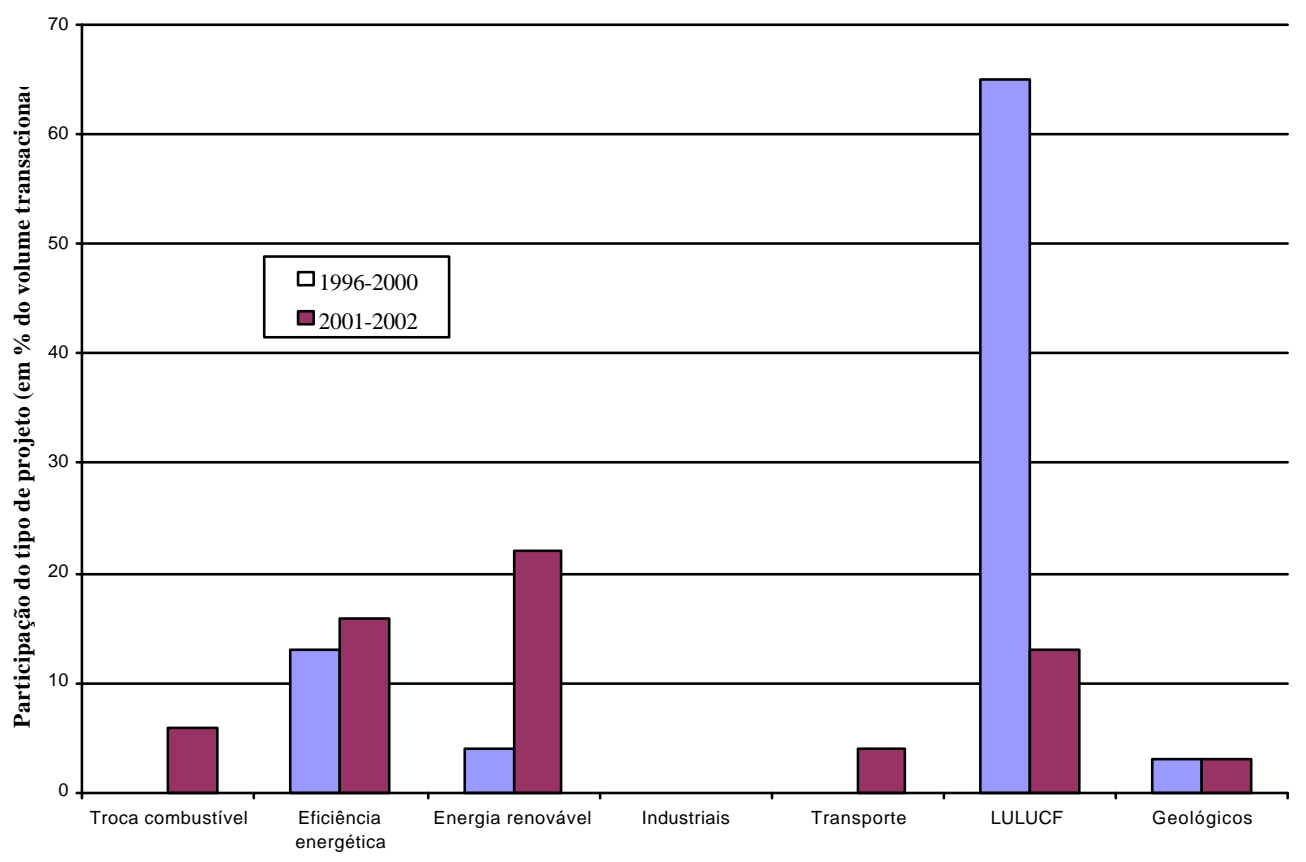

Figura 8- Porcentagem da participação do tipo de projeto no volume transacionado. Fonte: Adaptado de Lecocq \& Capoor (2002) 


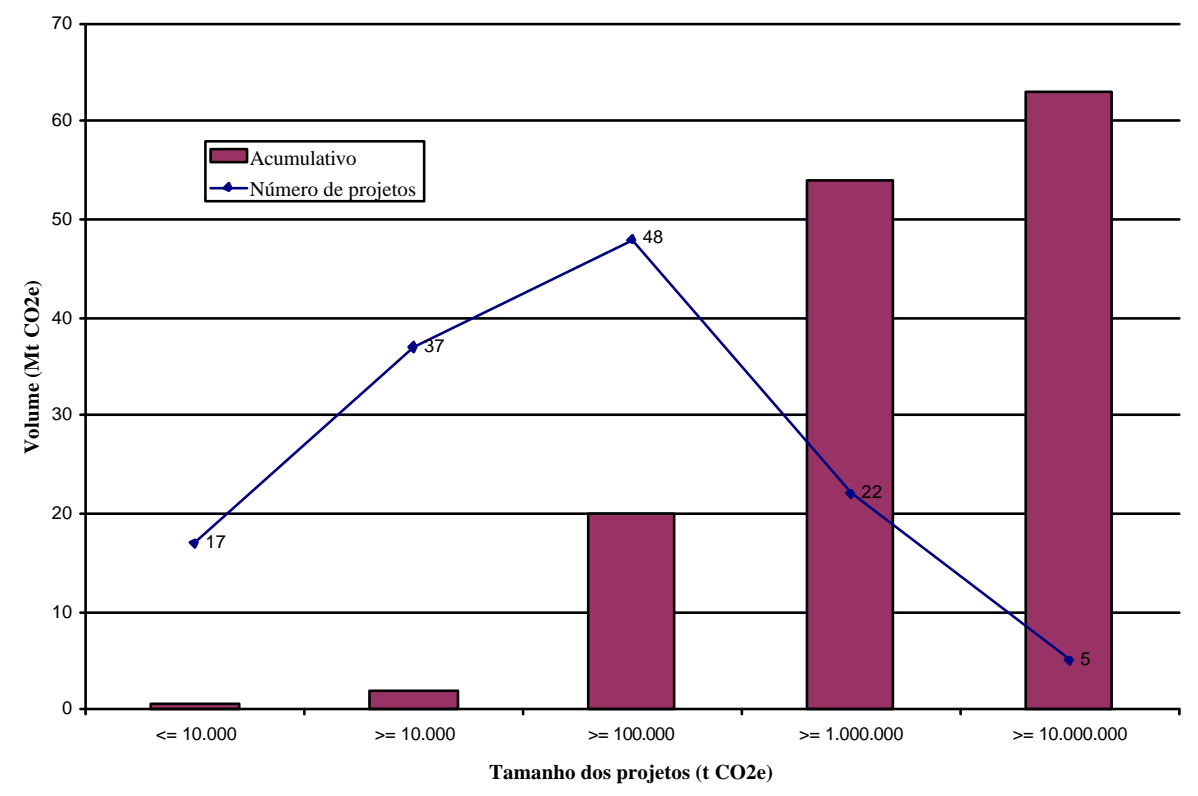

Figura 9 - Distribuição dos projetos por tamanho 1996-2002.

Fonte: Adaptado de Lecocq \& Capoor (2002)

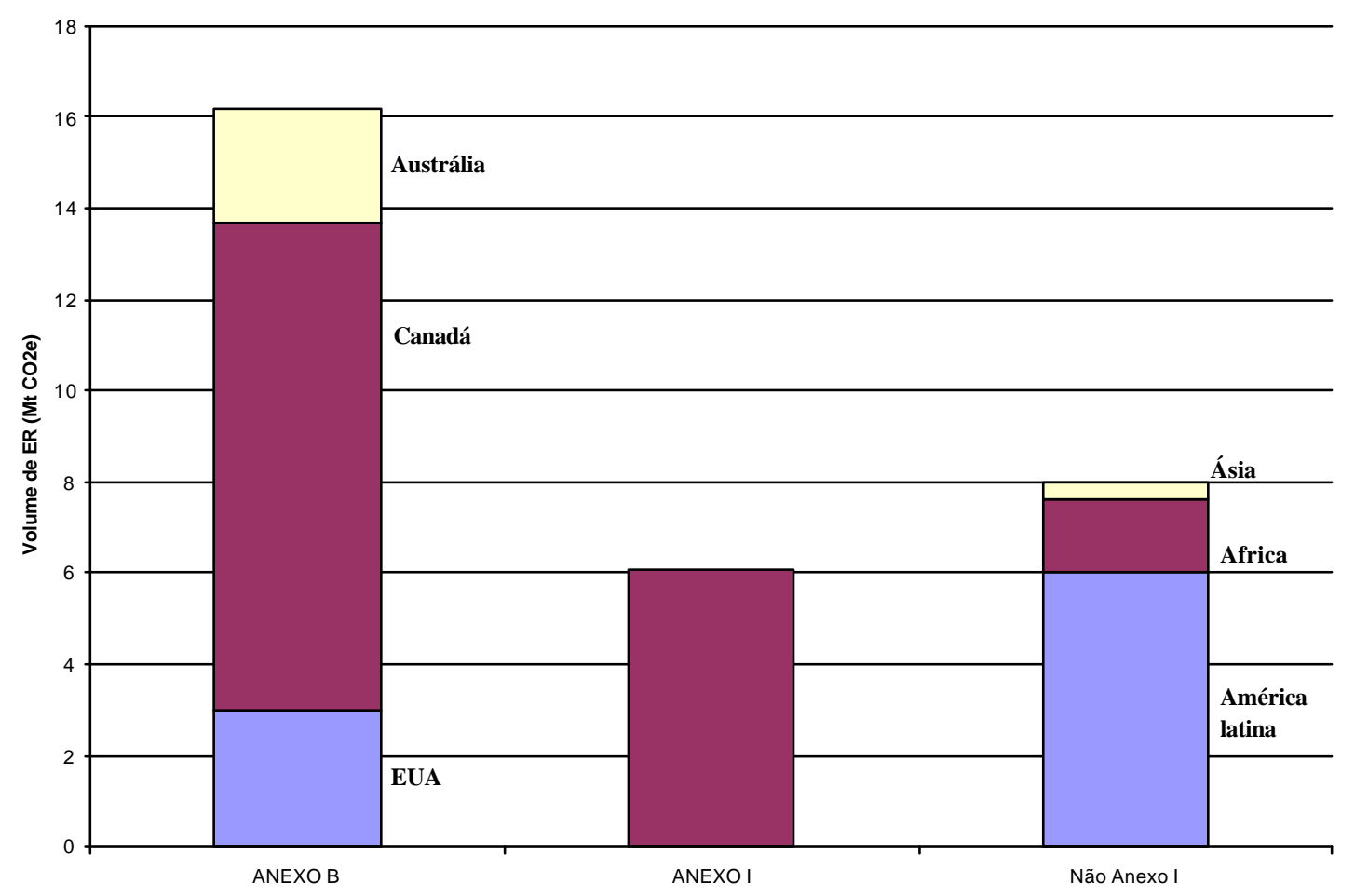

Figura 10- Distribuição do volume transacionado por tipo de país 2001-2002.

Fonte: Adaptado de Lecocq \& Capoor (2002) 
Os números apresentados nas páginas anteriores comprovam que o mercado de carbono já é uma realidade. Porém, como esse mercado ainda não está totalmente regulamentado, as transações efetuadas acabam diferindo muito entre si. A fim de ilustrar tais diferenças, alguns exemplos serão discutidos ${ }^{23}$ :

1. Mercado nacional: Emissions Trading Scheme, do Reino Unido;

2. Mercado nacional com compras de ER no exterior: CERUPT/ERUPT do governo holandês;

3. Programa voluntário norte-americano: Chicago Climate Exchange;

4. Programa de fomento de agência internacional: Prototype Carbon Fund do Banco Mundial; e

5. Programa de fomento de agência internacional para projetos de LULUCF: BioCarbon Fund do Banco Mundial.

\subsubsection{Emissions Trading Scheme do Reino Unido}

O Reino Unido lançou em 11 e 12 de março de 2002 o seu mercado nacional de carbono (UK Emissions Trading Scheme), com um leilão de 4.028.176 toneladas de $\mathrm{CO}_{2}$ equivalentes ou 1.098.593 toneladas de carbono. As 34 empresas que participaram desse leilão irão receber $£ 215$ milhões (US\$ 305 milhões) para cumprirem com as reduções propostas, ou seja, $£ 53,37$ para cada tonelada de $\mathrm{CO}_{2}$ equivalente abatida (Tabela 6). Esse valor está bem acima dos valores observados em outros mercados e não deverá se repetir nos leilões futuros, uma vez que, com a integração dos mercados (ver Figura 12), a concorrência provocará uma redução nos preços.

\footnotetext{
${ }^{23}$ Uma lista completa dos mercados existentes encontra-se no Apêndice 5.
} 
Tabela 6. Lista das empresas que participaram do leilão de lançamento do UK Emissions Trading Scheme.

\begin{tabular}{|c|c|c|}
\hline Empresas & $\begin{array}{l}\text { Metas de redução } \\
\text { (toneladas de } \mathrm{CO}_{2} \mathrm{e} \text { ) }\end{array}$ & Pagamento anual \\
\hline Ineos Fluor Ltd & 805.635 & $£ 8.599 .347,99$ \\
\hline Dupont (U.K.) Ltd & 500.000 & $£ 5.337 .000,00$ \\
\hline Shell UK Ltd & 438.750 & $£ 4.683 .217,50$ \\
\hline Rhodia Organique Fine Ltd & 430.000 & $£ 4.589 .820,00$ \\
\hline UK Coal Mining Ltd & 400.000 & $£ 4.269 .600,00$ \\
\hline British Petroleum plc & 353.500 & $£ 3.773 .259,00$ \\
\hline First Hydro Company & 285.000 & $£ 3.042 .090,00$ \\
\hline Lafarge Cement UK & 250.000 & $£ 2.668 .500,00$ \\
\hline British Airways plc & 125.000 & $£ 1.334 .250,00$ \\
\hline British Sugar plc & 100.000 & $£ 1.067 .400,00$ \\
\hline Asda Stores Ltd & 80.000 & $£ 853.920,00$ \\
\hline Tesco Stores Ltd & 74.000 & $£ 789.876,00$ \\
\hline Imerys Minerals Ltd & 37.000 & $£ 394,938,00$ \\
\hline Rolls-Royce plc & 27.000 & $£ 288.198,00$ \\
\hline Dalkia Utilities Services plc & 22.400 & $£ 239.097,60$ \\
\hline Ford Motor Company Ltd & 12.500 & $£ 133.425,00$ \\
\hline Dana UK Holdings Ltd & 12.247 & $£ 130.724,48$ \\
\hline Battle McCarthy Carbon Club & 11.528 & $£ 123.049,87$ \\
\hline Barclays Bank plc & 10.000 & $£ 106.740,00$ \\
\hline Dalkia Energy plc & 10.000 & $£ 106.740,00$ \\
\hline GKN (U.K.) plc & 10.000 & $£ 106.740,00$ \\
\hline Somerfield Stores Ltd & 6.000 & $£ 64.044,00$ \\
\hline Royal Ordnance plc & 5.500 & $£ 58.707,00$ \\
\hline Motorola GTSS & 5.000 & $£ 53.370,00$ \\
\hline General Domestic Appliances Ltd & 4.525 & $£ 48.299,85$ \\
\hline Budweiser Stag Brewing Co. Ltd & 4.303 & $£ 45.930,22$ \\
\hline Marks \& Spencer plc & 2.060 & $£ 21.988,44$ \\
\hline Quantum Gas Management & 1.500 & $£ 16.011,00$ \\
\hline
\end{tabular}




\begin{tabular}{lcc}
\hline Empresas & $\begin{array}{c}\text { Metas de redução } \\
\left.\text { (toneladas de } \mathrm{CO}_{2} \mathrm{e}\right)\end{array}$ & Pagamento anual \\
\hline Land Securities plc & 1.381 & $£ 14.740,79$ \\
Kirklees Metropolitan Council & 1.000 & $£ 10.674,00$ \\
The Natural History Museum & 1.000 & $£ 10.674,00$ \\
Lend Lease Real Estate Investment Services Ltd & 977 & $£ 10.428,50$ \\
Mitsubishi Corporation UK plc & 250 & $£ 2.668,50$ \\
EGNI (Wales) Ltd & 111 & $£ 1.184,81$ \\
Wates Group & 9 & $£ 96,07$ \\
\hline
\end{tabular}

Fonte: Adaptado de United Kingdom (2002b)

Ao se observar a Tabela 6, nota-se que existe uma variação muito grande entre as metas das empresas de 805.635 toneladas de $\mathrm{CO}_{2} \mathrm{e}$ até 9 toneladas apenas. Essa diferença pode ser explicada principalmente por dois fatores: 1) as empresas utilizam em diferentes proporções as energias não-renováveis; e 2) algumas empresas estão apenas realizando um exercício de conhecimento de mercado ("learning by doing").

Especialistas afirmam que esse mercado terá dificuldade em se integrar com os demais (United Kingdom, 2002a). Isso, porém, não significa dizer que as empresas que hoje atuam no mercado inglês não terão interesse em buscar CER de projetos de MDL, a fim de diversificar seus portfólios.

\subsubsection{CERUPT/ERUPT do governo holandês}

De acordo com o Protocolo de Quioto, a União Européia (UE) tem o compromisso de reduzir suas emissões de GEE para um nível 8\% abaixo do verificado em 1990, entre 2008 e 2012. A Holanda, como parte da EU, precisa reduzir suas emissões em 6\%. Para tanto, o governo holandês pretende que pelo menos $50 \%$ dessas reduções sejam feitas domesticamente. A outra parte será alcançada através da utilização dos mecanismos de flexibilização do Protocolo de Quioto, entre eles o MDL (Senter, 2001).

Através do CERUPT (Certified Emission Reduction Unit Procurement Tender), a 
Holanda pretende investir em projetos de MDL comprando pelo menos 3 milhões de toneladas de $\mathrm{CO}_{2}$ equivalente, em contratos mínimos de 100 mil toneladas. A compra será feita através de leilão onde as ofertas de preço serão feitas pelos proponentes de projetos. A autoridade holandesa responsável pelo programa (Senter) limitou os valores a serem pagos por tonelada de $\mathrm{CO}_{2}$ equivalente em função do tipo de projeto, como pode ser visto no Quadro 4.

\begin{tabular}{|l|l|}
\hline Tipo de projeto & Valor pago \\
\hline Energia renovável (excluindo biomassa) & EUR 5.50 \\
\hline $\begin{array}{l}\text { Produção de energia através de biomassa limpa e sustentável (excluindo } \\
\text { resíduos) }\end{array}$ & EUR 4.40 \\
\hline Incremento da eficiência energética & EUR 4.40 \\
\hline $\begin{array}{l}\text { Outros projetos, entre eles troca de combustíveis fósseis e aproveitamento } \\
\text { de metano }\end{array}$ & EUR 3.30 \\
\hline
\end{tabular}

Quadro 5- Valores máximos a serem pagos no CERUPT - 2001.

Fonte: Senter (2001)

Além do CERUPT, o governo holandês tem um programa para investir em projetos de Implementação Conjunta (JI - Implementação Conjunta) e Comércio de Emissões (ET - Emission Trade): ERUPT (Emission Reduction Unit Procurement Tender para projetos de Implementação Conjunta). Como esses mecanismos são restritos aos países do ANEXO I, do qual o Brasil não faz parte, o programa ERUPT não será aqui descrito.

\subsubsection{Chicago Climate Exchange}

Nos Estados Unidos, apesar da posição contrária ao Protocolo da administração republicana, existem várias iniciativas de ONGs e empresas privadas para criar um mercado nacional de carbono. Merece destaque o projeto "Chicago Climate Exchange" (CCX).

O CCX é o primeiro programa piloto privado para o comércio de GEE no meiooeste dos EUA. Aproximadamente 50 empresas e organizações estão participando da 
fase de planejamento. Os principais objetivos do CCX são provar que o conceito de "emissions trading" pode ser aplicado eficientemente para reduzir as emissões de GEE e identificar quais os preços associados a essas reduções. O CCX já definiu que irá buscar projetos de MDL no Brasil (CCX, 2002).

\subsubsection{O Prototype Carbon Fund do Banco Mundial ${ }^{24}$}

Em 20 de julho de 1999 os diretores executivos do Banco Mundial aprovaram a criação do Prototype Carbon Fund (PCF). O PCF tem como objetivo auxiliar na mitigação das mudanças climáticas, promovendo o desenvolvimento sustentável, demonstrando as possibilidades de relacionamento do setor privado e público, e oferecendo um aprendizado ("learning by doing") para as partes interessadas ("stakeholders").

Os projetos do PCF devem produzir reduções de emissões e/ou seqüestro de carbono que sejam aceitas dentro do Protocolo de Quioto. Para tanto, consultores independentes devem demonstrar a linha de base e a verificação/certificação do projeto.

Os recursos do PCF (atualmente US\$ 180 milhões) estão disponíveis tanto para o setor privado como público. Com isso, espera-se demonstrar que o conhecimento e experiência de cada setor podem ser utilizados em conjunto para promover o desenvolvimento sustentável.

Companhias e Governos que contribuíram para o PCF irão usar o Fundo para incentivar projetos de Implementação Conjunta (Implementação Conjunta - JI) e Mecanismo de Desenvolvimento Limpo (MDL). Os participantes irão receber uma parcela das emissões reduzidas, verificadas e certificadas de acordo com contratos estabelecidos com os países sede dos projetos. O esquema geral do ciclo de um projeto do PCF pode ser visto na Figura 3.

Desde a sua criação, o PCF recebeu, até o 30 de agosto de 2002, 238 consultas (Project Idea Note), das quais 54 foram desenvolvidas (Project Concept Note - PCN) e 34 aprovadas. Atualmente, 12 estão na fase de desenvolvimento da linha de base e do 
plano de monitoramento e verificação (Project Design Document - PDD) e 14, em fase de negociação do contrato (Emission Reductions Purchase Agreements - ERPA) Tabela 5.

Tabela 7. Lista de projetos aprovados pelo PCF.

\begin{tabular}{|c|c|c|c|}
\hline País/Projeto & $\begin{array}{c}\text { Contrato } \\
\text { (US\$ milhões) }\end{array}$ & $\begin{array}{c}\text { ERPA } \\
\text { (ERs tCO2e) }\end{array}$ & $\begin{array}{c}\text { TOTAL } \\
\text { (ER por projeto } t C O 2 e)\end{array}$ \\
\hline Letônia: Manejo de resíduos sólidos & 2,5 & 368.101 & 368.101 \\
\hline Chile: Pequena Central Hidroelétrica & 6,7 & 1.750 .000 & 2.597 .400 \\
\hline Uganda: Pequena Central Hidroelétrica & 3,9 & 1.300 .000 & 1.884 .102 \\
\hline Brasil: Seqüestro e uso de biomassa & 5,3 & 1.514.286 & 12.885 .986 \\
\hline România: Florestamento & 3,7 & 1.018 .000 & 1.018 .159 \\
\hline Costa Rica: Energia Eólica & 0,9 & 262.660 & 302.800 \\
\hline Costa Rica: Energia Eólica & 1,0 & 284.660 & 329.100 \\
\hline Costa Rica: Pequena Central Hidroelétrica & 0,6 & 172.120 & 173.700 \\
\hline Colômbia: Energia Eólica & 3,2 & 800.000 & 1.168 .247 \\
\hline Nicarágua & 0,5 & 141.600 & 212.395 \\
\hline República Tcheca: Eficiência Energética & 2,6 & 650.000 & 650.000 \\
\hline República Tcheca: Eficiência Energética & 2,6 & 650.000 & 650.000 \\
\hline Polônia: Geotérmico & 1,1 & 364.553 & 364.553 \\
\hline Polônia: Biomassa & 0,6 & 190.630 & 190.630 \\
\hline Guatemala: Pequena Central Hidroelétrica & 7,5 & 2.000 .000 & 2.100 .000 \\
\hline África do Sul: Manejo de resíduos sólidos & 10,0 & 3.350 .000 & 6.790 .000 \\
\hline Bulgária: Aquecimento urbano & 8,2 & 2.774 .973 & 2.774 .973 \\
\hline Bulgária: Biomassa & 2,7 & 897.293 & 897.293 \\
\hline Polônia: Geotérmico & 0,6 & 208.971 & 208.971 \\
\hline Polônia: Fábrica de papel & 3,5 & 1.000 .000 & 1.485 .000 \\
\hline Tailândia: Biomassa & 8,3 & 2.770 .000 & 2.770 .000 \\
\hline Usbekistão: Aquecimento & 1,0 & 330.000 & 1.240 .000 \\
\hline Índia: Manejo de resíduos sólidos & 10,5 & 3.513 .015 & 3.513 .015 \\
\hline Honduras: Energia Eólica & 4,8 & 1.374 .480 & 2.886 .408 \\
\hline Maurícius: Incineração de resíduos sólidos & 3,5 & 1.000 .000 & 1.080 .095 \\
\hline
\end{tabular}

${ }^{24}$ Esta seção está baseada em PCF (2002a). 


\begin{tabular}{lccc}
\hline País/Projeto & $\begin{array}{c}\text { Contrato } \\
\text { (US\$ milhões) }\end{array}$ & $\begin{array}{c}\text { ERPA } \\
\text { (ERs tCO2e) }\end{array}$ & $\begin{array}{c}\text { TOTAL } \\
\text { (ER por projeto tCO2e) }\end{array}$ \\
\hline Marrocos: Energia Eólica & 10,0 & 3.300 .000 & 5.818 .000 \\
TOTAL & 105,8 & 31.985 .342 & 54.358 .928 \\
\hline
\end{tabular}

Fonte: Adaptado de PCF (2002a)

\section{Elaboração do Projeto}

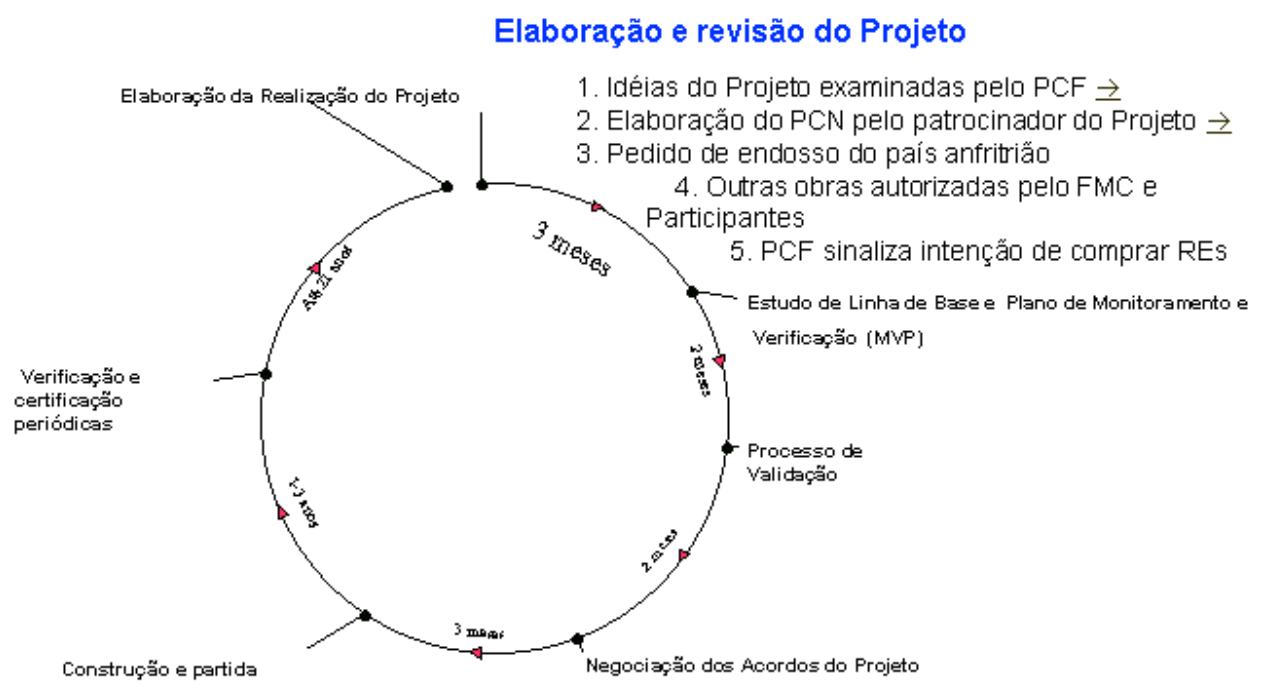




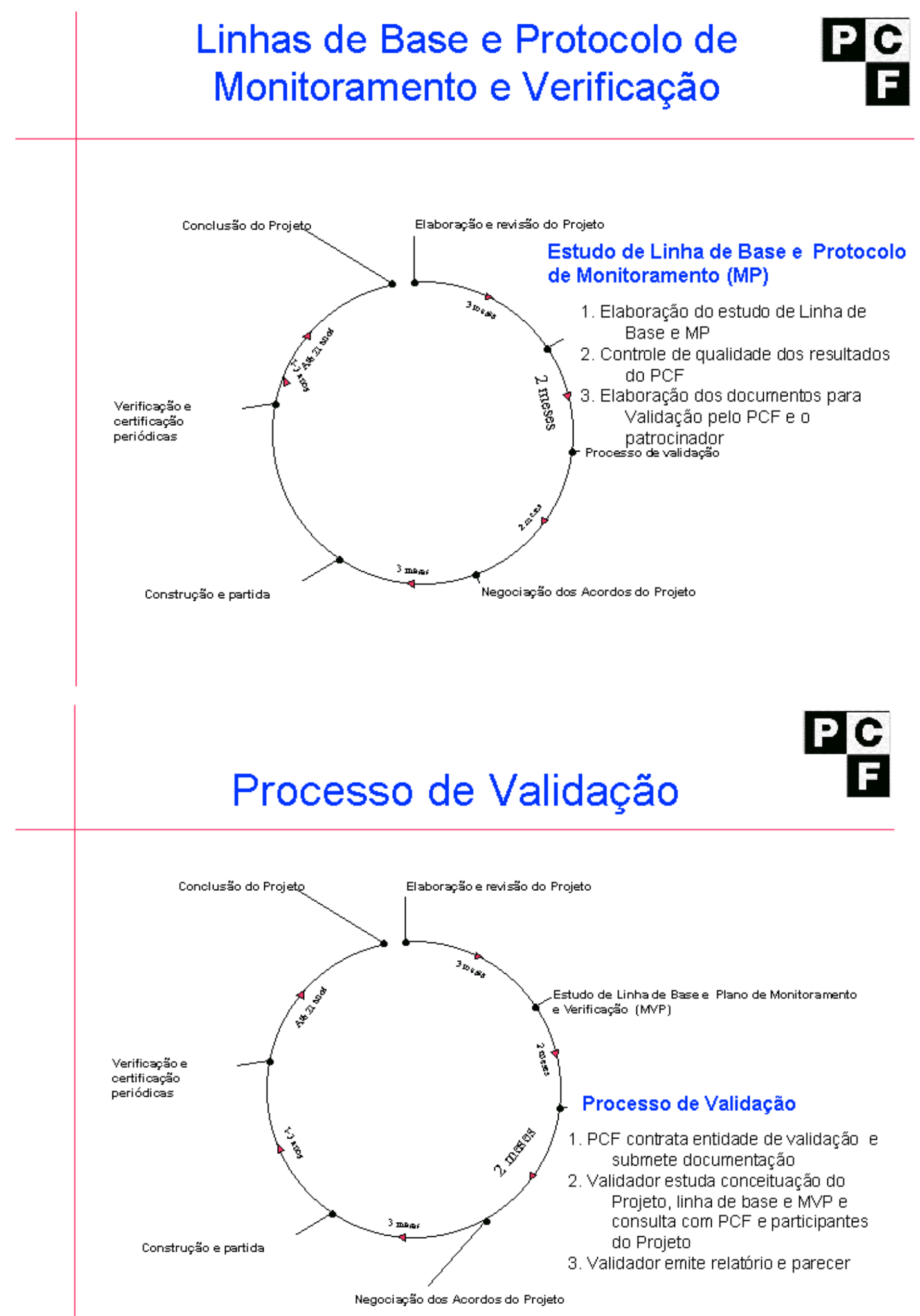




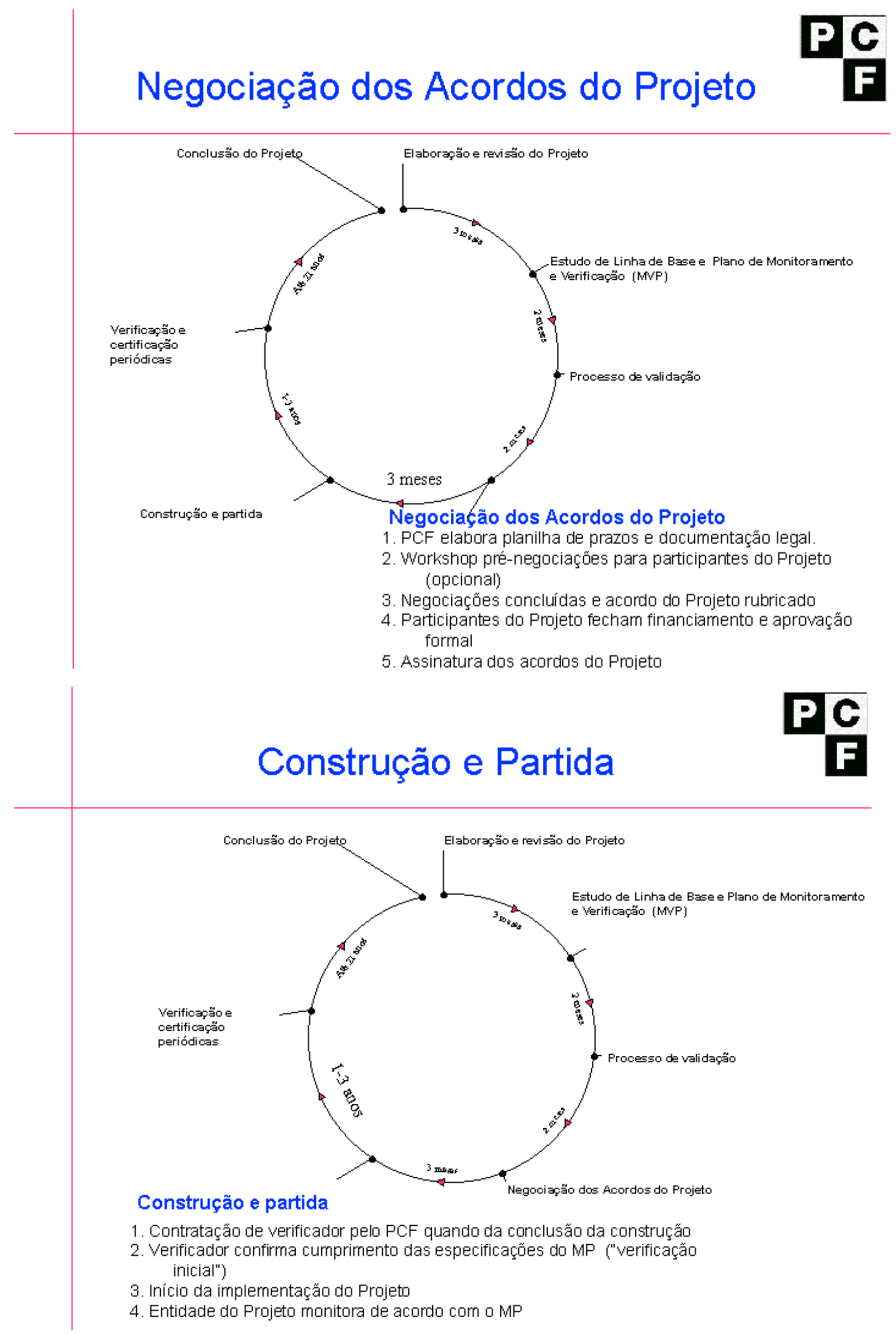




\section{Verificação e Certificação}

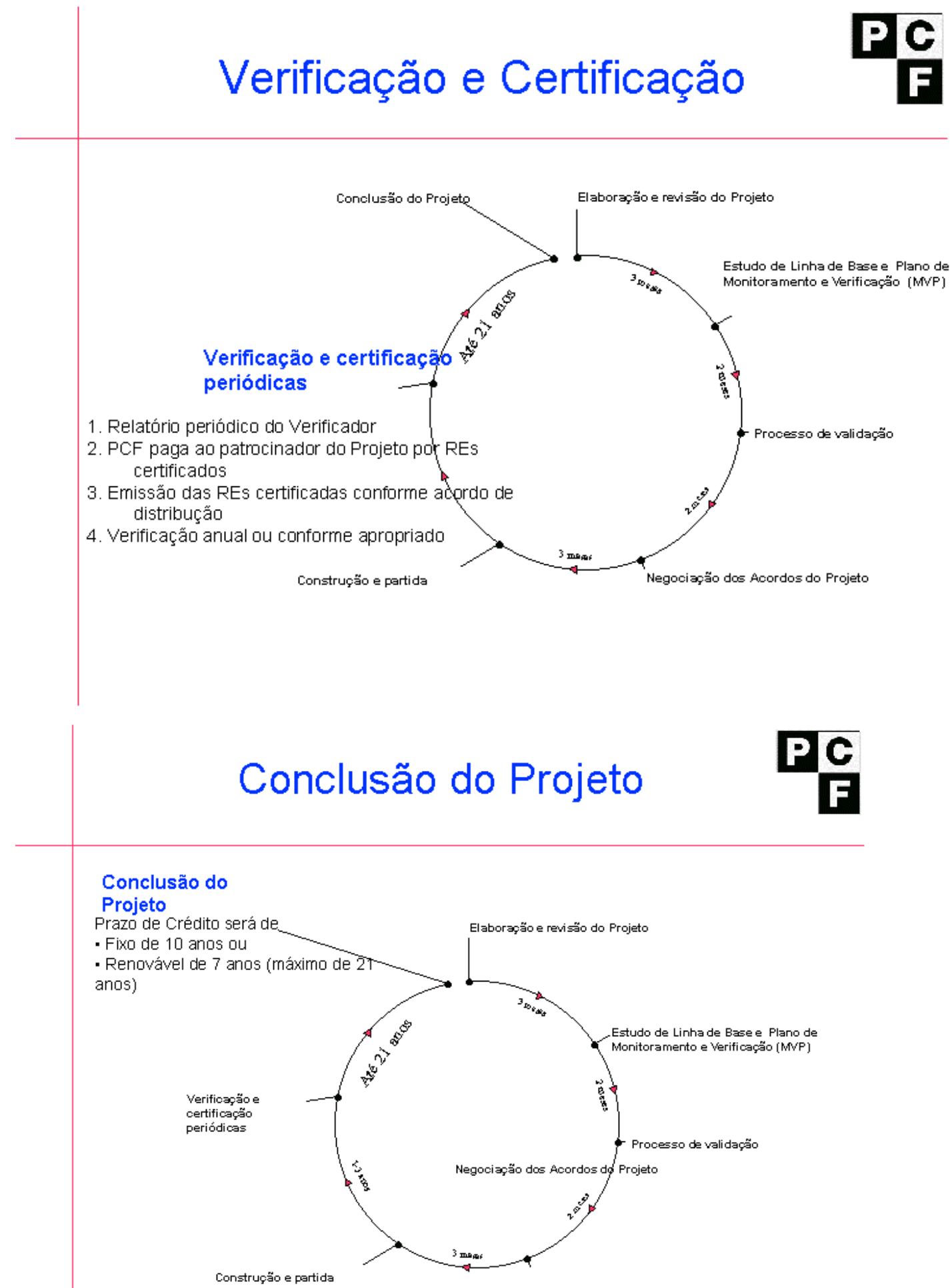




\section{Documentação do Projeto PCF $\mathbf{F}$}

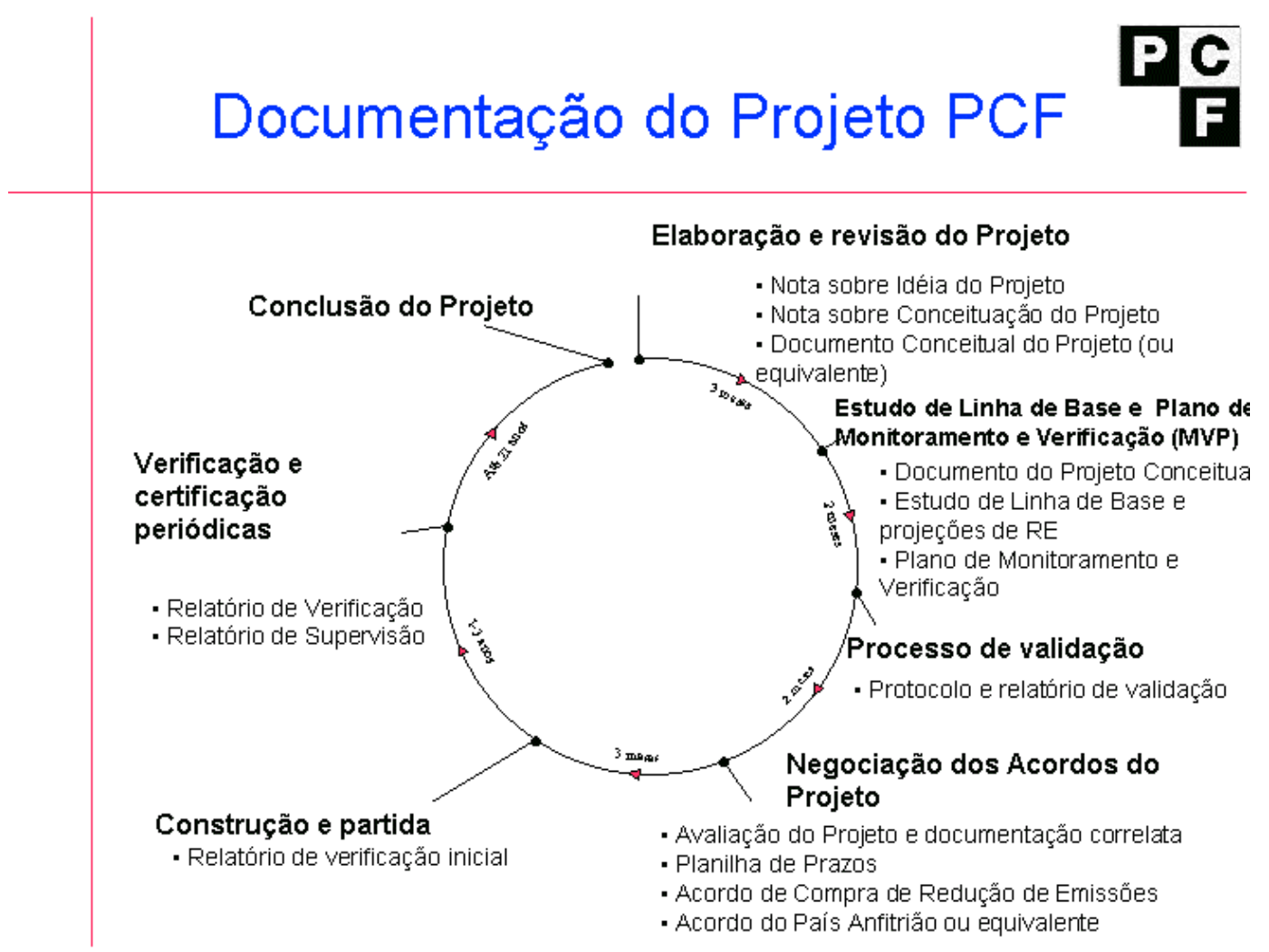

Figura 9 - Esquema geral de funcionamento do PCF.

Fonte: Adaptado de PCF (2002b)

\subsubsection{O BioCarbon Fund ${ }^{25}$}

O Banco Mundial está em processo de consulta para criar outro fundo nos moldes do PCF: o BioCarbon Fund. Esse fundo teria como objetivo financiar projetos agroflorestais de seqüestro de carbono com enfoque também na conservação da biodiversidade, no combate à desertificação e no desenvolvimento socioeconômico. O Banco espera com isso criar uma relação entre as três convenções adotadas no RIO-92: Convenção do Clima, da Biodiversidade e do Combate à Desertificação. Em outras palavras, o BioCarbon espera gerar créditos que possam financiar atividades que contribuam conjuntamente com os objetivos das três convenções.

\footnotetext{
${ }^{25}$ Esta seção está baseada em BioCarbon Fund (2002).
} 
Esse fundo teria duas frentes de atuação:

a. Projetos elegíveis dentro do Protocolo de Quioto: atividades de LULUCF (Land Use, Land Use Change e Forestry) em economias em transição e florestamento e reflorestamento dentro de projetos de MDL; e

b. Outros projetos: que hoje não são elegíveis, mas que poderiam trazer benefícios socioambientais além da mitigação do efeito estufa. Os "créditos" aqui gerados poderiam ser transacionados em mercados paralelos ao criado pelo Protocolo ou até mesmo em períodos futuros de compromisso.

As principais categorias de projetos que estão sendo analisadas são: manejo florestal; plantações e sistemas agroflorestais que contribuam para a conservação da biodiversidade; desmatamento evitado; manejo agrícola; e manejo de bacias hidrográficas.

A perspectiva do Banco Mundial é criar um fundo de aproximadamente US\$ 100 milhões até 2003, com a participação de governos, ONG e empresas privadas. A contribuição individual seria da ordem de US\$ 2-3 milhões.

\subsubsection{A criação e evolução de um mercado de emissões}

Como citado anteriormente, a proposta de se transacionar créditos/certificados para auxiliar no cumprimento de metas de redução de emissões não é original. Outras experiências já existiram e estão ocorrendo para outros tipos de gases (por exemplo, o $\mathrm{SO}_{2}$ ). Assim, existe um referencial teórico que pode ser utilizado como base para a formação do mercado de carbono. Esta seção irá discutir este referencial e sua aplicação no mercado de carbono. Nesta seção o termo crédito não se refere a CER, a não ser que assim seja especificado.

Um mercado de emissões constitui-se de três níveis: primário, secundário e derivativo (Beil, 1999 e Beil \& Assim, 2000):

Mercado primário - distribuição pelo governo de permissões, seja através de leilões ou "grandfathering rules";

$>$ Mercado secundário - compra e venda das permissões;

$>$ Mercado derivativo ou mercado futuro - compra e venda de produtos financeiros 
cujos valores derivam dos mercados primário e secundário. Os contratos futuros de permissões são exemplos de derivativos. Esses contratos buscam minimizar os riscos de preços e investimentos existentes nos mercados primário e secundário.

A criação de um mercado de emissões é similar ao estabelecimento de qualquer outro mercado de commodities. O desenvolvimento desse novo mercado começa com o governo definindo a quantidade de emissão que pode ser negociada. Um número correspondente de permissões é, então, colocado à disposição dos agentes. Cada permissão irá definir o direito de emitir uma quantidade de GEE em um determinado período de tempo.

Atualmente os mercados de carbono encontram-se no estágio de "Grey market" (Beil, 1999 e Beil \& Assim, 2000), no qual não existem legislações domésticas ou internacionais que possam legitimar os direitos associados às permissões ou créditos oriundos de projetos de seqüestro ou de redução de emissões que estão em andamento. Como consequiência, existem incertezas quanto à aceitação destas permissões e créditos nos mercados que irão se formar. Essa incerteza está refletida nos baixos preços do carbono observados atualmente.

Apesar dos baixos preços e incertezas, o "early trade" pode ser justificado pelas seguintes razões: demonstra uma atitude pró-ativa; um exercício de "learning by doing", como preparação para o mercado que irá se formar; especulação de preços; um hedge parcial; desenvolvimento de novas oportunidades de negócios; e, desenvolvimento de vantagens competitivas (Beil, 1999 e Beil \& Assim, 2000).

Podem existir no "Grey market" condições para o lançamento de um programa piloto de trocas. Esse programa piloto pode estar restrito a um ou mais setores da economia e ser induzido tanto pelo governo como pelo setor privado. Somente após a ratificação do Protocolo de Quioto, o governo poderá estabelecer um mercado formal para CER.

Para que este mercado formal seja eficiente, o setor financeiro precisa estar ativamente envolvido. $\mathrm{O}$ papel fundamental do setor financeiro será o de reduzir custos de transação e distribuir riscos de preços e investimentos. Bolsas como a BM\&F poderiam facilitar o encontro de compradores e vendedores. O nível de envolvimento das bolsas pode variar desde a simples emissão de boletins de preço até o 
estabelecimento de mercados secundários e de derivativos eletrônicos centralizados associados a câmaras de compensação.

Nordhaus (2000) enumera algumas dificuldades que precisam ser superadas para que um mercado internacional de carbono possa ser implementado. Esse autor baseia seus argumentos na transformação econômica de Chicago, cidade que antigamente tinha sua economia centrada na criação de porcos, daí ser chamada de "Porcópolis". Com o desenvolvimento do mercado de derivativos, em especial de "sulfur derivatives" provenientes do Programa de Chuva Ácida da EPA e do Clean Act na década de 70, a cidade passa a ser denominada por esse autor como "Sulfopolis". Essa transformação trouxe benefícios econômico-ambientais bastante expressivos. A transformação para "Carbopolis" (economia baseada na commodity carbono) envolve a extensão de um programa que funciona adequadamente em um único país onde existe um governo bem estruturado, regras bem definidas, uma commodity padronizada e um sólido sistema de implementação doméstica para uma arena internacional. Essa transformação é bastante complexa e custosa, em função das dificuldades em se definir a commodity carbono; em estabelecer implementações domésticas do programa e sistemas de monitoramento; em tratar adequadamente países não-democráticos e corruptos; em tratar o problema da "emissions bankruptcy"; e em definir um "benchmark" para emissões futuras.

Outros autores que também procuram definir qual o processo necessário para que o mercado de carbono possa evoluir são Sandor \& Walsh (2000). Para esses autores, o processo está baseado em 7 passos: 1) a ocorrência de mudanças estruturais que gerem demanda por capital; 2) a criação de uma padronização uniforme para a commodity; 3) o desenvolvimento de instrumentos legais que garantam o direito de propriedade; 4) o desenvolvimento de mercados à vista informais e de entrega futura (mercados a termo); 5) o aparecimento de bolsas; 6) a criação de mercados futuros e de opções organizados; e 7) a proliferação de mercados de balcão ("over-the-counter") ${ }^{26}$.

A história do desenvolvimento dos mercados atuais, em especial do mercado para $\mathrm{SO}_{2}$, é utilizada pelos autores para comprovar suas idéias. Os autores também citam

\footnotetext{
26 "Mercado em que as operações de valores mobiliários são realizadas por meio de uma rede de telefones e computadores em vez de ocorrerem no pregão de uma bolsa" (Downes \& Goodman, 1993).
} 
Schumpeter, que descreve três fases no processo de invenção: 1) a criação da idéia; 2) a comercialização; e, por fim, 3) a difusão ou replicação e disseminação.

A Convenção do Clima criou a idéia da comercialização (Protocolo de Quioto) e está gerando condições para essa comercialização ocorra (Acordo de Marrakesh). Desta forma o mercado de carbono existe e têm condições de se desenvolvover. O Banco Mundial prevê para 2006 e para 2010 as estruturas/distribuições de mercado observadas na Figura 12. 


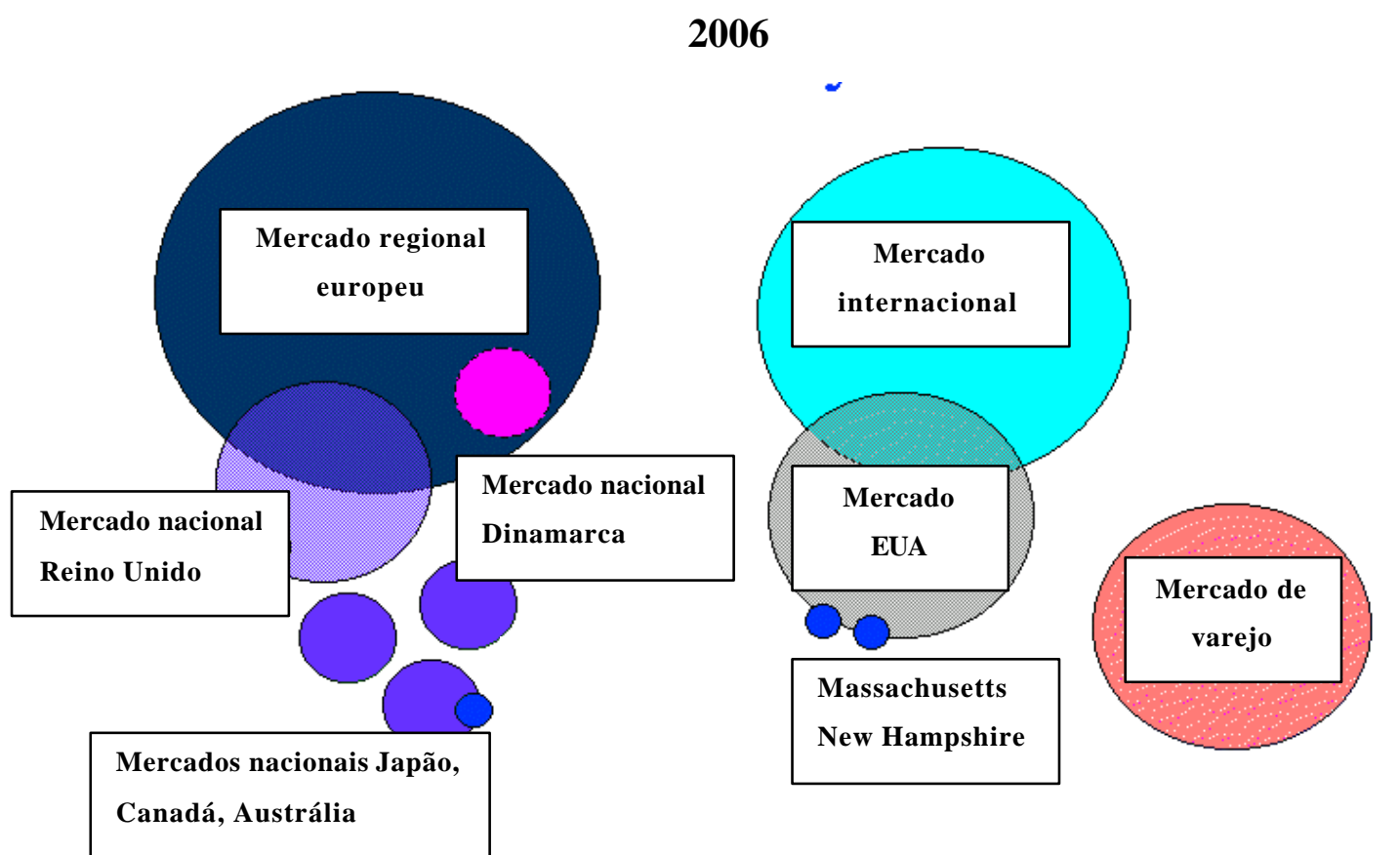

2010

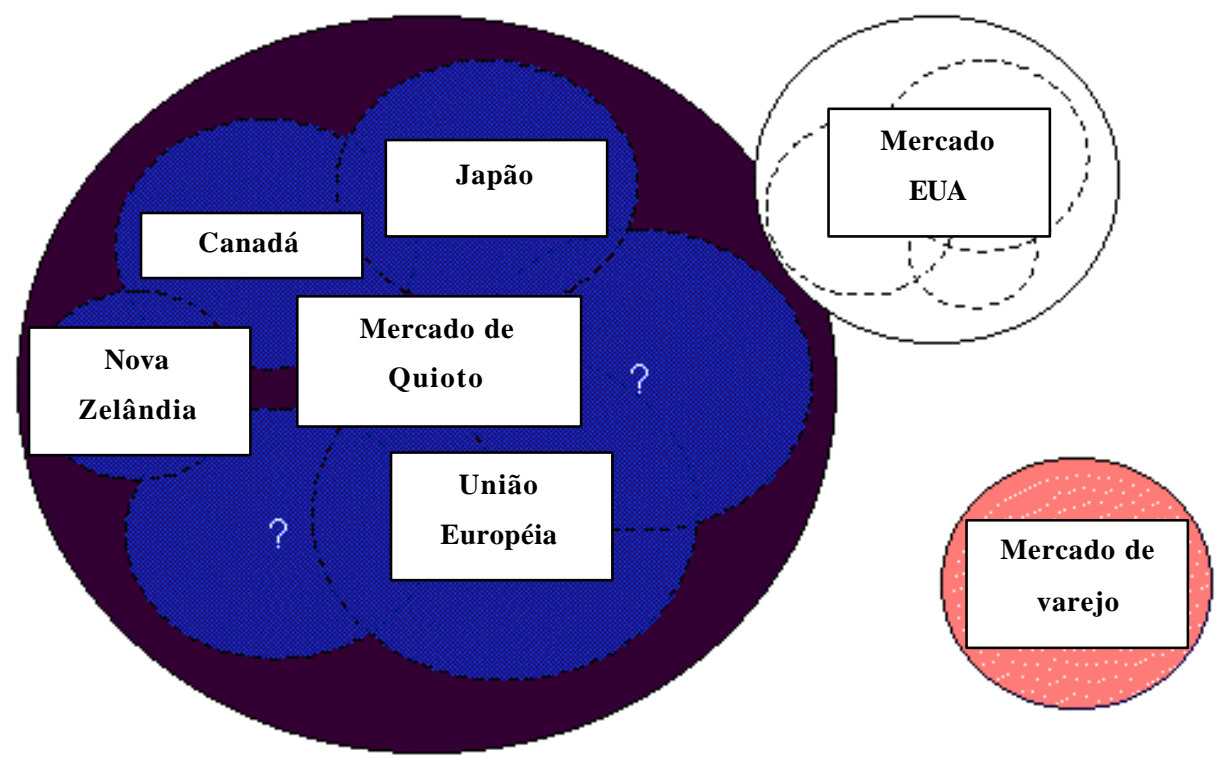

Figura 10 - Como será o mercado de carbono em 2006 e em 2010.

Fonte: Adaptado de Lecocq \& Capoor (2002)

Observa-se que, inicialmente (2006), os diferentes mercados nacionais/regionais 
de carbono estarão de certa forma isolados, sendo que apenas alguns deles terão ligações com outros mercados (ex: Reino Unido, Dinamarca e mercado regional europeu). $\mathrm{Na}$ metade do primeiro período de compromisso (2010), a situação será diferente, com todos os mercados totalmente integrados nos moldes do Protocolo de Quioto. A exceção será o mercado norte-americano, que poderá ter pequenas relações (comércio) com o mercado de Quioto. O tamanho de cada mercado varia em função das diferentes metas que as empresas dos diferentes países possuem.

\subsubsection{O mercado futuro}

O mercado de carbono irá evoluir a ponto de que os CER sejam comercializados em bolsas de mercadorias e futuros, a exemplo de algumas commodities agropecuárias?

Nos mercados futuros não se negociam produtos ou ativos, ao contrário do mercado à vista e a termo ${ }^{27}$, mas sim contratos. Segundo Marques \& Mello (1999), menos de $2 \%$ dos negócios são concretizados com a entrega física da mercadoria. Esses contratos nada mais são do que "compromissos padronizados de comprar ou vender certa mercadoria, ativo financeiro ou índice econômico por certo preço, fixado no posto de negociação de bolsa, com uma data específica de vencimento" (Montezano, 1987). A negociação destes compromissos busca minimizar os riscos de preços que porventura o produto/mercadoria venha a apresentar. Nesse tipo de negociação, merecem destaque dois agentes: hedgers (preocupados em se defender das oscilações de preços do mercado físico) e especuladores (interessados em assumir riscos de preços).

Portanto, torna-se claro que os mercados futuros surgem onde a volatilidade dos preços é alta. Outra condição necessária para a existência de mercados que negociem contratos futuros de um produto qualquer é que esse item seja perfeitamente padronizado, de forma que um contrato seja substituto perfeito de outro. Evidentemente, os benefícios econômicos gerados por esse tipo de mercado precisam ser superiores aos custos operacionais. Segundo Montezano (1987), "a comprovação de que a criação de

\footnotetext{
${ }^{27}$ Nos mercados à vista e a termo o comprador adquire um produto, por um preço previamente acordado e
} 
mercados futuros melhorará a qualidade dos preços formados nos mercados, de modo a gerar benefícios sociais de informação superiores aos custos de operação nos mercados futuros, é condição suficiente para sua existência".

Ainda segundo Montezano (1987), podem-se citar como benefícios da utilização dos mercados futuros, além da proteção contra riscos de preços, a redução dos custos de transação, o aumento do grau de competitividade no mercado à vista (em decorrência de uma maior visibilidade de preços), a possibilidade de realização de operações de financiamentos, e a alocação eficiente de recursos, entre outros. Para Cavalcanti \& Misumi (1998), as vantagens operacionais e econômicas dos contratos futuros são: garantia de preços futuros, melhoria da comercialização de produtos, atração de capitais de risco, disseminação dos preços das commodities, redução de custos de financiamento e maior disseminação de informações.

No Brasil, segundo Cavalcanti \& Misumi (1998), os contratos futuros iniciais tinham algumas imperfeições que dificultavam as operações. As principais, segundo estes autores, eram:

$>$ Riscos de crédito e performance;

$>$ Armazenagem inadequada;

$>$ Falta de qualidade padronizada;

$>$ Variações das condições de pagamento;

$>$ Preços não-disseminados;

$>$ Revenda (recompra) inviável; e

$>$ Litígios na liquidação.

Segundo Marques \& Mello (1999), “a evolução dos contratos futuros é uma consequiência da organização e aprimoramento dos mercados físicos. Enquanto perdurarem questões de classificação, padronização, falta de concorrência e de interesse na divulgação dos preços os mercados futuros ... não se desenvolverão".

Os contratos futuros são também conhecidos como derivativos, que podem ser definidos como "títulos cujos valores dependem dos valores de outras variáveis mais básicas" (Hull, 1996). O mercado de derivativos tem crescido bastante nos últimos anos. 
Um exemplo interessante de derivativos são as "weather derivatives", cuja função é "hedgear" as empresas contra efeitos adversos do clima. Estima-se que esse mercado tenha transacionado mais de US\$ 7 bilhões desde seu nascimento em 1997 (Amigos da Terra, 2000).

Segundo Sandor \& Walsh (2000), o mercado de carbono poderá evoluir até o aparecimento de mercados futuros. Porém, os projetos de MDL que atualmente estão sendo propostos e realizados no Brasil estão gerando Certificados de Emissões Reduzidas (CER), que não podem ser caracterizados como commodities (ver o item Commodities ambientais). Dessa forma, não é possível negociá-los como contratos futuros, cujo objetivo seria reduzir os riscos de "preços do carbono". Enfim, no estágio em que se encontra o mercado de carbono, não é possível afirmar que os "créditos" gerados sejam commodities, uma vez que cada projeto tem características muito peculiares e estão sendo negociados individualmente e não em um ambiente de bolsa. Assim, não existem condições para o aparecimento de mercados futuros de carbono. 


\section{METODOLOGIA}

Esta seção irá apresentar a metodologia utilizada para determinar o tamanho do mercado global e a participação do Brasil (através do MDL) em diversos cenários. Para estimar o tamanho do mercado utiliza-se o Modelo CERT (Carbon Emission Reduction Trade). O Modelo CERT estima a demanda e oferta do mercado potencial de comércio de emissões dentro Protocolo de Quioto, utilizando diferentes cenários e curvas de custo marginal de abatimento (MAC). O CERT não é um modelo de equilíbrio geral, mas um "meta-modelo" que utiliza informações de outros modelos.

\subsection{O Modelo CERT (Carbon Emission Reduction Trade) ${ }^{1}$}

O comércio de emissões ocorre devido a diferenças nos custos marginais de abatimento de $\mathrm{CO}_{2}$ entre diversos países. Como visto anteriormente, essa diferença pode chegar a centenas de dólares por tonelada de carbono abatida.

O Modelo CERT (Carbon Emission Reduction Trade) foi criado por Dr. Jürg M. Grütter (Grütter Consulting), Prof. Dr. Rolf Kappel (ETH Zürich) e por Dr. Peter Staub (ETH Zürich).

${ }^{1}$ Esta seção está baseada em Grütter (2001), Grütter et al. (2002), Kappel et al. (2001) e Kappel et al. (2002). 
Os resultados são calculados para diferentes cenários, levando em consideração diversas variáveis: inclusão ou não de "hot air" (excesso de reduções de emissões disponíveis na antiga União Soviética, devido ao colapso da economia desde 1991), diferentes taxas de implementação de projetos, inclusão ou não de custos de transação, etc. Para estimar o mercado de carbono o CERT, apresenta quatro etapas:

I) Determinar as emissões de GEE para cada país do ANEXO I no ano base. O CERT utiliza as informações disponíveis no site da UNFCCC (http://www.unfccc.int).

II) Determinar as metas de redução de Quioto para cada país do ANEXO I em 2010. O ANEXO B do Protocolo de Quioto especifica as metas de redução de cada país do ANEXO I para o primeiro período de compromisso (2008-2012). Para o CERT a meta de redução de cada país é calculada como uma média dos cinco anos. O ano de 2010 é utilizado como referência para o primeiro período de compromisso. Multiplicando as emissões de cada país do ANEXO I no ano base pela meta de redução, obtém-se a quantidade de abatimentos necessários.

III) Estimar as emissões de GEE no cenário de "business as usual" (BAU) para cada país do ANEXO I durante o primeiro período de compromisso.

IV) Estimar as curvas de custo marginal de abatimento (MAC).

Os países e regiões do Modelo CERT foram retirados do Modelo EPPA (Emission Prediction and Policy Assessment) do MIT (Massachusetts Institute of Technology). A estrutura regional é apresentada no Quadro 1. Ao total existem no Modelo 6 países/grupos de países do ANEXO B (com compromissos de redução das emissões de GEE) e 6 países/grupos de países não-ANEXO B (sem compromissos de redução das emissões de GEE e com a possibilidade de oferecer CER a partir de projetos de MDL). 
ANEXO B

1. USA: Estados Unidos

2. JPN: Japão

3. EEC: União Européia ${ }^{2}$

4. OOE: Outros países da OECD ${ }^{3}$

5. EET: Economias em transição ${ }^{4}$

6. FSU: Antiga União Soviética ${ }^{5}$

\section{Não-ANEXO B}

7. EEX: Países exportadores de energia ${ }^{6}$

8. CHN: China

9. IND: Índia

10. DAE: Economias Dinâmicas Asiáticas ${ }^{7}$

11. BRA: Brasil

12. ROW: resto do mundo ${ }^{8}$

Quadro 6 - Estrutura regional do CERT.

Fonte: Kappel et al. (2002)

\subsubsection{A solução algorítmica do Modelo}

A solução algorítmica do CERT é definida com o objetivo de minimizar o custo global da redução das emissões de GEE. As reduções das emissões dos países do ANEXO B são calculadas subtraindo-se das emissões em 2010 ("business as usual" BAU) os "assigned amount" (emissões de 1990 multiplicadas pelas metas do Protocolo de Quioto):

$$
\mathrm{QR}_{\mathrm{i}}=\mathrm{BAU}_{\mathrm{i}}-\left(\mathrm{KT}_{\mathrm{i}} \mathrm{E}_{1990 \mathrm{i}}\right) \quad \mathrm{i}=1,6
$$

Onde:

2 Áustria, Bélgica, Dinamarca, Finlândia, França, Alemanha, Grécia, Irlanda, Itália, Luxemburgo, Holanda, Portugal, Espanha, Suécia e Reino Unido.

3 Austrália, Nova Zelândia, Canadá, Turquia, Noruega, Groelândia e Suíça.

${ }^{4}$ Bulgária, Croácia, República Tcheca, Hungria, Polônia, Romênia, Eslováquia e Eslovênia.

${ }^{5}$ Estônia, Letônia, Lituânia, Rússia e Ucrânia.

6 Argélia, Bahrain, Bostwana, Egito, Indonésia, Irã, Iraque, Israel, Jordânia, Kuwait, Líbano, Lesoto, Líbia, Namíbia, Oman, Qatar, Arábia Saudita, Síria, África do Sul, Swaziland, Tunísia, Emirados Árabes, Venezuela e Iêmen.

${ }^{7}$ Coréia do Sul, Filipinas, Tailândia e Singapura.

${ }^{8}$ Outros países e regiões não incluídas na classificação anterior. 
$\mathrm{QR}=$ quantidade de emissões de GEE a serem reduzidas;

BAU = "business as usual", emissões em 2010;

$\mathrm{KT}=$ metas de redução presente no Protocolo de Quioto (porcentagem do ano base ou período);

$\mathrm{E}_{1990}=$ emissões em 1990; e

i = número de países e/ou grupo de países (ANEXO B).

As curvas de custo marginal de abatimento (MAC) são usadas para calcular o custo e a quantidade de redução em cada país e região. Dado um preço para as reduções de emissões, e assumindo competição perfeita, cada país e região irá reduzir suas emissões até o ponto em que o custo marginal se iguala ao preço. A integral das MAC representa o custo total das reduções de emissões. O CERT trabalha com dois tipos de MAC, uma função quadrática e outra exponencial:

$$
\begin{array}{ll}
\mathrm{MC}_{\mathrm{i}}=\mathrm{a}_{\mathrm{i}} \mathrm{Q}_{\mathrm{i}}^{2}+\mathrm{b}_{\mathrm{i}} \mathrm{Q}_{\mathrm{i}} & \mathrm{i}=1,12 \\
\mathrm{MC}_{\mathrm{i}}=\mathrm{a}_{\mathrm{i}}\left(\mathrm{e}^{\mathrm{biQi}}-1\right) & \mathrm{i}=1,12
\end{array}
$$

Onde:

$\mathrm{MC}=$ custo marginal das reduções das emissões;

$\mathrm{Q}=$ reduções das emissões; e

i = número de países e/ou grupo de países (ANEXO B e não-ANEXO B).

Dado um preço $\mathrm{P}_{\mathrm{k}}$, a quantidade de redução em cada país e região será de:

$$
\begin{array}{ll}
\mathrm{Q}_{\mathrm{i}}=-\mathrm{b}_{\mathrm{i}} / 2 \mathrm{a}_{\mathrm{i}}+\left(\left(\mathrm{b}_{\mathrm{i}} / 2 \mathrm{a}_{\mathrm{i}}\right)^{2}+\mathrm{P}_{\mathrm{k}} / \mathrm{a}_{\mathrm{i}}\right)^{1 / 2} & \mathrm{i}=1,12 \\
\mathrm{Q}_{\mathrm{i}}=\ln \left(\mathrm{P}_{\mathrm{k}} / \mathrm{a}_{\mathrm{i}}+1\right) / \mathrm{b}_{\mathrm{i}} & \mathrm{i}=1,12
\end{array}
$$

Onde:

$\mathrm{Q}=$ reduções das emissões;

$\mathrm{P}=$ preço para as reduções das emissões; $\mathrm{e}$ 
i = número de países e/ou grupo de países (ANEXO B e não-ANEXO B).

O custo das reduções das emissões é obtido pela integral das MAC:

$$
\begin{array}{ll}
\mathrm{C}_{\mathrm{i}}=1 / 3 \mathrm{a}_{\mathrm{i}} \mathrm{Q}_{\mathrm{i}}{ }^{3}+1 / 2 \mathrm{~b}_{\mathrm{i}} \mathrm{Q}_{\mathrm{i}}{ }^{2} & \mathrm{i}=1,12 \\
\mathrm{C}_{\mathrm{i}}=\left(\mathrm{a}_{\mathrm{i}} / \mathrm{b}_{\mathrm{i}}\right) \mathrm{e}^{\mathrm{biQi}}-\mathrm{a}_{\mathrm{i}} \mathrm{Q}_{\mathrm{i}}-\left(\mathrm{a}_{\mathrm{i}} / \mathrm{b}_{\mathrm{i}}\right) & \mathrm{i}=1,12
\end{array}
$$

Onde:

$\mathrm{C}=$ custo das reduções das emissões;

$\mathrm{Q}=$ reduções das emissões; $\mathrm{e}$

i = número de países e/ou grupo de países (ANEXO B e não-ANEXO B).

O equilíbrio de mercado ocorre quando o total de emissões a serem reduzidas se iguala ao total reduzido. Na condição de competição perfeita, o preço de equilíbrio é calculado por:

$$
\mathrm{TQR}=\mathrm{QR}_{\mathrm{i}} \quad \mathrm{i}=1,6 ; \mathrm{QR}_{\mathrm{i}}>0
$$

Onde:

$\mathrm{TQR}=$ total de emissões a serem reduzidas;

$\mathrm{QR}=$ emissões a serem reduzidas; $\mathrm{e}$

i = número de países e/ou grupo de países (ANEXO B).

$$
\mathrm{TQ}=\mathrm{Q}_{\mathrm{i}} \quad \mathrm{i}=1,12
$$

Onde:

$\mathrm{TQ}=$ total de emissões reduzidas;

$\mathrm{Q}=$ emissões reduzidas; $\mathrm{e}$

i = número de países e/ou grupo de países (ANEXO B e não-ANEXO B). 


$$
\mathrm{P}^{*}=\mathrm{P} \text { para } \mathrm{TQR}=\mathrm{TQ}
$$

Onde:

$\mathrm{P}^{*}=$ preço de equilíbrio para redução de GEE;

$\mathrm{TQR}=$ total de emissões a serem reduzidas; $\mathrm{e}$

$\mathrm{TQ}=$ total de emissões reduzidas.

O custo mundial de tal redução é:

$$
\mathrm{TC}=\mathrm{C}_{\mathrm{i}} \quad \mathrm{i}=1,12
$$

Onde:

TC = custo total da redução das emissões;

$\mathrm{C}=$ custo de redução das emissões; e

$\mathrm{i}$ = número de países e/ou grupo de países (ANEXO B e não-ANEXO B).

As metas de Quioto também poderiam ser atingidas sem o comércio de emissões. Nesta solução autárquica, cada país do ANEXO B vai reduzir suas emissões até atingir seu "assigned amount" (emissões de 1990 multiplicadas pelas metas do Protocolo de Quioto) de tal forma que $\mathrm{QR}_{\mathrm{i}}$ seja igual a $\mathrm{Q}$ para cada país do $\mathrm{ANEXO} \mathrm{B} \mathrm{com} \mathrm{QR}_{\mathrm{i}}>0$. O custo total da solução autárquica é:

$$
\begin{aligned}
& \mathrm{C}_{\mathrm{Ai}}=1 / 3 \mathrm{a}_{\mathrm{i}} \mathrm{Q}_{\mathrm{Ai}}{ }^{3}+1 / 2 \mathrm{~b}_{\mathrm{i}} \mathrm{Q}_{\mathrm{Ai}}{ }^{2} \quad \mathrm{i}=1,6 ; \mathrm{QR}_{\mathrm{i}}>0
\end{aligned}
$$

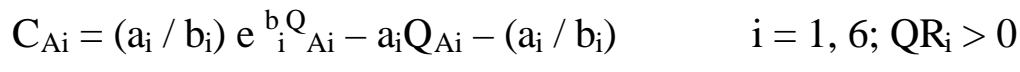

$$
\begin{aligned}
& \mathrm{TC}_{\mathrm{A}}=\mathrm{C}_{\mathrm{Ai}} \quad \mathrm{i}=1,6 ; \mathrm{QR}_{\mathrm{i}}>0
\end{aligned}
$$

Onde:

$\mathrm{C}_{\mathrm{Ai}}=$ custo da solução autárquica;

$\mathrm{Q}_{\mathrm{Ai}}=$ redução de emissão autárquica;

$\mathrm{TC}_{\mathrm{A}}=$ custo total da redução de emissão autárquica; e 
i = número de países e/ou grupo de países (ANEXO B).

A economia proporcionada pelo comércio pode ser calculada por:

$$
\mathrm{TS}=\left(\mathrm{TC}-\mathrm{TC}_{\mathrm{A}}\right) / \mathrm{TC}_{\mathrm{A}}
$$

Onde:

$\mathrm{TS}=$ economia decorrente do comércio de emissão em termos relativos (\%);

$\mathrm{TC}=$ custo total da redução das emissões com comércio; e

$\mathrm{TC}_{\mathrm{A}}=$ custo total da redução de emissão autárquica.

\subsubsection{Curvas de custo marginal de abatimento}

As curvas de custo marginal de abatimento (MAC) representam os "preçossombra" das metas de emissão, em função da quantidade abatida de emissões. Em outras palavras, as MAC representam o custo marginal de se reduzir as emissões de GEE. Um ponto na curva $(\mathrm{q}, \mathrm{p})$ representa o custo marginal para se abater uma unidade adicional de GEE. A Figura 13 ilustra uma curva de custo marginal de abatimento. A área abaixo da curva indica o custo total de abatimento da quantidade q de GEE para a região R. 


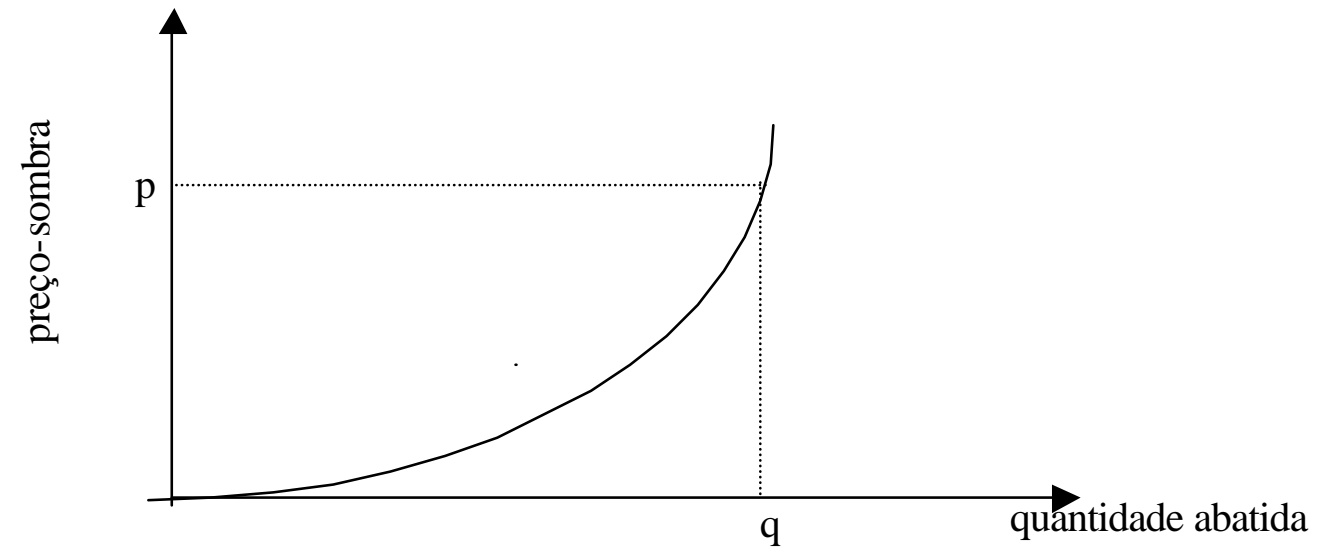

Figura 13 - Curva de custo marginal de abatimento para a região R.

Fonte: Adaptado de Ellerman \& Decaux (1998)

O custo total de abatimento, para duas regiões com diferentes MAC, será reduzido à medida que a região com maior custo induz a região com menor custo a realizar abatimentos por ela. Ao abater mais, a região com menor custo cria "permissões para emissão" que podem ser vendidas para a região com maior custo. A Figura 14 ilustra os ganhos decorrentes do comércio entre duas regiões, $R_{1}$ e $R_{2}$, sujeitas a diferentes metas de abatimento: redução de $\mathrm{CO}_{2}=\mathrm{q}_{1}$ para $\mathrm{R}_{1}$ e $\mathrm{q}_{2}$ para $\mathrm{R}_{2}$. $\mathrm{O}$ Quadro 2 apresenta os cálculos para a situação com e sem comércio. 


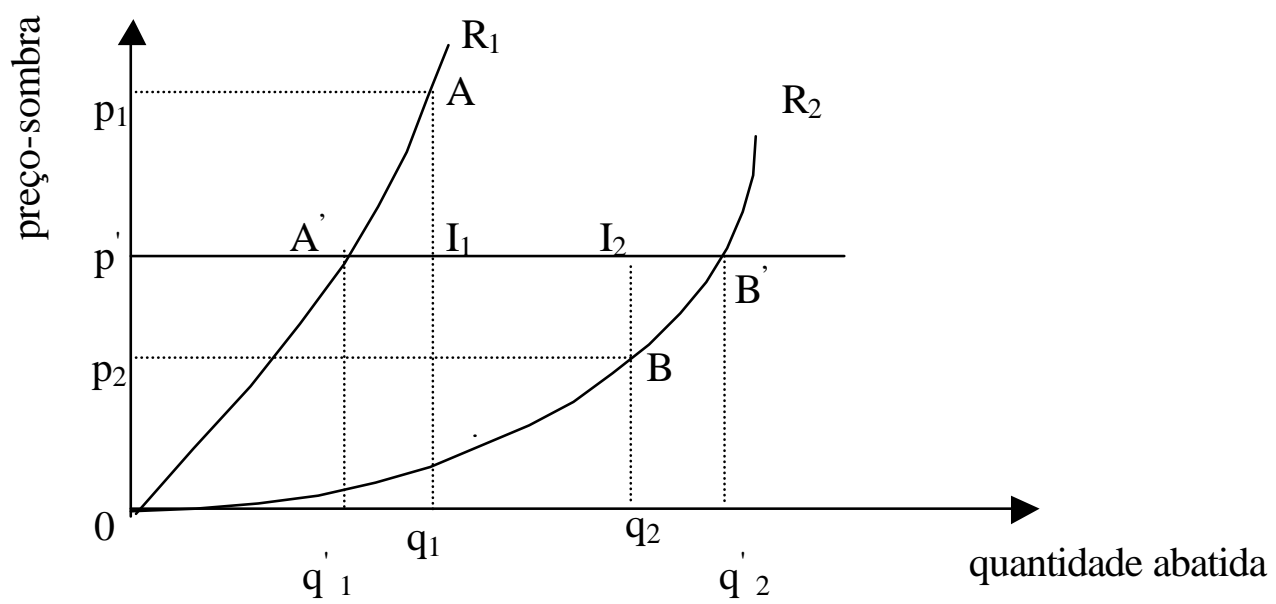

Figura 14 - Curvas de custo marginal de abatimento para diferentes regiões.

Fonte: Adaptado de Ellerman \& Decaux (1998)

\begin{tabular}{|c|c|c|}
\hline & Sem Comércio & Com Comércio \\
\hline Metas & $\begin{array}{l}\mathrm{R}_{1}: \mathrm{q}_{1} \\
\mathrm{R}_{2}: \mathrm{q}_{2}\end{array}$ & $\mathrm{R}_{1}$ e $\mathrm{R}_{2}: \mathrm{q}_{1}+\mathrm{q}_{2}$ \\
\hline Custo Marginal e Preço & $\begin{array}{l}\mathrm{R}_{1}: \mathrm{p}_{1} \\
\mathrm{R}_{2}: \mathrm{p}_{2}\end{array}$ & $\mathrm{R}_{1}$ e $\mathrm{R}_{2}: \mathrm{p}_{1}\left(\mathrm{q}_{1}\right)=\mathrm{p}_{2}\left(\mathrm{q}_{2}\right)=\mathrm{p}$ \\
\hline Custo de abatimento & $\begin{array}{l}\mathrm{R}_{1} \text { : área } \mathrm{A} 0 \mathrm{q}_{1} \\
\mathrm{R}_{2} \text { : área } \mathrm{B} 0 \mathrm{q}_{2}\end{array}$ & $\begin{array}{l}\mathrm{R}_{1} \text { : área } \mathrm{A} 0 \mathrm{q}_{1}^{\prime} \\
\mathrm{R}_{2} \text { : área } \mathrm{B}^{\prime} 0 \mathrm{q}_{2}\end{array}$ \\
\hline Comércio de emissões & --- & $\begin{array}{c}\mathrm{R}_{1} \text { : compra permissões para emitir } \mathrm{q}_{1}-\mathrm{q}_{1} \\
\mathrm{R}_{2} \text { : vende permissões para emitir } \\
\mathrm{q}_{2}-\mathrm{q}_{2}=\mathrm{q}_{1}-\mathrm{q}_{1}\end{array}$ \\
\hline Importação Exportação & --- & $\begin{array}{c}\mathrm{R}_{1} \text { : paga } \mathrm{p}\left(\mathrm{q}_{1}-\mathrm{q}_{1}\right)=\text { área } \mathrm{AI}_{1} \mathrm{q}_{1} \mathrm{q}_{1} \\
\text { para } \mathrm{R}_{2} \\
\mathrm{R}_{2} \text { : recebe } \mathrm{p}\left(\mathrm{q}_{2}^{\prime}-\mathrm{q}_{2}\right)=\text { área } \mathrm{B}^{\prime} \mathrm{I}_{2} \mathrm{q}_{2} \mathrm{q}_{2} \text { de } \mathrm{R}_{1}\end{array}$ \\
\hline Custo total & $\begin{array}{l}\mathrm{R}_{1} \text { : área } \mathrm{A} 0 \mathrm{q}_{1} \\
\mathrm{R}_{2} \text { : área } \mathrm{B} 0 \mathrm{q}_{2}\end{array}$ & $\begin{array}{l}\mathrm{R}_{1} \text { : área } \mathrm{A}^{\prime} 0 \mathrm{q}_{1}+\text { área } A \mathrm{I}_{1} \mathrm{q}_{1} \mathrm{q}_{1}<\text { área } \mathrm{A} 0 \mathrm{q}_{1} \\
\mathrm{R}_{2} \text { : área } \mathrm{B}^{\prime} 0 \mathrm{q}_{2} \text { - área } \mathrm{B}_{2} \mathrm{I}_{2} \mathrm{q}_{2}<\text { área } \mathrm{B} 0 \mathrm{q}_{2}\end{array}$ \\
\hline Economia & --- & $\begin{array}{l}\mathrm{R}_{1} \text { : área } \mathrm{AI}_{1} \mathrm{~A} \\
\mathrm{R}_{2} \text { : área } \mathrm{BI}_{2} \mathrm{~B}\end{array}$ \\
\hline
\end{tabular}

Quadro 7 - Cálculos para o comércio de emissão.

Fonte: Adaptado de Ellerman \& Decaux (1998)

As curvas de custo marginal de abatimento são a base para determinar a demanda e oferta por "permissões para emissão". Essas permissões representam um "direito a 
emitir" e podem ser decorrentes de abatimentos realizados acima de uma determinada meta ou de abatimentos realizados por uma região que não tinha uma meta de redução preestabelecida. A Figura 15 mostra quando um país exporta ou importa "permissões para emissão". A linha vertical representa a quantidade de abatimento necessária. Na ausência de comércio, a quantidade abatida será q' e o preço p'. Havendo a possibilidade de comércio, o país irá abater acima de q’ quando o preço de mercado das emissões estiver acima de p', tornando-se portanto um exportador de permissões. Caso o preço das permissões esteja abaixo de p', o país se torna um importador de permissões, deixando de abater internamente.

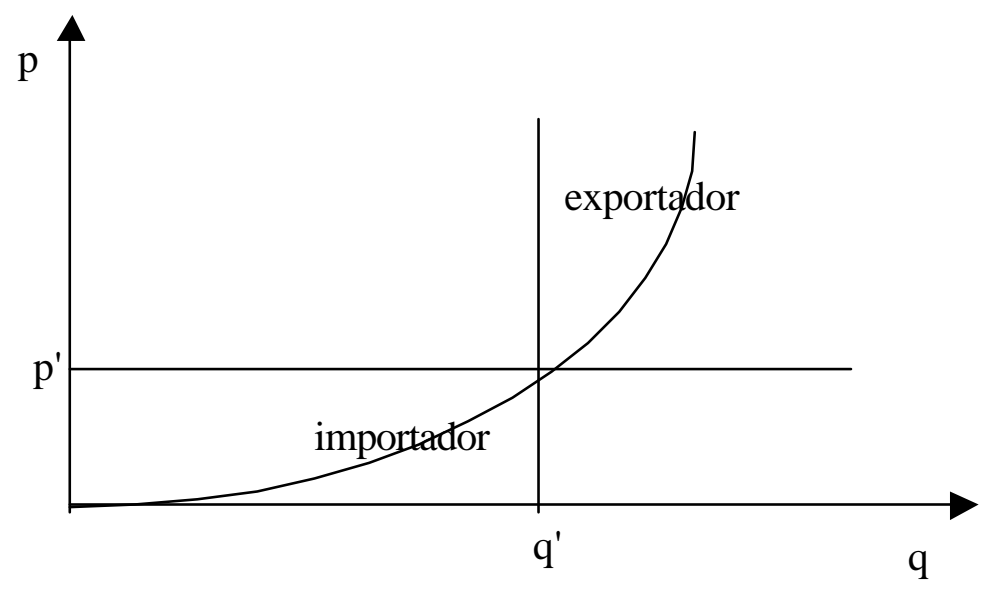

Figura 15 - Importação / Exportação de "permissões para emissão". Fonte: Adaptado de Ellerman \& Decaux (1998)

Existem duas maneiras de se determinar as MAC: abordagem "top-down" e "bottom-up". Na abordagem "top-down", os modelos de equilíbrio geral são calculados com diferentes níveis de abatimento de carbono (por exemplo: 10\%, 20\%, ou $30 \%$ abaixo do valor de referência). Para cada um desses níveis de abatimento, são determinados os respectivos preços-sombra regionais. Estes valores são plotados como uma função do nível de abatimento, para um tempo $\mathrm{T}$ e uma região $\mathrm{R}$. Uma linha pode ser estabelecida entre os pontos a fim de se determinar a MAC da região R no tempo T.

Na abordagem "bottom-up”, as MAC são derivadas a partir de funções de 
oferta de certificados de redução de emissões, provenientes de projetos de MDL e JI (Implementação Conjunta). A vantagem de se utilizar a abordagem "bottom-up" é que as MAC geradas tendem a ser mais realistas. Na abordagem "top-down", existe uma tendência de se superestimar o potencial de abatimento de projetos MDL/JI, uma vez que normalmente são ignoradas restrições, tais como substituição de energia (por exemplo: na abordagem "top-down", é possível a substituição de energia térmica por nuclear em países não-ANEXO B).

\subsubsection{A demanda e oferta do mercado}

De acordo com Vrolijk \& Grubb (2000), as reduções necessárias para atingir as metas do Protocolo de Quioto, ou seja, a demanda por reduções deve estar entre 600 e $1.400 \mathrm{MtCe}$ (Mt de $\mathrm{C}$ equivalente). Parte dessa redução pode ser alcançada por ações domésticas relacionadas à eficiência energética e/ou substituição de combustíveis (200 a $550 \mathrm{MtCe}$ ) e parte por atividades de LUCF (Land Use Change and Forestry - 5 a 50 (Artigo 3.3 do Protocolo de Quioto); 0 a 90 (Artigo 3.7 do Protocolo de Quioto) e 50 a $300 \mathrm{MtCe}$ (Artigo 3.4 do Protocolo de Quioto)). Ao total, as reduções domésticas seriam de 255 a $990 \mathrm{MtCe}$.

A quantidade de certificados de redução de emissões provenientes de projetos de MDL relacionados à eficiência energética e/ou substituição de combustíveis, segundo esses mesmos autores, deve ser de 50 a 375 MtCe, disponíveis a um custo de US\$ 10 a US\$ 40. Com a inclusão de "sinks" (sumidouros de carbono) nos projetos de MDL, haveria uma quantidade adicional de créditos de 40 a 100 MtCe a um custo de US\$ 5 a US\$ 40. A quantidade de "hot air" disponível é estimada entre 100 e 350 MtCe. No mercado, haveria uma oferta total de 190 a 825 MtCe.

O Modelo CERT calcula a demanda e oferta do mercado de comércio de emissões, como pode ser visto na Figura 16. 


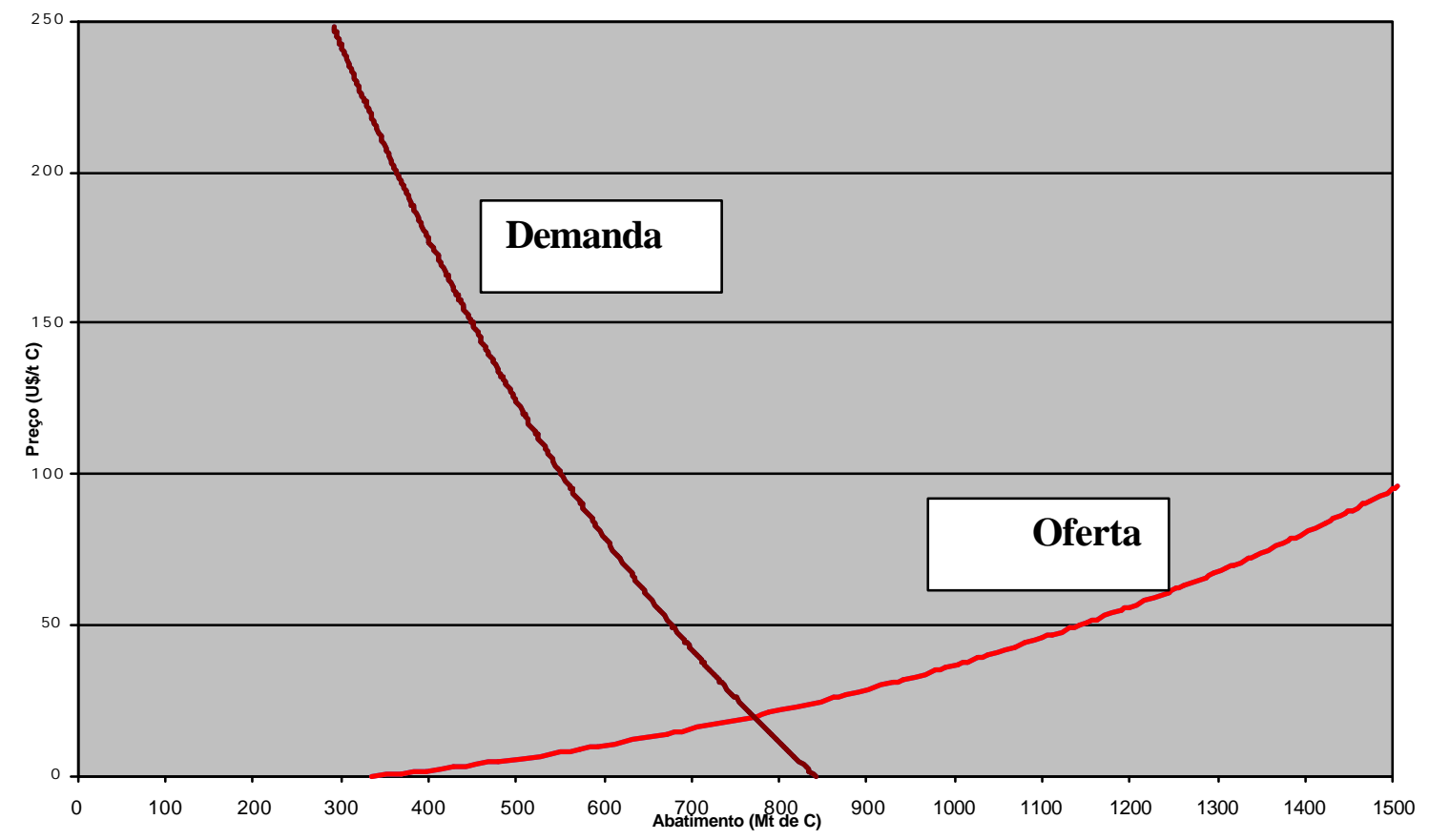

Figura 16 - Demanda e oferta do mercado de carbono.

Fonte: Grütter et al. (2002)

Nesse caso hipotético o equilíbrio de mercado ocorre com a comercialização de $771 \mathrm{M}$ t de $\mathrm{C}$ ao preço de US\$19,8 t/C.

\subsubsection{Os cenários de referência do Modelo}

Os cenários de referência do Modelo CERT presentes na versão 1.23 são:

Cenário 1 EPPA/Baixo: baixo crescimento das emissões, MAC do Modelo EPPA/MIT, somente $\mathrm{CO}_{2}$

- As emissões de 1990 estão baseadas nos dados do RIIA (Royal Institute of International Affairs) 
- As metas de Quioto estão baseadas nos dados do RIIA e em cálculos dos autores do Modelo CERT.

- As emissões "business as usual" (BAU) foram estimadas através de dados do Departamento de Energia dos Estados Unidos (US DOE) e cálculos dos autores do Modelo CERT.

- As MAC estão baseadas no Modelo do MIT (EPPA - Emission Prediction and Policy Assessment Model - Ellermann et al., 1998)

\section{Cenário 2 EPPA/Médio: crescimento médio das emissões, MAC do Modelo EPPA/MIT, somente $\mathrm{CO}_{2}$}

- As emissões de 1990 estão baseadas nos dados do RIIA

- As metas de Quioto estão baseadas nos dados do RIIA e em cálculos dos autores do Modelo CERT.

- As emissões BAU foram estimadas através de dados do US DOE e cálculos dos autores do Modelo CERT.

- As MAC estão baseadas no Modelo EPPA/MIT

\section{Cenário 3 EPPA/Alto: alto crescimento das emissões, MAC do Modelo EPPA/MIT, somente $\mathrm{CO}_{2}$}

- As emissões de 1990 estão baseadas nos dados do RIIA

- As metas de Quioto estão baseadas nos dados do RIIA e em cálculos dos autores do Modelo CERT

- As emissões BAU foram estimadas através de dados do US DOE e cálculos dos autores do Modelo CERT

- As MAC estão baseadas no Modelo EPPA/MIT

As MAC dos cenários 1, 2 e 3 podem ser vistas nas Figuras 17 e 18. Bas foram

derivadas a partir do Modelo EPPA (Emission Prediction and Policy Assessment Model - Ellermann et al., 1998), através de uma abordagem tipo “top-down”. São curvas 
quadráticas para o abatimento apenas do $\mathrm{CO}_{2}$.

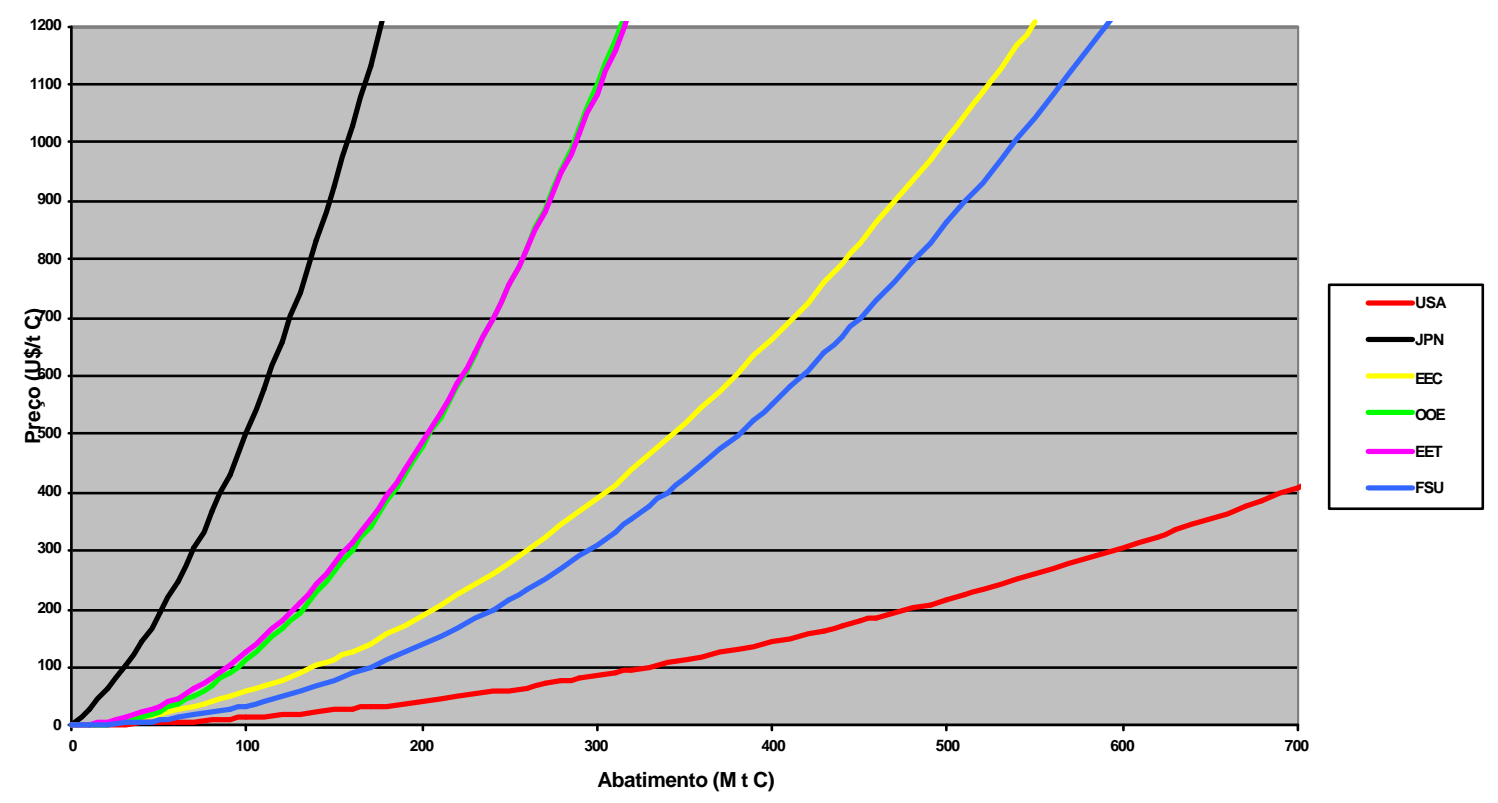

Figura 17 - MAC Cenários 1, 2 e 3 - Países ANEXO B.

Fonte: Grütter et al. (2002)

Legenda: USA - Estados Unidos; JPN - Japão; EEC - União Européia; OOE - Outros países da OECD; EET - Economias em transição; FSU - Antiga União Soviética 


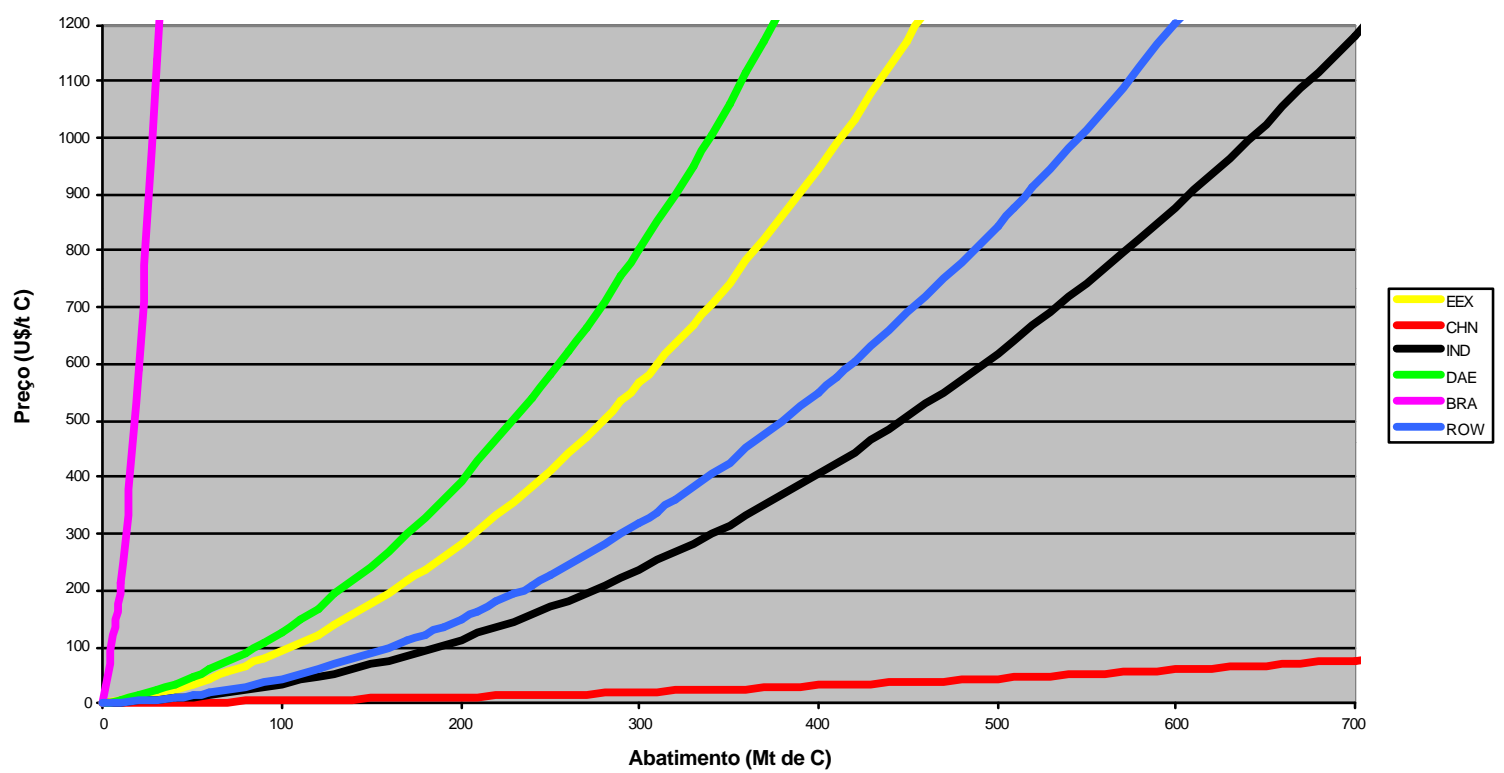

Figura 18- MAC Cenários 1, 2 e 3 - Países não-ANEXO B.

Fonte: Grütter et al. (2002)

Legenda: EEX - Países exportadores de energia; CHN - China; IND - Índia; DAE Economias Dinâmicas Asiáticas; BRA - Brasil; ROW - resto do mundo

\section{Cenário 4 GTEM/Baixo: baixo crescimento das emissões, MAC do Modelo GTEM, somente $\mathrm{CO}_{2}$}

- As emissões de 1990 estão baseadas nos dados do RIIA

- As metas de Quioto estão baseadas nos dados do RIIA e em cálculos dos autores do Modelo CERT

- As emissões BAU foram estimadas através de dados do US DOE e cálculos dos autores do Modelo CERT

- As MAC estão baseadas no Modelo Global Trade and Environment (GTEM Australian Bureau of Agricultural and Resource Economics, 2002) 


\section{Cenário 5 GTEM/Médio: crescimento médio das emissões, MAC do Modelo GTEM, somente $\mathrm{CO}_{2}$}

- As emissões de 1990 estão baseadas nos dados do RIIA

- As metas de Quioto estão baseadas nos dados do RIIA e em cálculos dos autores do Modelo CERT

- As emissões BAU foram estimadas através de dados do US DOE e cálculos dos autores do Modelo CERT

- As MAC estão baseadas no Modelo GTEM

Cenário 6 GTEM/Alto: alto crescimento das emissões, MAC do Modelo GTEM, somente $\mathrm{CO}_{2}$

- As emissões de 1990 estão baseadas nos dados do RIIA

- As metas de Quioto estão baseadas nos dados do RIIA e em cálculos dos autores do Modelo CERT

- As emissões BAU foram estimadas através de dados do US DOE e cálculos dos autores do Modelo CERT

- As MAC estão baseadas no Modelo GTEM

As MAC dos cenários 4, 5 e 6 podem ser vistas nos Figuras 19 e 20. Elas foram

derivadas a partir do Modelo Global Trade and Environment (GTEM - Australian Bureau of Agricultural and Resource Economics, 2002), através de uma abordagem tipo “top-down”. São curvas exponenciais para o abatimento apenas do $\mathrm{CO}_{2}$. 


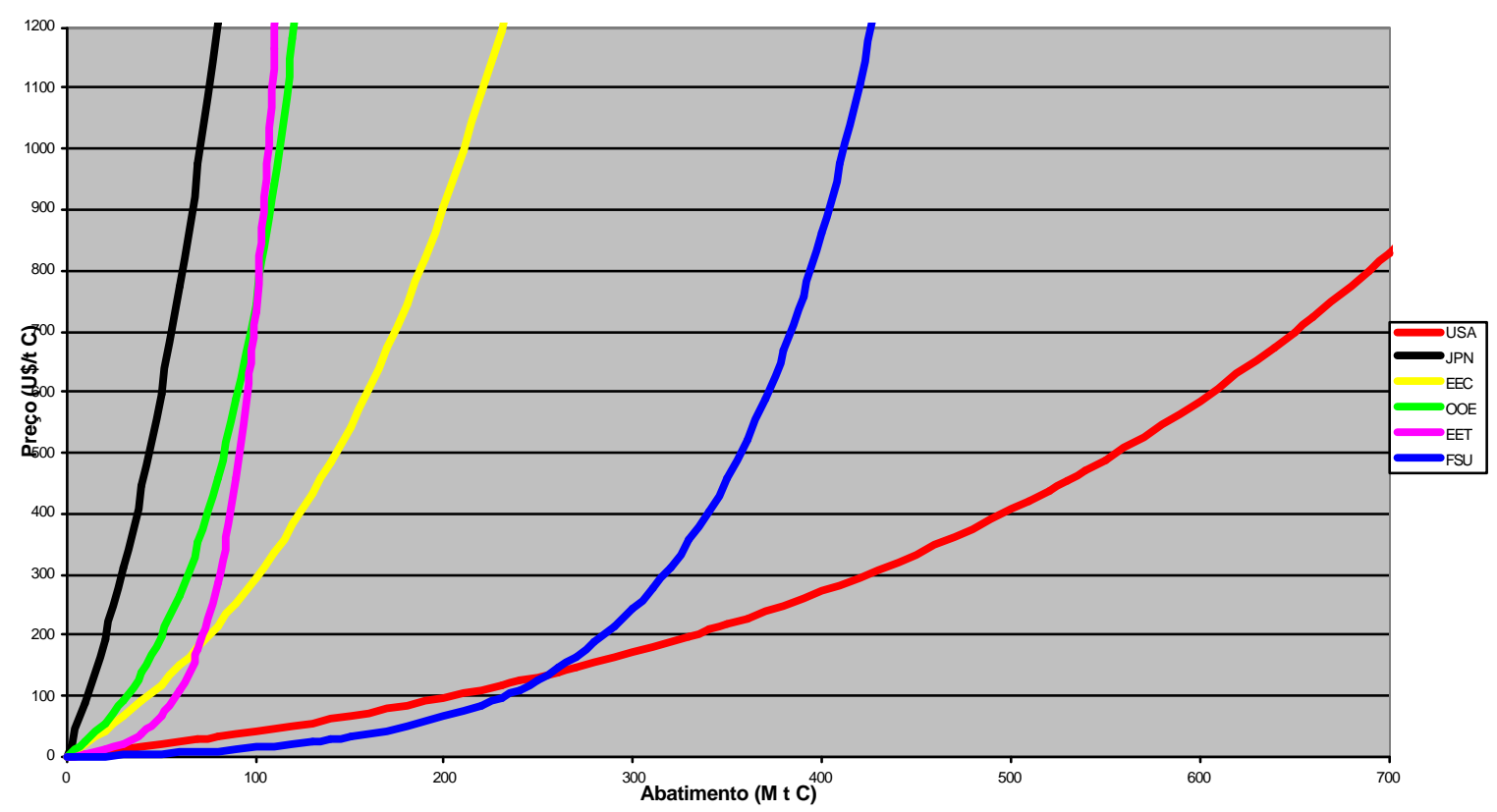

Figura 19 - MAC Cenários 4, 5 e 6 - Países ANEXO B.

Fonte: Grütter et al. (2002)

Legenda: USA - Estados Unidos; JPN - Japão; EEC - União Européia; OOE - Outros países da OECD; EET - Economias em transição; FSU - Antiga União Soviética 


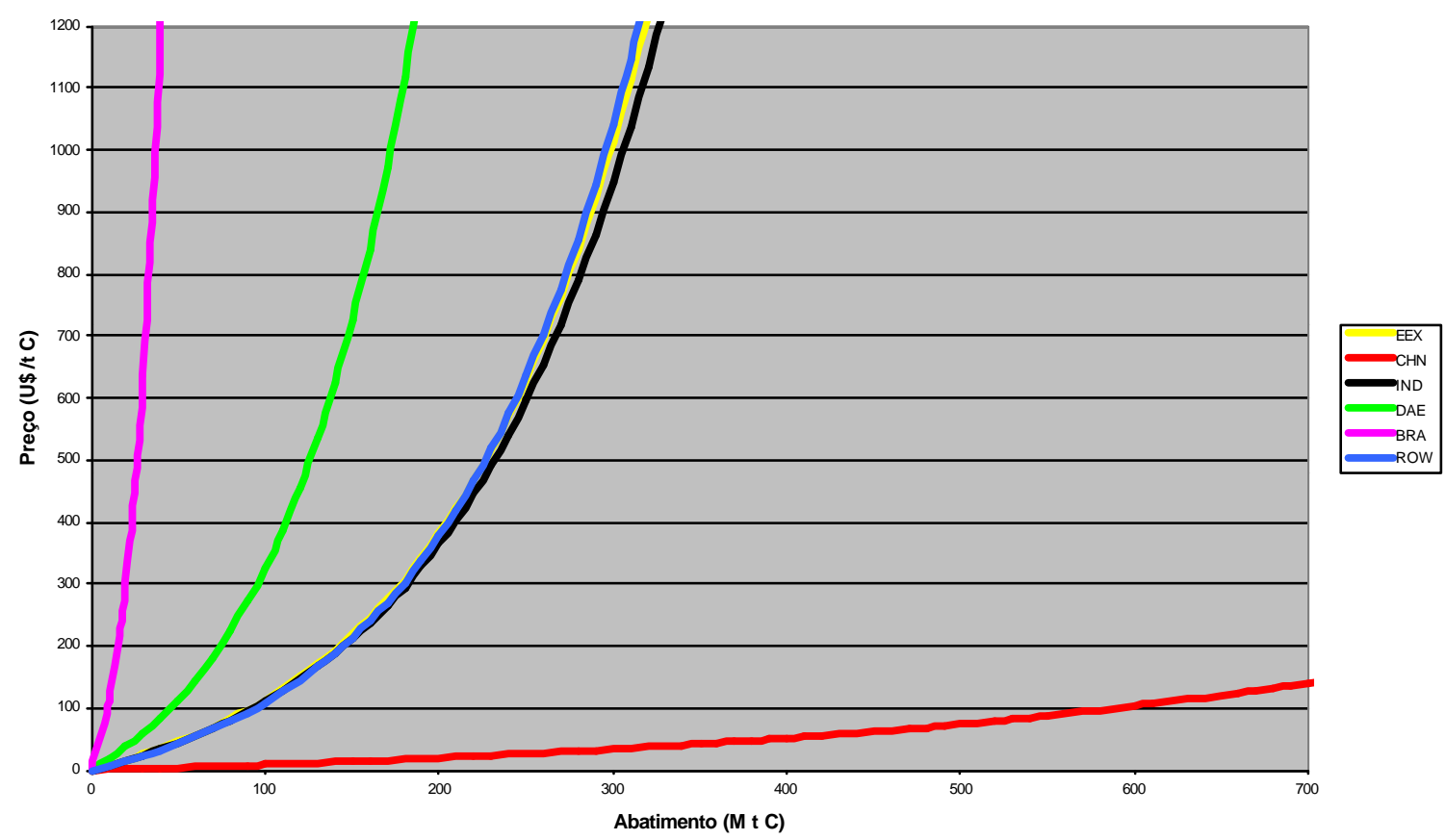

Figura 20 - MAC Cenários 4, 5 e 6 - Países não-ANEXO B.

Fonte: Grütter et al. (2002)

Legenda: EEX - Países exportadores de energia; CHN - China; IND - Índia; DAE Economias Dinâmicas Asiáticas; BRA - Brasil; ROW - resto do mundo

\section{Cenário 7 GTEM/Todos GEE:}

- As emissões de 1990 estão baseadas nos dados do GTEM

- As metas de Quioto estão baseadas nos dados do RIIA e em cálculos dos autores do Modelo CERT

- As emissões BAU e as MAC estão baseadas no Modelo GTEM

As MAC do cenário 7 podem ser vistas nas Figuras 21 e 22. Elas foram derivadas a partir do Modelo Global Trade and Environment (GTEM - Australian Bureau of Agricultural and Resource Economics, 2002), através de uma abordagem tipo "top-down". São curvas exponenciais para o abatimento de todos os GEE. 


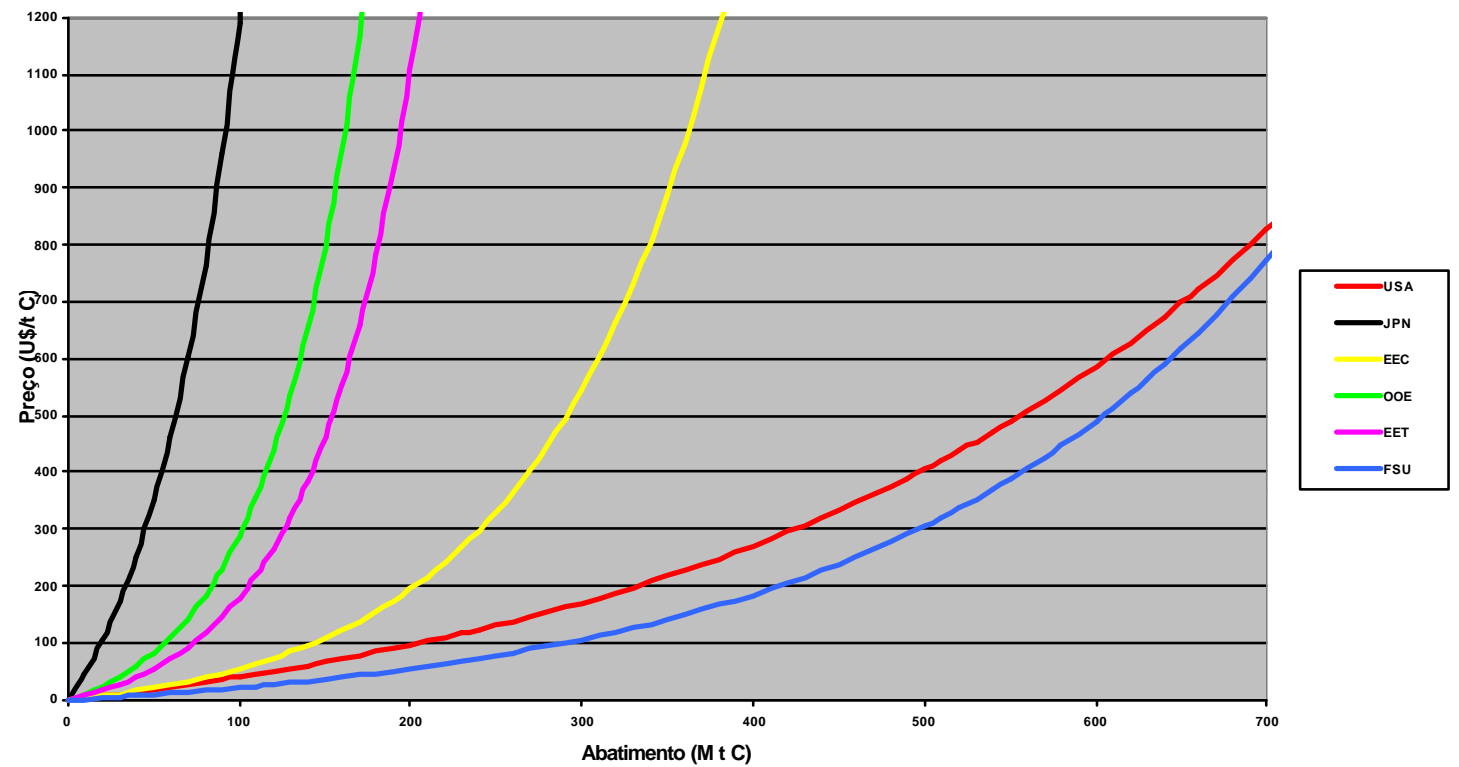

Figura 21 - MAC Cenário 7 - Países ANEXO B.

Fonte: Grütter et al. (2002)

Legenda: USA - Estados Unidos; JPN - Japão; EEC - União Européia; OOE - Outros países da OECD; EET - Economias em transição; FSU - Antiga União Soviética 


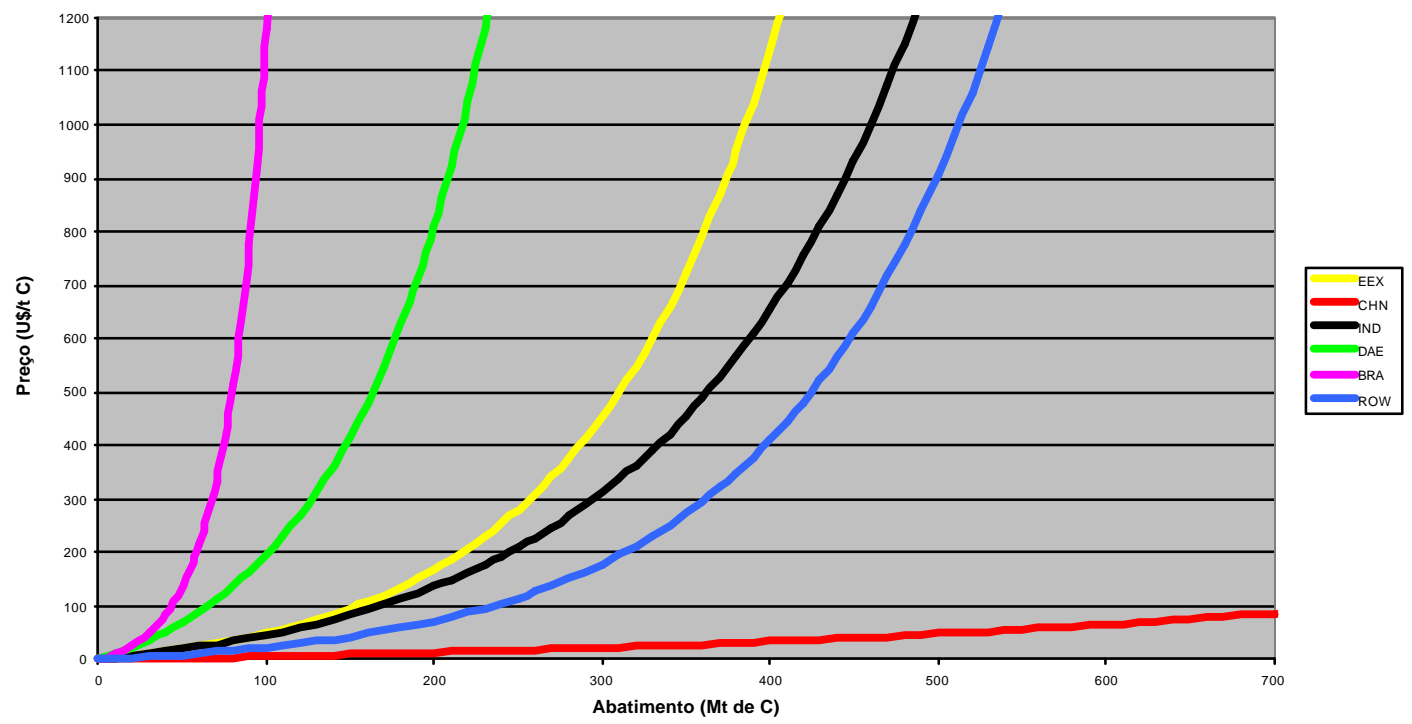

Figura 22 - MAC Cenário 7 - Países não-ANEXO B.

Fonte: Grütter et al. (2002)

Legenda: EEX - Países exportadores de energia; CHN - China; IND - Índia; DAE Economias Dinâmicas Asiáticas; BRA - Brasil; ROW - resto do mundo

Cenário 8 GTEM/Médio/Bottom-up: crescimento médio das emissões, MAC do tipo “Bottom-up", somente $\mathrm{CO}_{2}$

- As emissões de 1990 estão baseadas nos dados do RIIA

- As metas de Quioto estão baseadas nos dados do RIIA e em cálculos dos autores do Modelo CERT

- As emissões BAU foram estimadas através de dados do US DOE e cálculos dos autores do Modelo CERT

- As MAC estão baseadas no Modelo GTEM

As MAC do Cenário 8 podem ser vistas nas Figuras 23 e 24. Elas foram derivadas a partir do Modelo Global Trade and Environment (GTEM - Australian Bureau of Agricultural and Resource Economics, 2002), através de uma abordagem tipo “bottom-up". São curvas exponenciais para o abatimento apenas do $\mathrm{CO}_{2}$. 


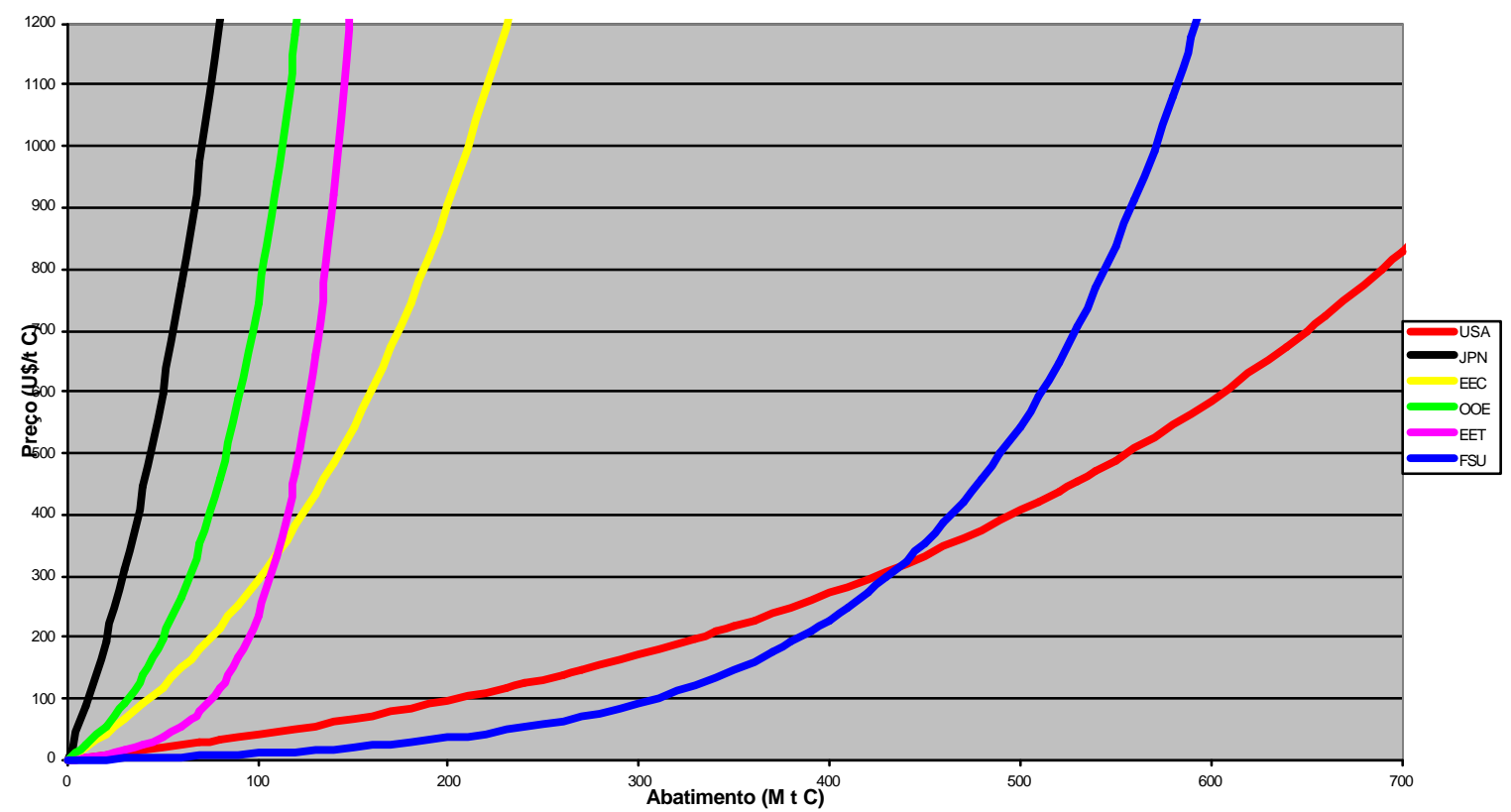

Figura 23 - MAC Cenário 8 - Países ANEXO B.

Fonte: Grütter et al. (2002)

Legenda: USA - Estados Unidos; JPN - Japão; EEC - União Européia; OOE - Outros países da OECD; EET - Economias em transição; FSU - Antiga União Soviética 


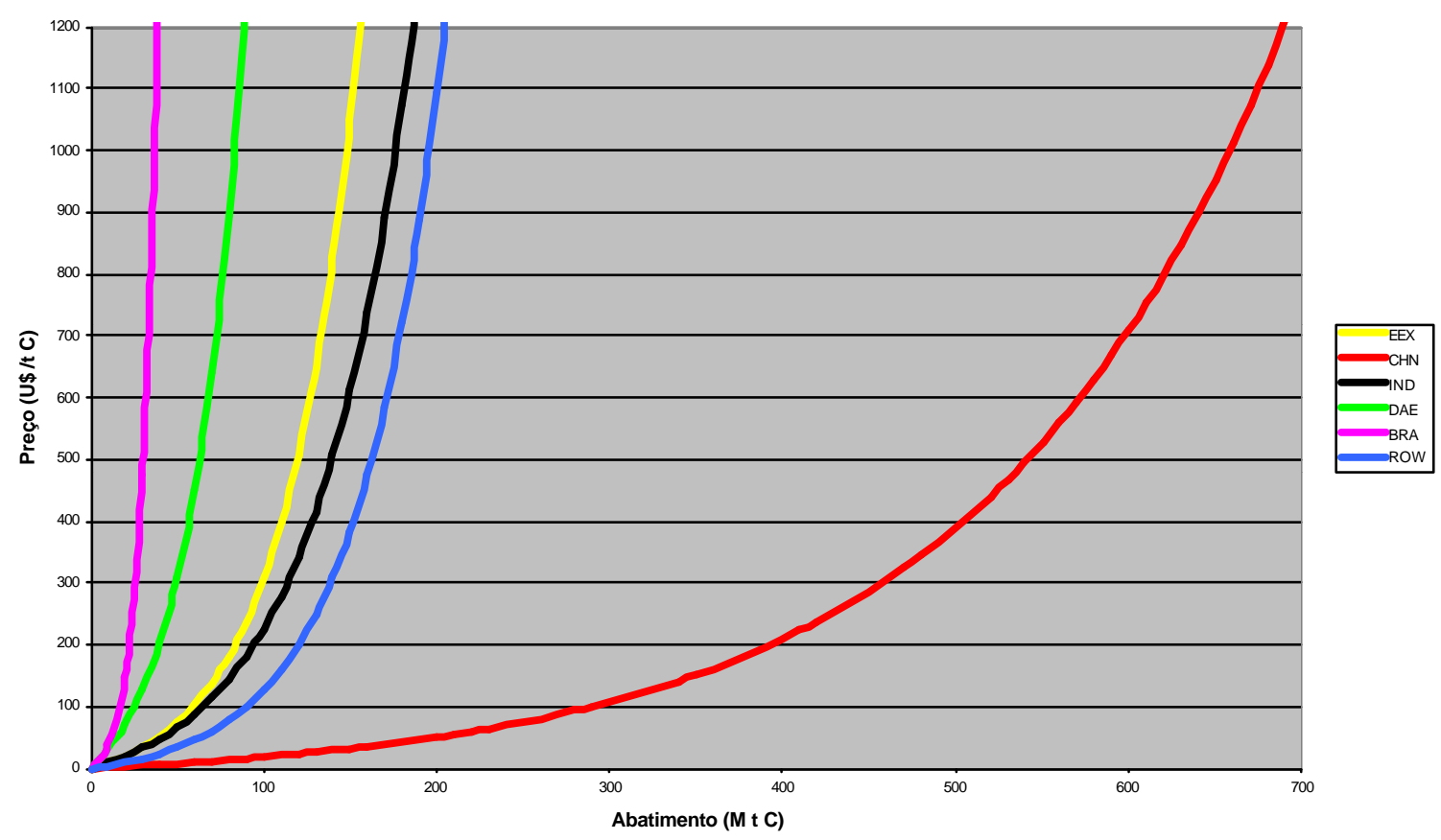

Figura 24 - MAC Cenário 8 - Países não-ANEXO B.

Fonte: Grütter et al. (2002)

Legenda: EEX - Países exportadores de energia; CHN - China; IND - Índia; DAE Economias Dinâmicas Asiáticas; BRA - Brasil; ROW - resto do mundo

Todos os cenários pressupõem: $100 \%$ de implementação dos projetos de MDL; 100\% de comercialização de "hot air" (excesso de reduções de emissões disponíveis na antiga União Soviética, devido ao colapso da economia desde 1991); custo de transação zero; uma taxa de $2 \%$ sobre os projetos de MDL para o Fundo de Adaptação; não levam em consideração os projetos de LULUCF; e assumem a participação dos EUA em $100 \%$.

Os cenários de referência do CERT baseados no Modelo EPPA utilizam a seguinte função quadrática para representar as curvas de custo marginal de abatimento para o Brasil: 


$$
C=0,5612 q^{2}+8,4974 q-\text { tipo “top-down”, Cenários } 1,2 \text { e } 3
$$

Fonte: Grütter et al. (2002)

Onde:

$C$ - o custo marginal de abatimento em $\mathrm{US} \$ / \mathrm{t}$ de $\mathrm{C}$

$q-\mathrm{o}$ abatimento em Mt de C

Os cenários de referência do CERT baseados no Modelo GTEM utilizam as seguintes funções exponenciais para representar as curvas de custo marginal de abatimento para o Brasil:

$$
\begin{aligned}
& C=136,04\left(\exp ^{0,05531723 q}-1\right)-\text { tipo “top-down”, Cenários 4, } 5 \text { e } 6 \\
& C=18,62\left(\exp ^{0,0407115 q}-1\right) \text { - tipo “top-down”, Cenário } 7 \\
& C=17,62\left(\exp ^{0,1081202 q}-1\right) \text { - tipo “bottom-up”, Cenário } 8
\end{aligned}
$$

Fonte: Grütter et al. (2002)

Onde:

$C$ - o custo marginal de abatimento em US $\$ / t$ de $C$

$q-\mathrm{o}$ abatimento em Mt de C

Os projetos de LULUCF são representados por funções exponenciais, porém como não são levados em consideração nos cenários de referência, não existem parâmetros preestabelecidos. 


\subsubsection{As opções do Modelo}

O Modelo CERT permite que o usuário modifique algumas de suas variáreis. O primeiro grupo de variáveis que podem ser modificadas refere-se aos mecanismos de flexibilização do Protocolo de Quioto, enquanto que o segundo grupo inclui variáveis e parâmetros de especial interesse para análise de sensibilidade do Modelo.

Algumas das variáveis do primeiro grupo que podem ser modificadas pelo usuário são:

- Porcentagem de "hot air" (excesso de reduções de emissões disponíveis na antiga União Soviética, devido ao colapso da economia desde 1991) comercializado: não existe nenhum limite pré-estabelecido nos Acordos de Bonn e Marrakesh. Os cenários de referência assumem que $100 \%$ do "hot air" é comercializado.

- Suplementaridade: o usuário pode estabelecer qual a porcentagem de redução de GEE que pode ser importada, ou seja, qual o limite para a utilização dos mecanismos de flexibilização. Não existe nenhum limite preestabelecido nos Acordos de Bonn e Marrakesh.

- Fundo de adaptação: o usuário pode estabelecer qual será a porcentagem sobre os investimentos em projetos de MDL que será repassada para o Fundo de Adaptação previsto no Acordo de Marrakesh. Na COP 7, foi estabelecido que no mínimo $2 \%$ das vendas de CER seriam destinadas a este fundo.

No segundo grupo de variáveis, as principais modificações que podem ser feitas são:

- Custo de transação: o usuário pode estabelecar os custos de transação (US\$ t/C) para os diferentes países e tipos de projetos (MDL, JI e Comércio de Emissão). Nos cenários de referência, o custo de transação é US\$ 0 t/C.

- Taxa de implementação dos projetos de MDL: o usuário pode determinar qual será a taxa de implementação de projetos de MDL nos países não-ANEXO B. Nos cenários de referência, a taxa de implementação de projetos é de $100 \%$.

- Introdução de MAC (exponenciais ou quadráticas): para projetos de 


\section{LULUCF}

\subsection{Os cenários alternativos}

A partir de entrevistas ${ }^{9}$ com alguns dos principais especialistas e lideranças sobre mudanças climáticas no Brasil foram, modificadas algumas variáveis do Modelo e com isto criados cenários alternativos. Nesses cenários, as seguintes variáveis do Modelo foram alteradas: taxas de implementação dos projetos de MDL para Brasil, China, Índia e resto do mundo, porcentagem de "hot air" comercializado, participação dos EUA e custos de transação dos projetos de MDL para Brasil, China, Índia e resto do mundo. Os resultados dessas entrevistas são apresentados no capítulo seguinte.

\subsubsection{MAC para o Brasil}

Além das variáveis modificadas a partir das entrevistas, nos cenários alternativos foram inseridas CMA para projetos de LULUCF no Brasil. Nos cenários alternativos assume-se que o Brasil oferece CER provenientes de projetos de LULUCF e que estes projetos possuem um custo marginal igual ao dos projetos de energia do resto do mundo. Para tal, utilizam-se as seguintes CMA presentes nos cenários de referência do CERT, como uma "proxy" para as CMA dos projetos de LULUCF:

\footnotetext{
${ }^{9}$ A lista de lideranças e especialistas consultadas encontra-se no Apêndice 6.
} 


$$
\begin{aligned}
& C=0,0021 q^{2}+0,0805 q-\text { tipo "top-down”, somente para } \mathrm{CO}_{2} \\
& C=67,17\left(\exp ^{0,00905099 q}-1\right)-\text { tipo “top-down", somente para } \mathrm{CO}_{2} \\
& C=18,24\left(\exp ^{0,007666301 q}-1\right) \text { - tipo “top-down", para todos os } \mathrm{GEE} \\
& C=17,29\left(\exp ^{0,02034329 q}-1\right)-\text { tipo "bottom-up", somente para } \mathrm{CO}_{2}
\end{aligned}
$$

Fonte: Grütter et al. (2002)

Onde:

$C$ - o custo marginal de abatimento em US\$/t de C; e

$q-\mathrm{o}$ abatimento em Mt de C.

Essas CMA originalmente são utilizadas pelo CERT para os projetos de energia do resto do mundo (ROW). Essas curvas não foram derivadas especificamente para os projetos de LULUCF no Brasil. Foram tomadas emprestadas do Modelo CERT e são específicas para projetos de energia. Como dito anteriormente, trata-se de uma "proxy" baseada na suposição de que o Brasil tem condições de oferecer CER de projetos de LULUCF ao mesmo custo que dos projetos de energia do resto do mundo. 


\section{RESULTADOS E DISCUSSÃO}

\subsection{O resultado das entrevistas}

As Figuras 25 a 28 mostram os resultados das entrevistas realizadas entre 22/10 e 20/12 de 2002 com alguns dos principais atores e especialistas em mudanças climáticas no Brasil. Observa-se uma grande variação nos valores informados pelos entrevistados, o que pode ser explicado pelo alto grau de incerteza que hoje existe sobre o tamanho e a forma do "mercado de carbono". Além disso, nem todos os entrevistados quiseram informar os valores, em especial devido ao momento de indecisão que hoje existe sobre a ratificação do Protocolo de Quioto e a participação do Brasil no mercado de carbono.

A taxa de implementação de projetos será, segundo os entrevistados, menor que $100 \%$, uma vez que existirão diversos projetos que não conseguirão cumprir todas as exigências legais do Comitê Executivo do MDL. Em outras palavras, muitos projetos não conseguirão passar por todas as etapas do Ciclo de um projeto de MDL proposto pelo Comitê Executivo (ver a Erro! A origem da referência não foi encontrada., na página Erro! Indicador não definido.). Em relação à taxa de implementação brasileira, pode-se observar dois grupos entre os entrevistados: os otimistas e pessimistas. O primeiro grupo acredita que o Brasil terá uma taxa maior que a China e a Índia, em especial devido às vantagens institucionais que o país possui, ou seja, o Brasil tem um ambiente institucional político-econômico mais favorável que a China e a Índia. Já o grupo dos pessimistas, acredita que o Brasil terá taxas de implementação menores em função dos altos custos marginais de abatimento (ver o item Curvas de custo marginal de abatimento, na página 75). 
Em relação à porcentagem de "hot air" a ser comercializada, a grande maioria dos entrevistados acredita que os países detentores desse "crédito" não terá condições de cumprir as exigências legais necessárias, o que levará a uma comercialização relativamente pequena (abaixo de 50\%). Além disso, estes países não teriam interesse de oferecer todos os "créditos" no momento em que o mercado apresenta baixos preços, preferindo aguardar por preços melhores.

Segundo os entrevistados, a participação norte-americana irá ocorrer, porém será menor que 100\%. Caso o EUA não ratifiquem o Protocolo de Quioto, somente algumas empresas irão buscar os CER. Essas empresas estariam sendo obrigadas a reduzir suas emissões por legislações estaduais (tais como o de Massachusetts), para ganhar experiência para futuros períodos de compromisso, ou para repassar os CER para suas filiais em países que ratificaram o Protocolo, entre outras razões.

Os custos de transação variam bastante entre os entrevistados (para o Brasil, essa variação vai de US\$ 0 t/C a US\$ 4,5 t/C). Essa variação é explicada pelas incertezas quanto aos mecanismos (burocracia) nacionais que irão existir para viabilizar a comercialização.

Devido ao baixo número de valores informados e ao fato de que os entrevistados possuem um alto grau de incerteza sobre os valores informados, optou-se por utilizar a média aritmética dos resultados para a construção dos cenários alternativos:

- Taxa de Implementação (\%): Brasil (38\%); China (41\%); Índia (36\%); Outros países $(36 \%)$

- Porcentagem de "hot air" a ser comercializada (\%): $41 \%$

- Custos de transação (US\$ t/C): Brasil (US\$ 1,73); China (US\$ 1,33); Índia (US\$ 1,40); Outros países (US\$ 1,75)

- Participação dos EUA (\%): $32 \%$ 


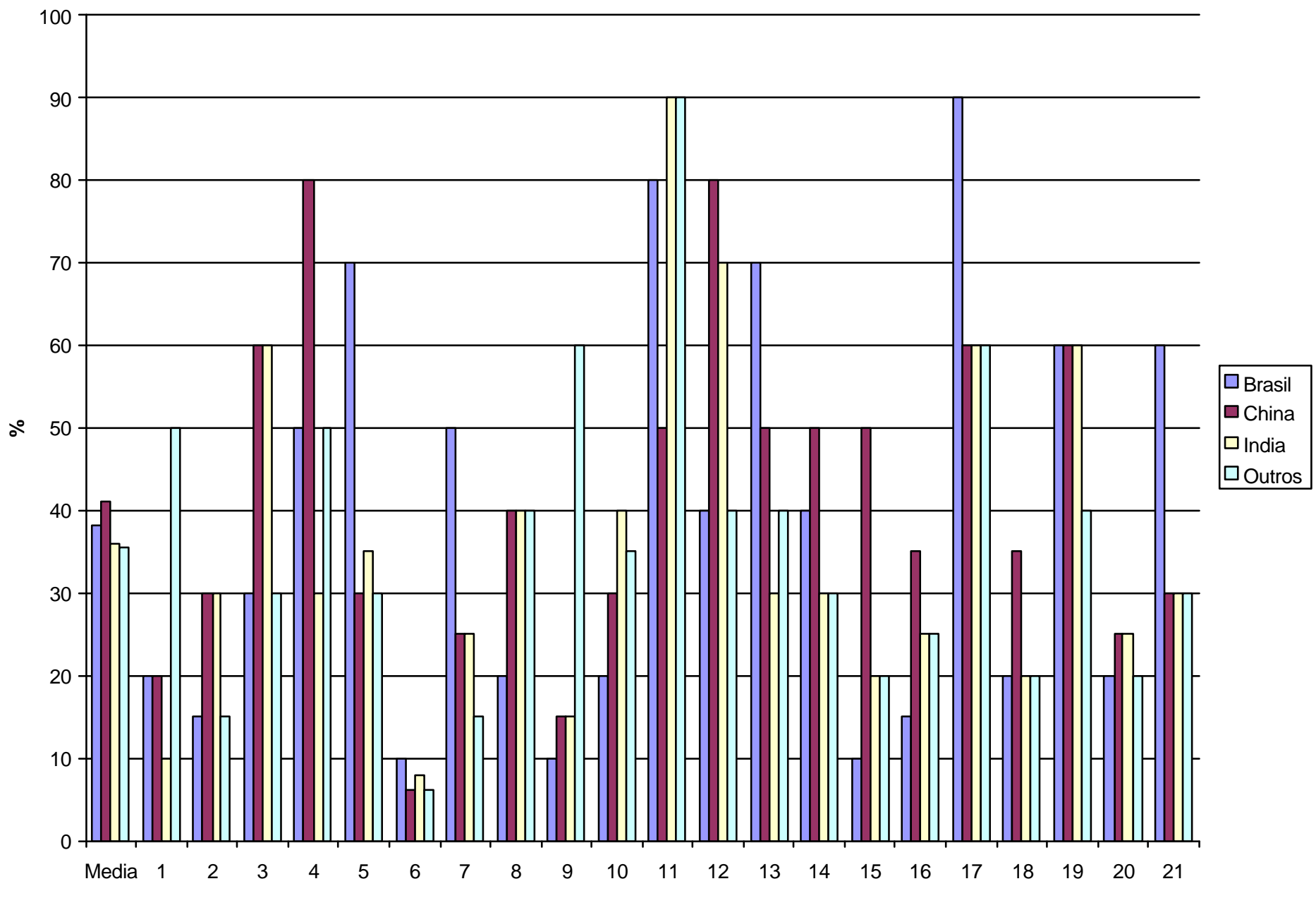

Figura 25 - Taxa de implementação dos projetos de MDL para Brasil, China, Índia e resto do mundo. Fonte: Entrevistas realizadas pelo autor. 


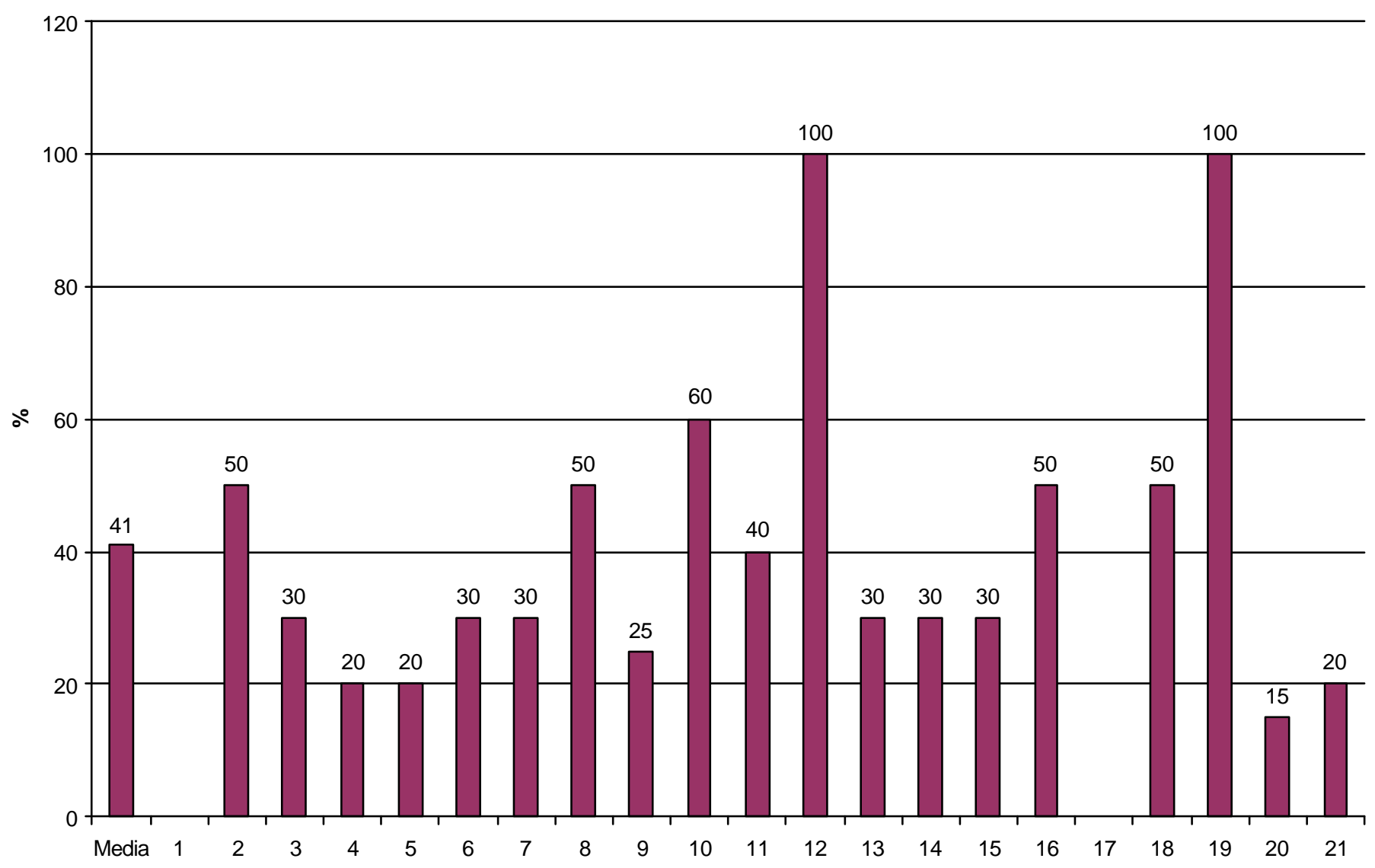

Figura 26 - Porcentagem de "hot air" a ser comercializada.

Fonte: Entrevistas realizadas pelo autor. 


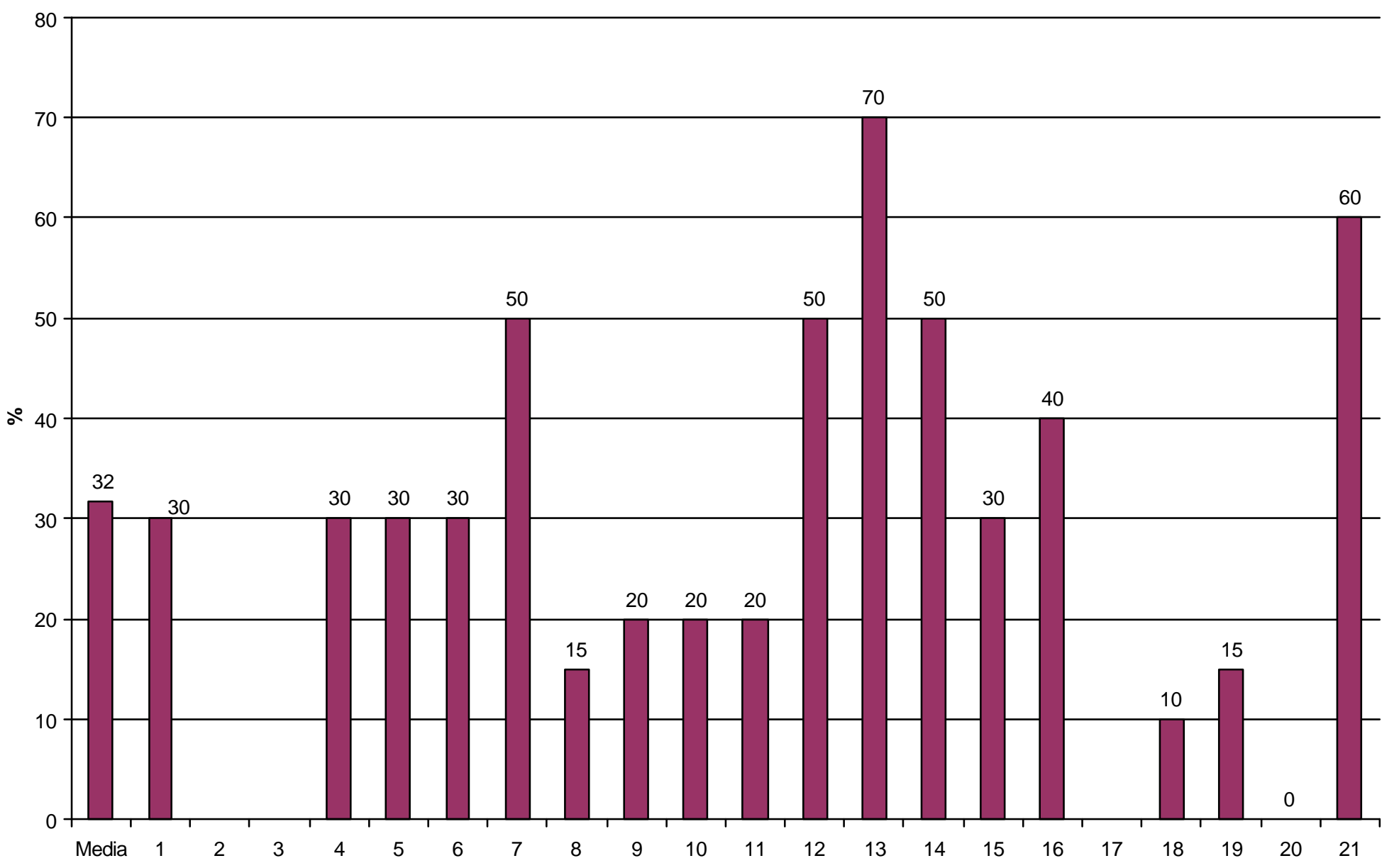

Figura 27 - Participação dos EUA.

Fonte: Entrevistas realizadas pelo autor. 


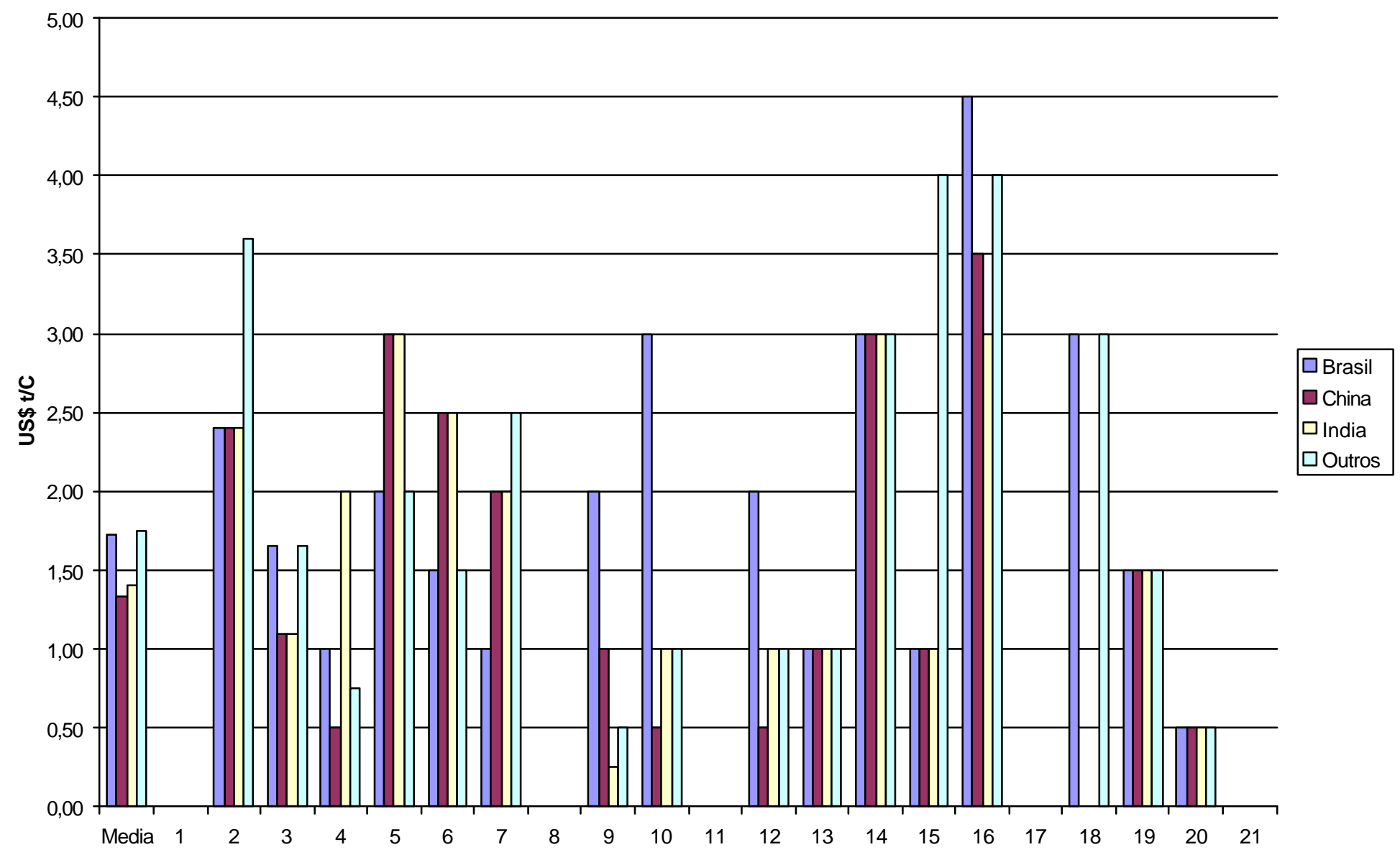

Figura 28 - Custos de transação dos projetos de MDL para Brasil, China, Índia e resto do mundo.

Fonte: Entrevistas realizadas pelo autor. 


\subsection{A participação brasileira nos cenários de referência ${ }^{10}$}

Os resultados aqui apresentados foram obtidos nos 8 cenários de referência do Modelo (veja a seção 1.1.4 Os cenários de referência do Modelo). As Figuras 29 a 32 mostram os volumes e preços de venda dos CER (créditos de projetos de MDL) na situação de equilíbrio de mercado, as vendas em termos financeiros (US\$ milhões de 2000) e em volume (M t C) para Brasil, China e Índia.

É importante lembrar que todos os cenários de referência pressupõem: 100\% de implementação dos projetos de MDL, $100 \%$ de comercialização de "hot air", custo de transação zero, uma taxa de $2 \%$ sobre os projetos de MDL para o Fundo de Adaptação, não levam em consideração os projetos de LULUCF, e assumem a participação dos EUA em $100 \%$.

O volume de venda dos CER provenientes de projetos de MDL (originados de todos os países não-ANEXO B) varia de 163 Mt C (Cenário 1) até 460,2 Mt C (Cenário 6). Já os preços por tonelada de carbono variam de US\$ 4,6 (Cenário 1) até US\$ 36,1, a valores de 2000 (Cenário 6). Esta diferença é explicada por variações nas emissões em 2010 ("business as usual" - BAU) e pelas curvas de custo marginal de abatimento (MAC).

No Cenário 1 (baixo crescimento das emissões), as emissões dos países do ANEXO B em 2010 totalizam 4.078 Mt de C, enquanto que no Cenário 6 (alto crescimento das emissões) totalizam 4.549 Mt de C. Isso significa que as reduções necessárias (BAU menos os "assigned amount"1 ${ }^{11}$ ) variam respectivamente de 698 a 1.009 Mt de C.

\footnotetext{
${ }^{10}$ As tabelas com os resultados encontram-se no Apêndice 7.

${ }^{11}$ Emissões de 1990 multiplicadas pelas metas do Protocolo de Quioto
} 


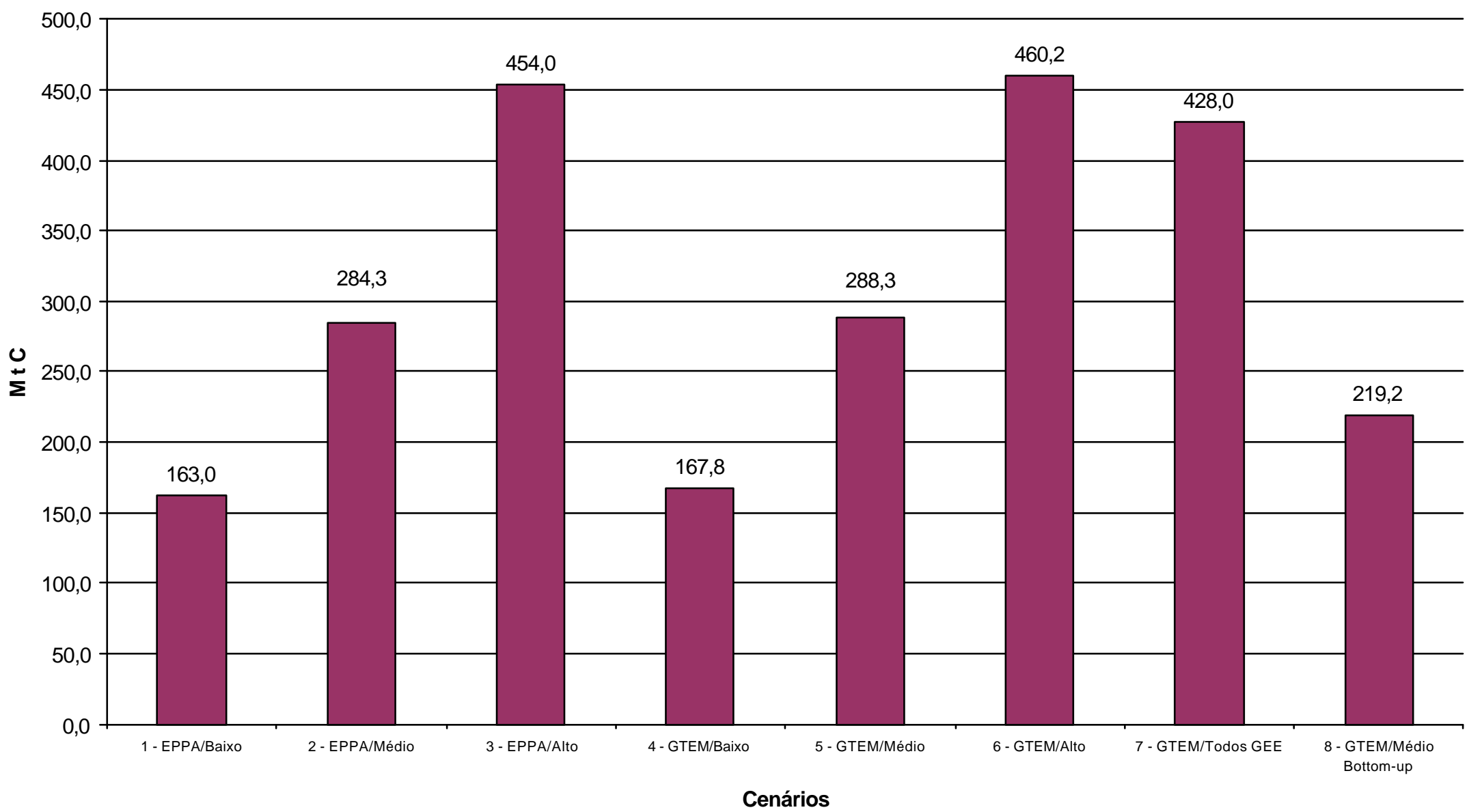

Figura 29 - Volume de vendas dos CER de MDL nos cenários de referência - 2010.

Fonte: Cálculos do autor. 


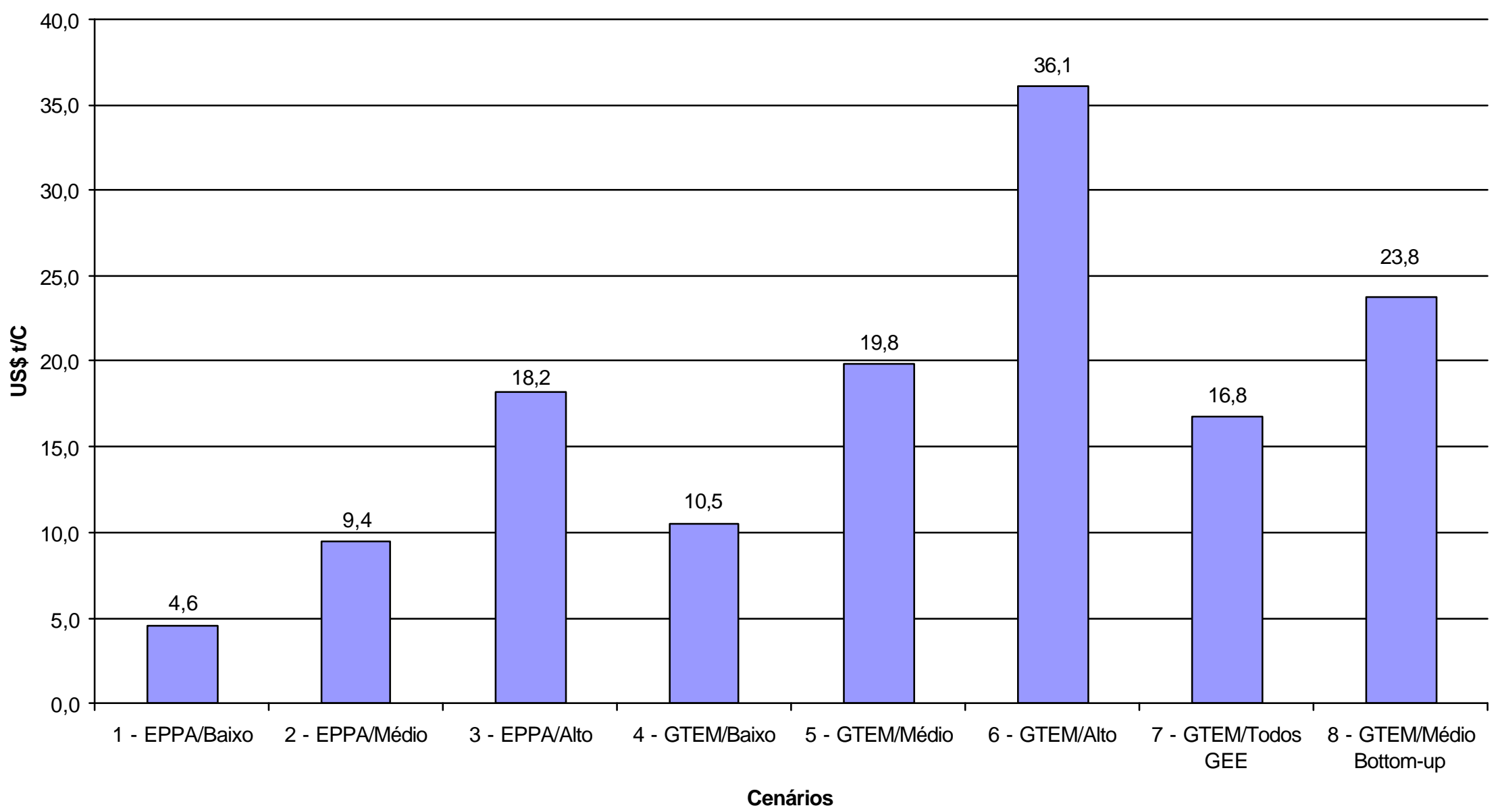

Figura 30 - Preço de venda dos CER de MDL nos cenários de referência - 2010.

Fonte: Cálculos do autor. 


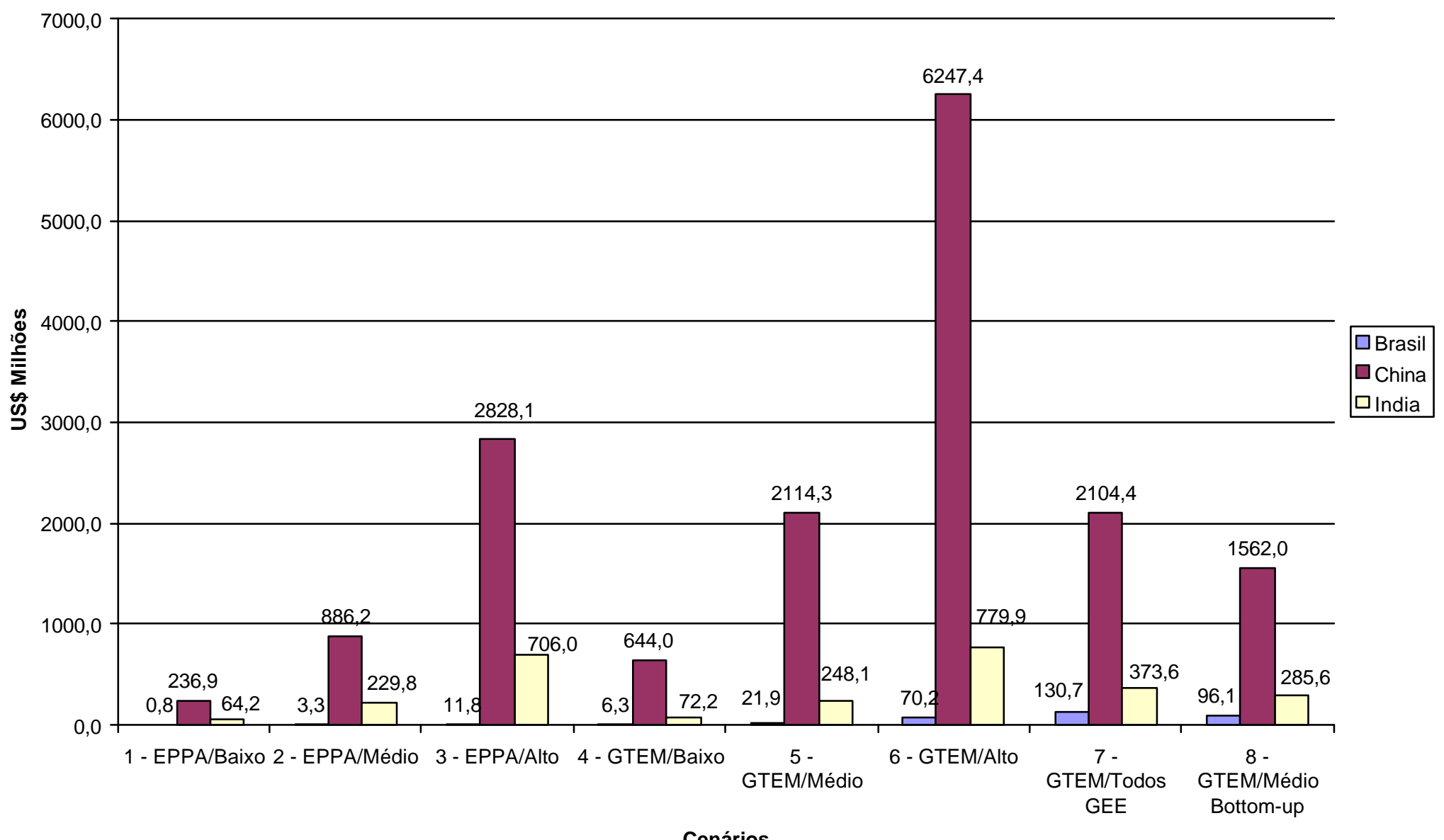

Figura 31 - Receita líquida das vendas de CER (US\$) nos cenários de referência - 2010.

Fonte: Cálculos do autor. 


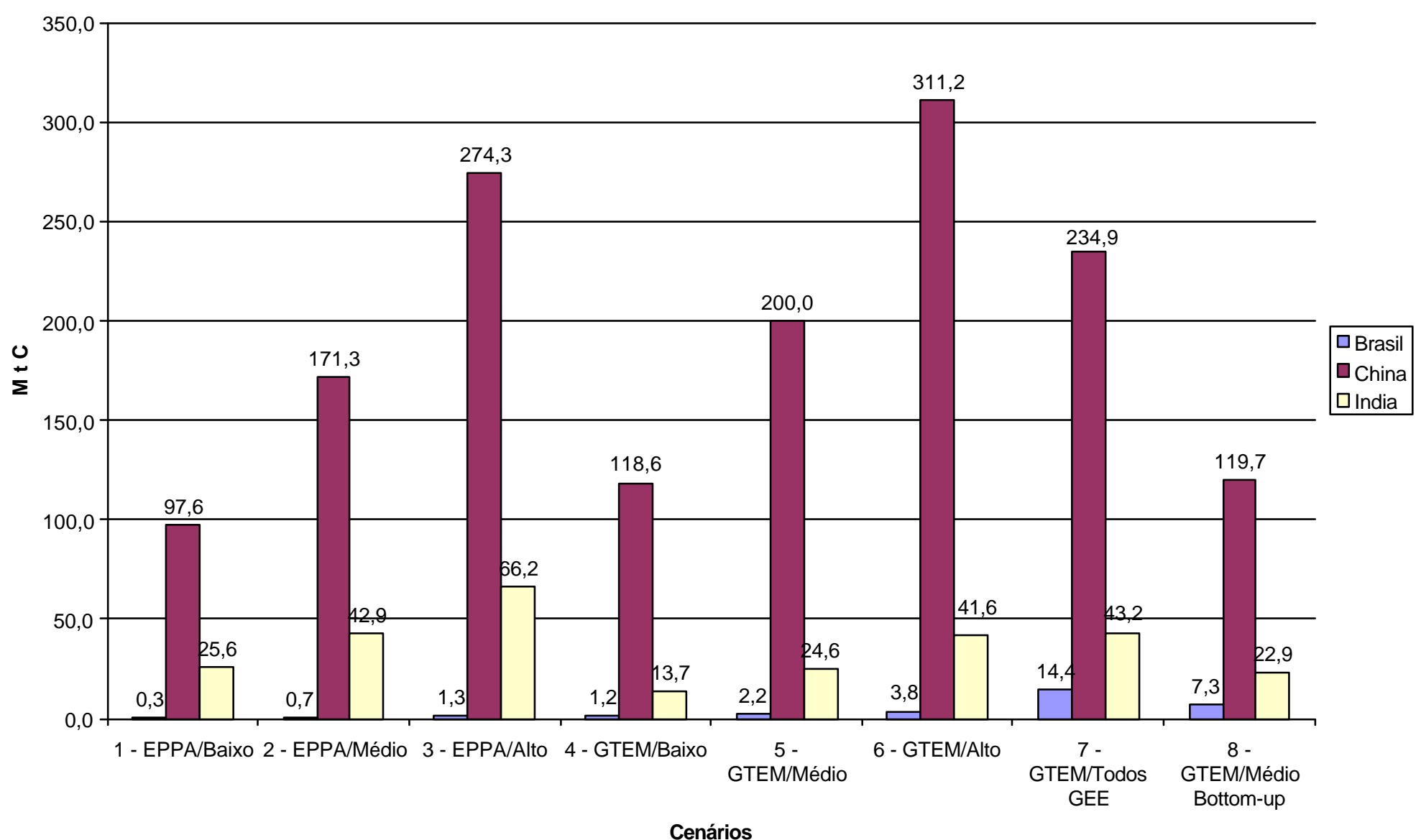

Figura 32 - Volume de vendas de CER (M t C) nos cenários de referência - 2010.

Fonte: Cálculos do autor. 
Quanto às MAC, o Cenário 1 (baseado no Modelo EPPA) utiliza funções do tipo quadrática, enquanto que o Cenário 6 (baseado no Modelo GTEM) utiliza funções do tipo exponencial. O Quadro 3 mostra os parâmetros utilizados nas diferente curvas e cenários. As curvas do tipo quadráticas apresentam custos inferiores aos custos do tipo exponencial de até 50,4\% (US\$ 36,1 do Cenário 6 comparados com US\$ 18,2 do Cenário 3).

\begin{tabular}{|l|r|r|r|r|r|r|r|}
\hline & \multicolumn{2}{|c|}{ USA } & \multicolumn{2}{c|}{ JPN } & \multicolumn{2}{c|}{ EEC } \\
\hline & Cenário 1 & Cenário 6 & Cenário 1 & Cenário 6 & Cenário 1 & Cenário 6 \\
\hline MAC Parâmetro: a & 0,0005 & 109,98 & 0,0155 & 564,58 & 0,0024 & 242,57 \\
\hline MAC Parâmetro: b & 0,0398 & 0,0029432 & 1,816 & 0,0134852 & 0,1503 & 0,0074003 \\
\hline & \multicolumn{2}{|c|}{ OOE } & \multicolumn{2}{|c|}{ EET } & \multicolumn{2}{c|}{ FSU } \\
\hline & Cenário 1 & Cenário 6 & Cenário 1 & Cenário 6 & Cenário 1 & Cenário 6 \\
\hline MAC Parâmetro: a & 0,0085 & 99,11 & 0,0079 & 6,57 & 0,0023 & 5,32 \\
\hline MAC Parâmetro: b & $-0,0986$ & 0,0205979 & 0,0486 & 0,0462774 & 0,0042 & 0,012496 \\
\hline & \multicolumn{2}{|r|}{ EEX } & \multicolumn{2}{|c|}{ CHN } & \multicolumn{2}{|c|}{ IND } \\
\hline & Cenário 1 & Cenário 6 & Cenário 1 & Cenário 6 & Cenário 1 & Cenário 6 \\
\hline MAC Parâmetro: a & 0,0032 & 75,13 & 0,00007 & 27,25 & 0,0015 & 77,59 \\
\hline MAC Parâmetro: b & 0,3029 & 0,0086214 & 0,0239 & 0,0024889 & 0,0787 & 0,0083134 \\
\hline & \multicolumn{2}{|r|}{ DAE } & \multicolumn{2}{|c|}{ BRA } & & & ROW \\
\hline & Cenário 1 & Cenário 6 & Cenário 1 & Cenário 6 & Cenário 1 & Cenário 6 \\
\hline MAC Parâmetro: a & 0,0047 & 116,31 & 0,5612 & 136,04 & 0,0021 & 67,17 \\
\hline MAC Parâmetro: b & 0,3774 & 0,0126542 & 8,4974 & 0,0553172 & 0,0805 & 0,009051 \\
\hline
\end{tabular}

Quadro 8 - Parâmetros utilizados nas MAC dos Cenários de referência 1 (Modelo EPPA - função tipo quadrática) e 6 (Modelo GTEM - função tipo exponencial).

Fonte: Grütter et al. (2002)

Legenda: USA: Estados Unidos; JPN: Japão; EEC: União Européia; OOE: Outros países da OECD; EET: Economias em transição; FSU: Antiga União Soviética; EEX: Países exportadores de energia; CHN: China; IND: Índia; DAE: Economias Dinâmicas Asiáticas; BRA: Brasil; ROW: resto do mundo 
É importante ressaltar que os valores acima mencionados referem-se ao custo de abatimento apenas do $\mathrm{CO}_{2}$ e foram estimados a partir de MAC tipo "top-down".

Ao levar em consideração o abatimento de todos os GEE, o custo cai de US\$ 19,8 t/C (Cenário 5 - abatimento de 842 Mt de C) para US\$ 16,8 t/C (Cenário 7 abatimento de $964 \mathrm{Mt}$ de C). Isso significa que as MAC para abatimento dos outros GEE são menores que as MAC para abatimento de $\mathrm{CO}_{2}$. Isso pode ser comprovados nos estudos de Australian Bureau of Agricultural and Resource Economics, 2002 (Quadro 4).

\begin{tabular}{|c|c|c|c|c|}
\hline & \multicolumn{2}{|r|}{$\mathrm{CO}_{2}$} & \multicolumn{2}{|c|}{ Todos GEE } \\
\hline & $\mathrm{a}$ & $\mathrm{b}$ & $\mathrm{a}$ & $\mathrm{b}$ \\
\hline \multicolumn{5}{|l|}{ ANEXO B } \\
\hline Austrália & 115.1 & 0.01482 & 60.2 & 0.01298 \\
\hline Estados Unidos & 115.0 & 0.00079 & 65.3 & 0.00083 \\
\hline Canadá & 95.4 & 0.01014 & 44.5 & 0.01009 \\
\hline Japão & 577.7 & 0.00364 & 215.5 & 0.00487 \\
\hline União européia & 242.0 & 0.00202 & 28.5 & 0.00261 \\
\hline Antiga União Soviética & 7.9 & 0.00316 & 41.5 & 0.00109 \\
\hline Leste europeu & 12.9 & 0.01078 & 37.9 & 0.00456 \\
\hline Outros & 149.8 & 0.05606 & 40.3 & 0.04086 \\
\hline \multicolumn{5}{|l|}{ Não-ANEXO B } \\
\hline & & & & \\
\hline Oriente médio & 120.4 & 0.00440 & 89.3 & 0.00398 \\
\hline Norte da África & 67.9 & 0.01907 & 31.3 & 0.01624 \\
\hline Sul da África & 98.2 & 0.01368 & 18.0 & 0.01670 \\
\hline China & 26.8 & 0.00069 & 22.1 & 0.00060 \\
\hline Taipei & 126.0 & 0.01852 & 124.8 & 0.01540 \\
\hline Coréia do Sul & 110.5 & 0.00790 & 117.1 & 0.00645 \\
\hline İndia & 77.6 & 0.00227 & 44.7 & 0.00181 \\
\hline Indonésia & 68.5 & 0.01036 & 26.4 & 0.01030 \\
\hline resto da Asia & 121.5 & 0.00611 & 69.8 & 0.00566 \\
\hline México & 58.7 & 0.00918 & 39.3 & 0.00851 \\
\hline Argentina & 73.7 & 0.03616 & 14.7 & 0.02988 \\
\hline Brasil & 136.0 & 0.01509 & 18.6 & 0.01110 \\
\hline Venezuela & 23.6 & 0.04391 & 12.5 & 0.04269 \\
\hline Colômbia & 45.9 & 0.04706 & 18.1 & 0.03420 \\
\hline resto do mundo & 75.2 & 0.00398 & 15.7 & 0.00320 \\
\hline
\end{tabular}

Quadro 9 - MAC para $\mathrm{CO}_{2}$ e todos os GEE.

Fonte: Australian Bureau of Agricultural and Resource Economics (2002) 
Ao se utilizar MAC do tipo "bottom-up" para projetos de MDL/JI, o custo aumenta de US\$ 19,8 (Cenário 5 - abatimento de 288,3 Mt de C) para US\$23,8 (Cenário 8 - abatimento de 219,2 Mt de C) para o abatimento de 842 Mt de C. O Quadro 5 mostra os parâmetros utilizados nas diferente curvas e cenários.

\begin{tabular}{|l|r|r|r|r|r|r|r|r|}
\hline & \multicolumn{2}{|c|}{ EET } & \multicolumn{2}{c|}{ FSU } & \multicolumn{2}{c|}{ EEX } & \multicolumn{2}{c|}{ CHN } \\
\hline & Cenário 5 & Cenário 8 & Cenário 5 & Cenário 8 & Cenário 5 & Cenário 8 & Cenário 5 & Cenário 8 \\
\hline MAC Parâmetro: a & 6,57 & 7,782579 & 5,32 & 7,210723 & 75,13 & 30,88 & 27,25 & 21,28 \\
\hline MAC Parâmetro: b & 0,046277 & 0,033503 & 0,012496 & 0,008488 & 0,008621 & 0,023093 & 0,002489 & 0,005742 \\
\hline & \multicolumn{2}{|c|}{ IND } & \multicolumn{2}{|c|}{ DAE } & \multicolumn{2}{|c|}{ BRA } & \multicolumn{3}{c|}{ ROW } \\
\hline & Cenário 5 & Cenário 8 & Cenário 5 & Cenário 8 & Cenário 5 & Cenário 8 & Cenário 5 & Cenário 8 \\
\hline MAC Parâmetro: a & 77,59 & 42,33 & 116,31 & 78,96 & 136,04 & 17,62 & 67,17 & 17,29 \\
\hline MAC Parâmetro: b & 0,008313 & 0,017671 & 0,012654 & 0,030356 & 0,055317 & 0,10812 & 0,009051 & 0,020343 \\
\hline
\end{tabular}

Quadro 10 - Parâmetros utilizados nas MAC dos Cenários de referência 5 (curvas tipo “top-down”) e 8 (curvas tipo “bottom-up”) para projetos de MDL/JI.

Fonte: Grütter et al. (2002)

Legenda: USA: Estados Unidos; JPN: Japão; EEC: União Européia; OOE: Outros países da OECD; EET: Economias em transição; FSU: Antiga União Soviética; EEX: Países exportadores de energia; CHN: China; IND: Índia; DAE: Economias Dinâmicas Asiáticas; BRA: Brasil; ROW: resto do mundo

A participação dos países através do MDL varia, como pode ser visto nas Figuras 31 e 32. A participação chinesa vai de 54,6\% (Cenário 8) até 70,7\% (Cenário 4), a participação indiana vai de 8,2\% (Cenário 4) até 15,7\% (Cenário 1), e a participação brasileira vai de 0,2\% (Cenário 1) até 3,4\% (Cenário 7). No Cenário 7 (melhor caso para o Brasil), a participação da China e Índia são respectivamente 54,9\% e 10,1\% (Figura 33). O resto do mundo tem uma participação que varia de 20,4\% (Cenário 4) até 31,7\% (Cenário 8). 


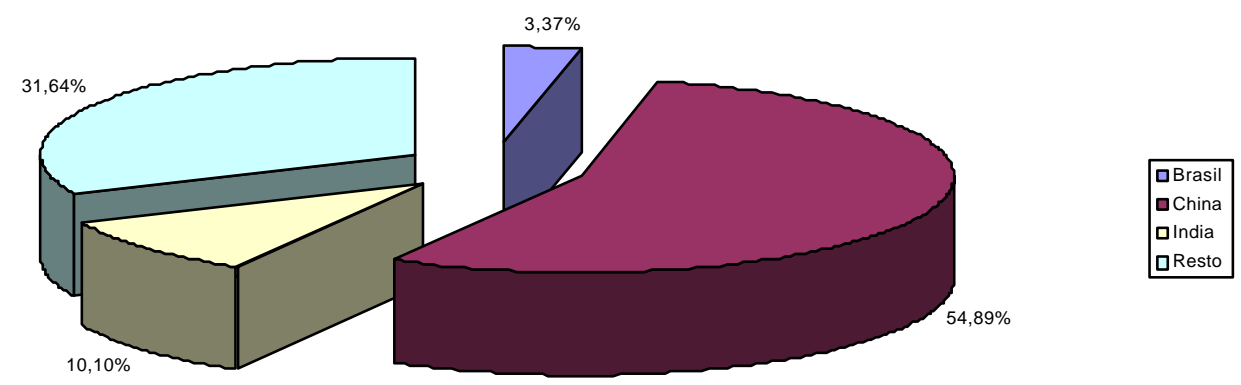

Figura 33 - Participação dos países no mercado de carbono via MDL (cenário de referência - melhor caso para o Brasil), 2010.

Fonte: Cálculos do autor.

No cenário de referência em que a participação brasileira é mais elevada (Cenário 7 - baseado no Modelo GTEM, com todos os gases de efeito estufa e curvas de custo marginal tipo "top-down"/exponencial), o equilíbrio de mercado ocorre com a comercialização de 860 Mt de C ao preço de US\$ 16,8 (Figura 22). Essa comercialização não é apenas de CER, mas também de ERU ${ }^{12}$.

O Quadro 11 compara o Cenário de referência 7, onde ocorre a maior participação brasileira $(3,4 \%)$ no mercado de carbono, com o Cenário 1 , onde ocorre a menor participação $(0,2 \%)$.

\footnotetext{
${ }^{12}$ ERU - Emissions Reduction Units (créditos gerados por projetos de JI).
} 


\begin{tabular}{|c|c|c|c|c|c|c|c|c|c|c|c|c|c|c|c|}
\hline ANEXO B & & USA & USA & JPN & JPN & $\mathrm{EEC}$ & EEC & $\mathrm{OOE}$ & $\mathrm{OOE}$ & EET & EET & FSU & FSU & Total & Total \\
\hline Cenários & & 1 & 7 & 1 & 7 & 1 & 7 & 1 & 7 & 1 & 7 & 1 & 7 & 1 & 7 \\
\hline Emissões em 2010 & (Milhões t C) & 1750 & 2088 & 309 & 367 & 964 & 1151 & 307 & 403 & 206 & 283 & 542 & 757 & 4078 & $\overline{504 c}$ \\
\hline Assigned Amount & (Milhões t C) & 1259 & 1409 & 274 & 289 & 822 & 1002 & 218 & 287 & 282 & 301 & 816 & 1032 & 3671 & 4319 \\
\hline Reduções & (Milhões t C) & 463 & 651 & 22 & 65 & 137 & 144 & 76 & 103 & -80 & -21 & \begin{tabular}{|c|c|}
-309 \\
\end{tabular} & -310 & 698 & 96 \\
\hline \multicolumn{16}{|l|}{ Solução autárquica } \\
\hline Preço marginal autárquico & $(\mathrm{U} \$ / \mathrm{t} C)$ & 188 & 701 & 73 & 536 & 98 & 101 & 62 & 307 & 0 & d & 0 & 0 & & \\
\hline Custos a utárquicos & (US\$ Milhões) & 31067 & 159535 & 772 & 14248 & 5210 & 5707 & 1433 & 11165 & 4 & & & 4 & 38482 & 19065 \\
\hline & & & & & & & & & & & & & & & \\
\hline \multicolumn{16}{|l|}{ Solução com comércio } \\
\hline Preço & $(\mathrm{U} \$ / \mathrm{t} C)$ & 4,6 & 16,8 & & & & & & & & & & & & \\
\hline Redução doméstica & (Milhões t C) & 48 & 44 & 2 & 4 & 16 & 41 & 26 & 14 & 17 & 20 & 36 & 80 & 144 & 204 \\
\hline \begin{tabular}{|l} 
Custos marginais domésticos \\
\end{tabular} & $\overline{(\mathrm{US} / \mathrm{tC})}$ & & 17 & 5 & 17 & & 17 & & 17 & 3 & 17 & 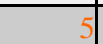 & 17 & & \\
\hline Importação & (Milhões t C) & 415 & 607 & 21 & 62 & 121 & 103 & 50 & 89 & 0 & 0 & 0 & 0 & 607 & 860 \\
\hline Exportação & (Milhões t C) & d & 0 & 0 & 0 & 0 & 0 & 0 & 0 & 97 & 42 & 345 & 390 & 442 & 432 \\
\hline Custos domésticos & (US\$ Milhões) & 97 & 362 & 4 & 31 & 35 & 323 & 23 & 116 & 29 & 159 & 56 & 635 & 244 & 1626 \\
\hline $\begin{array}{l}\text { Custos de importação } \\
\end{array}$ & (US\$ Milhões) & 1905 & 10189 & 96 & 1035 & 556 & 1726 & 231 & 1486 & 0 & & ( & & 2788 & 14436 \\
\hline Receitas de exportação & (US\$ Milhões) & d & 0 & 0 & 0 & 0 & 0 & 0 & 0 & 444 & 696 & 1584 & 6546 & 2029 & 7242 \\
\hline Custo total (- = Lucro) & (US\$ Milhões) & 2002 & 10551 & 99 & 1066 & 591 & 2049 & 254 & 1602 & -415 & -538 & -1529 & -5910 & 1003 & 8820 \\
\hline Economia (\% da solução autárquica & $(\%)$ & 94 & 93 & 87 & 93 & 89 & 64 & 82 & 86 & 0 & 0 & 0 & 0 & 97 & 95 \\
\hline & & & & & & & & & & & & & & & \\
\hline Não-ANEXO B & & EEX & EEX & $\mathrm{CHN}$ & CHN & IND & IND & DAE & DAE & BRA & BRA & ROW & ROW & Total & Total \\
\hline Cenários & & 1 & 7 & 1 & 7 & 1 & 7 & 1 & 7 & 1 & 7 & 1 & 7 & 1 & 7 \\
\hline Exportação & (Milhões t C) & 9,1 & 43,3 & 97,6 & 234,9 & 25,6 & 43,2 & 7,3 & 14,4 & 0,3 & 14,4 & 23,1 & 77,7 & \begin{tabular}{|c|}
163,0 \\
\end{tabular} & 428,0 \\
\hline Custos & (US\$ Milhões) & 19,4 & 332 & 202,5 & 1758,8 & 50,9 & 337,5 & 16,0 & 115,0 & 0,8 & 106, & 45,2 & 572,2 & 335, & 3222, \\
\hline Receitas & (US\$ Milhões) & 40,8 & 712,1 & 439,3 & 3863,2 & 115,1 & 711,1 & 32,9 & 236,9 & 1,6 & 237,0 & 104,2 & 1278,3 & 733,9 & 7038,6 \\
\hline Lucro & (US\$ Milhões) & 21,0 & 379,8 & 236,9 & 2104,4 & 64,2 & 373,6 & 16,9 & 121,9 & 0,8 & 130,7 & 59,0 & 706,1 & 398,8 & 3816,5 \\
\hline
\end{tabular}

Quadro 11 - Comparação entre os Cenários de Referência 1 (menor participação brasileira) e 7 (maior participação brasileira).

Fonte: Cálculos do autor. 


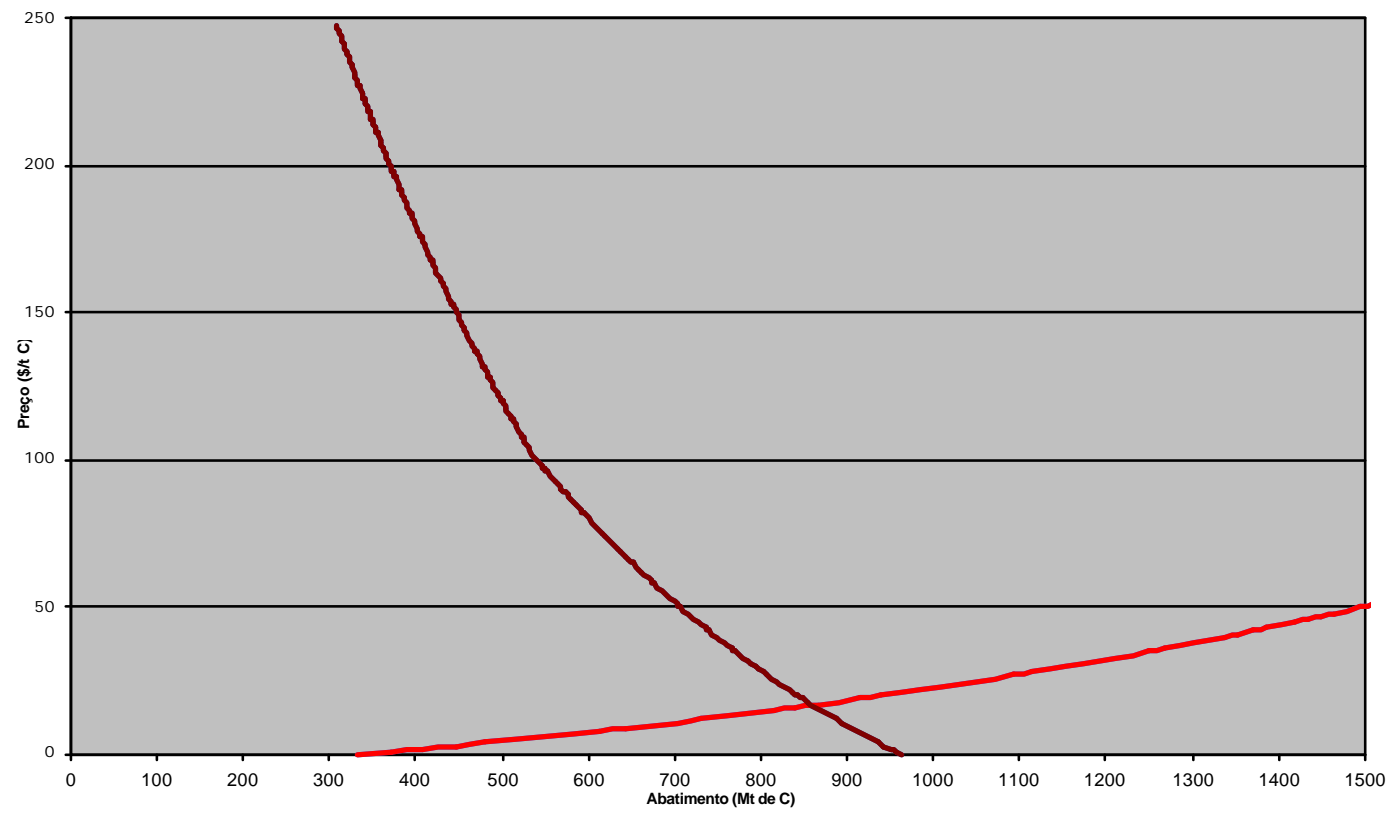

Figura 34 - Equilíbrio de mercado para o cenário de referência onde a participação brasileira é maior (Cenário 7).

Fonte: Cálculos do autor.

No Cenário 7, o Brasil exporta 14,4 milhões de toneladas de carbono, gerando uma receita de US\$ 237 milhões ao custo de US\$ 106,3 milhões. Além do custo, os projetos gerados no Brasil pagam ao Fundo de Adaptação US\$ 4,8 milhões. O lucro de todos os projetos de MDL no Brasil é de US\$130,7 milhões. 


\subsection{A participação brasileira nos cenários alternativos ${ }^{1}$}

Os resultados aqui apresentados foram obtidos nos cenários alternativos (veja a seção Erro! A origem da referência não foi encontrada. Erro! A origem da referência não foi encontrada.). As Figuras 36 a 39 mostram, respectivamente, os volumes e preços de venda dos CER de MDL na situação de equilíbrio de mercado, as vendas em termos financeiros (US\$ milhões de 2000) e em volume (M t C) para Brasil, China e Índia.

Nos cenários alternativos, os volumes de vendas dos CER provenientes de projetos de MDL variam de 63,8 Mt C (Cenário Alternativo 1) até 190,7 Mt C (Cenário Alternativo 6). Já os preços por tonelada de carbono variam de US\$ 5,4 (Cenário Alternativo 1) até US\$ 35,8, a valores de 2000 (Cenário Alternativo 6).

A grande diferença entre os volumes comercializados nos cenários de referência e nos alternativos deve-se principalmente à menor participação dos EUA nos últimos. A menor participação norte-americana foi inserida nos cenários alternativos diminuindo-se as emissões deste país em 2010. No Cenário alternativo 1 (baixo crescimento das emissões), as novas emissões dos países do ANEXO B totalizaram 3.763 Mt de C, enquanto que no Cenário alternativo 6 (alto crescimento das emissões) totalizaram 4.143 Mt de C. Isso significa que as reduções necessárias (BAU menos os "assigned amount") variaram respectivamente de 383 a 604 Mt de C.

Os preços tiveram pouca variação entre os cenários de referência e os cenários alternativos, como pode ser visto na Figura 2. Essa pequena diferença é explicada pelo fato de que as MAC continuaram sendo as mesmas em todos os casos, com exceção do Brasil que, nos cenários alternativos incorporou MAC para os projetos de LULUCF (ver item MAC para o Brasil).

\footnotetext{
${ }^{1}$ As tabelas com os resultados encontram-se no Apêndice 7.
} 


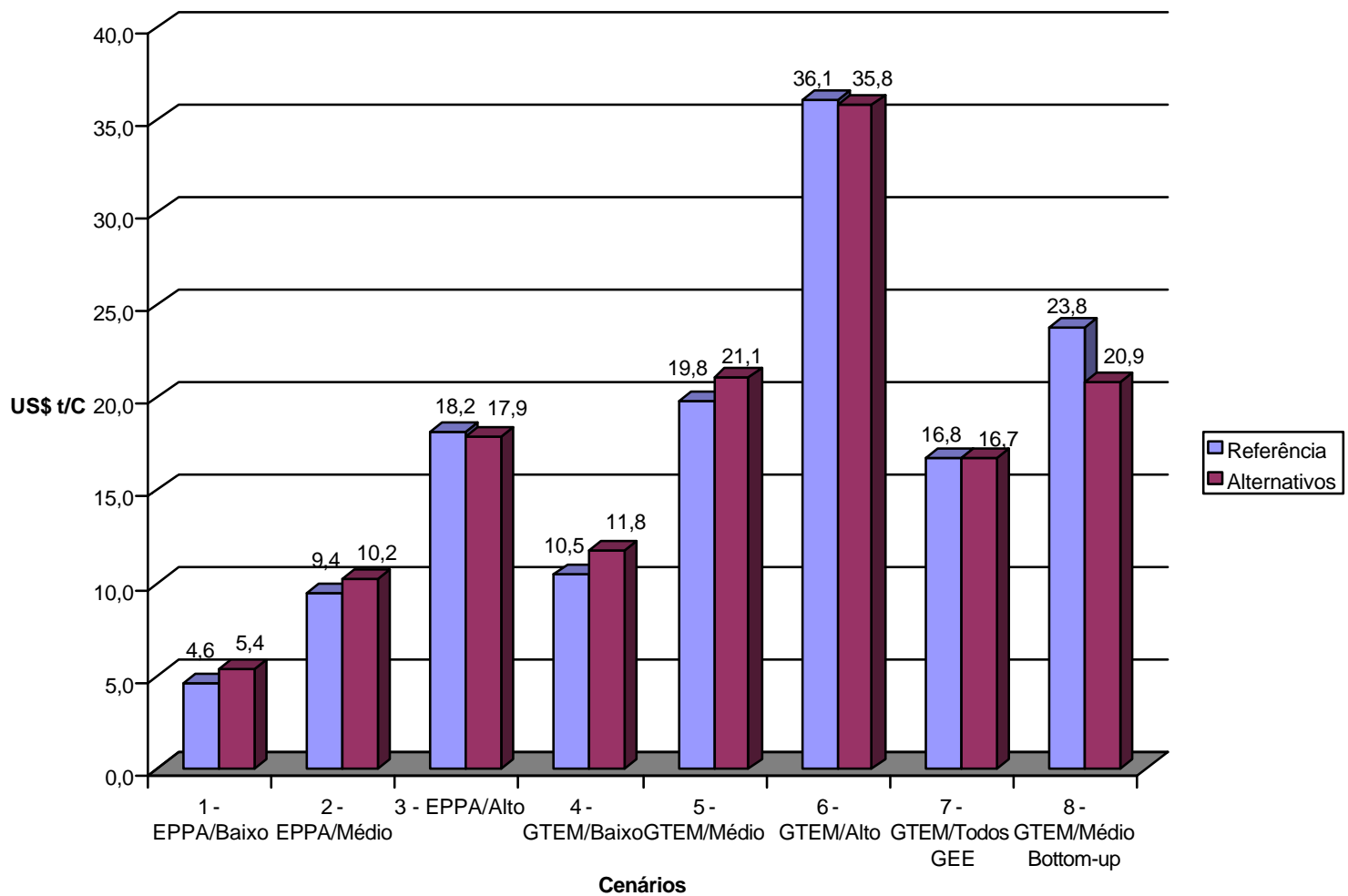

Figura 35 - Preços de equilíbrio de mercado nos cenários de referência e alternativos. Fonte: Cálculos do autor.

A participação dos países no mercado de carbono se alterou, como pode ser visto nas Figuras 38 e 39. A participação chinesa vai de 49,5\% (Cenário alternativo 8) até 68,4\% (Cenário alternativo 4), a participação indiana oscila de 6,9\% (Cenário alternativo 4) até $13 \%$ (Cenário alternativo 1), e a participação brasileira vai de 8\% (Cenário alternativo 4) até 17,8\% (Cenário alternativo 7). No Cenário alternativo 7, a participação da China e Índia são, respectivamente, 49,7\% e 7,9\% (Figura 40). O resto do mundo tem uma participação de varia de 17,6\% (Cenário alternativo 4) até 24,7\% (Cenário alternativo 8). 


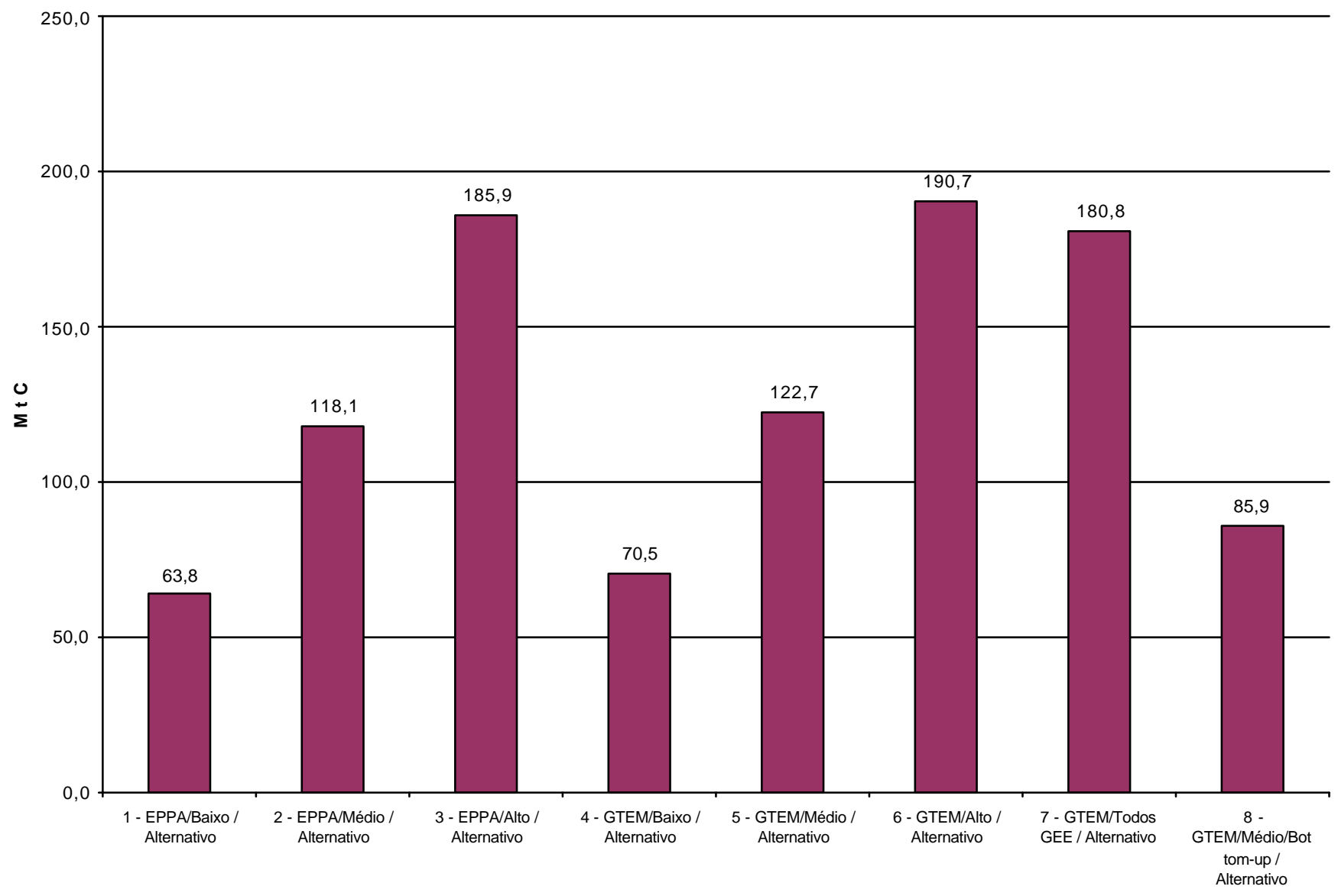

Figura 36 - Volume de vendas dos CER de MDL nos cenários alternativos - 2010.

Fonte: Cálculos do autor. 


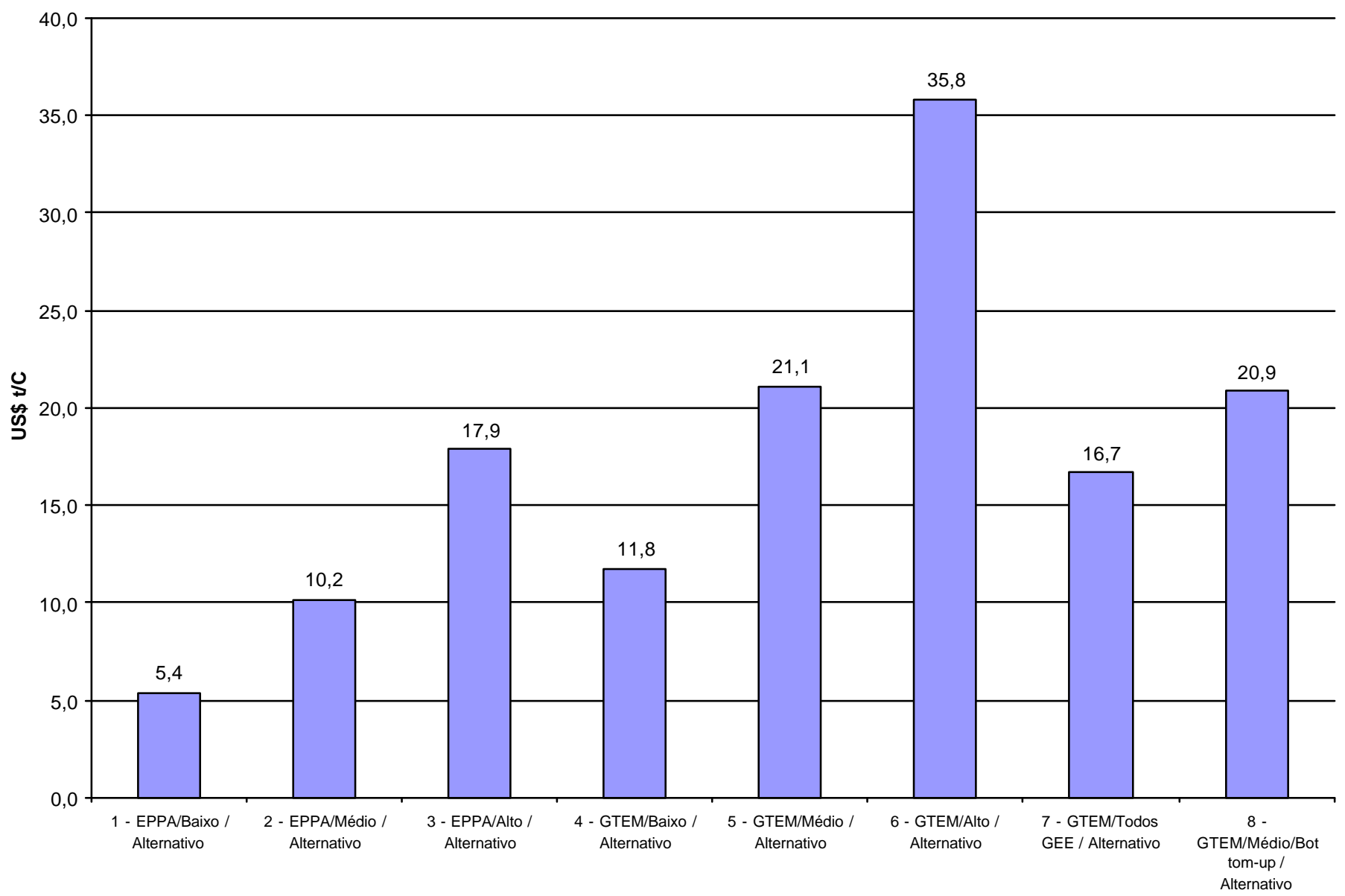

Figura 37 - Preço de venda dos CER de MDL nos cenários alternativos - 2010.

Fonte: Cálculos do autor. 


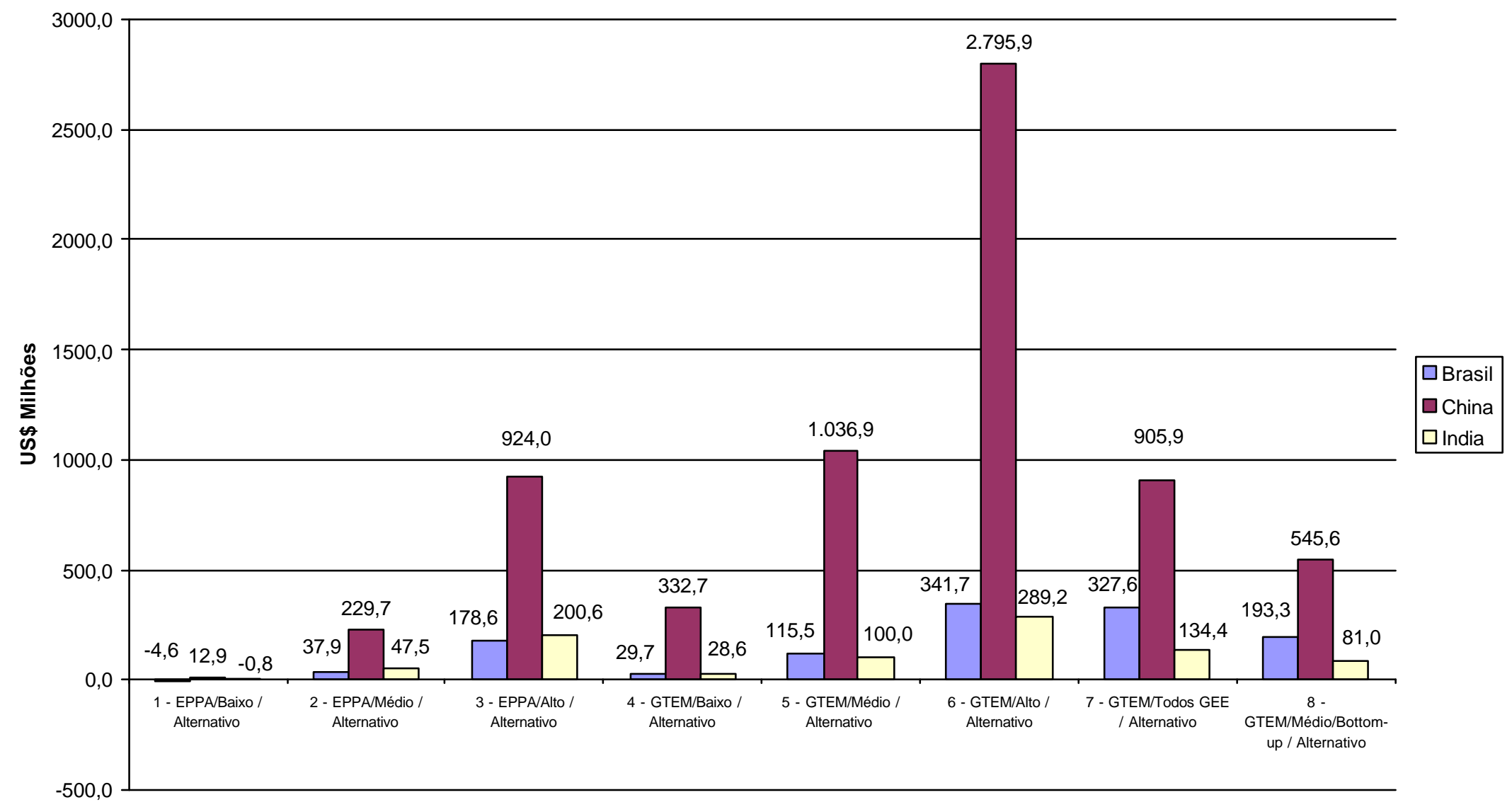

Figura 38 - Receita líquida das vendas de CER (US\$ milhões) nos cenários alternativos - 2010.

Fonte: Cálculos do autor. 


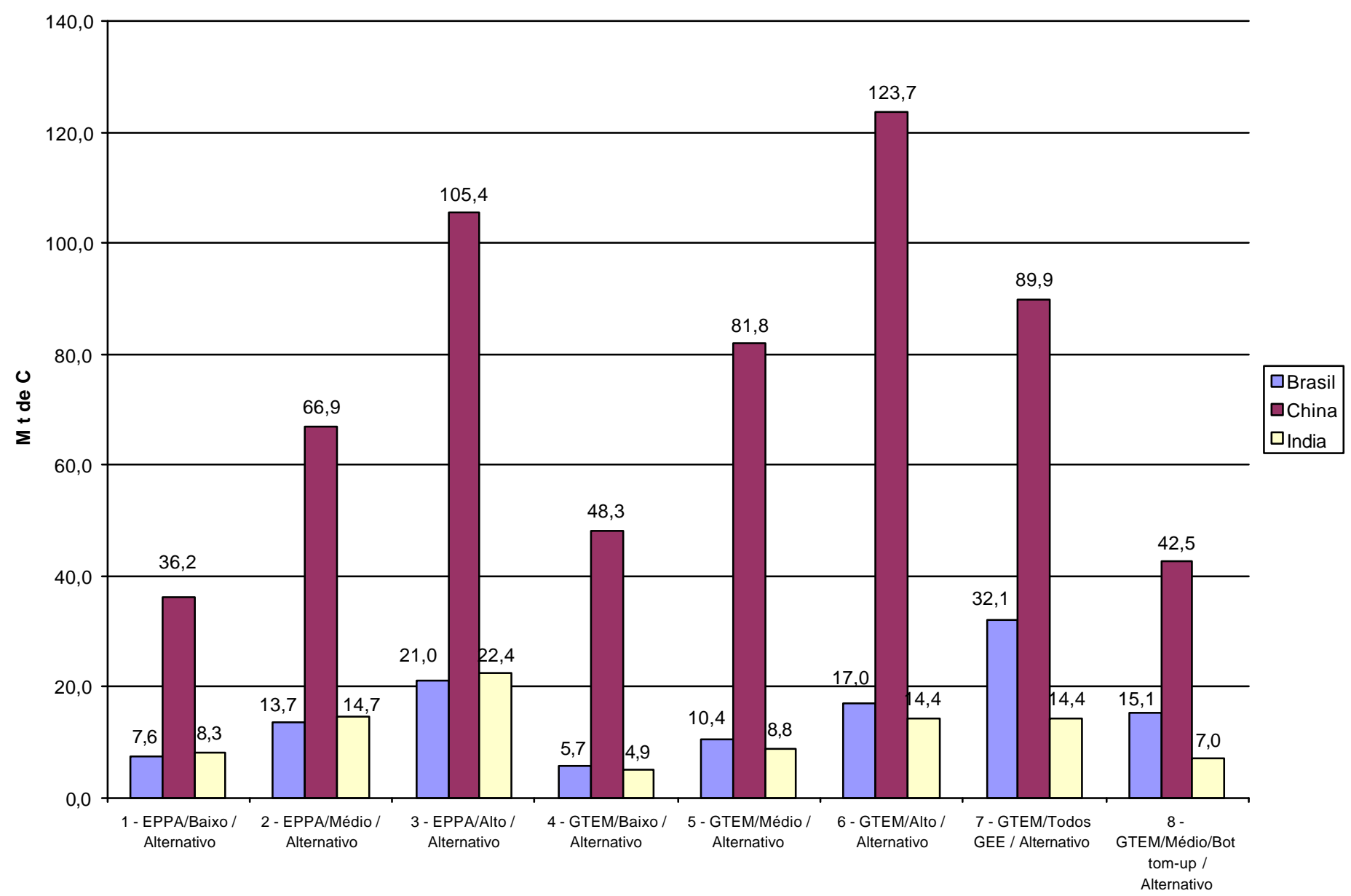

Figura 39 - Volume de vendas de CER (M t C) nos cenários alternativos - 2010.

Fonte: Cálculos do autor. 
Observa-se que no Cenário alternativo 1 o Brasil e a Índia apresentam vendas negativas de US\$ 4,6 milhões e US\$ 0,8 milhão respectivamente, ou seja, os custos para gerar os projetos de MDL são superiores às receitas geradas. Fica evidente que neste cenário nenhum desses países terá interesse em participar do mercado de carbono.

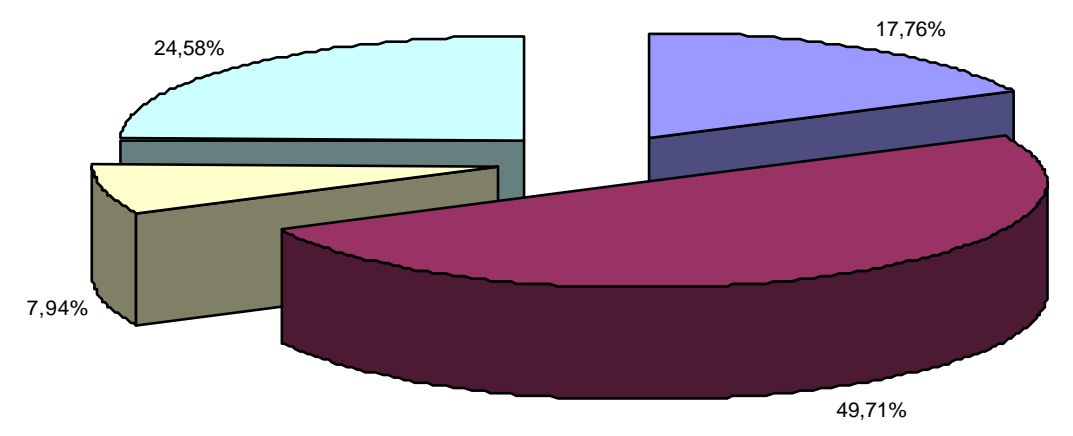

Figura 40 - Participação dos países no mercado de carbono via MDL (cenário alternativo - melhor caso para o Brasil), 2010.

Fonte: Cálculos do autor.

No cenário alternativo em que a participação brasileira é mais elevada (Cenário 7 - baseado no Modelo GTEM, com todos os gases de efeito estufa e curvas de custo marginal tipo “top-down"/exponencial) o equilíbrio de mercado ocorre com a comercialização de 417 Mt de C, ao preço de US\$ 16,7. Essa comercialização não é apenas de CER, mas também de ERU (Emissions Reduction Units - créditos gerados por projetos de JI).

No Cenário alternativo 7, o Brasil exporta 32,1 milhões de toneladas de carbono, gerando um receita de US\$ 525,6 milhões ao custo de US\$ 198 milhões. Além do custo, 
os projetos gerados no Brasil pagam ao Fundo de Adaptação US\$ 10,7 milhões. O lucro de todos os projetos de MDL no Brasil é de US\$ 327,6 milhões. Porém, os lucros brasileiros são maiores no Cenário alternativo 6: exportação de 17 milhões de toneladas de carbono, receitas de US\$ 597,4 milhões, custos de US\$ 255,7 milhões e lucro de US\$ 341,7 milhões. Apesar de ter lucros maiores, neste caso a participação brasileira é de apenas $8,9 \%$. O motivo que leva o Brasil a ter maiores lucros nesse cenário é o preço de equilíbrio de mercado: US\$ 35,8 por tonelada de carbono.

Ao comparar a participação brasileira nos cenários de referência e nos cenários alternativos, observa-se que o Brasil possui um desempenho melhor no segundo conjunto de cenários, com exceção do Cenário 1 (Figura 41). Nesse Cenário, o Brasil tem custos superiores às receitas e conseqüentemente possui vendas negativas de US\$ 4,6 milhões. Nos demais casos, o Brasil vende mais nos cenários alternativos, tanto em termos de receitas (US\$ milhões) como em termos de volume ( $\mathrm{M} \mathrm{t} \mathrm{C}$ ), como pode ser visto nas Figuras 41 e 42.

As diferenças podem ser explicadas pelo fato de que nos cenários alternativos, o Brasil oferece CER provenientes de projetos de LULUCF a um custo relativamente baixo. Assume-se, nesses casos, que o Brasil tem condições de oferecer CER ao mesmo custo que o resto do mundo oferece CER provenientes de projetos de energia (ver equações 20 a 23). Com isso é possível aumentar a vantagem brasileira em relação a Índia e à China. Deve-se lembrar que nos cenários de referência nenhum país oferece projetos de LULUCF e as CMA dos projetos de energia utilizadas pelo CERT são extremamente elevadas para o Brasil e muito baixas para a China e a Índia. 


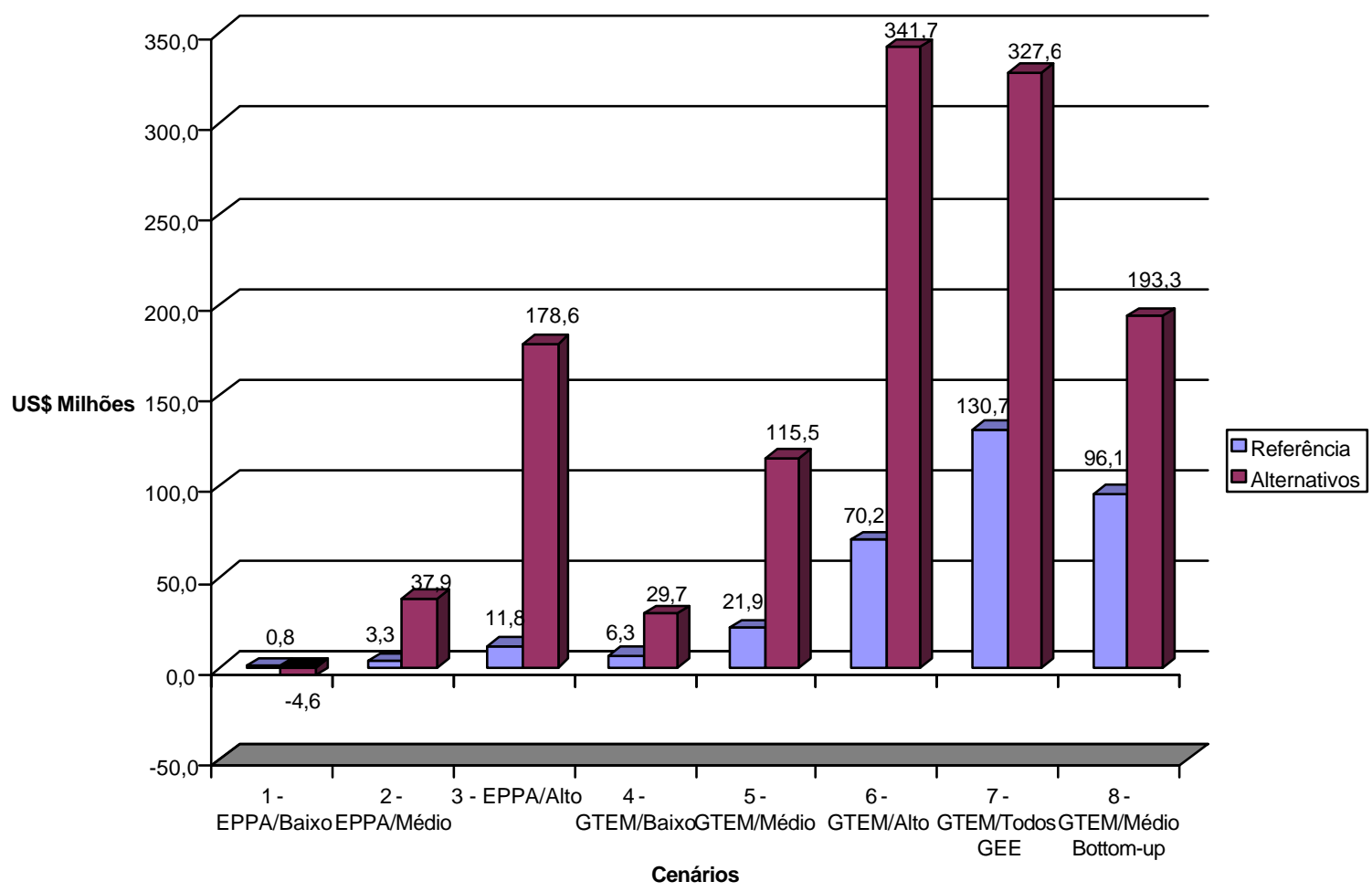

Figura 41 - Receita líquida das vendas de CER (US\$ milhões), Brasil nos cenários de referência e alternativos -2010 .

Fonte: Cálculos do autor. 


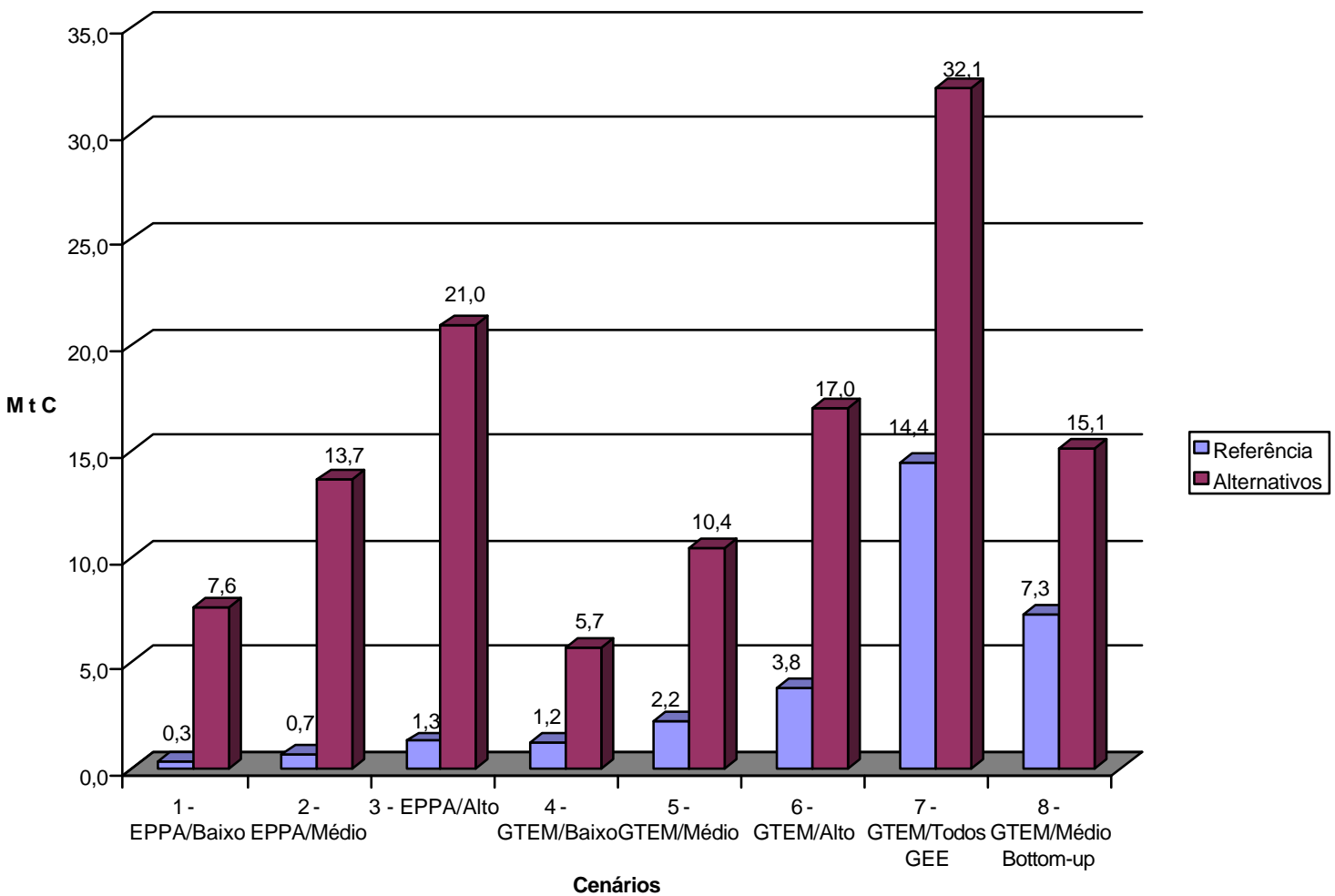

Figura 42 - Volume de vendas de CER (M t C), Brasil, nos cenários de referência e alternativos -2010 .

Fonte: Cálculos do autor. 


\section{CONCLUSÕES E RECOMENDAÇÕES}

As informações das seções anteriores indicam que um novo mercado está se formando: o mercado de carbono. Esse mercado terá como uma de suas "mercadorias" os Certificados de Emissões Reduzidas (CER), provenientes de projetos de Mecanismo de Desenvolvimento Limpo (MDL), entre eles os projetos de LULUCF Land Use, Land Use Change and Forestry (seqüestro de carbono). Outras "mercadorias" serão os certificados dos projetos de Implementação Conjunta e Emission Trade (outros mecanismos de flexibilização previstos no Protocolo de Quioto, nos quais o Brasil não pode participar por não fazer parte do ANEXO I).

Atualmente, o mercado de carbono encontra-se no estágio de "Grey market"; onde não existem legislações domésticas ou internacionais ${ }^{1}$ definidas que possam legitimar os direitos associados aos CER. Como consequiência, existem incertezas quanto à aceitação desses certificados no mercado. Essa incerteza está refletida nos baixos preços do "early credits" observados atualmente (US\$ 3,5 a US\$ 5,0 - Fonte: http://www.co2e.com).

Várias iniciativas estão sendo tomadas com o objetivo de diminuir as incertezas associadas à formação do mercado e aos projetos de MDL. Tomando como base os passos sugeridos por Sandor \& Walsh (2000) para que o mercado de carbono venha a ser criado, podem-se listar as principais iniciativas que já foram tomadas até o momento.

\footnotetext{
${ }^{1}$ Até o presente momento, o Protocolo de Quioto não foi ratificado de forma que não existem oficialmente projetos de MDL e tampouco os CER.
} 


\begin{tabular}{|c|c|}
\hline Passos & Iniciativas \\
\hline $\begin{array}{l}\text { 1) Ocorrência de mudanças estruturais } \\
\text { que gerem demanda por capital }\end{array}$ & $\begin{array}{l}\text { - Metas de redução das emissões dos países } \\
\text { do ANEXO B presentes do Protocolo de } \\
\text { Quioto } \\
\text { - Metas voluntárias de redução de emissões } \\
\text { em países não signatários do Protocolo de } \\
\text { Quioto (Ex: EUA) }\end{array}$ \\
\hline $\begin{array}{l}\text { 2) Criação de uma padronização } \\
\text { uniforme para a commodity }\end{array}$ & $\begin{array}{l}\text { - Protocolo de Quioto } \\
\text { - Acordo de Marrakesh } \\
\text { - Definições e modalidades para a inclusão } \\
\text { de atividades de reflorestamento e } \\
\text { florestamento em projetos de MDL (a serem } \\
\text { definidos na COP 9) }\end{array}$ \\
\hline $\begin{array}{l}\text { 3) Desenvolvimento de } \\
\text { legais que garantam o direito de } \\
\text { propriedade }\end{array}$ & $\begin{array}{l}\text { - Protocolo de Quioto } \\
\text { - Acordo de Marrakesh } \\
\text { - Definições e modalidades para a inclusão } \\
\text { de atividades de reflorestamento e } \\
\text { florestamento em projetos de MDL (a serem } \\
\text { definidos na COP 9) }\end{array}$ \\
\hline $\begin{array}{l}\text { 4) Desenvolvimento de mercados a vista } \\
\text { informais e de entrega futura (mercados a } \\
\text { termo) }\end{array}$ & $\begin{array}{l}\text { - PCF } \\
\text { - BioFund } \\
\text { - Mercados nacionais: Holanda/CERUPT e } \\
\text { EUA/CCX entre outros }\end{array}$ \\
\hline 5) Aparecimento de bolsas & $\begin{array}{l}\text { - Aparecimento de diferentes corretores } \\
\text { - Ocorrência de transações de "early credits" }\end{array}$ \\
\hline $\begin{array}{l}\text { 6) Criação de mercados futuros e de } \\
\text { opções organizados }\end{array}$ & - Nada até o momento \\
\hline 7) Proliferação de mercados de balcão & - Nada até o momento \\
\hline
\end{tabular}

Quadro 12 - Passos necessários para a criação do mercado de carbono e iniciativas tomadas para diminuir o grau de incerteza.

Fonte: Adpatado de Sandor \& Walsh (2000)

Uma vez superadas as incertezas, os CER não deverão se tornar, a princípio,

2 A Conferência das Partes 7 (COP 7) requisitou que o Subsidiary Body for Scientific and Technological Advice (SBSTA) desenvolvesse definições e modalidades para a inclusão de atividades de reflorestamento e florestamento em projetos de MDL no primeiro período de compromisso (20082012). Estas definições e modalidades devem levar em consideração os seguintes temas: nãopermanência, adicionalidade, vazamentos, incertezas e impactos socioeconômico e ambientais (incluindo impactos na biodiversidade de ecossistemas naturais) devem ser apresentadas na COP 9 para decisão em plenária. 
uma "commodity ambiental". Diante do que foi apresentado nas seções Erro! A origem da referência não foi encontrada., Erro! A origem da referência não foi encontrada. e Erro! A origem da referência não foi encontrada., pode-se observar que os CER gerados pelos projetos podem apresentar características bastante distintas, o que impede uma padronização do produto/serviço. Além disso os mercados atuais (seção Erro! A origem da referência não foi encontrada.) também apresentam características distintas. Isso motiva diferentes investidores/compradores (empresas dos países do ANEXO B) a buscarem diferentes tipos de projeto.

Essa diferenciação faz com que não seja possível negociar atualmente os CER como contratos futuros, cujo objetivo seria reduzir os riscos de preços do carbono. Além disso, tais créditos estão sendo negociados individualmente e não em um ambiente de bolsa. Portanto, não existem atualmente condições para o aparecimento de mercados futuros de carbono. O surgimento desse tipo de mercado irá depender da contínua formação do mercado de carbono; continuidade esta que depende de como serão estabelecidas as metas de redução para os futuros períodos de compromisso (pós 2012) e quais os instrumentos de mercado que irão existir para facilitar o cumprimento de tais metas.

Como o mercado está em um processo de formação, a negociação hoje é feita projeto a projeto, com o investidor/comprador buscando conhecer todas as características do projeto, em especial os benefícios associados ao mesmo, ou seja, quais as variáveis do projeto determinam o desenvolvimento sustentável. Devemos lembrar que os projetos de MDL têm um objetivo duplo: redução das emissões de GEE e/ou seqüestro de carbono e promover o desenvolvimento sustentável do país hospedeiro do projeto. Ao analisar o primeiro objetivo, o investidor/comprador olha apenas a adicionalidade das atividades do projeto (quantidade de CER gerada - análise quantitativa); porém, ao analisar o segundo objetivo, o investidor/comprador observa como a geração dos CER foi alcançada e quais os impactos socioambientais do projeto (análise qualitativa).

Existe portanto, a possibilidade de diferenciação dos CER. Isto pode trazer benefícios aos proponentes do projeto, uma vez que é possível agregar valor ao projeto 
atingindo com isso, preços maiores e nichos de mercado.

Uma das principais diferenciações que os investidores/compradores estão analisando dizem respeito às diferenças entre projetos de energia e LULUCF. Ao comparar os projetos, devem-se observar a linha de base, adicionalidade, vazamentos, medições, permanência e impactos socioambientais. Segundo Chomitz (/ 2000? /) é difícil encontrar distinções entre os projetos de energia e LULUCF usando estes critérios, exceto para a permanência. Os projetos de energia têm mais facilidade de demonstrar que os CER gerados são permanentes; enquanto que os projetos de LULUCF (em especial reflorestamento e florestamento) têm mais dificuldade em demonstrar a permanência $^{3}$, em especial devido aos riscos associados às atividades (incêndios, derrubadas, etc.).

Os projetos de LULUCF precisam então, agregar valor ao CER através de benefícios relacionados a questões sociais e ambientais. No processo de agregação de valor, é possível diferenciar os projetos. Os que têm um maior envolvimento das comunidades locais e repassam para estas parte dos benefícios gerados, conservam a biodiversidade, permitem a recuperação dos recursos hídricos, etc. poderão receber dos investidores/compradores um preço maior que os projetos de energia e LULUCF que não incorporem tais características.

Neste trabalho, essa agregação de valor e diferenciação de preços não foi analisada quantitativamente, uma vez que o Modelo CERT (Carbon Emission Reduction Trade) não permite tal análise. O Modelo CERT estima a demanda e oferta do mercado potencial de comércio de emissões dentro do Protocolo de Quioto, utilizando diferentes cenários e diferentes curvas de custo marginal de abatimento (MAC). O CERT não é um modelo de equilíbrio geral, mas um "meta-modelo" que

\footnotetext{
${ }^{3}$ Para superar o problema da possível não-permanência dos projetos de reflorestamento e florestamento, a União Européia, com base em uma proposta da Colômbia, propôs durante a COP 8 a criação de certificados temporários que venceriam em 5 anos (T-CERs - Temporary Certified Emission Reduction UNFCCC, 2002f). De acordo com esta proposta, os países do ANEXO B poderiam utilizar os T-CERs para cumprir suas metas de redução desde que quando o certificado vencesse, houvesse aquisição de novos certificados (T-CERs, CERs, ERUs). Caso esta proposta seja aceita, os projetos de energia (que terão certificados permanentes) poderão ser considerados mais vantajosos em relação aos projetos de LULUCF.
} 
utiliza informações de outros modelos. Os resultados são calculados para diferentes cenários levando em consideração diversas variáveis: inclusão ou não de "hot air", diferentes taxas de implementação de projetos, inclusão ou não de custos de transação etc.

Nos cenários de referência do Modelo, a participação brasileira no mercado de carbono é mais elevada no Cenário 7 (baseado no Modelo GTEM, levando em consideração todos os gases de efeito estufa e curvas de custo marginal tipo "topdown"/exponencial), chegando a 3,4\% do mercado de CER. Nesse caso, o equilíbrio de mercado ocorre com a comercialização de 860 Mt de $C^{4}$ ao preço de US\$ 16,8. Nesse Cenário, em 2010, o Brasil exporta 14,4 milhões de toneladas de carbono, gerando um receita de US\$ 237 milhões ao custo de US\$ 106,3 milhões. Além do custo, os projetos gerados no Brasil pagam ao Fundo de Adaptação US\$ 4,8 milhões. O lucro de todos os projetos de MDL no Brasil é de US\$130,7 milhões.

A participação brasileira no mercado de CER é pequena comparada com a da China $(54,9 \%)$, Índia $(10,1 \%)$ e resto do mundo $(31,6 \%)$, em especial porque o cenário de referência utiliza MAC para o Brasil que são extremamente elevadas (Erro! A origem da referência não foi encontrada., Erro! A origem da referência não foi encontrada., Erro! A origem da referência não foi encontrada. e Erro! A origem da referência não foi encontrada.). Além disso, os cenários de referência do Modelo não levam em consideração os projetos de LULUCF, mas apenas os projetos de energia.

Nos cenários alternativos, as seguintes variáveis foram modificadas a partir das entrevistas com alguns dos principais especialistas e lideranças sobre mudanças climáticas no Brasil: taxas de implementação dos projetos de MDL para Brasil, China, Índia e resto do mundo; porcentagem de "hot air" comercializado; participação dos EUA e custos de transação dos projetos de MDL para Brasil, China, Índia e resto do mundo. Houve uma grande variação nos valores informados pelos entrevistados, o que pode ser explicado pelo alto grau de incerteza que hoje existe sobre o tamanho e a forma do "mercado de carbono". Além disso, nem todos os entrevistados quiseram informar os

\footnotetext{
${ }^{4}$ Neste valor estão incluídos os créditos de projetos de JI (Implementação Conjunta).
} 
valores, em especial pelo do momento de indecisão que hoje existe sobre a ratificação do Protocolo de Quioto e a participação do Brasil. Foram também inseridas CMA para os projetos de LULUCF no Brasil, baseadas nas CMA dos projetos de energia para países do resto do mundo presentes nos cenários de referência do CERT.

Com isso, a participação brasileira no mercado de carbono nos cenários alternativos aumentou. No Cenário 7 ela chegou a 17,8\% do mercado de CER. Nesse caso, o equilíbrio do mercado ocorre com a comercialização de $417 \mathrm{Mt}$ de $\mathrm{C}^{5}$ ao preço de US\$ 16,7. No Cenário Alternativo 7, para o ano de 2010, o Brasil exporta 32,1 milhões de toneladas de carbono, gerando um receita de US\$ 525,6 milhões ao custo de US\$ 198 milhões. Além do custo, os projetos gerados no Brasil pagam ao Fundo de Adaptação US\$ 10,7 milhões. O lucro de todos os projetos de MDL no Brasil é de US\$ 327,6 milhões. Porém, os lucros brasileiros são maiores no Cenário Alternativo 6: exportação de 17 milhões de toneladas de carbono; receitas de US\$ 597,4 milhões; custos de US\$ 255,7 milhões e lucro de US\$ 341,7 milhões. Apesar de ter lucros maiores, nesse caso a participação brasileira é de apenas 9\%. O motivo que leva o Brasil a ter maiores lucros neste cenário é o preço de equilíbrio de mercado: US\$ 35,8 por tonelada de carbono. A participação brasileira aumenta nos cenários alternativos porque leva em consideração os projetos de LULUCF.

Em todos os cenários (referência e alternativos), as principais variáveis que influenciam nos resultados do Modelo CERT são a participação dos EUA e as curvas de custo marginal de abatimento. No caso da primeira variável, é correto afirmar que a participação norte-americana inicial no mercado de carbono será menor, uma vez que os EUA não irão ratificar o Protocolo de Quioto, e, com isso, as empresas norte-americanas não precisarão comprar tantos CER. Porém, essa participação irá ocorrer em parte, por três motivos principais: 1) a existência de legislações estaduais que obrigam as empresas a reduzir suas emissões de GEE (Ex: Massachusetts); 2) o fato de muitas empresas norte-americanas serem multinacionais e terem interesse em participar do mercado para adquirir conhecimento e/ou CER para suas filiais; e, 3) o fato de que algumas empresas

\footnotetext{
${ }^{5}$ Neste valor estão incluídos os créditos de projetos de JI (Implementação Conjunta).
} 
estejam se preparando para futuros períodos de compromisso e/ou outros protocolos, que por ventura os EUA venham a ratificar.

Quanto às curvas de custo marginal de abatimento, o Modelo CERT leva em consideração apenas as curvas para projetos de energia sem considerar projetos de LULUCF. Essa é uma característica do Modelo que desfavorece o Brasil, uma vez que a matriz energética brasileira é fortemente baseada em energia renovável (segundo International Energy Association, IEA (2002) 87,3\% da energia elétrica produzida no Brasil provém de hidroelétricas); enquanto que a China e a Índia possuem matrizes energéticas baseadas em combustíveis fósseis (segundo IEA (2002) apenas 16\% da energia elétrica produzida na China e apenas $13,7 \%$ da energia elétrica produzida na Índia provêm de hidroelétricas). Essa situação faz com que as CMA dos projetos de energia na China e na Índia sejam bastante inferiores às CMA de projetos no Brasil.

A fim de aprimorar os resultados é necessário incluir de curvas específicas para projetos de LULUCF. A título de ilustração, assumiu-se que o Brasil pode oferecer projetos de LULUCF a um custo igual ao dos projetos de energia do resto do mundo. Além disto, as curvas referentes aos projetos de energia utilizadas para o Brasil são muito mais elevadas que as curvas chinesas e indianas. É preciso calibrar todas as curvas para obter a real participação brasileira no mercado. Este trabalho não teve o objetivo de gerar curvas específicas para os projetos brasileiros. No caso dos projetos de LULUCF, tomaram-se emprestadas as CMA presentes nos cenários de referência para projetos de energia em países do resto do mundo (ROW).

Como dito, a taxa de implementação de projetos de MDL depende não apenas dos custos marginais de abatimento, como também do ambiente institucional políticoeconômico. Assim, alguns especialistas acreditam que o Brasil pode levar vantagem em relação a outros países. Para tanto, seria fundamental que o governo brasileiro indicasse claramente qual será a legislação nacional para os projetos de MDL.

Dentre as atribuições da Comissão Interministerial de Mudança do Clima está “definir critérios de elegibilidade conforme as políticas nacionais de desenvolvimento sustentável”. A lista proposta pela Secretaria de Qualidade Ambiental nos Assentamentos Humanos (SQA), do Ministério do Meio Ambiente, pode ser 
considerada extremamente extensa e onerosa e vir a prejudicar a competitividade de nossos projetos. O ideal seria apenas seguir as regras e diretrizes do Comitê Executivo, sem impor mais nenhum critério adicional.

A única preocupação seria garantir o desenvolvimento sustentável do país. Para tanto, bastaria que os projetos estivessem atentos às legislações nacionais sobre o tema, ou seja, bastaria respeitar as leis já existentes.

Esta tese teve como objetivo geral caracterizar o "mercado de carbono", em especial a participação do Brasil através do MDL. Para tanto, foi feita uma análise de como este mercado está sendo formado e como deverá ser sua evolução até a possível formação de mercados futuros. Os objetivos específicos foram: 1) determinar o tamanho do mercado global e a participação do Brasil (através do MDL) em diversos cenários; e, 2) analisar se os certificados de emissões reduzidas (CER) gerados em projetos de MDL, em especial por projetos de sequiestro de carbono, poderiam se tornar uma "commodity ambiental" ou não.

Ficou claro que o mercado de carbono já é uma realidade, porém se encontra em um estágio inicial de sua formação, sendo que os CER não podem ser considerados commodities e nem tampouco comercializados em um mercado futuro.

A participação brasileira, calculada pelo Modelo CERT, não é significativa quando comparada a de outros países em desenvolvimento, tais como a China e a Índia. Porém, o Mbdelo apresenta uma série de limitações, em especial referentes às curvas de custo marginal de abatimento utilizadas.

Para aumentar a participação brasileira nesse mercado, torna-se fundamental criar um ambiente institucional político-econômico adequado que permita um baixo custo de transação e gere confiança nos investidores/compradores. Para isso, o governo desempenha um papel fundamental através da Comissão Interministerial de Mudança do Clima. Outros atores do mercado, tais como ONG, corretores, bancos etc. também devem auxiliar na criação desse ambiente favorável. Outra maneira de aumentar a participação seria através da criação de projetos diferenciados que poderiam buscar nichos de mercado, onde o preço do CER seria maior.

Tudo isto precisa ser feito levando em consideração o que o país deseja como 
desenvolvimento sustentável. Hoje o Brasil não possui compromissos de reduzir suas emissões, porém, num futuro próximo, o país poderá ser cobrado a realizar tais reduções. Devemos estar preparados, iniciando hoje uma trajetória de crescimento econômico que seja socialmente justa, ambientalmente correta e sustentável no longo prazo. 


\section{REFERÊNCIAS BIBLIOGRÁFICAS}

AUSTRALIAN BUREAU OF AGRICULTURAL AND RESOURCE ECONOMICS. Global Trade and Environment Model (GTEM): a computable general equilibrium model of the global economy and environment. Canberra: ABARE, 2002. 136p.

AUSTRALIAN GREENHOUSE OFFICE - AGO. National emissions trading: designing the market. Canberra: Commonwealth of Australia, 1999. 56p. (AGO. Discussion Paper, 4)

AMARAL, W.A.N. Mudanças climáticas, mercado de carbono e potencialidades do Brasil para desenvolvimento de projetos para Mecanismo de Desenvolvimento Limpo. Preços Agrícolas, v.14, n.155, p.7-9, 1999.

AMIGOS DA TERRA. Mercado emergentes. Meio Circulante, v.1, n.1, 2000.

ANDERSON, D.; ROLAND, K.; SCHREINER, P.; SKJELVIK, J.M. Designing a domestic GHG emissions trading system: the example of Norway. In: JEPMA, C.J.; VAN DER GAAST, W. On the compatibility of flexible instruments. Dordrecht: Kluwer Academic Publishers, 1999. cap.9, p.109-124.

AUSTIN, D.; FAETH, P.; MOTTA, R.S. da; FERRAZ, C.; YOUNG, C.E.F.; JI, Z.; JUNFENG, L.; PATHAK, M.; SRIVASTAVA, L.; SHARMA, S. How much sustainable development can be expect from the Clean Development Mechanism ? Washington: WRI, Nov. 1999. 160p. (WRI - Climate Notes)

BEIL, S. Evolution and design of an emissions trading market of greenhouse gases. /Apresentado ao 2. Annual Emissions Trading Forum, 1999/

BEIL, S.; ASSIM, F. The "securitisation" of environmental markets: from theory to reality. /Apresentado no Workshop Forests in the Green Economy, Sidnei, 2000/

BERNA, V. Uma proposta para o seqüestro de carbono. vilmarberna@jornal-domeio-ambiente.com.br (10 abr. 2000) 
BIOCARBON FUND - BIOCF. BioCarbon Fund. http://www.biocarbonfund.org (13 nov. 2002)

BANCO NACIONAL DE DESENVOLVIMENTO ECONÔMICO E SOCIAL BNDES; MINISTÉRIO DA CIÊNCIA E TECNOLOGIA - MCT. Efeito estufa e a Convenção sobre Mudança do Clima. Rio de Janeiro: BNDES, Departamento de Relações Institucionais, 1999. 38p.

BRASIL. Decreto Presidencial de 7 de julho de 1999. Diário Oficial, 08 jul. 1999. Seção 1, p.1. Cria a Comissão Interministerial de Mudança Global do Clima com a finalidade de articular as ações de governo nessa área.

BRASIL. Ministério do Meio Ambiente. Secretaria de Qualidade Ambiental nos Assentamentos Humanos. Proposta revisada de critérios e indicadores de elegibilidade de projetos candidatos ao Mecanismo de Desenvolvimento Limpo (MDL). Brasília, 2002. 17p.

BRAZIL/U.S. ASPEN GLOBAL FORUM. Task force on early start projects for carbon emission reductions. São Paulo: AMCHAM, 2000. 39p.

CAVALCANTI, F.S.; MISUMI, J.Y. Mercado de capitais. Belo Horizonte: CNBV, 1998.

CHICAGO CLIMATE EXCHANGE - CCX. Chicago Climate Exchange. http://www.chicagoclimatex.com (20 oct. 2002)

CHOMITZ, K.M. Evaluating carbon offsets from forestry and energy projects: How do they compare ? Washington: World Bank, / 2000? /. 28p.

DOWNES, J.; GOODMAN, J.E. Dicionário de termos financeiros e de investimento. São Paulo: Nobel, 1993. 650p.

ELLERMAN, A.D.; JACOBY, H.D.; DECAUX, A. The effects on developing countries of the Kyoto Protocol and $\mathrm{CO}_{2}$ emissions trading. Cambridge: MIT, 1998. 42p. (MIT Report, 41)

ELLERMAN, A.D.; DECAUX, A. Analysis of Post-Kyoto $\mathbf{C O}_{2}$ emissions trading using marginal abatement curves. Cambridge: MIT, 1998. 32p. (MIT Report, 40)

ENVIRONMENTAL PROTECTION AGENCY - EPA. Acid Rain Program. http://www.epa.gov/airmarkets/arp/ (05 Mar. 2002)

EMISSIONS TRADING GROUP - ETG. Outline proposals for a UK emissions trading scheme. 2.ed. London: $\mathrm{CBI} / \mathrm{ACBE}, 2000$. 121p. 
FUNDO NACIONAL DO MEIO AMBIENTE - FNMA. Edital FNMA 09/2001. http://www.mma.gov.br/fnma/apoio/di/ed001.html (29 nov. 2001)

FUNDO NACIONAL DO MEIO AMBIENTE - FNMA. Resultados da seleção de projetos. http://www.mma.gov.br/fnma/apoio/di/red901.html (28 mar. 2002)

GOLDEMBERG, J. O Brasil e as mudanças climáticas. O Estado de São Paulo, São Paulo, 12 dez. 1999.

GRÜTTER, J.M. World Market for GHG Emission Reductions: an analysis of the World Market for GHG abetment, factors and trends that influence it based on the CERT model. Washington: World Bank, 2001. 36p.

GRÜTTER, J.M.; KAPPEL, R.; STAUB, P. CERT Model: Carbon Emission Reduction Trade Model (software). Heldswil: Grutter Consulting, 2002.

HULL, J. Introdução aos mercados futuros e de opções. São Paulo: BM\&F, 1996. 448p.

INTERNATIONAL ENERGY ASSOCIATION - IEA. Key world energy statistics. Paris, 2002. 75p.

INTERGOVERNMENTAL PANEL ON CLIMATE CHANGE - IPCC. Climate Change 2001: the scientific basis. HOUGHTON, J.T.; DING, Y.; GRIGGS, D.J.; NOGUER, M.; VAN DER LINDEN, P.J.; DAI, X.; MASKELL, K.; JOHNSON, C.A. (Ed.). Cambridge: Cambridge University Press, 2001a. 881p.

INTERGOVERNMENTAL PANEL ON CLIMATE CHANGE - IPCC. Climate Change 2001: impacts, adaptation, and vulnerability. MCCARTHY, J.J; CANZIANI, O.F.; LEARY, N.A.; DOKKEN, D.J.; WHITE, K.S. (Ed.). Cambridge: Cambridge University Press, 2001b. 1032p.

KAPPEL, R.; STAUB, P.; GRÜTTER, J.M. User's guide CERT: Carbon Emission Reduction Trade Model. Washington: World Bank, 2001. 15p.

KAPPEL, R.; STAUB, P.; GRUTTER, J.M. Simulating the market for greenhouse gas emission reductions: the CERT model. Heldswil: Grutter Consulting, 2002. 22p.

KHALILI, A.E. Commodities ambientais: novas alternativas de gerenciamento financeiro para o setor florestal. /Apresentado à Semana de Avaliação Rural, Curitiba, 2000/ 
KOSOBUD, R.F. Emissions emerges from the shadows. In: KOSOBUD, R.F.; SCHREDER, D.L.; BIGGS, H.M. Emissions trade: environmental policy's new approach. Hoboken: John Wiley \& Sons, 2000.

LECOCQ, F.; CAPOOR, K. State and trends of the carbon market(s). /Apresentado ao Workshop Como Desenvolver Projetos de Mecanismo de Desenvolvimento Limpo (MDL) Elegíveis ao Prototype Carbon Fund (PCF), São Paulo, 2002/

MACEDO, I.A. O ciclo da cana-de-açúcar e reduções adicionais nas emissões de $\mathrm{CO}_{2}$. In: SEMINÁRIO FONTES DE RECURSOS PARA PROJETO: O CDM, 1., São Paulo, 2000. Relatório. São Paulo: FGV, 2000. p.9-12.

MANFRINATO, W.; VIANA, V. Seqüestro de carbono como parte de uma estratégia de desenvolvimento sustentável de bacias hidrográficas. /Apresentado ao Workshop Mudanças Climáticas Globais e Agropecuária Brasileira, Jaguariúna, 1999/

MARLAND, G.; BODN, T.A.; ANDERS, R.J.; BRENKERT, A.L.; JOHNSTON, C. Global, regional and national $\mathrm{CO}_{2}$ emissions in trends: a compendium of data on global change. Oak Ridge: Oak Ridge National Laboratory, 1999.

MARQUES, P.V.; MELLO, P.C. de. Mercados futuros de commodities agropecuárias. São Paulo: BM\&F, 1999. 208p.

MEYERS, S.; SATHAYE, J.; LEHMAN, B.; SCHUMACHER, K.; VLIET, O.V.; MOREIRA, J.R. Preliminary assessment of potential CDM early start projects in Brazil. Berkeley: EPA, 2000. 46p.

MIGUEZ, J.M. O Brasil e o Protocolo de Quioto. Cenbio Notícias, v.3, n.8, p.3, 2000.

MONTEZANO, R.M. Introdução aos mercados futuros de índices de ações. São Paulo: BM\&F/IBMEC, 1987.

MORAES, M.A.F.D. Financiamento para a agroindústria canavieira: mercado de carbono e recursos externos. Preços Agrícolas, v.14, n.158, p.14-16, 1999.

MOURA-COSTA, P. A convenção climática e o surgimento de commodities ambientais. Gazeta Mercantil, São Paulo, dez. 1997.

MOURA-COSTA, P. Breve história da evolução dos mercados de carbono. Silvicultura, n.76, 1998.

MOUTINHO, P.; BUENO, M. O inventário brasileiro de emissões e o desmatamento na Amazônia. Clima em Revista, v.2, n.3, p.1, 2002. 
NORDHAUS, W.D. From Porcopolis to Carbopolis. In: KOSOBUD, R.F.; SCHREDER, D.L.; BIGGS, H.M. Emissions trade: environmental policy's new approach. Hoboken: John Wiley \& Sons, 2000.

PROTOTYPE CARBON FUND - PCF. Prototype Carbon Fund: annual report. Washington: World Bank, 2002a. 60p.

PROTOTYPE CARBON FUND - PCF. Ciclo do Projeto PCF. /Apresentado no Workshop Como Desenvolver Projetos de Mecanismo de Desenvolvimento Limpo (MDL) Elegíveis ao Prototype Carbon Fund (PCF), São Paulo, 2002b/

PEARCE, D.; PUTZ, F.; VANCLAY, J.K. A sustainable forest future. Norwich: CSERGE, 1999. (Working Paper GEC 99-15)

PEUGEOT. $\mathbf{C O}_{2}$ sink in Brazil. http://www.peugeot.com.br/marketing/hub_peugeot/ $\mathrm{pt} / \mathrm{PT} / \mathrm{html} / \mathrm{amazone} . \mathrm{html}$ (10 Oct. 2000)

REZENDE, D.; MERLIN, S.; SANTOS, M. Seqüestro de carbono: uma experiência concreta. 2.ed. Palmas: Instituto Ecológica, 2001. 178p.

SANDOR, R.L.; WALSH, M.J. Some observations on the evolution of the international greenhouse gas emissions trading market. In: KOSOBUD, R.F.; SCHREDER, D.L.; BIGGS, H.M. Emissions trade: environmental policy's new approach. Hoboken: John Wiley \& Sons Inc, 2000.

SCHARF, R. Commodities ambientais chegam às bolsas. /Apresentado à Semana de Avaliação Rural, Curitiba, 2000/

SENTER. Terms of reference: CERUPT 2001. The Hague: Senter International, 2001. $47 \mathrm{p}$.

SOCIEDADE DE PESQUISA EM VIDA SELVAGEM EEDUCAÇÃO AMBIENTAL - SPVS. Projetos de seqüestro de carbono. http://www.spvs.org.br/projetos/carbono.html (17 jul. 2002)

TIETENBERG, T. Tradable permits and the control of air pollution in the United States. Zeitschrift für Angewandte Umweltforschung, v.9, 1998. 33p.

UNITED KINDGOM. Department for Environment, Food \& Rural Affairs. UK Emissions Trading http://www.defra.gov.uk/environment/climatechange/trading/index.htm 2002a)

UNITED KINDGOM. Department for Environment, Food \& Rural Affairs. Emissions Trading Scheme Auction. http://www.defra.gov.uk/environment/climatechange/trading/auctionwin.htm 
Apr. 2002b)

UNITED NATIONS FRAMEWORK CONVENTION ON CLIMATE CHANGE UNFCCC. Convenção sobre Mudança do Clima. 2.ed. Brasília: MCT, 2001a. $30 \mathrm{p}$.

UNITED NATIONS FRAMEWORK CONVENTION ON CLIMATE CHANGE UNFCCC. Protocolo de Quioto. 2.ed. Brasília: MCT, 2001b. 34p.

UNITED NATIONS FRAMEWORK CONVENTION ON CLIMATE CHANGE UNFCCC. Overview of Project Activity Cycle. http://unfccc.int/cdm/dmprojslide.html (15 Nov. 2002c)

UNITED NATIONS FRAMEWORK CONVENTION ON CLIMATE CHANGE UNFCCC. Draft decision -/CMP.1: land use, land-use change and forestry (FCCC/CP/2001/13/Add.1). http://unfccc.int/ (15 Nov. 2002d)

UNITED NATIONS FRAMEWORK CONVENTION ON CLIMATE CHANGE UNFCCC. Activities Implemented Jointly (AIJ). http://unfccc.int/program/coop/aij/aijproj.html (15 Nov. 2002e)

UNITED NATIONS FRAMEWORK CONVENTION ON CLIMATE CHANGE UNFCCC. Views from parties on issues related to modalities for the inclusion of afforestation and reforestation project activities under the clean development mechanism in the first commitment period (FCCC/SBSTA/2002/MISC.22). http://unfccc.int/ (15 Nov. 2002f)

VROLIJK, C.; GRUBB, M. Quantifying Kyoto: how will COP 6 decisions affect the market? In: WORKSHOP QUANTIFYING KYOTO, London, 2000. Report. London: Royal Institute of International Affairs, 2000. 11p.

WORLD RESOURCE INSTITUTE - WRI. Forest and land-use change carbon sequestration projects. http://www.wri.org/wri/climate/sequester.html $(30$ mar. 2002) 


\section{APÊNDICES}




\section{APÊNDICE 1 - Memória de cálculo das emissões desta tese.}

Os cálculos aqui apresentados são uma estimativa das emissões causadas pelo autor nas principais viagens nacionais e internacionais que foram realizadas para buscar informações que pudessem auxiliar na realização deste trabalho. Para tanto foi utilizado os programas de cálculo presentes nos sites: www.safeclimate.net/calculator $\mathrm{e}$ www.futureforests.com/calculators:

\begin{tabular}{|c|c|c|c|c|}
\hline Evento & $\begin{array}{c}\text { Emissões } \\
\mathrm{Kg} \mathrm{CO}_{2} \\
\end{array}$ & $\begin{array}{l}\text { Viagens } \\
\text { Avião } \\
(\mathrm{km})\end{array}$ & $\begin{array}{l}\text { Viagens } \\
\text { Carro } \\
(\mathrm{km}) \\
\end{array}$ & Offset \\
\hline $\begin{array}{l}2000 \text { - Task forces on early start projects for carbon emission } \\
\text { reductions; } 22 \text { a } 24 \text { de junho, São Paulo. }\end{array}$ & 129 & & 300 & 1 \\
\hline $\begin{array}{l}2000 \text { - Brazil/U.S. Aspen Global Forum - Implementation of } \\
\text { carbon emission reduction projects \& development of climate } \\
\text { change policies; } 10 \text { a } 12 \text { de agosto; São Paulo. }\end{array}$ & 129 & & 300 & 1 \\
\hline $\begin{array}{l}2000 \text { - O setor financeiro e o meio ambiente, } 17 \text { de agosto, Rio de } \\
\text { Janeiro. }\end{array}$ & 130 & 718 & & 1 \\
\hline $\begin{array}{l}\text { 2001- I Simpósio Ibero-Americano de Gestão e Economia } \\
\text { Florestal; } 04 \text { a } 07 \text { de julho, Porto Seguro. }\end{array}$ & 400 & 2.246 & & 1 \\
\hline $\begin{array}{l}2001 \text { - UNFCCC - Conference of the Parties - COP } 6 \text { Part II; } 16 \text { a } \\
27 \text { de julho, Bonn Alemanha. }\end{array}$ & 2.190 .000 & 19.908 & & 3 \\
\hline $\begin{array}{l}2001 \text { - 5th UNCTAD/Earth Council Policy Fórum on Trade and } \\
\text { Climate Change: The State of the Greenhouse Gás (GHG) Market, } \\
29-31 \text { de Agosto, Rio de Janeiro. }\end{array}$ & 130 & 718 & & 1 \\
\hline $\begin{array}{l}2001 \text { - 5th Annual Fall Meeting \& hternational Conference } \\
\text { Emissions Marketing Association, } 30 \text { de Setembro a } 2 \text { de Outubro, } \\
\text { Carolina do Sul. }\end{array}$ & 2.130 .000 & 19.364 & & 3 \\
\hline $\begin{array}{l}2001 \text { - UNFCCC - Conference of the Parties - COP 7; } 29 \text { de } \\
\text { Outubro a } 10 \text { de Novmebro, Marrakesh, Marrocos. }\end{array}$ & 2.080 .000 & 18.932 & & 3 \\
\hline $\begin{array}{l}2001 \text { - I Curso A Ecologia do Ciclo do Carbono, } 8 \text { a } 15 \text { de } \\
\text { Dezembro, Brasília. }\end{array}$ & 310 & 1.748 & & 1 \\
\hline $\begin{array}{l}2002 \text { - Rio } 02 \text { World Climate \& Energy Event, } 6 \text { a } 10 \text { de Janeiro, } \\
\text { Rio de Janeiro. }\end{array}$ & 130 & 718 & & 1 \\
\hline $\begin{array}{l}2002 \text { - Seminário: O Acordo de Marrakesh e seus efeitos sobre } \\
\text { projetos de MDL no Brasil, } 14 \text { de Janeiro, São Paulo. }\end{array}$ & 129 & & 300 & 1 \\
\hline $\begin{array}{l}2002 \text { - National Round Table on the Environment and the } \\
\text { Economy, } 30 \text { e } 31 \text { de Janeiro, Toronto. }\end{array}$ & 2.000 .000 & 18.214 & & 3 \\
\hline $\begin{array}{l}2002 \text { - UNEP Finance Initiatives - Innovative financing for } \\
\text { sustainability, } 14 \text { e } 15 \text { de Março, Rio de Janeiro. }\end{array}$ & 130 & 718 & & 1 \\
\hline $\mid \begin{array}{l}2002-4 . \text { Semana de Meio Ambiente FIESP/CIESP } \\
\text { Desenvolvimento e Sustentabilidade, } 03 \text { a } 07 \text { de Junho, São Paulo. }\end{array}$ & 129 & & 300 & 1 \\
\hline 2002 - Fórum de Energia Limpa, 29 e 30 de & 130 & 718 & & 1 \\
\hline
\end{tabular}




\begin{tabular}{|l|c|c|c|c|}
\hline 2002 - Apresentação dos Relatórios de Referência para o & & & & \\
$\begin{array}{l}\text { Inventário Brasileiro de Emissões Antrópicas Líquidas de Gases de } \\
\text { Efeito estufa não controlados pelo Protocolo de Montreal, 13,14 e } \\
15 \text { de Agosto de 2002, Ministério das Relações Exteriores, }\end{array}$ & & & & \\
Brasília.
\end{tabular}

Fonte: Cálculos do autor. 


\section{APÊNDICE 2 - Países membros do ANEXO I.}

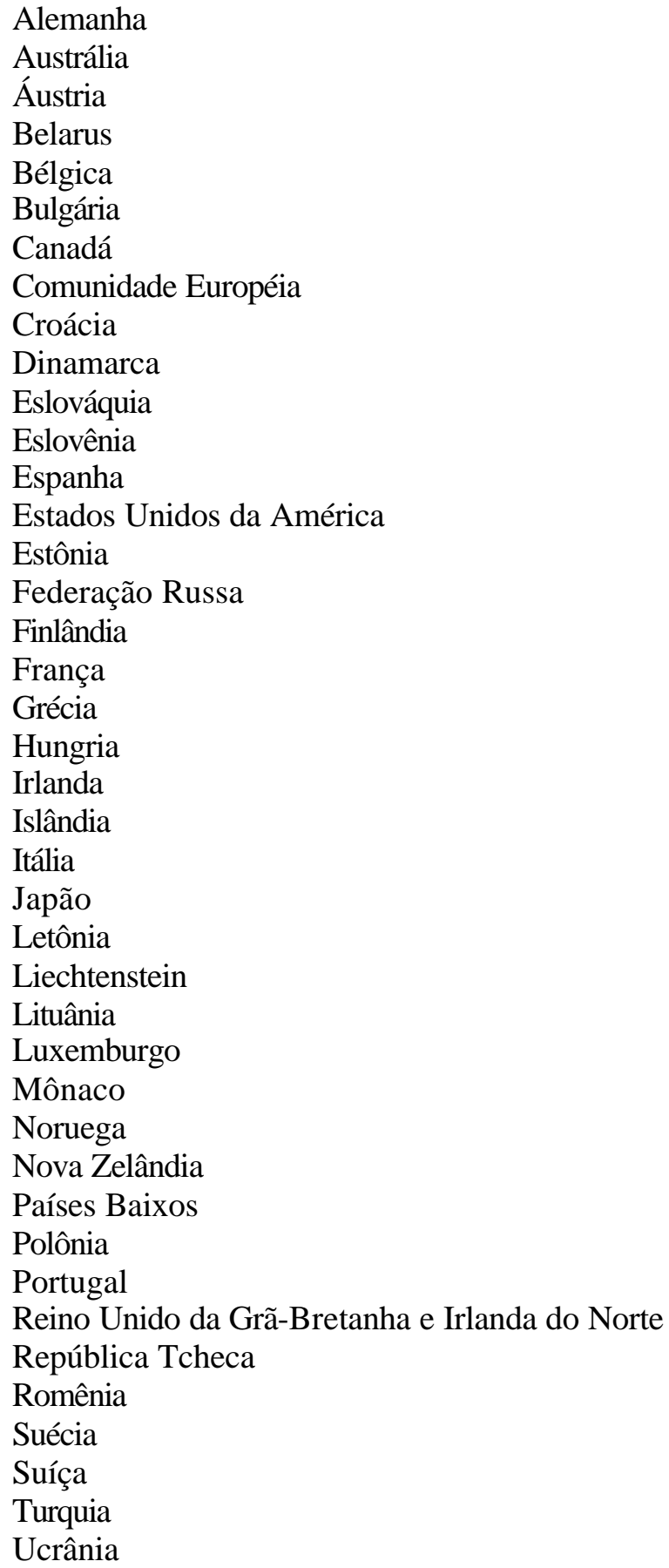

Fonte: Adaptado de UNFCCC (2001a) 


\section{APÊNDICE 3 - Compromisso de redução ou limitação quantificada de emissões (porcentagem do ano base ou período).}

$\begin{array}{lc}\text { Alemanha } & 92 \\ \text { Austrália } & 108 \\ \text { Áustria } & 92 \\ \text { Bélgica } & 92 \\ \text { Bulgária* } & 92 \\ \text { Canadá } & 94 \\ \text { Comunidade Européia } & 92 \\ \text { Croácia* } & 95 \\ \text { Dinamarca } & 92 \\ \text { Eslováquia* } & 92 \\ \text { Eslovênia* } & 92 \\ \text { Espanha } & 92 \\ \text { Estados Unidos da América } & 93 \\ \text { Estônia* } & 92 \\ \text { Federação Russa* } & 100 \\ \text { Finlândia } & 92 \\ \text { França } & 92 \\ \text { Grécia } & 92 \\ \text { Hungria* } & 94 \\ \text { Irlanda } & 92 \\ \text { Islândia } & 110 \\ \text { Itália } & 92 \\ \text { Japão } & 94 \\ \text { Letônia* } & 92 \\ \text { Liechtenstein } & 92 \\ \text { Lituânia* } & 92 \\ \text { Luxemburgo } & 92 \\ \text { Mônaco } & 92 \\ \text { Noruega } & 101 \\ \text { Nova Zelândia } & 100 \\ \text { Países Baixos } & 92 \\ \text { Polônia* } & 94 \\ \text { Portugal } & 92 \\ \text { Reino Unido da Grã-Bretanha e Irlanda do Norte } & 92 \\ \text { República Tcheca* } & 92 \\ \text { Romênia* } & 92 \\ \text { Suécia } & 92 \\ \text { Suíça } & 92 \\ \text { Ucrânia* } & 100 \\ & \end{array}$

Fonte: UNFCCC (2001b)

* Países em processo de transição para uma economia de mercado. 


\section{APÊNDICE 4 - Roteiro de Suporte para a Avaliação de Critérios e Indicadores de Elegibilidade de Projetos Candidatos ao Mecanismo de Desenvolvimento Limpo (MDL).}

\section{A - Descrição sumária do projeto}

O projeto deve ser apresentado de forma sumária e em formato livre. Porém, esta primeira descrição deve conter as seguintes informações básicas: dados do proponente; objetivo, localização e dimensão do projeto, tempo de duração, gás de efeito estufa a ser evitado ou sequiestrado e atores envolvidos.

\section{B - Informações para análise}

Este roteiro tem o objetivo de auxiliar a operacionalização da análise dos projetos.

\section{B.1 - Critérios de elegibilidade}

\section{Critério 1: Setores de atividade de projetos qualificáveis para o MDL}

Descreva, sucintamente, a atividade do projeto.

\section{Critério 2: Benefícios reais e mensuráveis e cenário de referência}

Fornecer os dados de entrada para o cálculo das emissões evitadas/seqüestradas em carbono equivalente e descrição da metodologia utilizada.

Como será realizado o monitoramento das emissões ao longo da duração do projeto?

Quais os elementos que foram considerados para a definição do cenário de referência?

\section{Critério 3: Adicionalidade financeira}

Integral ou parcialmente, o financiamento do projeto provém de algum organismo de assistência ambiental e/ou de desenvolvimento internacional? Os recursos são provenientes de algum fundo internacional específico de MDL?

Informar a participação percentual e dados básicos dos financiadores.

\section{Critério 4: Adicionalidade de investimento}

Por que o projeto não seria executado sem o MDL?

Quais são as barreiras e/ou riscos que podem estar associadas à implantação do projeto? 
Qual é o grau de pioneirismo do projeto?

Existe algum custo de transação inerente ao projeto?

\section{B.2 - Indicadores para priorização}

\section{Indicador 1: Contribuição para a mitigação das mudanças climáticas globais}

Qual é a redução líquida de GEE apresentada pelo projeto em relação ao cenário de referência, de acordo com as informações solicitadas no Critério 2?

\section{Indicador 2: Contribuição para a sustentabilidade ambiental local}

Quais são, qualitativa e quantitativamente, as emissões locais de poluentes sólidos, líquidos e/ou gasosos (de não efeito estufa) associadas ao projeto? Como seriam estas no cenário de referência? Qual é o plano de monitoramento e controle destas emissões?

Indicar e descrever outros impactos ambientais associados ao projeto, tais como:

- poluição sonora;

- poluição visual;

- erosão do solo;

- contaminação de recursos hídricos;

- perda da biodiversidade;

- áreas inutilizadas.

Quais são as características de ocupação antrópica (residencial, comercial, industrial e agrícola) e de localização ambiental (proximidade de recursos hídricos e de florestas nativas) na área de influência do empreendimento?

\section{Indicador 3: Contribuição para a geração líquida de empregos}

Qual é o número de empregos, diretos e indiretos, gerados pelo projeto, em relação ao cenário de referência? Indicar o tipo de qualificação, duração, nível de insalubridade e periculosidade, e nível de salários dos empregos.

\section{Indicador 4: Impactos na distribuição de renda}

Quais são os impactos distributivos do projeto para a população de baixa renda em comparação com o cenário de referência? Por exemplo, o projeto irá proporcionar o fornecimento de energia elétrica a comunidades que antes não eram atendidas por este serviço? 


\section{Indicador 5: Contribuição para a sustentabilidade da balança de pagamento}

Quais são os gastos em bens e serviços importados a serem utilizados no cenário do projeto? E no cenário de referência? Os bens e serviços importados são adquiridos diretamente no exterior ou são adquiridos por meio de intermediários nacionais?

Qual o valor despendido em royalties e em licenças tecnológicas, caso existam? Qual a frequiência e os gastos com assistência técnica internacional, caso exista?

\section{Indicador 6: Contribuição para a sustentabilidade macroeconômica}

O proponente tem informações sobre uma possível redução direta de investimentos públicos e subsídios evitados em decorrência da implementação do projeto?

\section{Indicador 7: Custo-efetividade}

Para a análise deste indicador, fornecer as seguintes informações referentes aos cenários de projeto e de referência:

- Investimento inicial;

- Vida útil;

- Prazo de construção;

- Custo de operação e manutenção;

- Receita (com o fornecimento de dados que a fundamentem).

Para projetos no setor energético, além das informações acima, fornecer:

- Custo de combustível;

- Capacidade instalada;

- Fator de capacidade;

- Rendimento.

\section{Indicador 8: Contribuição para a auto-suficiência tecnológica}

Para a avaliação deste indicador são necessárias as informações requisitadas no indicador 5, excetuando-se as referentes aos insumos (como combustíveis).

XIII. Maximização dos benefícios do proprietário do projeto e do país não-ANEXO I

Como será feita a distribuição dos CER gerados pelo projeto?

XIV. Possibilidades de integração regional e articulação com outros setores 
Existe a possibilidade de associações com Ecopolos regionais e com programas socioambientais regionais como reciclagem e aproveitamento de resíduos?

Existe articulação entre o projeto e setores de pesquisa e desenvolvimento, associações, fabricantes de equipamentos, fornecedores de insumos e outros setores que possuam alguma possibilidade de integração? Em que nível se desenvolve esta articulação?

Das articulações referidas acima, quais que se encontram no âmbito regional.

\section{Potencial de inovação tecnológica}

A tecnologia utilizada no projeto é pioneira no país?

Qual é o potencial de replicabilidade da tecnologia empregada no projeto?

Qual a capacidade de adaptação e o grau de domínio do uso da tecnologia adquirida por parte do receptor?

Fonte: Brasil (2002) 


\section{APÊNDICE 5 - Lista dos mercados de carbono existentes (Fonte: adaptado de http://www.ieta.org)}

\section{Austrália}

País: Austrália

Tipo: Sistema nacional de "cap and trade".

Começo: Sem previsão, dada a não ratificação do Protocolo de Quioto pela Austrália.

Período de Cumprimento: Nenhuma informação disponível.

Relação com outros mercados: Créditos de projetos de MDL e JI serão reconhecidos, em adição aqueles associados com seqüestro de $\mathrm{C}$.

Metas: Nenhuma informação disponível.

Abrangência Todos GEE expressos como $\mathrm{CO}_{2} \mathrm{e}$.

Participação: O sistema irá cobrir os participantes do "Australian Greenhouse Office's Greenhouse Challenge" (http://www.greenhouse.gov.au/challenge), o que equivale a $25 \%$ das emissões nacionais de GEE. O sistema será focado em grandes emissores e empresas de energia.

\section{Alocação: \\ “Banking” e empréstimo:}

Monitoramento e registro: O sistema proposto irá usar o manual para monitoramento e registro do "Australian Greenhouse Office (AGO) Greenhouse Challenge", com verificação independente dos inventários de emissão.

Mecanismos de cumprimento: Nenhuma sugestão foi feita, aguardando o desenvolvimento do sistema internacional.

Regime de cumprimento: Nenhuma sugestão foi feita, aguardando o desenvolvimento do sistema internacional.

Taxas e custos de transação: Nenhuma informação disponível.

Outros: De acordo com jornais o ministro do meio ambiente australiano David Kemp planeja engajar grupos ambientalistas e de empresários no desenvolvimento do sistema.

\section{Maiores informações:}

Australian Greenhouse Office (AGO) - http://www.greenhouse.gov.au

AGO Emissões Trading Team - http://www.greenhouse.gov.au/emissõestrading

AGO Greenhouse Challenge - http://www.greenhouse.gov.au/challenge

Australasian Emissions Trading Forum - $\underline{\text { http://www.aetf.net.au }}$

Última atualização

20 Agosto 2002 


\section{Austrália - New South Wales NSW}

País: Austrália (New South Wales)

Tipo: Comércio de emissões baseado em um programa existente de redução de emissões associado com licenças de distribuição de eletricidade.

Começo: 1 Janeiro 2003.

Período de Cumprimento: Metas são estabelecidas anualmente.

Relação com outros mercados: Créditos de seqüestro de carbono são permitidos no sistema. A floresta tem que estar na Austrália e atender as regras sobre "sinks" do Protocolo de Quioto, assim como as regras do "NSW Framework on Carbon Sequestration".

Metas: O sistema requer que os distribuidores de energia reduzam as emissões de GEE em 5\% abaixo do níveis de 1990 por capta e manter as emissões neste novo nível, ou abaixo dele, até 2012. Devido ao aumento da população haverá um aumento nas metas de 2007 até 2012 . Reduções totais em 2012 serão de aproximadamente $13 \mathrm{M} \mathrm{t} \mathrm{CO}_{2}$ e abaixo das emissões "BAU”. As metas anuais serão:

\begin{tabular}{|l|l|l|l|l|l|l|l|l|l|l|}
\hline Ano & $\mathbf{2 0 0 3}$ & $\mathbf{2 0 0 4}$ & $\mathbf{2 0 0 5}$ & $\mathbf{2 0 0 6}$ & $\mathbf{2 0 0 7}$ & $\mathbf{2 0 0 8}$ & $\mathbf{2 0 0 9}$ & $\mathbf{2 0 1 0}$ & $\mathbf{2 0 1 1}$ & $\mathbf{2 0 1 2}$ \\
\hline $\mathrm{t} \mathrm{CO}_{2} \mathrm{e} /$ capita & 8,65 & 8,31 & 7,62 & 7,27 & 7,27 & 7,27 & 7,27 & 7,27 & 7,27 & 7,27 \\
\hline Total $\mathrm{M} \mathrm{t} \mathrm{CO} \mathrm{CO}_{2} \mathrm{e}$ & 57,9 & 56,3 & 54,4 & 52,7 & 50,7 & 51,2 & 51,6 & 52,1 & 52,6 & 53,1 \\
\hline
\end{tabular}

Abrangência Todos os GEE expresso em uma tonelada de $\mathrm{CO}_{2} \mathrm{e}$.

Participação: Participação é compulsória para os distribuidores de energia de NSW, e estenderá para os atacadistas e consumidores diretos.

Alocação: Cada participante tem uma obrigação de redução anual. Eles podem cumprir estas metas através da mudança por tecnologias de geração de energia que sejam menos intensivas em carbono, reduzindo o consumo de energia de seus clientes ou comprando créditos de seqüestro de carbono.

“Banking" e empréstimo: Existe limites para "banking”. Créditos de seqüestro de carbono não pode ser usados no futuro.

Monitoramento e registro: O "Independente Pricing and Regulatory Tribunal" (http://www.ipart.nsw.gov.au) é responsável por licenciar o mo nitoramento, e será também responsável pelas penalidades de não cumprimento. Haverá verificação independente dos créditos de seqüestro de carbono, e auditorias a cada dois anos das metodologias utilizadas para mensurar o seqüestro de carbono.

Mecanismos de cumprimento: O sistema irá operar com penalidades financeiras, não superiores a AUS\$15 (aproximadamente US\$8.5) por tonelada de $\mathrm{CO}_{2} \mathrm{e}$ emitida. Esta penalidade está acima dos custos marginais de cumprimento.

Regime de cumprimento: Vendedores serão forçados em manter registro do seqüestro de carbono a fim de validar os créditos guardados ou vendidos.

Taxas e custos de transação: Nenhuma informação é dada, mas espera-se obter custos mínimos de transação.

Maiores informações: 
Ministry of Energy and Utilities - Government of New South Wales - http://www.energia.nsw.gov.au Australasian Emissions Trading Forum - $\underline{\text { htp: } / / \text { www.aetf.net.au }}$

Última atualização

25 Julho 2002.

\section{BP}

País: Unidades da BP ao redor do mundo.

Tipo: Sistema de comércio interno na empresa.

Começo: Iniciou em Janeiro de 2000 após um período de experiência em 12 unidades de setembro de 1998 até dezembro de 1999.

Período de Cumprimento: Metas anuais para o período de 2000-2010.

\section{Relação com outros mercados:}

Metas: Redução de 10\% até 2010 em relação aos níveis de 1990, o que equivale a uma redução de 9 M t $\mathrm{CO}_{2} \mathrm{e}$. Uma taxa de redução anual de $2 \%$ foi estabelecida para 2001 a fim de distribuir as permissões.

Abrangência $\mathrm{CO}_{2} \mathrm{e} \mathrm{CH}_{4}$, excluindo as emissões da compra de energia e calor.

Participação: Obrigatória para todas as unidades da BP no mundo.

Alocação: Cada Unidade de Negócios recebeu permissões referentes às emissões do grupo em 2001 baseadas na redução anual de $2 \%$.

"Banking" e empréstimo: 5\% das permissões podem ser guardadas. Empréstimos não serão permitidos para futuras permissões.

Monitoramento e registro: O sistema da BP é operado pelo "BP Integrated Supply and Trading Group", que registra e monitora todas as transações. Os dados são operados através de uma Intranet.

Mecanismos de cumprimento: Cada Unidade de Negócio tem um contrato de performance que precisa ser cumprido. O relatório de cumprimento deve conter dados financeiros.

Regime de cumprimento: Nenhuma informação dada.

Taxas e custos de transação: A estrutura do sistema, baseada no monitoramento via intranet, garante que os custos de transação sejam mantidos baixos.

Outros: BP estima que as reduções de emissões de GEE trarão benefícios econômicos de US\$ 650 milhões.

\section{Maiores informações:}

$\mathrm{BP}$ information centre on climate change -

http://www.bp.com/environ social/environment/climate change/info centre

BP's ET System-

http://www.bp.com/environ social/environment/climate change/emmisions trad/bp et sys.asp 
Última atualização

25 Julho 2002.

\section{Canadá - CleanAir Canadá}

País: Canadá

Tipo: O "Pilot Emissions Reduction Trading Project" (PERT), agora chamado de CleanAir, é uma organização sem fins lucrativos, que permite aos seus membros o registro e comércio de redução de emissões.

Começo: PERT começou em 1996, com revisão e registro de emissões de $\mathrm{CO}_{2}$ de 1998. CleanAir se tornou operacional em setembro de 2000.

Período de Cumprimento: Não aplicável para este sistema.

Relação com outros mercados: Não existe relações pré-estabelecidas. Veja "Canada's MDL and JI Office" para maiores informações (http://www.dfait-maeci.gc.ca/MDL-ji).

Metas: Existem 50 projetos (18 com apenas $\mathrm{CO}_{2} \mathrm{e}$ ) totalizando $16,4 \mathrm{M} \mathrm{t} \mathrm{CO}_{2} \mathrm{e}$, com outros 22 aplicações

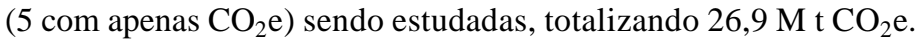

Abrangência Vários poluentes $\left(\mathrm{CO}_{2}, \mathrm{CO}, \mathrm{VOC}, \mathrm{SO}_{2}\right.$, Ozônio NOx, e Não-Ozônio NOx). Todos GEE são convertidos para $\mathrm{CO}_{2}$ equivalente.

Participação: Voluntária.

Alocação: Aplicações precisam ser submetidas para CleanAir para revisão. A equipe de revisão aceita, ou sugere modificações. Uma vez aceitada os créditos são registrados.

“Banking” e empréstimo: As reduções registradas nos PERT serão reconhecidas na província de Ontário para futuros compromissos.

Monitoramento e registro: Registro e monitoramento dos créditos dos projetos são feitos em um fórum aberto mantido pelo CleanAir. Registro será feito através de um Protocolo descrevendo o projeto. Um relatório anual descreve a quantidade de reduções alcançadas.

Mecanismos de cumprimento: Não aplicável a este sistema.

Regime de cumprimento: $O$ sistema não verifica ou certifica créditos, mas deixa para o comprador verificar a qualidade dos créditos comercializados.

Taxas e custos de transação: Nenhuma informação dada.

Maiores informações:

CleanAir Canada - http://www.cleanaircanada.org

The CleanAir Canada Registry (free registration required) - http://www.epregistry.com/cacir

Canada's MDL e JI Office - http://www.dfait-maeci.gc.ca/MDL-ji

Última atualização

25 Julho 2002. 


\section{Canadá - GERT}

País: Canadá

Tipo: O "Greenhouse Gas Emis sions Reduction Trading Pilot" (GERT) é uma associação onde os participantes podem registrar projetos de redução de emissões e comercializar créditos. Projetos registrados através do GERT are registrados também no "Climate Change Voluntary Challenge \& Registry Inc. (VCR Inc.) - http://www.vcr-mvr.ca.

Começo: O piloto começou em junho de 1998 e irá terminar em 2002. Projetos revisados e as reduções registradas serão mantidas pela VCR Inc.

Período de Cumprimento: Não aplicável a este sistema.

Relação com outros mercados: Projetos pilotos podem ser estabelecidos em qualquer lugar do mundo, desde que o comprador ou o vendedor sejam canadenses. Reduções de emissões de projetos de MDL e/ou JI podem em teoria ser incluídos no sistema.

Metas: 4 projetos comercializados pelo GERT através da VCR Inc tem metas de redução de 325.000 toneladas $\mathrm{CO}_{2} \mathrm{e}$. Existem 5 projetos registrados que ainda não atraíram compradores.

Abrangência Todos GEE convertidos para $\mathrm{CO}_{2} \mathrm{e}$.

Participação: Participação é voluntária. GERT tem um total de 11 participantes não governamentais e 10 governamentais.

Alocação: Projetos são submetidos para GERT revisados por um comitê técnico para garantir que as redução de emissões são mensuráveis, verificáveis de acordo com as regras do sistema. Caso o projeto seja aceito as reduções são registradas e podem ser comercializadas.

"Banking" e empréstimo: Banking de créditos é permitido, mas seu uso fica sujeito às regras futuras do Canadá.

Monitoramento e registro: $\mathrm{O}$ registro no GERT é mantido pelo "Climate Change Voluntary Challenge \& Registry Inc. (VCR Inc.) - http://www.vcr-mvr.ca

Mecanismos de cumprimento: Não aplicável a este sistema.

Regime de cumprimento: Nenhuma informação dada.

Taxas e custos de transação: Nenhuma informação dada.

Maiores informações:

GERT - http://www.gert.org

GERT Registry at VCR Inc. - http://www.vcr-mvr.ca/gert

Última atualização

25 Julho 2002.

\section{Canadá - PERT}


País: Ver CleanAir Canadá

Tipo: Ver CleanAir Canadá

Começo: Ver CleanAir Canadá

Período de Cumprimento: Ver CleanAir Canadá

Relação com outros mercados:Ver CleanAir Canadá

Metas: Ver CleanAir Canadá

Abrangência Ver CleanAir Canadá

Participação: Ver CleanAir Canadá

Alocação: Ver CleanAir Canadá

“Banking” e empréstimo: Ver CleanAir Canadá

Monitoramento e registro: Ver CleanAir Canadá

Mecanismos de cumprimento: Ver CleanAir Canadá

Regime de cumprimento: Ver CleanAir Canadá

Taxas e custos de transação: Ver CleanAir Canadá

Outros: Ver CleanAir Canadá

Maiores informações: Ver CleanAir Canadá

Última atualização

30 Julho 2002.

\section{Canadá - TPWG/DETWG}

País: Canadá

Tipo: O “Tradable Permits Working Group (TPWG)" entregou seu relatório final em abril de 2000, apresentado uma proposta para um sistema de comércio doméstico de emissões para o Canadá. O estudo feito pelo TPWG continuou através do "Domestic Emissions Trading Working Group (DETWG)", que realizou até agora 3 reuniões para definição das características do sistema.

Começo: Um sistema com começo previsto para 2005 e um sistema começando com o primeiro período de compromisso do Protocolo de Quioto estão sendo discutidos.

Período de Cumprimento: Nenhuma decisão foi tomada, mas um sistema com cumprimentos anuais é esperado.

Relação com outros mercados: Nenhum consenso foi alcançado. 
Metas: Nenhuma decisão foi tomada.

Abrangência $\mathrm{O}$ TPWG sugeriu um sistema apenas de $\mathrm{CO}_{2}$, com a possibilidade de abranger outros GEE depois.

Participação: O TPWG sugeriu o use de uma abordagem "upstream" no uso de combustíveis fósseis, o DETWG discutiu 4 modelos diferentes. Dois sistemas com participação voluntária, um cobrindo os grande emissores e outro cobrindo os emissores finais, o terceiro sistema com participação obrigatória para grande emissores finais, e finalmente uma sistema voluntário onde os participantes seriam determinados por um sistema de comércio de 2008. Nenhum consenso foi alcançado, mas existe uma tendência de focar nos grandes emissores finais, responsáveis por aproximadamente $48 \%$ do total de emissões GEE).

Alocação: O TPWG propôs o uso de leilões com permissões grátis adicionais. O DETWG considerou leilões, permissões grátis, e a combinação de ambos sugerida pelo TPWG. Nenhum consenso foi alcançado.

“Banking” e empréstimo: Nenhum consenso foi alcançado.

Monitoramento e registro: O DETWG recomenda o desenvolvimento de instituições, tais como as de monitoramento, verificação e certificação.

Mecanismos de cumprimento: Duas opções são discutidas: perda de incentivos e penalidade financeiras. Nenhuma preferência foi expressa.

Regime de cumprimento: Nenhuma informação disponível.

Taxas e custos de transação: Nenhuma informação disponível.

Outros: O DETWG reconhece que o Canadá precisa iniciar um sistema de comércio o quanto antes. No momento este trabalho depende da ratificação por parte do Canadá.

Maiores informações:

National Climate Change Process - http://www.nccp.ca

National Round Table on the Environment and the Economy - http://www.nrtee-trnee.ca

Environment Canada's Green Lane - http://www.ec.gc.ca

Última atualização

02 Outubro 2002.

\section{República Techca JI}

País: República Techca

Tipo: Joint Implemantation.

Começo: As regras foram aprovadas em janeiro de 2002.

Período de Cumprimento: 2008-2012.

Relação com outros mercados: Créditos de projeto de JI na República Techca podem ser usados de acordo com as regras do Protocolo de Quioto e em sistemas domésticos onde as regras permitem a inclusão de créditos. 
Metas: Aproximadamente $2 \mathrm{M}$ t CO2e foram alocados anualmente para o período de 2008-2012 ( 10M t no total).

Abrangência: O programa abrange todos GEE expressos em 1 tonelada de CO2e.

Participação: Projetos ou grupos de projetos precisam levar em consideração as leis Techcas e não podem causar poluição no ar, argua, e solo.Áreas prioritárias para projetos são: utilização de energia renovável, conservação de energia em aquecimento de prédios públicos, economia de energia em prédios residenciais, aproveitamento de biogás de aterros, transporte público limpo, e outros projetos que reduzam emissões de GEE.

Alocação: O seleção de contratos é feita pelo governo. Projetos tem que provar as reduções anuais de GEE, o preços das ERU, benefícios econômicos e ambientais do projeto, adicionalidade e cumprimento das leis,.

“Banking” e empréstimo: Permitido de acordo com as regras do Protocolo de Quioto.

Monitoramento e registro: Nenhuma informação disponível.

Mecanismos de cumprimento: Não aplicável.

Regime de cumprimento: Nenhuma informação disponível.

Taxas e custos de transação: Nenhuma informação disponível.

Outros: O "National Reference Centre for AIJ/JI" preparou "guidelines" para a submissão de projetos e estará publicando este material em breve.

Maiores informações:

Ministry of the Environment - http://www.env.cz

Última atualização

25 Julho 2002.

\section{Dinamarca}

País: Dinamarca

Tipo: Sistema nacional de "cap and trade". Base legal no " $\mathrm{CO}_{2}$ Quota Act" de 2001.

Começo: 2001 (previsto para 2000).

Período de Cumprimento: 2001-2003.

Relação com outros mercados: O sistema a princípio está aberto para a inclusão de créditos de JI ou MDL, mas até o momento nenhum foi incluído. Um manual detalhando os procedimentos para aprovação dos créditos foi publicada pela "Danish Energy Agency" em maio de 2002 e está disponível na Web. A primeira transação ocorreu entre a Shell (UK) e Elsam (Dinamarca) em maio de 2002.

Metas: $22 \mathrm{Mt} \mathrm{CO}_{2}$ para 2001, $21 \mathrm{Mt} \mathrm{CO}_{2}$ para 2002, e $20 \mathrm{Mt} \mathrm{CO}_{2}$ para 2003. 
Abrangência $\mathrm{O}$ sistema é para $\mathrm{CO}_{2}$, cobrindo o setor elétrico como um todo e excluindo as empresas de energia que produzem menos de 100.000 toneladas de $\mathrm{CO}_{2}$ por ano. O número total de empresas é 8 (ver tabela abaixo). Mais de $90 \%$ do total das emissões de $\mathrm{CO}_{2}$ decorrentes da produção de eletricidade aproximadamente $\sim 30 \%$ das emissões totais do país - são cobertas pelo sistema.

Participação: Participação é obrigatório para todas as empresas que produzem mais de 100.000 toneladas de $\mathrm{CO} 2$ por ano.

Alocação: Permissões são alocadas baseando-se na média das emissões históricas de 1994-1998 das empresas participantes (30,3 Mt CO2 média anual para o período). Permissões são alocadas por empresas, e não por unidade ou planta. A tabela abaixo mostra a alocação das permissões para o período de cumprimento (em $\mathrm{Mt} \mathrm{CO}_{2}$ ). A alocação para 2003 é preliminar.

\begin{tabular}{|l|c|c|c|}
\hline Empresa & $\mathbf{2 0 0 1}$ & $\mathbf{2 0 0 2}$ & $\mathbf{2 0 0 3}$ \\
\hline Energi E2 A/S & 8,221 & 7,577 & 7,135 \\
\hline Elsam A/S & 10,533 & 9,873 & 9,420 \\
\hline EON/PreussenElektra & 0,965 & 0,838 & 0,751 \\
\hline I/S Avedorevaerket 2 & 0,094 & 0,527 & 0,510 \\
\hline Ostkraft Produktion A/S & 0,062 & 0,060 & 0,058 \\
\hline Energi Reers Prod. A/S & 0,198 & 0,198 & 0,198 \\
\hline Dansk Shell A/S & 0,102 & 0,102 & 0,102 \\
\hline NRGI Amba (Anholt) & 0,001 & 0,001 & 0,001 \\
\hline Sem permissões & 1,825 & 1,825 & 1,825 \\
\hline Total cap & $\mathbf{2 2 , 0 0 0}$ & $\mathbf{2 1 , 0 0 0}$ & $\mathbf{2 0 , 0 0 0}$ \\
\hline
\end{tabular}

“Banking” e empréstimo: Permissões não utilizadas em um ano podem ser utilizadas em anos subseqüentes, com limitações técnicas para 2001 e 2002.

Monitoramento e registro: Os participantes informaram as emissões de $2001 \mathrm{em} 31$ de março de 2002. A decisão final referente ao cumprimento, "banking", e as possíveis penalidades do não cumprimento serão estabelecidas pela "Danish Energia Agency" em 2002. Monitoramento é baseado em sistemas já existentes para consumo de combustíveis e padrões de conversão combustível-CO 2 presentes no "CO2 Quota Act".

Mecanismos de cumprimento: As penalidades por não cumprimento são de US\$ 5 ( 40 DKK) por tonelada de $\mathrm{CO}_{2}$ emitida em excesso. As receitas das penalidades serão investidas em iniciativas de economia de energia.

Regime de cumprimento: $\mathrm{O}$ " $\mathrm{CO}_{2}$ Quota Act" não informa sobre o regime de cumprimento, mas a prática mostra que o sistema operará com responsabilidade do vendedor.

Taxas e custos de transação: Mais informações serão disponibilizadas no futuro.

Outros: O sistema para o período posterior a 2003 será renegociado, baseado nas experiências do sistema atual e das decisões das COPs/MOPs do Protocolo de Quioto.

Maiores informações:

Danish Energy Agency (DEA) - http://www.ens.dk

Publications DEA - $\underline{\mathrm{http}: / / \mathrm{www} . e n s . d k / \mathrm{sw} 419 . \mathrm{asp}}$

Danish Ministry of Environment - http://www.mim.dk 
Última atualização

25 Julho 2002.

EU

País: Comunidade Européia

Tipo: Sistema de "cap and trade".

Começo: Uma fase preliminar de 2005 até o fim de 2007 irá preceder o sistema completo proposto para começar em 2008. A decisão sobre o formato final do sistema é esperada durante a Presidência Dinamarquesa entre julho e dezembro de 2002.

Período de Cumprimento: Permissões correspondentes às emissões atuais devem ser submetidas a cada ano, tanto para o período de 2005 a 2007 como para períodos subseqüentes de compromisso.

Relação com outros mercados: O sistema proposto não prevê a inclusão de créditos de mecanismos nacionais ou internacionais, tais como JI e MDL, porém a Comissão acredita que a eventual inclusão de tais créditos é desejada e as novas regras destes mecanismos está sendo preparada. Relação com outros países não membros da Comunidade será decidida futuramente.

Metas: As reduções de emissões para a fase inicial dependem da alocação: cada Estado membro estabelece para o período, levando em consideração os compromissos assumidos no Protocolo. A Comunidade Européia é de $8 \%$.

Abrangência $\mathrm{O}$ sistema proposto irá trabalhar apenas com $\mathrm{CO}_{2}$ no começo, a inclusão de todos GEE e "sinks" será em 2008.

Participação: Os seguintes setores serão cobertos entre 2005-2007, representando aproximadamente $46 \%$ das emissões de GEE em 2010 e contando com cerca de 4.000 a 5.000 instalações:

Atividades de energia:

- Combustão com a produção acima de 20 MW (exceto incineração de lixo)

- Refinarias de óleo

- Fornos de coque

Produção e processamento de metais ferrosos:

- Instalações para a produção de ferro gusa ou aço (fusão primário ou secundária) com capacidade superior a 2,5 toneladas por hora

Indústria mineral:

- Instalações para a produção de cimento com a capacidade superior a 50 toneladas por dia

- Instalações para a produção de vidro

- Instalações para a produção de produtos cerâmicos

Outras atividades:

- Instalações para a produção de papel e celulose

Alocação: Cada Estado membro irá criar permissões para o primeiro período de compromisso, baseado em um sistema comum. Na fase inicial a alocação será sem custo. Estas permissões terão que ser comunicadas para a Comissão e poderão ser rejeitadas. 
"Banking" e empréstimo: O sistema permite "banking" irrestrito no período inicial (2005-2007). Estados membros são livres para decidir se permissões do período inicial podem ser transferidas para 2008-2012.

Monitoramento e registro: Monitoramento do sistema será feito pela "Community Monitoring Mechanism" (estabelecida pela Decisão 93/389/EEC).

Mecanismos de cumprimento: Uma penalidade para o período de 2005-2007 é proposta em $€ 50$ por tonelada de $\mathrm{CO}_{2}$ ou duas vezes o preço de mercado, aquele que for maior Caso uma empresa falhe na verificação de suas emissões perderá o direito de transferência até que volte a estar em cumprimento.

Regime de cumprimento: Nenhuma informação é dada.

Taxas e custos de transação: Taxas e custos de transação serão determinados pelo mercado.

\section{Outros:}

Maiores informações:

Emissions trading - European Commission - http://europa.eu.int/comm/environment/climat/emission.htm Climate Change - European Commission - http://europa.eu.int/comm/environment/climat/home en.htm

European Environment Agency - http://www.eea.eu.int

Última atualização

25 Julho 2002.

\section{França}

País: França

Tipo: Um acordo voluntário entre indústria e governo para a redução das emissões de GEE. Foi uma alternativa frente a um taxa nacional de energia.

Começo: A base para o acordo foi fechada em julho de 2002.

Período de Cumprimento: Maiores informações no futuro.

Relação com outros mercados: Participantes podem alcançar suas metas através de créditos obtidos via mecanismo de flexibilização de Quioto .

Metas: Estabelecidas em valores absolutos ou em termos relativos à produção. Participantes podem revisar suas metas em casos de "circunstâncias econômicas excepcionais" ou mudanças legais.

\section{Abrangência: Todos GEE.}

Participação: Participação é voluntária.

Alocação: Empresas tem até a metade de 2003 para assinar o acordo e estabelecer suas metas. Emissões indiretas, tais como as de transporte, podem ser incluídas.

"Banking” e empréstimo: Maiores informações no futuro.

Monitoramento e registro: Monitoramento será feito por uma nova associação de indústrias, auditada por um comitê independente. 
Mecanismos de cumprimento: Sanções por não cumprimento das metas serão aplicadas no final de 2004 e 2007. A proposta não menciona penalidades financeiras.

Regime de cumprimento: Maiores informações no futuro.

Taxas e custos de transação: Maiores informações no futuro.

\section{Maiores informações:}

Movement des Enterprises de France - $\underline{\text { http://www.medef.fr }}$

French Ministry of Environment - http://www.environnement.gouv.fr

Última atualização

08 Agosto 2002.

\section{Alemanha}

País: Alemanha

Tipo: Sistema piloto de 3 anos.

Começo: 2005.

Período de Cumprimento: Cumprimento anual no período de 2005 a 2007.

Relação com outros mercados: ERU e CER de projetos de JI e MDL podem ser incluído no sistema assim que regras sobre as inclusões estiverem concluídas.

Metas: O sistema estabelecerá um limite para o participantes, abaixo das emissões "BAU".

Abrangência Todos GEE serão incluídos no sistema. Porém, por razões técnicas espera-se começar apenas com $\mathrm{CO}_{2}$.

Participação: A princípio todos os setores devem integrar o sistema, incluindo o transporte e setores privados, mas a integração será gradual. Nenhuma decisão foi tomada em como incluir as emissões da entrega de eletricidade. Intermediários poderão participar também.

Alocação: A alocação inicial de permissões será feita sem custo, com a distribuição de uma parcela das permissões através leilões, e as receitas destes leilões serão distribuídas entre os participantes. O ano base para a alocação inicial será a media de 1990-1992.

“Banking” e empréstimo: Banking não é mencionado na proposta, mas dada a estrutura proposta para o sistema pode-se assumir que banking será permitido no período de teste.

Monitoramento e registro: Um sistema "padronizado e transparente de monitoramento, verificação e informação" é considerado indispensável, mas nenhum recomendação adicional é dada.

Mecanismos de cumprimento: Uma sistema de sanções para o não cumprimento será introduzido, mas nenhum recomendação adicional é dada.

Regime de cumprimento: Nenhuma informação disponível. 
Taxas e custos de transação: Nenhuma informação disponível.

Outros: A "German Emissions Trading Association" (BVEK - http://www.bvek.de) foi oficialmente registrada. O BVEK pretende promover o conceito de comércio de emissões e os mecanismos do Protocolo de Quioto.

Maiores informações:

German Federal Environment Ministry - http://www.bmu.de/english/fset1024.php

German Emissions Trading Association (BVEK) - $\underline{\text { http://www.bvek.de }}$

Última atualização

08 Agosto 2002.

\section{Japão}

País: Japão

Tipo: Um sistema para a compra de créditos de países estrangeiros. O sistema ainda está sendo preparado.

Começo: Um teste é esperado para 2002.

Período de Cumprimento: Maiores informações no futuro.

Relação com outros mercados: O sistema vai operar como uma mistura de comércio de emissões, projetos de JI e MDL. Os projetos de MDL serão operados pela "New Energy and Industrial Technology Development Organization” (NEDO - http://www.nedo.go.jp/english).

Metas: Japão tem a meta de reduzir em 6\% suas emissões de acordo com o Protocolo de Quioto e planeja que cerca de 1/3 destas reduções (1,6 por cento) seja através de mecanismos de flexibilização.

Abrangência Maiores informações no futuro.

Participação: 20 companhias vão oferecer créditos para o teste do mercado. Estas companhias vão receber ajuda financeira para adquirir capacidade para o comércio. Para participar no sistema as companhias vão ter que submeter planos de redução de emissões para o Ministério da Economia, Comércio e Industria (http://www.meti.go.jp/english) antes de receber os certificados de comércio. Para participar companhias devem submeter um plano de redução de GEE para o ministério antes do fim de 2007. A companhia receber então um certificado provisório.

Alocação: Maiores informações no futuro.

“Banking” e empréstimo: Maiores informações no futuro.

Monitoramento e registro: O Ministério da Economia, Comércio e Industria planeja criar banco de dados do comércio de emissões envolvendo o governo e as empresas.

Mecanismos de cumprimento: Não cumprimento irá resultar na emissão de um certificado e publicação do nome da companhia. Nenhuma multa é planejada para o sistema.

Regime de cumprimento: Maiores informações no futuro.

Taxas e custos de transação: Maiores informações no futuro. 
Outros: O Japão treinar equipes e realizar pesquisas em conjunto para projetos de redução de $\mathrm{CO}_{2}$ na China, Índia, Indonésia, Malásia, Filipinas, Tailândia e Vietnam.

O Ministério do Meio Ambiente anunciou em agosto de 2002 a decisão de pagar a comunidades 50 ien por quilograma de $\mathrm{CO}_{2}$ (aproximadamente US\$ 0,42 por quilograma de $\mathrm{CO}_{2}$ ) reduzido.

Japão e as ilhas do Pacífico acordaram em cooperar na redução de GEE.

Maiores informações:

Ministry of Economy, Trade and Industry - http://www.meti.go.jp/english

New Energy and Industrial Technology Development Organization (NEDO) http://www.nedo.go.jp/english

Ministry of the Environment - http://www.env.go.jp/en

Última atualização

02 Outubro 2002.

\section{Coréia}

País: Coréia

Tipo: Coréia vai estabelecer um mercado nacional em 2004 e adotar um sistema internacional em um estágio posterior.

Começo: 2004.

Período de Cumprimento: Nenhuma informação disponível.

Relação com outros mercados:Nenhuma informação disponível.

Metas: Nenhuma informação disponível.

Abrangência Nenhuma informação disponível.

Participação: Industria manufatureira.

Alocação: Nenhuma informação disponível.

“Banking” e empréstimo: Nenhuma informação disponível.

Monitoramento e registro: Nenhuma informação disponível.

Mecanismos de cumprimento: Nenhuma informação disponível.

Regime de cumprimento: Nenhuma informação disponível.

Taxas e custos de transação: Nenhuma informação disponível

Outros: O sistema fará parte do plano integrado de preço da energia, que será finalizado em junho de 2006. O plano irá expandir o uso de gás natural (LNG) e fixar o uso de energia nuclear a um dados nível. O governo também irá incentivar o uso de energia solar, eólica e células de combustível até o final de 
2004. É esperado que a indústria do carvão tenha uma queda de $20 \%$ na produção em função do plano de energia.

Maiores informações:

Ver Coréia Times (2002 Setembro 19) -

http://www.hankooki.com/times/200209/t2002091917440240110.htm

Última atualização

04 Outubro 2002.

\section{NAFTA}

País: Canadá, México, e EUA.

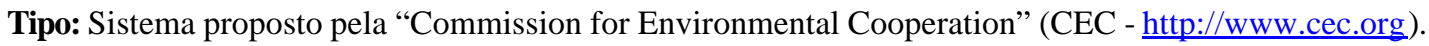

Começo: Nenhuma proposta foi feita.

Período de Cumprimento: Nenhuma proposta foi feita.

Relação com outros mercados: Ficará de fora do Protocolo de Quioto. Relação irá depender de como os sistema fora Quioto irão se relacionar com o Mercado de Quioto.

Metas: Nenhuma proposta foi feita.

Abrangência Nenhuma proposta foi feita.

Participação: Nenhuma proposta foi feita.

Alocação: Nenhuma proposta foi feita.

“Banking” e empréstimo: São considerados essenciais.

Monitoramento e registro: Um sistema de monitoramento e verificação é visto como muito importante.

Mecanismos de cumprimento: Algum tipo de penalidade pelo não cumprimento terá que ser imposta. As penalidades não precisam ser iguais para cada país, mas algum tipo de padronização será necessária. A experiência com $\mathrm{SO}_{2}$ do "Clean Air Act" (Amendments de 1990) sugere que penalidades relativamente elevadas são críticas para a integridade ambiental e econômica.

Regime de cumprimento: Um regime de cumprimento padronizado é considerado essencial.

Taxas e custos de transação: Nenhuma informação disponível.

Outros: O Protocolo de Quioto é claro em dizer que o comércio de emissões e JI podem ocorrer apenas entre signatários do Protocolo. México ratificou o Protocolo em setembro de 2000. Dado que os EUA não ratificar, e a indecisão canadenses, a validade deste sistema é questionável.

\section{Maiores informações:}

Commission for Environmental Cooperation (CEC) of North America - http://www.cec.org

Publications and documents on environmental challenges and opportunities of the North American electricity market (full CEC report and background documents) - 
http://www.cec.org/pubs docs/documents/index.cfm?ID=842

Última atualização

25 Julho 2002.

\section{Holanda}

País: Holanda

Tipo: Mercado nacional ("cap and trade").

Começo: Um estágio inicial irá existir de 2005 até o fim de 2007.

Período de Cumprimento: Permissões anuais.

Relação com outros mercados: Uma regra da Comunidade Européia sobre a inclusão de créditos de projeto de JI e MDL é esperada.

Metas: A proposta original feita pela "Vogtländer Commissie" dividia os participantes em dois setores: um setor com metas absolutas, e outro com metas relativas (baseadas em performance). Ainda não foram decididos qual usar.

Abrangência $\mathrm{O}$ sistema vai levar em consideração inicialmente $\mathrm{CO}_{2}$, mas espera-se que inclua outros GEE, e sinks, em etapas futuras (após 2008).

Participação: O número de participantes na proposta original era bastante ambicioso. Seguindo a proposta européia os participantes serão: atividades de energia, a produção e processamento de metais ferrosos, a indústria de minério, a produção de celulose e papel.

Alocação: Será feita por autoridades nacionais. Seguindo a proposta européia a alocação será feita sem custo no período inicial.

“Banking” e empréstimo: Free banking será permitido no estágio inicial.

\section{Monitoramento e registro:}

Mecanismos de cumprimento: A proposta da Comunidade Européia sugere uma penalidade pelo não cumprimento de $€ 50$ por tonelada $\mathrm{CO}_{2}$ ou o dobro do preço de mercado, o que for maior.

Regime de cumprimento: Nenhuma informação é dada.

Taxas e custos de transação: Nenhuma informação é dada.

\section{Outros:}

Maiores informações:

Dutch Ministry of Housing, Spatial Planning and the Environment (VROM) - $\underline{\text { http://www.minvrom.nl }}$

Última atualização

25 Julho 2002. 


\section{Holanda - CAF}

País: A Holanda e a CAF (Agência de Cooperação Andina).

Tipo: Um acordo entre Holanda e CAF para facilitar a compra de créditos.

Começo: O acordo foi assinado em junho de 2002.

Período de Cumprimento: CAF vai investir projetos nos próximos três anos. Os créditos gerados serão usados no período de 2008-2012.

Relação com outros mercados: Os créditos podem ser usados em sistemas internacionais sujeito a regras para a inclusão de créditos de MDL nestes sistemas e no Protocolo de Quioto.

Metas: gerar créditos no volume superior a 10 M t CO2e nos próximos três anos.

Abrangência $\mathrm{O}$ sistema inclui todos $\mathrm{GEE}$ convertidos em $\mathrm{CO}_{2}$ equivalente.

Participação: setor público e privado localizado em qualquer país membro do CAF, mas também aceitará projetos de paises na América Latina e Caribe que não são membros do CAF.

Alocação: Os projetos submetidos serão avaliados pela CAF, alguns selecionados para validação e registro, um acorde de compra é assinado antes dos pagamentos serem feitos.

“Banking” e empréstimo: O créditos gerado serão usados para o período de compromisso de 2008-2012 e podem ser guardados de acordo com o Protocolo de Quioto.

Monitoramento e registro: $O$ design inicial dos projetos tem que ser validados por um auditor independente.

Mecanismos de cumprimento: Não aplicável a este sistema.

Regime de cumprimento: Nenhuma informação disponível.

Taxas e custos de transação: CAF vai cobrir os custos administrativos.

Outros: CAF criou o "Latin American Carbon Program" (PLAC) em 1999 para auxiliar os países em participar do mercado de carbono.

\section{Maiores informações:}

Andean Development Corporation (CAF) - http://www.caf.com

Official information on MDL na Holanda - $\underline{\text { http://www.MDLinfo.nl e }}$

http://www.caf.com/ingles_old/05c01.asp

Última atualização

13 Setembro 2002.

\section{Holanda - CERUPT}

País: Holanda - investimento em projetos de MDL em países em desenvolvimento na Ásia, África e América Latina. 
Tipo: O "Certified Emission Reduction Units Procurement Tender" (CERUPT) é o programa holandês através do governo são compradas as reduções de emissões de GEE em países não-ANEXO I.

Começo: 2001.

Período de Cumprimento: 2008-2012.

Relação com outros mercados: Os CER do CERUPT podem ser utilizados em sistemas internacionais que aceitam créditos de projetos de MDL.

Metas: Os projetos selecionados para validação no CERUPT 2001 totalizam 32 M t CO2e. Os emissões reduzidas por projeto variam de 0,1 até $6,5 \mathrm{M}$ t CO2e.

Abrangência Todos GEE, expresso em unidades de uma tonelada de CO2e.

Participação: Um total de 80 Cartas de Intenções foram recebidas pelo CERUPT 2001, sendo que 26 projetos foram convidados a preparar um "Projetc Design Document" (ver abaixo). Um total de 13 países hospedeiros foram selecionados: El Salvador (1), Costa Rica (4), Panamá (3), Jamaica (1), Peru (1), Bolívia (1), Brasil (2), Índia (6), Indonésia (2), China (2), Nigéria (1), Kenia (1), e Uganda (1).

O governo holandês assinou recentemente um "Memorand of Understeing" (MoUs; ás vezes chamado de "Host Country agreements") com Colômbia (25 Mt CO2e), Costa Rica (30 Mt CO2e), El Salvador (5 Mt CO2e), Guatemala (10 Mt CO2e) Panamá (20 Mt CO2e), e Peru (30 Mt CO2e). Estes MoUs devem ser seguidos por propostas concretas dos projetos e não são contratos. Porém, indicam interesse do país em participar do programa. Os MoUs servem não apenas para CERUPT, mas também para o CAF, IFC, e IBRD programas.

Alocação: Companhias expressam seu interessem em participar, e algumas são convidadas a submeter uma proposta de projeto. As companhias terão que preparar um PDD incluindo um estuda da linha de base (o deadline para apresentação de PDDs para o CERUPT 2001 foi 26 de setembro de 2002). O PDD tornase público para comentários. Um Estudo de Impacto Ambiental pode fazer parte do processo, se pedido pelo Governo Hospedeiro. A transferência de CER para Holanda precisa ser aprovada pelo Governo Hospedeiro. O governo holandês espera ter os contratos finais para implementação dos projetos até 28 de novembro de 2002.

“Banking” e empréstimo: Os créditos serão utilizados para cumprir com as metas de Quioto, porém "banking" é permitido apenas entre agora e 2008, e entre o primeiro período de compromisso de acordo com as regras do Protocolo de Quioto. Pode haver algum "banking” no segundo período de compromisso.

Monitoramento e registro: Verificação independente do PDD e da linha de base.

Mecanismos de cumprimento: Não aplicável a este sistema.

Regime de cumprimento: $\mathrm{O}$ sistema opera com responsabilidade do vendedor.

Taxas e custos de transação: Carboncredits.nl (http://www.senter.nl/asp/page.asp?alias=erupt) irá cobrir os custos do MDL, porém outros custos precisam ser negociados.

Outros: O período de crédito para projetos de MDL é ou 10 anos fixo, ou 7 anos renováveis com um máximo de 14 anos. Carboncredits.nl recomenda 10 anos para reduzir as incertezas.

\section{Maiores informações:}

Carboncredits.nl - http://www.senter.nl/asp/page.asp?alias=erupt

Oficial information on MDL na Holanda - http://www.MDLinfo.nl 
Point Carbon feature on CERUPT 2001 (17 Julho 2002) -

http://www.pointcarbon.com/article view.php?id=1873

Última atualização

13 Setembro 2002.

\section{Holanda - ERUPT}

País: Holanda - investimento em projetos de JI na Europa Central e do Leste.

Tipo: O "Emission Reduction Units Procurement Tender" (ERUPT) é o programa holandês através do governo são compradas as reduções de emissões de GEE em países ANEXO I.

Começo: 2000.

Período de Cumprimento: Anual, com ciclos de 3 meses (exemplo: edital é lançado, depois de 3 meses os projetos são convidados a preparar o PDD, que devem ser apresentados em 3 meses, e serão analisados em até 3 meses).

Relação com outros mercados: Os ERU do ERUPT podem ser utilizados em sistemas internacionais que aceitam créditos de projetos de JI.

Metas: Um total de $5 \mathrm{M}$ t CO2e foram comprados através do ERUPT 2000. Os projetos selecionados para validação para o ERUPT 2001 totalizam $5 \mathrm{M} \mathrm{t} \mathrm{CO2e,} \mathrm{variando} \mathrm{de} \mathrm{0,5} \mathrm{to} \mathrm{1,6} \mathrm{M} \mathrm{t} \mathrm{CO2e} \mathrm{por} \mathrm{projeto.}$

Abrangência Todos os GEE, expresso em unidades de uma tonelada de CO2e.

Participação: ERUPT 2001 teve 27 cartas de intenções e selecionou 6 projetos para validação. Os projetos estão localizados na: Estônia (1), Eslováquia (1), Hungria (1), Romênia (2), e Nova Zelândia (1).

Alocação: e projeto. As companhias terão que preparar um PDD incluindo um estuda da linha de base. O PDD torna-se público para comentários. Um Estudo de Impacto Ambiental pode fazer parte do processo, se pedido pelo Governo Hospedeiro. A transferência de ERU para Holanda precisa ser aprovada pelo Governo Hospedeiro.

"Banking" e empréstimo: Os créditos serão utilizados para cumprir com as metas de Quioto, porém "banking" de ERU é permitido de acordo com as regras do Protocolo de Quioto segundo as quais projetos de JI só podem gerar créditos para o período de 2008-2012. É importante ressaltar que Senter/Carboncredit.nl estão interessados em "early credits" (antes de 2008).

Monitoramento e registro: Verificação independente do PDD e da linha de base.

Mecanismos de cumprimento: Não aplicável a este sistema.

Regime de cumprimento: Nenhuma informação dada.

Taxas e custos de transação: Nenhuma informação dada.

Outros: ERUPT 3 foi lançado em 25 de outubro de 2002. Cartas de Intenção serão aceitas até 30 de janeiro de 2003.

\section{Maiores informações:}


Carboncredits.nl - $\underline{\text { http://www.senter.nl/asp/page.asp?alias=erupt }}$

Dutch Ministry of Economic Affairs - $\underline{\text { http://www.minez.nl }}$

Última atualização

06 Novembro 2002

\section{Holanda - IBRD}

País: A Holanda e o "International Bank for Reconstruction e Development" (IBRD), membro do "World Bank Group".

Tipo: Um acordo entre a Holanda e O IBRD para facilitar a compra de Créditos de redução de emissões de GEE.

Começo: Assinado em maio de 2002.

Período de Cumprimento: Vai operar por dois anos, com a possibilidade de renovação por mais dois anos. Os créditos gerados serão usados para o período de 2008-2012.

Relação com outros mercados: Os créditos podem ser utilizados em outros sistemas internacionais.

Metas: Mais de $€ 70$ milhões (aproximadamente US\$68 milhões) em projetos de redução de emissões de aproximadamente $16 \mathrm{M} \mathrm{t} \mathrm{CO2e.} \mathrm{Um} \mathrm{montante} \mathrm{semelhante} \mathrm{pode} \mathrm{ser} \mathrm{aplicado} \mathrm{no} \mathrm{período} \mathrm{subseqüente.}$

Abrangência Todos GEE convertidos em $\mathrm{CO}_{2}$ equivalente.

Participação: O sistema vai comprar créditos para energia renovável, eficiência de energia, troca de combustíveis, mas não de florestamento e reflorestamento.

Alocação: Alguns projetos submetidos são selecionados para validação e registro no Protocolo de Quioto, um contrato é assinado antes que os pagamentos sejam transferidos.

"Banking" e empréstimo: Os créditos gerados serão usados para o primeiro período de compromisso do Protocolo: 2008-2012 e podem ser comercializados de acordo com as regras do Protocolo de Quioto.

Monitoramento e registro: $\mathrm{O}$ design inicial do projeto tem que ser validado por um auditor independente.

Mecanismos de cumprimento: Não aplicável a este sistema.

Regime de cumprimento: Nenhuma informação disponível.

Taxas e custos de transação: IBRD vai cobrir os custos administrativos.

Maiores informações:

International Bank for Reconstruction e Development (IBRD) -

http://web.worldbank.org/WBSITE/EXTERNAL/EXTABOUTUS/0,,contentMDK:20049553 menuPK:5 8859 pagePK:34542 piPK:36600 OSitePK:29708,00.html

Dutch Ministry of Housing, Spatial Planning and Environment (VROM) - http://www.minvrom.nl

Official information on MDL na Holanda - http://www.MDLinfo.nl

The World Bank and the environment -

http://lnweb18.worldbank.org/ESSD/essdext.nsf/41ByDocName/Environment 
Última atualização

13 Setembro 2002.

\section{Holanda - IFC}

País: Holanda e a "International Finance Corporation" (IFC).

Tipo: Um acordo entre a Holanda e a IFC para facilitar a compra de Créditos de redução de emissões de GEE.

Começo: Assinado em maio de 2002.

Período de Cumprimento: Vai investir em projetos nos próximos três anos. Os créditos gerados serão utilizados no período de 2008-2012.

Relação com outros mercados: Os créditos podem ser utilizados em outros sistemas internacionais.

Metas: €44 milhões (aproximadamente US\$43 milhões) em projetos de redução de emissões de aproximadamente $10 \mathrm{M} \mathrm{t} \mathrm{CO2e..}$

Abrangência: Todos GEE convertidos em $\mathrm{CO}_{2}$ equivalente.

Participação: O sistema irá comprar créditos de: energia renovável, eficiência de energia, aproveitamento de biogás de aterros, e troca de combustíveis. Foco será no setor privado.

Alocação: Alguns projetos submetidos são selecionados para validação e registro no Protocolo de Quioto, um contrato é assinado antes que os pagamentos sejam transferidos. O ciclo pode variar de pouco meses até 6-8 meses.

"Banking" e empréstimo: Os créditos serão utilizados para cumprir com as metas de Quioto de 20082012, porém "banking" pode ocorrer de acordo com as regras do Protocolo de Quioto.

Monitoramento e registro: $\mathrm{O}$ design inicial do projeto tem que ser validado por um auditor independente.

Mecanismos de cumprimento: Não aplicável a este sistema.

Regime de cumprimento: Nenhuma informação disponível.

Taxas e custos de transação: IFC vai cobrir os custos administrativos.

Maiores informações:

IFC-Holanda Carbon Facility - http://www.ifc.org/enviro/EMG/CarbonFinance/carbonfinance.htm

Dutch Ministry of Housing, Spatial Planning and Environment (VROM) - http://www.minvrom.nl

Official information on MDL na Holanda - http://www.MDLinfo.nl

World Bank and the environment

http://lnweb18.worldbank.org/ESSD/essdext.nsf/41ByDocName/Environment

Última atualização

13 Setembro 2002. 


\section{Noruega}

País: Noruega

Tipo: Sistema nacional de "cap and trade".

Começo: 2005.

Período de Cumprimento: Anual para o período de 3 anos (2005-2007). De 2008 em diante o sistema irá seguir as regras do Protocolo de Quioto.

Relação com outros mercados: Créditos gerados através de projetos/mecanismos (domésticos e internacionais) serão aceitos. Serão estabelecidos links com mercados internacionais se possível.

Metas: 20\% de redução dos níveis de 1990 (1,6 M t CO2e para o período inicial de 3 anos).

Abrangência $\mathrm{O}$ sistema as indústrias de processamento que emitem $\mathrm{CO}_{2}, \mathrm{~N}_{2} \mathrm{O}, \mathrm{PFCs}$, e $\mathrm{SF}_{6}$, assim como as emis sões de $\mathrm{CO}_{2}$ pela combustão estacionária de algumas indústrias. $\mathrm{O}$ sistema irá tentar cobrir as fontes de emissões que não estejam sujeitas a taxas de $\mathrm{CO}_{2}$.

Participação: Participação será obrigatória para as indústrias selecionadas. O sistema irá cobrir aproximadamente $30 \%$ das emissões de GEE em 1990, aproximadamente 17 M t CO2e.

Alocação: Sem custo. Não se sabe em que ano será baseada.

“Banking" e empréstimo: Banking de créditos é permitido entre os anos de 2005-2007. Créditos reconhecidos pelo Protocolo de Quioto, incluindo MDL e JI, podem ser guardados para o primeiro período de compromisso de acordo com os limites do Protocolo.

Monitoramento e registro: Um sistema será criado, mas os detalhes ainda não são conhecidos.

Mecanismos de cumprimento: O sistema vai operar com uma penalidade pelo não cumprimento, mas o valor ainda não foi decidido.

Regime de cumprimento: Nenhuma informação disponível.

Taxas e custos de transação: Nenhuma informação disponível.

Maiores informações:

Norwegian Ministry of the Environment - http://odin.dep.no/md/engelsk/index-b-n-a.html

White papers - English summaries - http://odin.dep.no/md/engelsk/publ/stmeld/index-b-n-a.html

Última atualização

25 Julho 2002.

\section{Partnership for Climate Action}

País: O "Partnership for Climate Action" (PCA) é um programa voluntário criado pela "Environmental Defense" e as companhias: Alcan, BP, DuPont, Entergy, Ontario Power Generation, Pechiney, Shell, e Suncor 
Tipo: Acordo voluntário.

Começo: Lançado em outubro de 2000.

Período de Cumprimento: Específico para cada companhia.

Relação com outros mercados: BP, Pechiney, e Shell tem sistemas internos, enquanto que outras dependem de sistemas externos (Shell planeja um sistema de MDL). Ontario Power tem um projeto de reflorestamento no sul de Ontário, um projeto de AIJ em eficiência energética na Jordânia (junto com o "E7 partners" - http://www.e7.org, e também adquiriu aproximadamente 12,6 M t CO2e de vários projetos no Canadá, EUA, e Europa.

Metas: Cada companhia tem uma meta de redução das emissões de GEE, resultando em um redução de pelo menos 80 Mt CO2e em 2010. As metas individuais são:

- Alcan: Reduções anuais de 500.000 toneladas até 2004.

- BP: 10\% abaixo de 1990 até 2010.

- DuPont: 65\% abaixo de 1990 até 2010.

- Entergy: Estabilizar nos níveis de 2000 para 2001-2005

- Ontario Power Gen.: Estabilizar as emissões de GEE nos níveis de 1990 começando em 2000.

- Pechiney: $15 \%$ abaixo de 1990 até 2012.

- Suncor Energia: 6\% abaixo de 1990 até 2010.

Abrangência Todos GEE expressos em unidades de CO2e.

Participação: Participação é voluntária. Cada membro precisa concordar em:

- declarar publicamente uma meta de redução, baseada em ações, políticas e incentivos;

- mensurar e tornar pública a performance;

- empregar estratégias inovadoras com os parceiros, clientes e fornecedores, para maximizar as oportunidades de reduzir as emissões de GEE; e

- liderar através do exemplo, o engajamento positivo, a colaboração, a comunicação pública, e a troca de experiências.

Alocação: Específica para cada companhia:

- Alcan: irá desenvolver baseada na performance do últimos anos.

- BP: baseada nas emissões de 1998.

- DuPont: baseada nas emissões de 1990.

- Entergy: baseada no ano de 2000 (existe um fundo de US\$5 milhões/ano (US\$25 milhões no total) para projetos internos).

- Ontario Power Gen.: baseada no ano de 1990.

- Pechiney: baseada no ano de 1990

- Shell: A linha de base é 1990, o programa interno usa 1998 como ano base, alocando 98\% das emissões de 1998. Uma porcentagem das permissões são leiloadas para incentivar o desenvolvimento do program de comércio de emissões interno.

- Suncor: baseada nas emissões de 1990.

“Banking” e empréstimo: Regras para "banking” e empréstimo são específicas para cada companhia, ou estabelecidas pelo Protocolo de Quioto.

Monitoramento e registro: Todos membros tem auditorias internas, e cinco companhias também têm auditorias externas (Alcan, Entergy, e Suncor Energia têm planos de incluir a verificação externa).

Mecanismos de cumprimento: Mecanismos de cumprimento são específicos para cada companhia.

Regime de cumprimento: Nenhuma informação disponível. 
Taxas e custos de transação: Nenhuma informação disponível.

Outros: Duas transações ocorreram graças ao PCA: a primeira de 6 M t CO2e (2001-2005) da Blue Source para a Ontario Power Generation com a opção de mais 3 M t CO2e (2002-2004). A segunda de 125.000 toneladas de CO2e (2001) da Dupont para a Entergy.

Em junho de 2001 a Petróleos Mexicanos (PEMEX), empresa de petróleo e gás, se juntou ao PCA com o objetivo de reduzir suas emissões em $1 \%$ abaixo os níveis 1999 , usando um sistema interno de troca nos primeiros 6 meses. Depois disto metas para um período de 10 anos serão estabelecidas para a segunda fase do programa.

\section{Maiores informações:}

Partnership for Climate Action - http://www.pca-online.org

The Partnership for Climate Action: Common Elements Among Advanced Greenhouse Gas Management Programs (pdf)

http://www.environmentaldefense.org/pdf.cfm?contentid=1885\&filename=PCAbooklet $\% 2$ Epdf

Environmental Defense - http://www.environmentaldefense.org/home.cfm

Alcan - http://www.alcan.com

BP - http://www.bp.com

DuPont - $\underline{\text { http://www.dupont.com }}$

Entergy - http://www.entergy.com

Ontario Power Generation - http://www.opg.com/default3.asp

Pechiney

http://www.pechiney.com/pechiney/webpechiney.nsf/Internet/HomeV5 VINT?OpenDocument

Shell - http://www.shell.com/home/Framework?siteId=home

Suncor - http://www.suncor.com/bins/index.asp

Última atualização

05 Novembro 2002

\section{Shell}

País: Sistema interno cobrindo Austrália, Canadá, Europa, e EUA.

Tipo: O “Shell Tradable Emission Permit System” (STEPS) é um sistema de "cap and trade”.

Começo: STEPS começou em janeiro de 2000 e está planeja para ir até o fim de 2002.

Período de Cumprimento: Períodos anuais de compromisso.

Relação com outros mercados: Um sistema para MDL é previsto, onde companhias da Shell em países não-ANEXO I podem comprar CER e participar do STEPS.

Metas: $10 \%$ de redução das emissões de $\mathrm{CO}_{2}$ e até 2002 comparada com os níveis de 1990.

Abrangência: $\mathrm{CO}_{2}$ e metano, usando GWP para conversão em $\mathrm{CO}_{2} \mathrm{e}$.

Participação: Participação é voluntária. Seis unidades estão participando. Estão baseadas na Austrália, Canadá, Europa, e EUA, representando $30 \%$ das emissões - $32 \mathrm{Mt} \mathrm{CO}_{2}$ e por ano. O sistema é operado pela Shell Energia. 
Alocação: O sistema aloca 98\% das emissões de GEE de 1998. A porcentagem de permissões são leiloadas a fim de incentivar o desenvolvimento do sistema. Cada permissão corresponde a 100 toneladas de $\mathrm{CO}_{2} \mathrm{e}$.

"Banking" e empréstimo: Se as emissões forem menores que as permissões pode-se guardar para os próximos anos.

Monitoramento e registro: O sistema o inventário já feito para as emissões de GEE e é verificado externamente pela KPMG.

Mecanismos de cumprimento:

Regime de cumprimento: Nenhuma informação dada.

Taxas e custos de transação: Custos são minimizados através de um "Trading Manager" que publica preços e volumes na intranet da Shell.

Maiores informações:

Shell and Climate Change - http://www2.shell.com

STEPS - an overview (download) - $\underline{\text { http://www2.shell.com }}$

Última atualização

25 Julho 2002 


\section{Eslováquia}

País: Eslováquia

Tipo: Sistema nacional de "cap and trade".

Começo: Primeiro período de 2005 até o fim de 2007. Períodos subseqüentes seguirão o Protocolo de Quioto.

Período de Cumprimento: Regime anual para o primeiro período.

Relação com outros mercados: Pretende ser compatível com o sistema da Comunidade Européia.

Metas: Nenhuma decisão foi tomada.

Abrangência: Apenas $\mathrm{CO}_{2}$ com possibilidade de extensão para outros gases no futuro.

Participação: O sistema será baseado em uma abordagem "downstream", focando companhias com capacidade superior a 5MW. No total, aproximadamente $70 \%$ das emissões de $\mathrm{CO}_{2}(55 \%$ das emissões de GEE) serão cobertas pelo sistema, com a inclusão de 358 companhias nos seguinte setores: cimento, cogeracão, construção, combustíveis, ferro e aço, aquecimento público, maquinaria, metalurgia, papel e celulose, têxtil, e madeiras.

Alocação: Ainda não foi decidida, mas poderá ser baseado na distribuição das emissões históricas com uma pequena porcentagem indo a leilão. $\mathrm{O}$ ano base ainda não foi decidido.

“Banking” e empréstimo: O sistema irá permitir "banking” entre 2005-2007 e 2008-2012, assim como entre os períodos.

Monitoramento e registro: O Ministério do Meio Ambiente pretende administrar o sistema.

Mecanismos de cumprimento: Penalidades financeiras pelo não cumprimento irão existir. Ainda não foram decididos os valores.

Regime de cumprimento: Nenhuma informação disponível.

Taxas e custos de transação: Nenhuma informação disponível.

Outros: Eslováquia já possui um sistema de "cap and trade” para $\mathrm{SO}_{2}$.

Maiores informações:

Ministry of Environment - http://www.lifeenv.gov.sk/minis/index.html

Última atualização

25 Julho 2002.

\section{Suécia}

País: Suécia

Tipo: Sistema de comércio para substituir taxa de $\mathrm{CO}_{2}$ planejada para 2005. Pretende ser compatível com o sistema da Comunidade Européia. Uma comissão para o uso dos mecanismos de flexibilização irá 
entregar o primeiro relatório sobre o sistema em dezembro 2002.

Começo: 2005

Período de Cumprimento: Metas anuais para o período de 2005-2007.

Relação com outros mercados: Pretende ser compatível com o sistema da Comunidade Européia e irá aprovar (ou desaprovar ) créditos de MDL e/ou JI. A "National Energy Agency" é responsável pelos projetos de AIJ, JI e MDL e têm um orçamento de €20 milhões para o período de 1998 -2004. A Suécia participa também do Prototype Carbon Fund onde contribuiu com US\$10 milhões.

Metas: Nenhuma decisão foi tomada.

Abrangência: Apenas $\mathrm{CO}_{2}$ para o período inicial de 2005-2007.

Participação: Exclui as empresas não sujeitas a taxa de $\mathrm{CO}_{2}$. Seguindo a proposta da Comunidade Européia os participantes serão: atividades de energia, produção e processamento de metais ferrosos, indústria de mineração e papel e celulose. Aproximadamente 30\% das emissões de 1998 serão cobertas. Uma total de aproximadamente 400 empresas devem participar do sistema.

Alocação: Será feita por autoridades nacionais. Será feita sem custo para as empresas. Sugere-se que seja feita através de leilões.

"Banking” e empréstimo: Free banking será permitido no período inicial.

\section{Monitoramento e registro:}

Mecanismos de cumprimento: Multas serão cobradas pelo não-cumprimento.

Regime de cumprimento: Nenhuma informação disponível.

Taxas e custos de transação: Nenhuma informação disponível.

\section{Maiores informações:}

Swedish Ministry of Environment - $\underline{\mathrm{http}: / / \text { miljo.regeringen.se/ }}$

Última atualização

02 Outubro 2002

\section{Suíça}

País: Suíça

Tipo: Sistema voluntário para redução de emissões de $\mathrm{CO}_{2}$.

Começo: Julho de 2001. Se os resultados não forem satisfatório uma taxa pode ser colocada nos combustíveis fósseis em 2004.

Período de Cumprimento: De acordo com contratos estabelecidos.

Relação com outros mercados: Permitirá o uso de : AAU e RMU (sinks) suíços, AAU e RMU de outros países, e ERU e CER de projetos de JI e MDL. 
Metas: $10 \%$ de redução para as emissões de $\mathrm{CO}_{2}$ no total, $15 \%$ de redução das emissões de $\mathrm{CO}_{2}$ dos combustíveis, e $8 \%$ de redução para as emissões de $\mathrm{CO}_{2}$ para motores a combustão, em relação a 1990, a serem alcançadas em 2008-2012. Metas específicas são negociadas entre as empresas e o governo.

\section{Abrangência: Apenas $\mathrm{CO}_{2}$.}

\section{Participação:}

Alocação: Os participantes tem que negociar suas metas para 2010, e para 2008-12 será permitido as metas de 2010 vezes cinco. As permissões serão distribuídas gratuitamente.

“Banking” e empréstimo: Nenhuma informação disponível.

Monitoramento e registro: Um sistema nacional será criado.

Mecanismos de cumprimento: Não cumprimento resultará no pagamento da taxa de $\mathrm{CO}_{2}$.

\section{Regime de cumprimento:}

Taxas e custos de transação: $\mathrm{O}$ Lei de $\mathrm{CO}_{2}$ estabelece que a taxa depende da diferença entre as emissões atuais e as metas, com o limite máximo de aproximadamente US\$140 por tonelada de $\mathrm{CO}_{2}$.

Outros: Pretende ser compatível com o sistema da Comunidade Européia.

\section{Maiores informações:}

Swiss Agency for the Environment, Forest and Landscape - http://www.umwelt-schweiz.ch

Swiss Climate Policy - http://www.umwelt-schweiz.ch/buwal/de/fachgebiete/fg klima/politik/index.html

Swiss Federal Office for Energy - http://www.energie-schweiz.ch

Swiss AIJ Pilot Program (SWAPP) - $\underline{\text { http://www.admin.ch/swissaij }}$

Última atualização

15 Julho 2002.

\section{UK}

País: Reino Unido

Tipo: Sistema voluntário nacional de "cap and trade"

Começo: O "UK Emissões Trading Scheme" (ETS) foi lançado em 14 de agosto de 2001, as regras foram estabelecidas em 2002, e um leilão foi feito em março 2002. O sistema começou a operar em abril 2002.

Período de Cumprimento: O primeiro período de compromisso começou em 1 de janeiro de 2002. Participantes tem que demonstrar reduções anuais. O sistema irá funcionar por um período de 5 anos: 2002-2006.

Relação com outros mercados: Créditos de projetos internacionais que resultarem em redução de emissões verificadas podem ser incluídos no sistema, porém as regras para a inclusão ainda não foram criadas.

Metas: Reduções das emissões serão feitas de acordo com a linha de base de 1998-2000. As metas foram 
estabelecidas através de leilão em março de 2002 (UK£215 milhões em incentivos). A meta total é da redução de 4.028.176 toneladas $\mathrm{CO}_{2} \mathrm{e}$ abaixo da linha de base em 2006. Isto equivale a um redução total de 12.084.528 toneladas $\mathrm{CO}_{2}$ e para o período de 5 anos.

Abrangência: Participantes podem escolher entre $\mathrm{CO}_{2}$ e todos GEE.

Participação: Participação é voluntária. Existem 4 maneiras de participar do ETS:

- Assumindo um valor absoluto de redução em relação a linha de base de 1998-2000. Esta meta será estabelecida através de leilão onde os participantes fazem suas ofertas em valores absolutas de redução em função dos incentivos monetários oferecidos pelo governo. Mais leilões serão feitos em estágios posteriores mas os detalhes ainda não foram divulgados.

- Setores sujeitos ao "Climate Change Levy" (CCL) podem assinar "Climate Change Agreements" (CCA) e receber um desconte de $80 \%$ se atingirem suas metas. Ao assinar o CCA a empresa pode participar do ETS. As metas são relativas, em função da performance ou índices de eficiência. Existem certas restrições para o comércio das empresas desta categoria.

- Organizações que tem projetos de redução no Reino Unido ou fora dele podem vender as reduções verificadas. Regras para esta inclusão ainda não foram estabelecidas.

- Qualquer empresa pode operar uma conta no "Emissions Trading Registry” e comercializar permissões.

Um total de 34 organizações receberam incentivos através do leilão de março de 2002. Outras 6.000 empresas, com CCA, são esperadas para este ano.

Alocação: Empresas que atingiram suas metas para 2002, comprovada através de verificação em JaneiroMarço 2003, vão receber os pagamentos em abril de 2003.

“Banking" e empréstimo: Não existe limite para "banking" de um ano para o outro durante o período de 2002-2006. Provavelmente irá existir algum limite para "banking" para o primeiro período de compromisso do Protocolo de Quioto.

Monitoramento e registro: Todos participantes devem informar suas emissões através do "Guidelines for the Measurement and Reporting of Emissions for the UK ETS”. Informação deve ser consistente com as diretrizes do IPCC, e haverá verificação por parte de certificadores acreditados.

Mecanismos de cumprimento: Nos casos de não cumprimento existe um período de três meses após o fim do período de compromisso para que as empresas possam entrar em cumprimento. Os participantes que não conseguirem e tiverem um CCA terão o seu desconto de $80 \%$ para os próximos 2 anos. Não cumprimento para companhias metas absolutas irá resultar no não pagamento dos incentivos e devolução dos pagamentos anteriores com correção monetária. As permissões para o próximo ano serão reduzidas em $30 \%$.

Penalidade financeiras são esperadas. Os valores destas penalidades são estimados em GBP 20 por tonelada de $\mathrm{CO} 2 \mathrm{e}$, ou o dobro do preço médio vigente durante os três meses de reconciliação.

Regime de cumprimento: As regras ainda não foram estabelecidas.

Taxas e custos de transação: Os recursos recebidos estão sujeitos a taxas.

\section{Maiores informações:}

UK Emissões Trading Scheme - http://www.defra.gov.uk/environment/climatechange/trading/index.htm UK Department for Environment, Food \& Rural Affairs - http://www.defra.gov.uk

Última atualização

25 Julho 2002. 


\section{EUA - Califórnia Climate Action Registry}

País: Califórnia, EUA.

Tipo: O "California Climate Action Registry" é um sistema privado, sem fins lucrativos, voluntário para o registro de emissões de GEE, estabelecido pelo estado da Califórnia. Seu propósito é auxiliar empresas a medir suas emissões e estabelecer linhas de base.

Começo: Outubro 2002.

Período de Cumprimento: Não aplicável.

Relação com outros mercados: O Registro permitirá a informação de redução não certificadas em conjunto com as emissões totais anuais das empresas. Certificação poderá ser pedida no futuro.

Metas: Não requeridas.

Abrangência: Empresas vão medir suas emissões de $\mathrm{CO}_{2}$ (ou na Califórnia apenas ou a nível nacional) e informar durante os três primeiros anos de participação. Depois de três anos de Registro, companhias que emitem outros GEE também devem informá-los em unidades de $\mathrm{CO}_{2} \mathrm{e}$. Participantes concordam em calcular emissões diretas e indiretas.

Participação: No lançamento do sistema havia 25 membros, incluindo empresas como a BP, QUALCOMM, New United Motor Manufacturing Inc. (General Motors-Toyota joint venture) e Pacific Gas and Electric Corporation, cidades como Los Angeles e San Diego, Los Angeles Department of Water and Power grupos ambientalista como a "Union of Concerned Science" e o NRDC.

Alocação: Não aplicável.

“Banking” e empréstimo: Nenhuma informação disponível.

Monitoramento e registro: Informação sobre as emissões de GEE devem ser fornecidas anualmente e submetidas a certificação independente. Os protocolos foram desenvolvidos com base nos princípios do "World Resources Institute" e "World Business Council on Sustainable Development". O Registro publicou o "General Reporting Protocol" e a "Certification Protocol" para auxiliar seus membros. Um site na Web também foi desenvolvido para auxiliar na identificação, estimativas, cálculos e informação das emissões de GEE.

Mecanismos de cumprimento: Não aplicável.

Regime de cumprimento: Não aplicável.

Taxas e custos de transação: $O$ sistema opera com taxas que podem ser vistas no site: http://www.climateregistry.org/files/fee structure 071502.pdf. O sistema possui estimativas de custo no site: http://www.climateregistry.org/files/certification estimates 0902.pdf

Maiores informações:

California Climate Action Registry - http://www.climateregistry.org

Última atualização

08 Novembro 2002 


\section{EUA - Chicago Climate Exchange}

País: Região dos Grande Lagos, EUA. Inclui também empresas do resto dos EUA, Brasil, Canadá, e México.

Tipo: Voluntário

Começo: Previsto para iniciar no final de 2002.

Período de Cumprimento: Anual.

Relação com outros mercados: Créditos são gerados por projetos nos EUA e fora dele. Créditos gerados através de MDL e JI podem ser incluídos. O sistema foi originalmente pensado para ter total fungibilidade com os sistemas internacionais. No entanto, devido a saída dos EUA do Protocolo de Quioto links só podem ser feitos com sistemas fora de Quioto.

Metas: Sistema diferentes metas começando com 2\% abaixo os níveis de 1999 durante 2002, e 1\% por ano para os próximos períodos de compromisso.

Abrangência Todos GEE, expressos em $\mathrm{CO}_{2} \mathrm{e}$

Participação: Participação é voluntária. Os participantes concordam em reduzir suas emissões e seguir as regras de monitoramento e informação do sistema. As emissões anuais da empresa devem ser superiores a 250.000 toneladas de $\mathrm{CO}_{2} \mathrm{e}$ para poder participar do sistema.

CCX aceitou projetos em 7 estados norte-americanos para 2002: Iowa, Illinois, Indiana, Michigan, Minnesota, Ohio, e Wisconsem (Região dos Grandes Lagos). Um total de 46 companhias e organizações assinaram para a primeira fase do programa. Créditos de redução de emissões de projetos no Brasil são esperados.

Alocação:

“Banking” e empréstimo: Nenhuma informação disponível.

Monitoramento e registro: O programa irá operar com regras próprias com um banco de dados central para registro e transferência de permissões e créditos.

Mecanismos de cumprimento: O sistema vai operar com penalidades pelo não cumprimento. Nenhuma informação disponível para este tópico.

Regime de cumprimento: Nenhuma informação disponível.

Taxas e custos de transação: Nenhuma informação disponível.

Maiores informações:

Chicago Climate Exchange - http://www.chicagoclimatex.com

Última atualização

25 Julho 2002. 


\section{EUA - Clean Energia Group}

País: EUA

Tipo: Legislação multi-poluente com sistema "cap and trade" (The Integrated Air Quality Planning Act) proposto pelo "Clean Energy Group", consiste das companhias Conectiv (http://www.conectiv.com/civ/index.cfm), Consolidated Edison (http://www.coned.com), KeySpan (http://www.keyspanenergia.com), Exelon (http://www.exeloncorp.com), NorOast Utilities (http://www.nu.com), PG\&E (http://www.pge.com), PSEG (http://www.pseg.com), e Sempra Energia (http://www.sempra.com).

Começo: O sistema é proposto para começar em 2004 com o estabelecimento de critérios de elegibilidade, sistemas de monitoramento, etc. As metas de redução serão para 2008.

Período de Cumprimento: Períodos anuais.

Relação com outros mercados: Nenhuma informação disponível.

Metas: $\mathrm{CO}_{2}$ - estabilização nos níveis de 2000 até 2008, no níveis de 1990 até 2012, com a inclusão de mecanismos de flexibilização internacionais até 2015.

$\mathrm{NO}_{\mathrm{x}}$ : 2,11 Mt (ou aproximadamente redução de 50 nas emissões atuais) até 2008.

$\mathrm{SO}_{2}:$ 4,5 Mt até 2008 e 3,6 M t até 2012.

Mercúrio: 26 toneladas até 2008 e 5-16 toneladas até 2012.

Abrangência $\mathrm{NO}_{\mathrm{x}}, \mathrm{SO}_{2}$, mercúrio, e $\mathrm{CO}_{2}$.

\section{Participação:}

Alocação: Permissões de $\mathrm{CO}_{2}$ serão distribuídas de forma a não superar as metas, menos uma quantidade para reserva. $\mathrm{NO}_{\mathrm{x}}$ e mercúrio alocados em função das emissões históricas. Permissões de $\mathrm{SO}_{2}$ serão as mesmas que existem no sistema atual de troca de $\mathrm{SO}_{2}$ (Acid Rain).

“Banking” e empréstimo: Permissões para ações de projetos domésticos e internacionais iniciados no período de 1990 a 2008 são limitadas a 10\%. Nenhuma informação adicional disponível.

Monitoramento e registro: Nenhuma informação disponível.

Mecanismos de cumprimento: Não cumprimento resultará em penalidades financeiras (ainda não determinadas).

Regime de cumprimento: Nenhuma informação disponível.

Taxas e custos de transação: Nenhuma informação disponível.

Maiores informações:

The Clean Energy Group - http://www.mjbradley.com/CEG.htm

Última atualização

25 Julho 2002. 


\section{EUA - Clean Power Group}

País: EUA

Tipo: Legislação multi-poluente com sistema "cap and trade" proposto pelo "Clean Power Group", constituído das companhias NiSource (http://www.nisource.com), Calpine (http://www.calpine.com), Trigen (http://www.trigen.com), e El Paso http://www.epenergia.com). Enron http://www.enron.com) era membro do grupo.

Começo: Nenhuma proposta foi feita até o momento.

Período de Cumprimento: Períodos anuais.

Relação com outros mercados: Nenhuma informação disponível.

Metas: Específica para cada poluente $\left(\mathrm{CO}_{2}, \mathrm{NO}_{\mathrm{x}}, \mathrm{SO}_{2}\right.$, mercúrio $)$ com cada meta declinando continuamente. Para cada poluente um mecanismo de "cost circuit breaker" será criado. Caso o preço de Mercado da permissão superar o "circuit breaker" as metas param de declinar. Nenhum valor foi proposto para o $\mathrm{CO}_{2}$, mas os "circuit breakers" os outros poluentes é estimado em US\$ 600 por tonelada de $\mathrm{SO}_{2}$, US $\$ 3.000$ por tonelada $\mathrm{NO}_{\mathrm{x}}$, e US\$ 35.000 por libra de mercúrio.

Abrangência: $\mathrm{NO}_{\mathrm{x}}, \mathrm{SO}_{2}$, mercúrio, e $\mathrm{CO}_{2}$.

Participação: A proposta substitui o "Clean Air Act", e os participantes seriam as usinas de energia que hoje são cobertas pelo "Act", assim como novas empresas hoje sujeitas a instrumentos de comando e controle.

Alocação:

“Banking” e empréstimo: Nenhuma informação disponível.

Monitoramento e registro: Nenhuma informação disponível.

Mecanismos de cumprimento: Nenhuma informação disponível.

Regime de cumprimento: Nenhuma informação disponível.

Taxas e custos de transação: Nenhuma informação disponível.

Maiores informações:

The Clean Power Group - http://cleanpowergroup.com/index.html

Última atualização

25 Julho 2002.

\section{EUA - Massachusetts}

País: Massachusetts, EUA.

Tipo: Legislação multi-poluente com padrões de emissões para usinas de energia. Regras são esperadas para o 2002. 
Começo: Assinada em abril de 2001.

Período de Cumprimento: Os padrões de emissões para $\mathrm{NO}_{\mathrm{x}}$ e $\mathrm{SO}_{2}$ precisam ser cumpridos até 2004. A meta de $\mathrm{CO}_{2}$ precisa ser cumprida uma ano após o primeiro cumprimento de $\mathrm{NO}_{\mathrm{x}} / \mathrm{SO}_{2}$, e. Cumprimento precisa ser demonstrado anualmente.

Relação com outros mercados: Aa regras para a inclusão de reduções de emissões de GEE, domésticas e internacionais, ainda precisam ser estabelecidas.

Metas: Serão estabelecidas primeiramente em função das emissões históricas de $\mathrm{CO}_{2}$ do período de 1997 a 1999. Os padrões de emissões são $1.800 \mathrm{lbs} / \mathrm{MWh}$ para $\mathrm{CO}_{2}$, correspondente a uma redução de $10 \%$ de 1997-1999, 1,5 lbs/MWh para $\mathrm{NO}_{x}$, e 3,0 lbs/MWh para $\mathrm{SO}_{2}$, representando cortes de $50 \%$ para NOx e de $53 \%$ a $74 \%$ para $\mathrm{SO}_{2}$.

Novas usinas com capacidade de 100MW devem reduzir $1 \%$ das emissões de $\mathrm{CO} 2$ durante os próximos 20 anos. Esta redução pode ser feita através de contribuições a programas de mitigação de $\mathrm{CO}_{2}$ ao custo de US $\$ 1,50$ por tonelada de $\mathrm{CO}_{2}$.

Abrangência: $\mathrm{NO}_{\mathrm{x}}, \mathrm{SO}_{2}$, mercúrio, e $\mathrm{CO}_{2}$.

Participação: empresas cujas emissões de $\mathrm{NO}_{\mathrm{x}}$ e $\mathrm{SO}_{2}$ excederam 500 toneladas em qualquer um dos anos 1997-1999, estejam no programa "US Acid Rain", possuem capacidade instalada acima de 100MW, e não possuem "Prevention of Significant Deterioration based air permit" de 1998. Isto faz com que as 6 usinas de energia mais poluentes do estado estejam incluídas. As emissões destas usinas representam mais de $48 \%$ das emissões de $\mathrm{SO}_{2}$ no estado, $20 \%$ das emissões de $\mathrm{NO}_{\mathrm{x}}$, e $30 \%$ das emissões de mercúrio. As emissões de $\mathrm{CO}_{2}$ destas usinas são responsáveis por $87 \%$ das emissões de todas as usinas do estado.

Alocação: As metas de redução das emissões de $\mathrm{CO}_{2}$ são estabelecidas de acordo com a média das emissões históricas entre 1997 e 1999. Regras ainda não foram estabelecidas.

“Banking” e empréstimo: Regras ainda não foram estabelecidas

Monitoramento e registro: Diretrizes sobre certificação estão na lei. O Departamento de Meio Ambiente pode verificar o cumprimento através de visitas e testes nos locais.

Mecanismos de cumprimento: O Departamento de Meio Ambiente vai determinar as penalidades apropriadas para os casos de não cumprimento caso a caso.

Regime de cumprimento: Nenhuma informação disponível.

Taxas e custos de transação: Nenhuma informação disponível.

Maiores informações:

Massachusetts Department of Environmental Protection - http://www.state.ma.us/dep

Full text (310 CMR 7.29) - http://www.state.ma.us/dep/bwp/daqc/files/regs/729final.doc

Última atualização

17 Julho 2002.

\section{EUA - New Hampshire}


País: New Hampshire, EUA

Tipo: "New Hampshire Clean Power Strategy", lançado em janeiro de 2001, impõe limites nas emissões da geração de eletricidade.

Começo: Primeiro estágio: 2006 a 2010.

Período de Cumprimento: Períodos anuais.

Relação com outros mercados: Permissões de programas federais ou regionais podem ser utilizadas. MDL e JI não são mencionados.

Metas: As emissões de $\mathrm{CO}_{2}$ provenientes da geração de eletricidade devem ser reduzidas em $7 \%$ abaixo dos níveis de 1990 a partir de 2006 (equivale a reduções anuais de 5 Mt $\mathrm{CO}_{2}$ ). Metas existem também para $\mathrm{SO}_{2}\left(75 \%\right.$ redução), $\mathrm{NO}_{\mathrm{x}}(70 \%)$, e mercúrio (75\%). Novas metas para o período posterior a 2010 serão recomendadas até 31 de março de 2004.

Abrangência $\mathrm{CO}_{2}, \mathrm{NO}_{\mathrm{x}}, \mathrm{SO}_{2}$ e mercúrio.

Participação: As metas valem para as usinas com queima de combustível fóssil com capacidade igual ou superior a $25 \mathrm{MW}$.

Alocação: 93\% das emissões dos participantes em 1990 serão alocadas a cada ano. As empresas devem possuir créditos relativos a esta quantidade ao final de cada ano, e os participantes são livres para comprar créditos de qualquer programa federal ou regional. Um método para a alocação ainda não foi decidido.

“Banking” e empréstimo: "Banking” antes e durante 2006 a 2010 é permitido. Não existem menções para banking para os períodos posteriores (depois de 2010).

Monitoramento e registro: O registro é mantido pelo Departamento de Meio Ambiente. Verificação pode ser feita pelo Departamento ou terceiros e deve: (1) checar se as reduções são quantificadas, (2) checar que os cálculos estão corretos, e (3) confirmar através de inspeções no local que as reduções ocorreram.

Mecanismos de cumprimento: Existem várias multas por não estar em cumprimento, não superando o valor de US\$25.000 para cada violação, e para cada dia fora do cumprimento.

Regime de cumprimento: Nenhuma informação disponível.

Taxas e custos de transação: Nenhuma informação disponível.

Outros: Uma nova versão da lei foi aprovada em abril de 2002 e entrou em vigor em 1 de julho de 2002.

Maiores informações:

New Hampshire Department of Environmental Services - Air Resources http://www.des.state.nh.us/ard intro.htm

New Hampshire Clean Power Strategy - Press Release - http://www.des.state.nh.us/ard/nhcps.htm

Full text de O Bill (HB 0284) - http://www.gencourt.state.nh.us/legislation/2002/hb0284.html

Última atualização

25 Julho 2002. 


\section{EUA - New Jersey}

País: New Jersey, EUA.

Tipo: "New Jersey Open Market Emissions Trading (OMET)" e "GHG Trading Protocol Project".

Começo: O programa OMET é resultado de uma legislação assinada em 1995. Aa regras para a criação do sistema para gerar e armazenar créditos de GEE foram estipuladas em maio de 2000. O program foi abandonado em setembro de 2002, aguardando o desenvolvimento e propostas de um mercado federal.

Período de Cumprimento: Limitados a um ano, mas podem ser estendidos sucessivamente caso o "NJ Department of Environmental Protection" assim o desejar.

Relação com outros mercados: O sistema foi estruturado para se relacionar com outros sistemas.

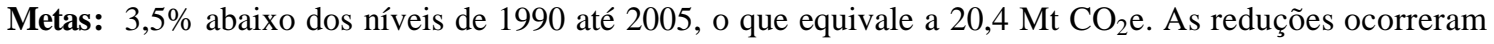
nos seguintes setores:

- Prédios residências: $1,5 \mathrm{Mt} \mathrm{CO}_{2} \mathrm{e}(5,8 \%$ da linha de base $)$

- Prédio comerciais: $8,2 \mathrm{Mt} \mathrm{CO}_{2} \mathrm{e}(30,7 \%$ da linha de base)

- Indústrias: 3,5 $\mathrm{Mt} \mathrm{CO}_{2} \mathrm{e}(11,3 \%$ da linha de base $)$

- Transporte: $2,2 \mathrm{Mt} \mathrm{CO}_{2} \mathrm{e}(4,8 \%$ da linha de base)

- Aterros: 4,5 $\mathrm{Mt} \mathrm{CO}_{2} \mathrm{e}(22,7 \%$ da linha de base)

- Recursos Naturais: 0,5 Mt $\mathrm{CO}_{2} \mathrm{e}(29,4 \%$ da linha de base)

Abrangência Todos GEE, expressos em unidades de $\mathrm{CO}_{2} \mathrm{e}$.

Participação: Participação é voluntária. O gerador do crédito precisa ser de New Jersey.

Alocação: O gerador do crédito reduz as emissões e submete ao registro. Os créditos são calculados em função da linha de base. Depois do registro os créditos podem ser transferidos para outra empresa.

“Banking” e empréstimo: Banking dos créditos é permitido.

Monitoramento e registro: O OMET aceita "Requests for Proposal" de terceiros. Empresas privadas servem como verificadores da geração dos créditos.

Mecanismos de cumprimento: Não cumprimento pode resultar em ações civis e criminais.

Regime de cumprimento: Nenhuma informação disponível.

Taxas e custos de transação: Nenhuma informação disponível.

Outros: New Jersey e Holanda assinaram um carta de intenções em 1998 concordando em cooperar em tópicos relacionados com mudanças climáticas, entre eles "identificar mecanismos de comércio e identificar e elaborar um protótipo de um sistema para comércio de emissões ".

Maiores informações:

New Jersey Open Market Emissions Trading Program - $\underline{\text { http://www.state.nj.us/dep/aqm/omet }}$

Última atualização

17 Outubro 2002 


\section{EUA - Óregon}

País: Óregon, EUA.

Tipo: O estado do Óregon requer das novas usinas de energia que cumpram com limites de emissões de $\mathrm{CO}_{2}$. O "Climate Trust" pelo estado para implementar projetos de redução de $\mathrm{CO}_{2}$ a fim de auxiliar as usinas a cumprirem com os limites. Os créditos comprados através do "Climate Trust" podem ser utilizados em sistemas de comércio futuros.

Começo: Julho 1997.

Período de Cumprimento: Certificações locais estão baseadas em períodos de 5 anos.

Relação com outros mercados: Seattle City Light (http://www.citydeseattle.net/light), a usina municipal de Seatte, Washington, vai cumprir com os limites de emissões de GEE em função das compras feitas da turbina de gás natural de "Klamath Falls". Um "Greenhouse Gas Partnership" foi feito entre a "Seattle City Light" e o "Climate Trust". O "Climate Trust" está aberto para a compra de créditos tanto nos EUA como no mundo, porém alguns créditos precisam ser comprados no Óregon.

Metas: 0,675 libras de $\mathrm{CO}_{2}$ por kWh. Este limite está $17 \%$ abaixo das emissões da usina de gás mais eficiente dos EUA.

Na busca por projetos em 2001 o "Climate Trust" buscou de 3 a 10 projetos por um mínimo de US $\$ 5,5$ milhões. "Seattle City Light" buscou 1 a 4 projetos totalizando 247.000 toneladas de $\mathrm{CO}_{2}$ e. Um total de 78 propostas foram recebidas, e 7 projetos totalizando aproximadamente $3 \mathrm{Mt} \mathrm{CO}_{2}$ foram selecionados.

Abrangência: Apenas $\mathrm{CO}_{2}$. "Seattle City Light" busca projetos envolvendo $\mathrm{CO} 2$ e outros GEE.

Participação: Nova usinas no estado são obrigadas a cumprir com as metas de $\mathrm{CO}_{2}$. Elas podem escolher entre a co-geração, ou fornecendo recursos para o "Climate Trust" ao valor de US $\$ 0,85$ por tonelada de $\mathrm{CO}_{2}$.

Proponentes de projetos pode ser organizações sem fins lucrativos e com fins lucrativos, agências governamentais, laboratórios nacionais, indivíduos, e combinações destes.

Os setores cobertos pelos 7 projetos incluem: eficiência energética pelo lado da demanda, geração distribuída, co-geração industrial, reflorestamento, transporte, e substituição de materiais.

Alocação: Propostas de projetos são enviadas para o "Climate Trust". São então avaliados antes da elaboração de uma lista final. Após negociações os contratos são assinados entre os proponentes e o "Climate Trust".

“Banking” e empréstimo: Os créditos podem em teoria ser guardados indefinidamente.

Monitoramento e registro: Propostas devem incluir planos de monitoramento e verificação, e o use de terceiros para a verificação é preferível.

Mecanismos de cumprimento: Qualquer nova usina precisa estar em cumprimento antes de receber as licenças de operação. O não cumprimento resulta em pagamentos para o "Climate Trust" (US\$ 0,85 por tonelada de $\mathrm{CO}_{2}$ ).

Regime de cumprimento: Os proponentes são responsáveis pelas reduções das emissões. 
Taxas e custos de transação: Nenhuma informação disponível.

Outros: O custo médio das propostas recebidas em 2001 foi de US\$ 2-3 por tonelada. Os contratos finais devem ser fechados até o final de 2002.

Maiores informações:

Climate Trust - http://www.climatetrust.org

Oregon Office of Energy - http://www.energia.state.or.us

Seattle City Lights - Climate Change - http://www.citydeseattle.net/light/climatechange

Última atualização

25 Julho 2002.

\section{World Bank - BioCF}

País: World Bank BioCarbon Fund. Uma parceria multilateral pública e privada do Banco Mundial.

Tipo: O BioCF foi criado para oferecer assistência financeira para a demonstração de projetos de seqüestro em floresta e sistemas agrícolas. Planeja gerar créditos a custo competitivo, enquanto promove a conservação da biodiversidade e o desenvolvimento sustentável.

Começo: Novembro 2002.

Período de Cumprimento: Os projetos do BioCF vão gerar créditos para serem usados em programas nacionais e internacionais (quando permitido). Períodos de compromisso serão específicos para cada programa.

Relação com outros mercados: BioCF vai complementar outros dois fundos do Banco Mundial: Prototype Carbon Fund (PCF), e o Community Development Carbon Fund (CDCF).

Metas: A meta é US\$100 milhões. A contribuição mínima é de US\$2,5 milhões.

Participação: 14 companhias e governos assinaram um "Memoreum of Understeing" com o BioCF. Entre eles: Caisse des Depots et Consignations e Eco-Carbone da França; Chugoku, Shikoku, Okinawa, e Tokyo Electric; Mitsui, Marsh Specialty Operations, Rabobank da Holanda, Suncor Energia do Canadá, St Microelectronics, Swiss Re, e Sustainable Forest Management.

Alocação: O BioCarbon Fund irá focar em projetos que não aconteceriam sem os recursos do carbono. Os participantes vão receber ER verificadas que tem o potencial de serem reconhecidas por programas nacionais e internacionais de comércio de emissão. O clico do projeto para o BioCF ainda não é conhecido. Deve ser semelhante ao ciclo de projetos do PCF.

“Banking” e empréstimo: Créditos gerados pelo BioCF seguem as regras do Protocolo de Quioto.

Monitoramento e registro: Os projetos serão validados e verificados por terceiros.

Mecanismos de cumprimento: Não aplicável a este sistema.

Regime de cumprimento: O sistema vai funcionar com base na responsabilidade dos vendedores. Em geral, nos contratos entre o país hospedeiro e o BioCF, o vendedor (país hospedeiro) é responsável se o projeto não funcionar. 


\section{Taxas e custos de transação:}

Maiores informações:

BioCarbon Fund - http://www.biocarbonfund.org

Última atualização

06 Novembro 2002

\section{World Bank - CDCF}

País: World Bank Community Development Carbon Fund.

Tipo: Iniciativa multilateral do Banco Mundial em colaboração com a "International Emissions Trading Association". O fundo irá auxiliar projetos de pequena escala em países em desenvolvimento e em áreas rurais.

Começo: Setembro 2002.

Período de Cumprimento: Os projetos do CDCF vão gerar créditos para serem usados em programas nacionais e internacionais (quando permitido). Períodos de compromisso serão específicos para cada programa.

Relação com outros mercados: Os projetos do CDCF vão gerar créditos para serem usados em programas nacionais e internacionais (quando permitido).

Metas: US\$ 100 milhões em projetos.

Abrangência: Todos os GEE, expressos em unidades de $\mathrm{CO}_{2} \mathrm{e}$.

Participação: Mais de doze companhias e governos assinaram um "Memoreum of Understeing" com o CDCF a fim de ajudar a desenvolver o fundo. Entre eles o governo da Holanda e Noruega, e as companhias Swiss Re, Rabobank, Chugoku Electric, Idemitsu Kosan, TransAlta, o Commonwealth Bank da Austrália, Industrikraft Midt-Norge, e RATP.

Alocação: O clico do projeto para o CDCF ainda não é conhecido. Deve ser semelhante ao ciclo de projetos do PCF.

"Banking” e empréstimo: Créditos gerados pelo CDCF seguem as regras do Protocolo de Quioto.

Monitoramento e registro: Os projetos serão validados e verificados por terceiros.

Mecanismos de cumprimento: Não aplicável a este sistema.

Regime de cumprimento: $\mathrm{O}$ sistema vai funcionar com base na responsabilidade dos vendedores. Em geral, nos contratos entre o país hospedeiro e o CDCF, o vendedor (país hospedeiro) é responsável se o projeto não funcionar.

\section{Taxas e custos de transação:}

Maiores informações:

Community Development Carbon Fund - http://www.communitycarbonfund.org 
Press Release do $\quad$ Banco $\quad$ Mundial

http://lnweb18.worldbank.org/ESSD/essdext.nsf/41DocByUnid/61DA6C92E388733A85256C250051FA8

9?Opendocument

Última atualização

02 Outubro 2002

\section{World Bank - PCF}

País: Prototype Carbon Fund.

Tipo: Iniciativa multilateral do Banco Mundial para projetos de MDL/JI.

Começo: 1999

Período de Cumprimento: Os projetos do PCF vão gerar créditos para serem usados em programas nacionais e internacionais. Períodos de compromisso serão específicos para cada programa.

Relação com outros mercados: Os projetos do CDCF vão gerar créditos para serem usados em programas nacionais e internacionais.

Metas: Mais de 50 acordos valendo aproximadamente US\$ 350 milhões estão sendo negociados. O preço

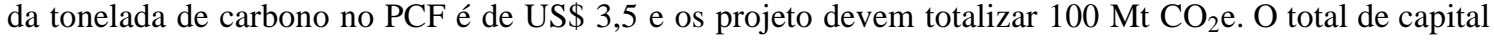
investido no fundo é US\$ 180 milhões em junho de 2002, correspondendo ao um potencial de redução de emissões de 45-72 $\mathrm{Mt} \mathrm{CO}_{2}$ e usando os preços de compra de US\$ 2,5-4,0. Até o fim de 2001 o PCF fechou 15 contratos de US\$ 45-50 milhões, com outros US\$ 35 milhões planejado para 2002.

Abrangência: Todos os GEE, expressos em unidades de $\mathrm{CO}_{2} \mathrm{e}$.

Participação: 6 governos participam do PCF: Canadá, Finlândia, Holanda , Noruega, Suécia, e Japão. 17 companhias participam: RWE - Alemanha http://www.rwe.com/de/de.jsp) Gaz de França (http://www.gazdeFrança.com), Tokyo Electric Power (http://www.tepco.co.jp/index-e.html), Deutsche Bank (http://group.deutsche-bank.de/ghp/index e.htm), Chubu Electric (http://www.chuden.co.jp/english), Chugoku Electric (http://www.energia.co.jp/energiae), $\quad$ Kyushu $\quad$ Electric (http://www.kyuden.co.jp/english/English-Home.html), Shikoku Electric (http://www.yonden.co.jp/index e.htm), Tohoku Electric (http://www.tohoku-epco.co.jp/index-e.htm), Mitsui (http://www.mitsui.co.jp/tkabz/english/index.html), Mitsubis hi (http://www.mitsubishi.com/index e.cfm), Electrabel (http://www.electrabel.com/en), Norsk Hydro (http://www.hydro.com/en), Statoil (http://www.statoil.com), BP (http://www.bp.com), Fortum (http://www.fortum.com), RaboBank (http://www.rabobank.com).

Alocação: O ciclo de um projeto no PCF começa com o design, segue com o estudo da linha de base e plano de monitoramento, seguido da validação. O contrato de compra é então negociado, e se um acordo é alcançado, o projeto segue para a implementação verificação inicial.

As reduções são produzidas e monitoradas, através de verificação e certificação periódica. O PCF paga pelos créditos para o proponente, e estes são transferidos para os participantes do Fundo.

“Banking” e empréstimo: Créditos gerados pelo PCF seguem as regras do Protocolo de Quioto.

Monitoramento e registro: Os projetos serão validados e verificados por terceiros. 
Mecanismos de cumprimento: Não aplicável a este sistema.

Regime de cumprimento: O sistema vai funcionar com base na responsabilidade dos vendedores. Em geral, nos contratos entre o país hospedeiro e o PCF, o vendedor (país hospedeiro) é responsável se o projeto não funcionar.

\section{Taxas e custos de transação:}

Outros: O período de crédito para projetos de MDL é fixo em 10 anos ou então em 7 anos renováveis no máximo por 14 anos.

\section{Maiores informações:}

Prototype Carbon Fund - http://prototypecarbonfund.org

Última atualização

16 Agosto 2002 


\section{APÊNDICE 6 - Questionário e lista dos especialistas e lideranças consultadas.}

Qual seria uma taxa de implementação de projetos de MDL adequada (de 0 a 100\%)?

Brasil:

China:

Índia:

resto do mundo:

Qual seria a porcentagem de "Hot Air" comercializado no mercado internacional?

Qual seria o custo de transação (US\$ t/C) de projetos de MDL?

Brasil:

China:

Índia:

resto do mundo:

Qual será a participação norte-americana no mercado de carbono (porcentagem)?

1) Adriano Santiago de Oliveira - MMA

2) Alexandre Kossoy - Banco Mundial

3) Aline Ribas - COPPE/UFRJ

4) André Ferretti - SPVS

5) André Guimarães - Instituto BioAtlântica

6) André Santos Pereira - COPPE/UFRJ

7) Augusto Jucá - UNDP

8) Carlos de Mathias Martins Jr. - Ecoinvest

9) Cláudio Pádua - Instituto de Pesquisa Ecológicas (IPÊ)

10) Divaldo Rezende - Ecológica

11) Eduardo H. Ditt - Instituto de Pesquisa Ecológicas (IPÊ)

12) Emílio La Róvere - COPPE/UFRJ 
13) Giovanni Barontini - De Rosa Siqueira Advogados Associados

14) Isaura Frondize - BNDES

15) Joe Keenan - The Nature Conservancy (TNC)

16) John Forgach - A2R Fundos Ambientais

17) José Domingos Gonzalez Miguez - MCT

18) Lap Chan - EcoMapuá

19) Laura Valente de Macedo - ICLEI

20) Leonardo da Silva Ribeiro - MMA

21) Ludovino Lopes - Menezes e Lopes Advogados Associados

22) Luiz Gylvan Meira Filho - MCT

23) Marcos Fujihara - PriceWaterHouseCoopers

24) Marina Freitas Gonçalves Grossi - Fórum Brasileiro de Mudanças Climáticas

25) Mario Monzoni - Amigos da Terra

26) Nuno Silva - Ecosecurities

27) Patrícia Garffer - The Nature Conservancy

28) Pedro Leitão - Fundo Brasileiro para a Biodiversidade (FUNBIO)

29) Pedro Moura Costa - Ecosecurities

30) Peter May - Insitituto Pró-Natura

31) Ricardo Esparta - Ecoinvest

32) Ronaldo Seroa da Motta - IPEA

33) Samy Hotimsky - ERM

34) Sineilton Fávero - UNDP

35) Thelma Krug - MCT

36) Warwick Manfrinato - CEPEA/ESALQ/USP

37) Wener Kornexl - Banco Mundial 


\section{APÊNDICE 7 - Resultados do Modelo CERT (cenários de referência e cenários alternativos)}

\section{Cenário 1 - referência (Ref.) e alternativo (New):}

\begin{tabular}{|c|c|c|c|c|c|c|c|c|c|c|c|c|c|c|c|}
\hline Annex B Regions & & USA & USA & JPN & JPN & EEC & EEC & OOE & OOE & EET & EET & FSU & FSU & Total & Total \\
\hline & & Ref. & New & Ref. & New & Ref. & New & Ref. & New & Ref. & New & Ref. & New & Ref. & New \\
\hline Emissions 2010 & $(\mathrm{M}$ tons $\mathrm{C})$ & 1750 & 1435 & 309 & 309 & 964 & 964 & 307 & 307 & 206 & 206 & 542 & 542 & 4078 & 3763 \\
\hline Assigned Amount & $(\mathrm{M}$ tons $\mathrm{C})$ & 1259 & 1259 & 274 & 274 & 822 & 822 & 218 & 218 & 282 & 282 & 816 & 816 & 3671 & 3671 \\
\hline Reduction Requirement & $(\mathrm{M}$ tons $\mathrm{C})$ & 463 & 148 & 22 & 22 & 137 & 137 & 76 & 76 & -80 & -80 & -309 & -309 & 698 & 383 \\
\hline \multicolumn{16}{|l|}{ Autarkic Solution } \\
\hline Autarkic Marginal Price & $(\$ /$ ton $\mathrm{C})$ & 188 & 25 & 73 & 73 & 98 & 98 & 62 & 62 & 0 & 0 & 0 & 0 & & \\
\hline Autarkic Costs & $(\mathrm{M} \$)$ & 31067 & 1454 & 772 & 772 & 5210 & 5210 & 1433 & 1433 & 0 & 0 & 0 & 0 & 38482 & 8869 \\
\hline \multicolumn{16}{|l|}{ Solution with Trade } \\
\hline World Market Price & $(\$ /$ tonC $)$ & 4,6 & 5,4 & & & & & & & & & & & & \\
\hline Domestic Reduction & $(\mathrm{M}$ tons $\mathrm{C})$ & 48 & 54 & 2 & 2 & 16 & 19 & 26 & 27 & 17 & 19 & 36 & 39 & 144 & 159 \\
\hline Domestic Marginal Costs & $(\$ /$ ton $\mathrm{C})$ & 5 & 5 & 5 & 5 & 5 & 5 & 5 & 5 & 5 & 5 & 5 & 5 & & \\
\hline Imports & $(\mathrm{M}$ tons $\mathrm{C})$ & 415 & 94 & 21 & 21 & 121 & 119 & 50 & 49 & 0 & 0 & 0 & 0 & 607 & 282 \\
\hline Exports & $(\mathrm{M}$ tons $\mathrm{C})$ & 0 & 0 & 0 & 0 & 0 & 0 & 0 & 0 & 97 & 51 & 345 & 165 & 442 & 217 \\
\hline Domestic Costs & $(\mathrm{M} \$)$ & 97 & 126 & 4 & 5 & 35 & 46 & 23 & 31 & 29 & 37 & 56 & 71 & 244 & 317 \\
\hline Cost of Imports & $(\mathrm{M} \$)$ & 1905 & 506 & 96 & 111 & 556 & 641 & 231 & 263 & 0 & 0 & 0 & 0 & 2788 & 1521 \\
\hline Export Revenues & $(\mathrm{M} \$)$ & 0 & 0 & 0 & 0 & 0 & 0 & 0 & 0 & 444 & 277 & 1584 & 893 & 2029 & 1170 \\
\hline Total Costs (- = Profits) & $(\mathrm{M} \$)$ & 2002 & 632 & 99 & 116 & 591 & 687 & 254 & 294 & -415 & -239 & -1529 & -822 & 1003 & 668 \\
\hline Savings as \% of Autarky & $(\%)$ & 94 & 57 & 87 & 85 & 89 & 87 & 82 & 79 & 0 & 0 & 0 & 0 & 97 & 92 \\
\hline \multirow[t]{2}{*}{ Non-Annex B Regions } & & EEX & EEX & CHN & CHN & IND & IND & $\overline{\text { DAE }}$ & $\overline{\text { DAE }}$ & $\overline{\text { BRA }}$ & $\overline{\text { BRA }}$ & ROW & ROW & Total & Total \\
\hline & & Ref. & New & Ref. & New & Ref. & New & Ref. & New & Ref. & New & Ref. & New & Ref. & New \\
\hline Exports & $(\mathrm{M}$ tons $\mathrm{C})$ & 9,1 & 2,6 & 97,6 & 36,2 & 25,6 & 8,3 & 7,3 & 2,1 & 0,3 & 7,6 & 23,1 & 7,0 & 163,0 & 63,8 \\
\hline Costs & $(\mathrm{M} \$)$ & 19,8 & 17,3 & 202,5 & 178,5 & 50,9 & 44,6 & 16,0 & 13,9 & 0,8 & 44,6 & 45,2 & 43,5 & 335,1 & 342,3 \\
\hline Export Revenues & (M \$) & 40,8 & 13,9 & 439,3 & 191,5 & 115,1 & 43,8 & 32,9 & 11,2 & 1,6 & 40,0 & 104,2 & 37,2 & 733,9 & 337,6 \\
\hline \multirow[t]{3}{*}{ Profits } & (M \$) & 21,0 & $-3,3$ & 236,9 & 12,9 & 64,2 & $-0,8$ & 16,9 & $-2,7$ & 0,8 & $-4,6$ & 59,0 & $-6,3$ & 398,8 & $-4,7$ \\
\hline & & & & & & & & & & & & & & & \\
\hline & & Ref. & New & & & & & & & & & & & & \\
\hline Convention Fund & $(\mathrm{M} \$)$ & 0 & 0 & & & & & & & & & & & & \\
\hline Adaptation Fund & $(\mathrm{M} \$)$ & 15 & 7 & & & & & & & & & & & & \\
\hline
\end{tabular}

Fonte: Cálculos do autor. 


\section{Cenário 2 - referência (Ref.) e alternativo (New):}

\begin{tabular}{|c|c|c|c|c|c|c|c|c|c|c|c|c|c|c|c|}
\hline Annex B Regions & & USA & $\overline{\text { USA }}$ & $\mathbf{J P N}$ & $\mathbf{J P N}$ & EEC & EEC & OOE & OOE & EET & EET & $\overline{\text { FSU }}$ & $\overline{\text { FSU }}$ & Total & Total \\
\hline & & Ref. & New & Ref. & New & Ref. & New & Ref. & New & Ref. & New & Ref. & New & Ref. & New \\
\hline Emissions 2010 & $(\mathrm{M}$ tons $\mathrm{C})$ & 1809 & 1454 & 330 & 330 & 1011 & 1011 & 324 & 324 & 227 & 227 & 575 & 575 & 4276 & 3921 \\
\hline Assigned Amount & $(\mathrm{M}$ tons $\mathrm{C})$ & 1259 & 1259 & 274 & 274 & 822 & 822 & 218 & 218 & 282 & 282 & 816 & 816 & 3671 & 3671 \\
\hline Reduction Requirement & $(\mathrm{M}$ tons $\mathrm{C})$ & 522 & 167 & 43 & 43 & 184 & 184 & 93 & 93 & -59 & -59 & -276 & -276 & 842 & 488 \\
\hline \multicolumn{16}{|l|}{ Autarkic Solution } \\
\hline Autarkic Marginal Price & $(\$ /$ ton $\mathrm{C})$ & 235 & 31 & 162 & 162 & 163 & 163 & 96 & 96 & 0 & 0 & 0 & 0 & & \\
\hline Autarkic Costs & (M \$) & 43496 & 1997 & 3198 & 3198 & 11297 & 11297 & 2769 & 2769 & 0 & 0 & 0 & 0 & 60759 & 19260 \\
\hline \multicolumn{16}{|l|}{ Solution with Trade } \\
\hline World Market Price & $(\$ /$ tonC $)$ & 9,4 & 10,2 & & & & & & & & & & & & \\
\hline Domestic Reduction & $(\mathrm{M}$ tons $\mathrm{C})$ & 79 & 83 & 3 & 4 & 29 & 30 & 34 & 35 & 25 & 26 & 52 & 53 & 222 & 232 \\
\hline Domestic Marginal Costs & $(\$ /$ ton $C)$ & 9 & 10 & 9 & 10 & 9 & 10 & 9 & 10 & 9 & 10 & 9 & 10 & & \\
\hline Imports & $(\mathrm{M}$ tons $\mathrm{C})$ & 442 & 84 & 40 & 40 & 155 & 154 & 59 & 58 & 0 & 0 & 0 & 0 & 697 & 336 \\
\hline Exports & $(\mathrm{M}$ tons $\mathrm{C})$ & 0 & 0 & 0 & 0 & 0 & 0 & 0 & 0 & 84 & 51 & 328 & 167 & 412 & 217 \\
\hline Domestic Costs & (M \$) & 313 & 352 & 16 & 18 & 122 & 138 & 78 & 88 & 88 & 98 & 165 & 184 & 781 & 879 \\
\hline Cost of Imports & $(\mathrm{M} \$)$ & 4178 & 852 & 379 & 405 & 1469 & 1565 & 560 & 593 & 0 & 0 & 0 & 0 & 6586 & 3416 \\
\hline Export Revenues & (M \$) & 0 & 0 & 0 & 0 & 0 & 0 & 0 & 0 & 796 & 515 & 3095 & 1697 & 3891 & 2211 \\
\hline Total Costs (- = Profits) & $(\mathrm{M} \$)$ & 4491 & 1204 & 394 & 424 & 1590 & 1703 & 639 & 681 & -708 & -416 & -2931 & -1512 & 3476 & 2084 \\
\hline Savings as \% of Autarky & $(\%)$ & 90 & 40 & 88 & 87 & 86 & 85 & 77 & 75 & 0 & 0 & 0 & 0 & 94 & 89 \\
\hline \multirow{2}{*}{ Non-Annex B Regions } & & EEX & EEX & CHN & $\mathrm{CHN}$ & IND & IND & DAE & DAE & BRA & BRA & ROW & ROW & Total & Total \\
\hline & & Ref. & New & Ref. & New & Ref. & New & Ref. & New & Ref. & New & Ref. & New & Ref. & New \\
\hline Exports & $(\mathrm{M}$ tons $\mathrm{C})$ & 17,2 & 5,6 & 171,3 & 66,9 & 42,9 & 14,7 & 13,9 & 4,5 & 0,7 & 13,7 & 38,2 & 12,7 & 284,3 & 118,1 \\
\hline Costs & $(\mathrm{M} \$)$ & 75,5 & 48,0 & 699,9 & 437,3 & 167,2 & 98,8 & 61,1 & 38,8 & 3,2 & 98,7 & 145,8 & 94,9 & 1152,7 & 816,5 \\
\hline Export Revenues & $(\mathrm{M} \$)$ & 159,6 & 56,0 & 1586,1 & 666,9 & 397,1 & 146,4 & 129,0 & 45,3 & 6,4 & 136,5 & 353,2 & 126,9 & 2631,5 & 1178,1 \\
\hline \multirow[t]{3}{*}{ Profits } & $(\mathrm{M} \$)$ & 84,1 & 8,1 & 886,2 & 229,7 & 229,8 & 47,5 & 67,9 & 6,4 & 3,3 & 37,9 & 207,5 & 32,0 & 1478,8 & 361,6 \\
\hline & & & & & & & & & & & & & & & \\
\hline & & Ref. & New & & & & & & & & & & & & \\
\hline Convention Fund & $(\mathrm{M} \$)$ & 0 & 0 & & & & & & & & & & & & \\
\hline Adaptation Fund & $(\mathrm{M} \$)$ & 54 & 24 & & & & & & & & & & & & \\
\hline
\end{tabular}

Fonte: Cálculos do autor. 
Cenário 3 - referência (Ref.) e alternativo (New):

\begin{tabular}{|c|c|c|c|c|c|c|c|c|c|c|c|c|c|c|c|}
\hline Annex B Regions & & USA & USA & JPN & JPN & EEC & EEC & OOE & OOE & EET & EET & FSU & FSU & Total & Total \\
\hline & & Ref. & New & Ref. & New & Ref. & New & Ref. & New & Ref. & New & Ref. & New & Ref. & New \\
\hline Emissions 2010 & $(\mathrm{M}$ tons $\mathrm{C})$ & 1883 & 1477 & 353 & 353 & 1062 & 1062 & 343 & 343 & 236 & 236 & 672 & 672 & 4549 & 4143 \\
\hline Assigned Amount & $(\mathrm{M}$ tons $\mathrm{C})$ & 1259 & 1259 & 274 & 274 & 822 & 822 & 218 & 218 & 282 & 282 & 816 & 816 & 3671 & 3671 \\
\hline Reduction Requirement & $(\mathrm{M}$ tons $\mathrm{C})$ & 596 & 190 & 66 & 66 & 235 & 235 & 112 & 112 & -50 & -50 & -179 & -179 & 1009 & 604 \\
\hline \multicolumn{16}{|l|}{ Autarkic Solution } \\
\hline Autarkic Marginal Price & $(\$ /$ ton $C)$ & 301 & 38 & 283 & 283 & 251 & 251 & 143 & 143 & 0 & 0 & 0 & 0 & & \\
\hline Autarkic Costs & $(\mathrm{M} \$)$ & 63252 & 2783 & 8263 & 8263 & 21791 & 21791 & 5026 & 5026 & 0 & 0 & 0 & 0 & 98333 & 37863 \\
\hline \multicolumn{16}{|l|}{ Solution with Trade } \\
\hline Domestic Reduction & $(\mathrm{M}$ tons $\mathrm{C})$ & 121 & 120 & 6 & 6 & 46 & 46 & 44 & 44 & 36 & 36 & 72 & 71 & 326 & 323 \\
\hline Domestic Marginal Costs & $(\$ /$ ton $C)$ & 18 & 18 & 18 & 18 & 18 & 18 & 18 & 18 & 18 & 18 & 18 & 18 & & \\
\hline Imports & $(\mathrm{M}$ tons $\mathrm{C})$ & 475 & 70 & 60 & 60 & 189 & 189 & 68 & 68 & 0 & 0 & 0 & 0 & 791 & 388 \\
\hline Exports & $(\mathrm{M}$ tons $\mathrm{C})$ & 0 & 0 & 0 & 0 & 0 & 0 & 0 & 0 & 86 & 56 & 251 & 145 & 337 & 201 \\
\hline Domestic Costs & $(\mathrm{M} \$)$ & 881 & 859 & 57 & 55 & 363 & 353 & 220 & 214 & 236 & 230 & 441 & 431 & 2198 & 2143 \\
\hline Cost of Imports & (M \$) & 8637 & 1253 & 1094 & 1078 & 3436 & 3390 & 1236 & 1221 & 0 & 0 & 0 & 0 & 14402 & 6942 \\
\hline Export Revenues & $(\mathrm{M} \$)$ & 0 & 0 & 0 & 0 & 0 & 0 & 0 & 0 & 1568 & 1010 & 4569 & 2591 & 6137 & 3602 \\
\hline Total Costs (- = Profits) & $(\mathrm{M} \$)$ & 9518 & 2112 & 1151 & 1133 & 3799 & 3743 & 1456 & 1436 & \begin{tabular}{l|l|}
-1332 \\
\end{tabular} & $\begin{array}{ll}-780 \\
\end{array}$ & -4128 & -2161 & 10463 & 5483 \\
\hline \multirow[t]{2}{*}{ Non-Annex B Regions } & & EEX & EEX & CHN & CHN & IND & IND & $\overline{\text { DAE }}$ & $\overline{\text { DAE }}$ & BRA & BRA & ROW & ROW & Total & Total \\
\hline & & Ref. & New & Ref. & New & Ref. & New & Ref. & New & Ref. & New & Ref. & New & Ref. & New \\
\hline Exports & $(\mathrm{M}$ tons $\mathrm{C})$ & 29,8 & 9,7 & 274,3 & 105,4 & 66,2 & 22,4 & 24,2 & 7,9 & 1,3 & 21,0 & 58,2 & 19,4 & 454,0 & 185,9 \\
\hline Costs & $(\mathrm{M} \$)$ & 243,4 & 111,2 & 2064,1 & 925,7 & 475,4 & 192,4 & 198,1 & 90,5 & 11,2 & 189,3 & 409,4 & 178,9 & 3401,7 & 1688,1 \\
\hline Export Revenues & $(\mathrm{M} \$)$ & 531,6 & 171,0 & 4892,3 & 1849,7 & 1181,5 & 393,0 & 431,3 & 138,6 & 23,0 & 368,0 & 1037,3 & 341,0 & 8097,0 & 3261,3 \\
\hline \multirow[t]{2}{*}{ Profits } & $(\mathrm{M} \$)$ & 288,2 & 59,8 & 2828,1 & 924,0 & 706,0 & 200,6 & 233,2 & 48,1 & 11,8 & 178,6 & 627,9 & 162,1 & 4695,3 & 1573,2 \\
\hline & & Ref & New & & & & & & & & & & & & \\
\hline Convention Fund & $(\mathrm{M} \$)$ & 0 & 0 & & & & & & & & & & & & \\
\hline Adaptation Fund & $(\mathrm{M} \$)$ & 165 & 67 & & & & & & & & & & & & \\
\hline
\end{tabular}

Fonte: Cálculos do autor. 


\section{Cenário 4 - referência (Ref.) e alternativo (New):}

\begin{tabular}{|c|c|c|c|c|c|c|c|c|c|c|c|c|c|c|c|}
\hline Annex B Regions & & USA & USA & JPN & JPN & EEC & EEC & OOE & OOE & EET & EET & FSU & $\overline{\text { FSU }}$ & Total & Total \\
\hline & & Ref. & New & Ref. & New & Ref. & New & Ref. & New & Ref. & New & Ref. & New & Ref. & New \\
\hline Emissions 2010 & $(\mathrm{M}$ tons $\mathrm{C})$ & 1750 & 1435 & 309 & 309 & 964 & 964 & 307 & 307 & 206 & 206 & 542 & 542 & 4078 & 3763 \\
\hline Assigned Amount & $(\mathrm{M}$ tons $\mathrm{C})$ & 1259 & 1259 & 274 & 274 & 822 & 822 & 218 & 218 & 282 & 282 & 816 & 816 & 3671 & 3671 \\
\hline Reduction Requirement & $(\mathrm{M}$ tons $\mathrm{C})$ & 463 & 148 & 22 & 22 & 137 & 137 & 76 & 76 & -80 & -80 & -309 & -309 & 698 & 383 \\
\hline \multicolumn{16}{|l|}{ Autarkic Solution } \\
\hline Autarkic Marginal Price & $(\$ /$ ton $C)$ & 351 & 66 & 220 & 220 & 470 & 470 & 412 & 412 & 0 & 0 & 0 & 0 & & \\
\hline Autarkic Costs & $(\mathrm{M} \$)$ & 63347 & 4516 & 2341 & 2341 & 26870 & 26870 & 11736 & 11736 & 0 & 0 & 0 & 0 & 104294 & 45463 \\
\hline \multicolumn{16}{|l|}{ Solution with Trade } \\
\hline Domestic Reduction & $(\mathrm{M}$ tons $\mathrm{C})$ & 28 & 32 & 1 & 1 & 5 & 6 & 4 & 5 & 19 & 21 & 82 & 88 & 141 & 153 \\
\hline Domestic Marginal Costs & $(\$ /$ ton $\mathrm{C})$ & 11 & 12 & 11 & 12 & 11 & 12 & 11 & 12 & 11 & 12 & 11 & 12 & & \\
\hline Imports & $(\mathrm{M}$ tons $\mathrm{C})$ & 434 & 116 & 21 & 21 & 132 & 131 & 72 & 71 & 0 & 0 & 0 & 0 & 659 & 340 \\
\hline Exports & $(\mathrm{M}$ tons $\mathrm{C})$ & 0 & 0 & 0 & 0 & 0 & 0 & 0 & 0 & 99 & 54 & 392 & 215 & 491 & 269 \\
\hline Domestic Costs & (M \$) & 147 & 183 & 7 & 8 & 27 & 34 & 23 & 29 & 87 & 103 & 361 & 426 & 652 & 783 \\
\hline Cost of Imports & (M \$) & 4574 & 1367 & 223 & 248 & 1390 & 1546 & 753 & 836 & 0 & 0 & 0 & 0 & 6941 & 3997 \\
\hline Export Revenues & $(\mathrm{M} \$)$ & 0 & 0 & 0 & 0 & 0 & 0 & 0 & 0 & 1046 & 631 & 4124 & 2530 & 5169 & 3161 \\
\hline Total Costs (- = Profits) & $(\mathrm{M} \$)$ & 4722 & 1550 & 230 & 256 & 1418 & 1580 & 776 & 864 & -958 & -528 & -3763 & -2104 & 2424 & 1619 \\
\hline & & & & & & & & & & & & & & & \\
\hline \multirow[t]{2}{*}{\begin{tabular}{|l|} 
Non-Annex B Regions \\
\end{tabular}} & & EEX & EEX & CHN & $\mathbf{C H N}$ & IND & IND & DAE & DAE & BRA & BRA & ROW & ROW & Total & Total \\
\hline & & Ref. & New & Ref. & New & Ref. & New & Ref. & New & Ref. & New & Ref. & New & Ref. & New \\
\hline Exports & $(\mathrm{M}$ tons $\mathrm{C})$ & 13,6 & 4,7 & 118,6 & 48,3 & 13,7 & 4,9 & 6,1 & 2,1 & 1,2 & 5,7 & 14,4 & 5,0 & 167,8 & 70,5 \\
\hline Costs & (M \$) & 68,9 & 26,9 & 580,1 & 223,7 & 69,4 & 27,5 & 31,2 & 14,9 & 6,1 & 35,8 & 72,8 & 28,0 & 828,6 & 356,7 \\
\hline Export Revenues & (M \$) & 140,8 & 54,0 & 1224,1 & 556,4 & 141,6 & 56,1 & 63,3 & 24,2 & 12,4 & 65,5 & 149,0 & 57,2 & 1731,2 & 813,4 \\
\hline \multirow[t]{3}{*}{ Profits } & $(\mathrm{M} \$)$ & 71,9 & 27,2 & 644,0 & 332,7 & 72,2 & 28,6 & 32,1 & 9,4 & 6,3 & 29,7 & 76,2 & 29,1 & 902,6 & 456,7 \\
\hline & & & & & & & & & & & & & & & \\
\hline & & Ref. & New & & & & & & & & & & & & \\
\hline Convention Fund & $(\mathrm{M} \$)$ & 0 & 0 & & & & & & & & & & & & \\
\hline Adaptation Fund & (M\$) & 35 & 17 & & & & & & & & & & & & \\
\hline
\end{tabular}

Fonte: Cálculos do autor. 


\section{Cenário 5 - referência (Ref.) e alternativo (New):}

\begin{tabular}{|c|c|c|c|c|c|c|c|c|c|c|c|c|c|c|c|}
\hline Annex B Regions & & USA & USA & JPN & JPN & EEC & EEC & OOE & OOE & EET & EET & $\overline{\text { FSU }}$ & $\overline{\text { FSU }}$ & Total & Total \\
\hline & & Ref. & $\mathrm{New}$ & Ref. & New & Ref. & New & Ref. & New & Ref. & $\mathrm{New}$ & Ref. & New & Ref. & New \\
\hline Emissions 2010 & $(\mathrm{M}$ tons $\mathrm{C})$ & 1809 & 1454 & 330 & 330 & 1011 & 1011 & 324 & 324 & 227 & 227 & 575 & 575 & 4276 & 3921 \\
\hline Assigned Amount & $(\mathrm{M}$ tons $\mathrm{C})$ & 1259 & 1259 & 274 & 274 & 822 & 822 & 218 & 218 & 282 & 282 & 816 & 816 & 3671 & 3671 \\
\hline Reduction Requirement & $(\mathrm{M}$ tons $\mathrm{C})$ & 522 & 167 & 43 & 43 & 184 & 184 & 93 & 93 & -59 & -59 & -276 & -276 & 842 & 488 \\
\hline \multicolumn{16}{|l|}{ Autarkic Solution } \\
\hline \begin{tabular}{|l|} 
Autarkic Marginal Price \\
\end{tabular} & $(\$ /$ ton $\mathrm{C})$ & 441 & 77 & 495 & 495 & 776 & 776 & 631 & 631 & 0 & 0 & 0 & 0 & & \\
\hline Autarkic Costs & $(\mathrm{M} \$)$ & 86626 & 5902 & 9703 & 9703 & 55727 & 55727 & 20495 & 20495 & 0 & 0 & 0 & 0 & 172551 & 91827 \\
\hline \multicolumn{16}{|l|}{ Solution with Trade } \\
\hline Domestic Reduction & $(\mathrm{M}$ tons $\mathrm{C})$ & 52 & 55 & 2 & 2 & 10 & 10 & 8 & 9 & 29 & 30 & 118 & 122 & 219 & 228 \\
\hline Domestic Marginal Costs & $(\$ /$ ton $\mathrm{C})$ & 20 & 21 & 20 & 21 & 20 & 21 & 20 & 21 & 20 & 21 & 20 & 21 & & \\
\hline Imports & $(\mathrm{M}$ tons $\mathrm{C})$ & 470 & 113 & 41 & 41 & 175 & 174 & 85 & 84 & 0 & 0 & 0 & 0 & 771 & 412 \\
\hline Exports & $(\mathrm{M}$ tons $\mathrm{C})$ & 0 & 0 & 0 & 0 & 0 & 0 & 0 & 0 & 87 & 54 & 395 & 236 & 482 & 289 \\
\hline Domestic Costs & $(\mathrm{M} \$)$ & 499 & 561 & 23 & 26 & 95 & 107 & 78 & 88 & 222 & 243 & 895 & 974 & 1812 & 1999 \\
\hline \begin{tabular}{|l} 
Cost of Imports \\
\end{tabular} & (M \$) & 9324 & 2375 & 816 & 865 & 3462 & 3672 & 1683 & 1781 & 0 & 0 & 0 & 0 & 15285 & 8693 \\
\hline Export Revenues & (M \$) & 0 & 0 & 0 & 0 & 0 & 0 & 0 & 0 & 1733 & 1133 & 7825 & 4971 & 9559 & 6103 \\
\hline Total Costs (- = Profits) & (M \$) & 9823 & 2937 & 839 & 891 & 3557 & 3779 & 1761 & 1869 & -1511 & -890 & -6931 & -3997 & 7538 & 4589 \\
\hline \multirow[t]{2}{*}{\begin{tabular}{|l|} 
Non-Annex B Regions \\
\end{tabular}} & & EEX & EEX & CHN & CHN & IND & IND & DAE & DAE & BRA & BRA & ROW & ROW & Total & Total \\
\hline & & Ref. & New & Ref. & New & Ref. & New & Ref. & New & Ref. & New & Ref. & New & Ref. & New \\
\hline Exports & $(\mathrm{M}$ tons $\mathrm{C})$ & 24,5 & 8,6 & 200,0 & 81,8 & 24,6 & 8,8 & 11,2 & 3,9 & 2,2 & 10,4 & 25,8 & 9,1 & 288,3 & 122,7 \\
\hline Costs & (M \$) & 228,9 & 80,1 & 1773,5 & 655,7 & 230,8 & 82,4 & 105,8 & 40,2 & 21,0 & 99,8 & 240,0 & 83,4 & 2599,9 & 1041,5 \\
\hline Export Revenues & (M \$) & 475,4 & 178,2 & 3887,8 & 1692,6 & 478,9 & 182,4 & 217,0 & 81,3 & 42,9 & 215,3 & 500,6 & 187,7 & 5602,7 & 2537,5 \\
\hline \multirow[t]{3}{*}{ Profits } & (M \$) & 246,6 & 98,1 & 2114,3 & 1036,9 & 248,1 & 100,0 & 111,2 & 41,1 & 21,9 & 115,5 & 260,6 & 104,3 & 3002,8 & 1495,9 \\
\hline & & & & & & & & & & & & & & & \\
\hline & & Ref. & New & & & & & & & & & & & & \\
\hline Convention Fund & (M\$) & 0 & 0 & & & & & & & & & & & & \\
\hline \begin{tabular}{|l|} 
Adaptation Fund \\
\end{tabular} & $(\mathrm{M} \$)$ & 114 & 52 & & & & & & & & & & & & \\
\hline
\end{tabular}

Fonte: Cálculos do autor. 


\section{Cenário 6 - referência (Ref.) e alternativo (New):}

\begin{tabular}{|c|c|c|c|c|c|c|c|c|c|c|c|c|c|c|c|}
\hline Annex B Regions & & USA & $\overline{\text { USA }}$ & JPN & JPN & EEC & EEC & OOE & OOE & EET & EET & FSU & FSU & Total & Total \\
\hline & & Ref. & New & Ref. & New & Ref. & New & Ref. & New & Ref. & New & Ref. & New & Ref. & New \\
\hline Emissions 2010 & $(\mathrm{M}$ tons $\mathrm{C})$ & 1883 & 1477 & 353 & 353 & 1062 & 1062 & 343 & 343 & 236 & 236 & 672 & 672 & 4549 & 4143 \\
\hline Assigned Amount & $(\mathrm{M}$ tons $\mathrm{C})$ & 1259 & 1259 & 274 & 274 & 822 & 822 & 218 & 218 & 282 & 282 & 816 & 816 & 3671 & 3671 \\
\hline Reduction Requirement & $(\mathrm{M}$ tons $\mathrm{C})$ & 596 & 190 & 66 & 66 & 235 & 235 & 112 & 112 & -50 & -50 & -179 & -179 & 1009 & 604 \\
\hline \multicolumn{16}{|l|}{ Autarkic Solution } \\
\hline Autarkic Marginal Price & $(\$ /$ ton $\mathrm{C})$ & 577 & 91 & 900 & 900 & 1254 & 1254 & 985 & 985 & 0 & 0 & 0 & 0 & & \\
\hline Autarkic Costs & $(\mathrm{M} \$)$ & 124104 & 7807 & 25502 & 25502 & 106728 & 106728 & 35628 & 35628 & 0 & 0 & 0 & 0 & 291961 & 175664 \\
\hline \multicolumn{16}{|l|}{ Solution with Trade } \\
\hline Domestic Reduction & $(\mathrm{M}$ tons $\mathrm{C})$ & 89 & 88 & 4 & 4 & 17 & 17 & 14 & 14 & 39 & 39 & 158 & 157 & 320 & 319 \\
\hline Domestic Marginal Costs & $(\$ /$ ton $C)$ & 36 & 36 & 36 & 36 & 36 & 36 & 36 & 36 & 36 & 36 & 36 & 36 & & \\
\hline Imports & $(\mathrm{M}$ tons $\mathrm{C})$ & 507 & 102 & 62 & 62 & 218 & 218 & 98 & 98 & 0 & 0 & 0 & 0 & 886 & 480 \\
\hline Exports & $(\mathrm{M}$ tons $\mathrm{C})$ & 0 & 0 & 0 & 0 & 0 & 0 & 0 & 0 & 89 & 59 & 337 & 231 & 425 & 290 \\
\hline Domestic Costs & (M \$) & 1531 & 1512 & 75 & 74 & 303 & 299 & 239 & 236 & 500 & 496 & 1965 & 1949 & 4612 & 4566 \\
\hline Cost of Imports & $(\mathrm{M} \$)$ & 18292 & 3648 & 2246 & 2233 & 7869 & 7821 & 3539 & 3519 & 0 & 0 & 0 & 0 & 31946 & 17220 \\
\hline Export Revenues & $(\mathrm{M} \$)$ & 0 & 0 & 0 & 0 & 0 & 0 & $\overline{0}$ & 0 & 3195 & 2115 & 12151 & 8266 & 15346 & 10381 \\
\hline Total Costs (- = Profits) & $(\mathrm{M} \$)$ & 19823 & 5160 & 2321 & 2307 & 8171 & 8120 & 3778 & 3755 & -2695 & -1619 & -10186 & -6317 & 21213 & 11404 \\
\hline \multirow{2}{*}{\begin{tabular}{|l|} 
Non-Annex B Regions \\
\end{tabular}} & & EEX & EEX & CHN & CHN & IND & IND & DAE & DAE & BRA & BRA & ROW & ROW & Total & Total \\
\hline & & Ref. & New & Ref. & New & Ref. & New & Ref. & New & Ref. & New & Ref. & New & Ref. & New \\
\hline Exports & $(\mathrm{M}$ tons $\mathrm{C})$ & \begin{tabular}{l|l}
41,2 \\
\end{tabular} & 14,1 & 311,2 & 123,7 & 41,6 & 14,4 & 19,2 & 6,6 & 3,8 & 17,0 & 43,1 & 14,8 & 460,2 & 190,7 \\
\hline Costs & $(\mathrm{M} \$)$ & 682,6 & 210,9 & 4755,6 & 1549,7 & 690,2 & 216,3 & 325,6 & 105,2 & 65,1 & 255,7 & 709,1 & 217,4 & 7228,2 & 2555,2 \\
\hline Export Revenues & $(\mathrm{M} \$)$ & 1456,5 & 496,6 & 11003,0 & 4345,6 & 1470,1 & 505,5 & 680,5 & 231,4 & 135,4 & 597,4 & 1522,8 & 519,7 & 16268,3 & 6696,3 \\
\hline \multirow[t]{3}{*}{ Profits } & $(\mathrm{M} \$)$ & 773,9 & 285,8 & 6247,4 & 2795,9 & 779,9 & 289,2 & 354,9 & 126,2 & 70,2 & 341,7 & 813,8 & 302,2 & 9040,1 & 4141,1 \\
\hline & & & & & & & & & & & & & & & \\
\hline & & Ref. & New & & & & & & & & & & & & \\
\hline Convention Fund & $(\mathrm{M} \$)$ & 0 & 0 & & & & & & & & & & & & \\
\hline Adaptation Fund & (M\$) & 332 & 137 & & & & & & & & & & & & \\
\hline
\end{tabular}

Fonte: Cálculos do autor. 


\section{Cenário 7 - referência (Ref.) e alternativo (New):}

\begin{tabular}{|c|c|c|c|c|c|c|c|c|c|c|c|c|c|c|c|}
\hline Annex B Regions & & USA & $\overline{\text { USA }}$ & JPN & JPN & $\overline{\text { EEC }}$ & EEC & OOE & OOE & EET & EET & FSU & $\overline{\text { FSU }}$ & Total & Total \\
\hline & & Ref. & New & Ref. & New & Ref. & New & Ref. & New & Ref. & New & Ref. & New & Ref. & New \\
\hline Emissions 2010 & $(\mathrm{M}$ tons $\mathrm{C})$ & 2088 & 1645 & 367 & 367 & 1151 & 1151 & 403 & 403 & 283 & 283 & 757 & 757 & 5049 & 4606 \\
\hline Assigned Amount & $(\mathrm{M}$ tons $\mathrm{C})$ & 1409 & 1409 & 289 & 289 & 1002 & 1002 & 287 & 287 & 301 & 301 & 1032 & 1032 & 4319 & 4319 \\
\hline Reduction Requirement & $(\mathrm{M}$ tons $\mathrm{C})$ & 651 & 208 & 65 & 65 & 144 & 144 & 103 & 103 & -21 & -21 & -310 & -310 & 964 & 520 \\
\hline \multicolumn{16}{|l|}{ Autarkic Solution } \\
\hline Autarkic Marginal Price & $(\$ /$ ton $\mathrm{C})$ & 701 & 102 & 536 & 536 & 101 & 101 & 307 & 307 & 0 & 0 & 0 & 0 & & \\
\hline Autarkic Costs & $(\mathrm{M} \$)$ & 159535 & 9499 & 14248 & 14248 & 5707 & 5707 & 11165 & 11165 & 0 & 0 & 0 & 0 & 190655 & 40618 \\
\hline \multicolumn{16}{|l|}{ Solution with Trade } \\
\hline Domestic Reduction & $(\mathrm{M}$ tons $\mathrm{C})$ & 44 & 44 & 4 & 4 & 41 & 41 & 14 & 14 & 20 & 20 & 80 & 80 & 204 & 203 \\
\hline Domestic Marginal Costs & $(\$ /$ ton $C)$ & 17 & 17 & 17 & 17 & 17 & 17 & 17 & 17 & 17 & 17 & 17 & 17 & & \\
\hline Imports & $(\mathrm{M}$ tons $\mathrm{C})$ & 607 & 164 & 62 & 62 & 103 & 103 & 89 & 89 & 0 & 0 & 0 & 0 & 860 & 417 \\
\hline Exports & $(\mathrm{M}$ tons $\mathrm{C})$ & 0 & 0 & 0 & 0 & 0 & 0 & 0 & 0 & 42 & 29 & 390 & 207 & 432 & 236 \\
\hline Domestic Costs & (M \$) & 362 & 359 & 31 & 31 & 323 & 320 & 116 & 115 & 159 & 158 & 635 & 630 & 1626 & 1612 \\
\hline Cost of Imports & $(\mathrm{M} \$)$ & 10189 & 2733 & 1035 & 1031 & 1726 & 1720 & 1486 & 1480 & 0 & 0 & 0 & 0 & 14436 & 6964 \\
\hline Export Revenues & $(\mathrm{M} \$)$ & 0 & 0 & 0 & 0 & 0 & 0 & 0 & 0 & 696 & 480 & 6546 & 3457 & 7242 & 3937 \\
\hline Total Costs (- = Profits) & $(\mathrm{M} \$)$ & 10551 & 3092 & 1066 & 1061 & 2049 & 2041 & 1602 & 1595 & -538 & -323 & -5910 & -2827 & 8820 & 4639 \\
\hline \multirow{2}{*}{\begin{tabular}{|l|} 
Non-Annex B Regions \\
\end{tabular}} & & EEX & EEX & CHN & CHN & IND & IND & DAE & DAE & BRA & $\overline{\mathrm{BRA}}$ & ROW & ROW & Total & Total \\
\hline & & Ref. & New & Ref. & New & Ref. & New & Ref. & New & Ref. & New & Ref. & New & Ref. & New \\
\hline Exports & $(\mathrm{M}$ tons $\mathrm{C})$ & 43,3 & 14,2 & 234,9 & 89,9 & 43,2 & 14,4 & 14,4 & 4,7 & 14,4 & 32,1 & 77,7 & 25,6 & 428,0 & 180,8 \\
\hline Costs & $(\mathrm{M} \$)$ & 332,3 & 95,1 & 1758,8 & 565,5 & 337,5 & 100,7 & 115,0 & 37,1 & 106,3 & 198,0 & 572,2 & 154,9 & 3222,1 & 1151,4 \\
\hline Export Revenues & $(\mathrm{M} \$)$ & 712,1 & 231,7 & 3863,2 & 1471,4 & 711,1 & 235,1 & 236,9 & 76,3 & 237,0 & 525,6 & 1278,3 & 419,7 & 7038,6 & 2959,8 \\
\hline \multirow[t]{3}{*}{ Profits } & $(\mathrm{M} \$)$ & 379,8 & 136,6 & 2104,4 & 905,9 & 373,6 & 134,4 & 121,9 & 39,2 & 130,7 & 327,6 & 706,1 & 264,8 & 3816,5 & 1808,4 \\
\hline & & & & & & & & & & & & & & & \\
\hline & & Ref. & New & & & & & & & & & & & & \\
\hline Convention Fund & $(\mathrm{M} \$)$ & 0 & 0 & & & & & & & & & & & & \\
\hline Adaptation Fund & (M\$) & 144 & 60 & & & & & & & & & & & & \\
\hline
\end{tabular}

Fonte: Cálculos do autor. 


\section{Cenário 8 - referência (Ref.) e alternativo (New):}

\begin{tabular}{|c|c|c|c|c|c|c|c|c|c|c|c|c|c|c|c|}
\hline Annex B Regions & & USA & USA & JPN & JPN & EEC & EEC & OOE & OOE & EET & EET & FSU & FSU & Total & Total \\
\hline & & Ref. & New & Ref. & New & Ref. & New & Ref. & New & Ref. & New & Ref. & New & Ref. & New \\
\hline Emissions 2010 & $(\mathrm{M}$ tons $\mathrm{C})$ & 1809 & 1454 & 330 & 330 & 1011 & 1011 & 324 & 324 & 227 & 227 & 575 & 575 & 4276 & 3921 \\
\hline Assigned Amount & $(\mathrm{M}$ tons $\mathrm{C})$ & 1259 & 1259 & 274 & 274 & 822 & 822 & 218 & 218 & 282 & 282 & 816 & 816 & 3671 & 3671 \\
\hline Reduction Requirement & $(\mathrm{M}$ tons $\mathrm{C})$ & 522 & 167 & 43 & 43 & 184 & 184 & 93 & 93 & -59 & -59 & -276 & -276 & 842 & 488 \\
\hline \multicolumn{16}{|l|}{ Autarkic Solution } \\
\hline Autarkic Marginal Price & $(\$ /$ ton $C)$ & 441 & 77 & 495 & 495 & 776 & 776 & 631 & 631 & 0 & 0 & 0 & 0 & & \\
\hline Autarkic Costs & (M \$) & 86626 & 5902 & 9703 & 9703 & 55727 & 55727 & 20495 & 20495 & 0 & 0 & 0 & 0 & 172551 & 91827 \\
\hline \multicolumn{16}{|l|}{ Solution with Trade } \\
\hline Domestic Reduction & $(\mathrm{M}$ tons $\mathrm{C})$ & 61 & 54 & 3 & 2 & 12 & 10 & 10 & 9 & 40 & 37 & 163 & 152 & 288 & 264 \\
\hline $\begin{array}{l}\text { Domestic Marginal } \\
\text { Costs }\end{array}$ & $(\$ /$ ton $C)$ & 24 & 21 & 24 & 21 & 24 & 21 & 24 & 21 & 24 & 21 & 24 & 21 & & \\
\hline Imports & $(\mathrm{M}$ tons $\mathrm{C})$ & 461 & 113 & 41 & 41 & 173 & 174 & 83 & 84 & 0 & 0 & 0 & 0 & 758 & 413 \\
\hline Exports & (M tons $\mathrm{C})$ & 0 & 0 & 0 & 0 & 0 & 0 & 0 & 0 & 99 & 61 & 439 & 265 & 538 & 326 \\
\hline Domestic Costs & (M \$) & 703 & 551 & 33 & 26 & 135 & 105 & 110 & 86 & 370 & 308 & 1506 & 1256 & 2858 & 2332 \\
\hline Cost of Imports & (M \$) & 10953 & 2362 & 967 & 857 & 4106 & 3637 & 1983 & 1765 & 0 & 0 & 0 & 0 & 18008 & 8620 \\
\hline Export Revenues & (M \$) & 0 & 0 & 0 & 0 & 0 & 0 & 0 & 0 & 2342 & 1275 & 10447 & 5543 & 12789 & 6818 \\
\hline Total Costs (- = Profits) & (M \$) & 11656 & 2913 & 1000 & 882 & 4241 & 3742 & 2093 & 1851 & -1972 & -967 & -8940 & -4287 & 8077 & 4134 \\
\hline \multirow[t]{2}{*}{ Non-Annex B Regions } & & EEX & EEX & CHN & CHN & IND & IND & DAE & DAE & BRA & BRA & ROW & ROW & Total & Total \\
\hline & & Ref. & New & Ref. & New & Ref. & New & Ref. & New & Ref. & New & Ref. & New & Ref. & New \\
\hline Exports & $(\mathrm{M}$ tons $\mathrm{C})$ & 22,5 & 6,8 & 119,7 & 42,5 & 22,9 & 7,0 & 7,8 & 2,3 & 7,3 & 15,1 & 39,1 & 12,1 & 219,2 & 85,9 \\
\hline $\begin{array}{ll}\text { Costs } \\
\end{array}$ & $(\mathrm{M} \$)$ & 238,3 & 58,5 & 1225,9 & 325,2 & 247,5 & 62,0 & 87,2 & 25,0 & 72,9 & 116,5 & 391,9 & 90,1 & 2263,8 & 677,2 \\
\hline Export Revenues & (M \$) & 524,7 & 139,9 & 2787,9 & 870,8 & 533,1 & 143,0 & 182,0 & 47,4 & 169,1 & 309,8 & 910,3 & 247,4 & 5107,2 & 1758,3 \\
\hline \multirow[t]{3}{*}{\begin{tabular}{|l} 
Profits \\
\end{tabular}} & (M \$) & 286,4 & 81,4 & 1562,0 & 545,6 & 285,6 & 81,0 & 94,8 & 22,5 & 96,1 & 193,3 & 518,5 & 157,3 & 2843,4 & 1081,1 \\
\hline & & & & & & & & & & & & & & & \\
\hline & & Ref. & New & & & & & & & & & & & & \\
\hline \begin{tabular}{|l} 
Convention Fund \\
\end{tabular} & $(\mathrm{M} \$)$ & 0 & 0 & & & & & & & & & & & & \\
\hline \begin{tabular}{|l|} 
Adaptation Fund \\
\end{tabular} & (M\$) & 104 & 36 & & & & & & & & & & & & \\
\hline
\end{tabular}

Fonte: Cálculos do autor. 